\title{
Republic of Madagascar: Poverty Reduction Strategy Paper- Annual Progress Report for 2007 and First Semester of 2008
}

Poverty Reduction Strategy Papers (PRSPs) are prepared by member countries in broad consultation with stakeholders and development partners, including the staffs of the World Bank and the IMF. Updated every three years with annual progress reports, they describe the country's macroeconomic, structural, and social policies in support of growth and poverty reduction, as well as associated external financing needs and major sources of financing. This country document for the Republic of Madagascar, dated March 2008, is being made available on the IMF website by agreement with the member country as a service to users of the IMF website.

Copies of this report are available to the public from

International Monetary Fund • Publication Services $70019^{\text {th }}$ Street, N.W. • Washington, D.C. 20431

Telephone: (202) 623-7430 • Telefax: (202) 623-7201

E-mail: publications@imf.org • Internet: http://www.imf.org

Price: $\$ 18.00$ a copy

\section{International Monetary Fund Washington, D.C.}




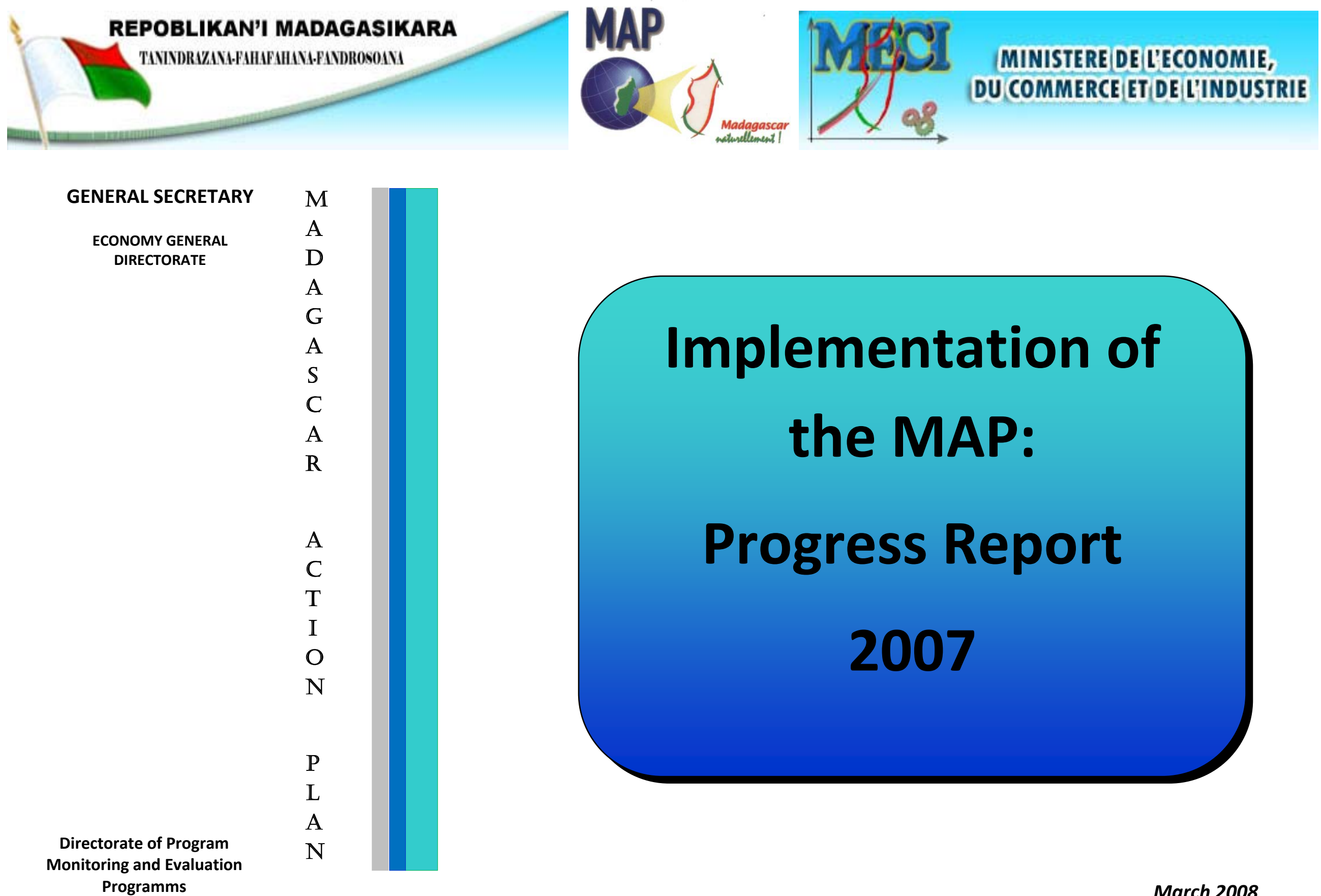

\section{Implementation of}

\author{
the MAP:
}

Progress Report

2007 



\section{Implementation of the MAP: Progress Report}

\section{7}




\section{SUMMARY}

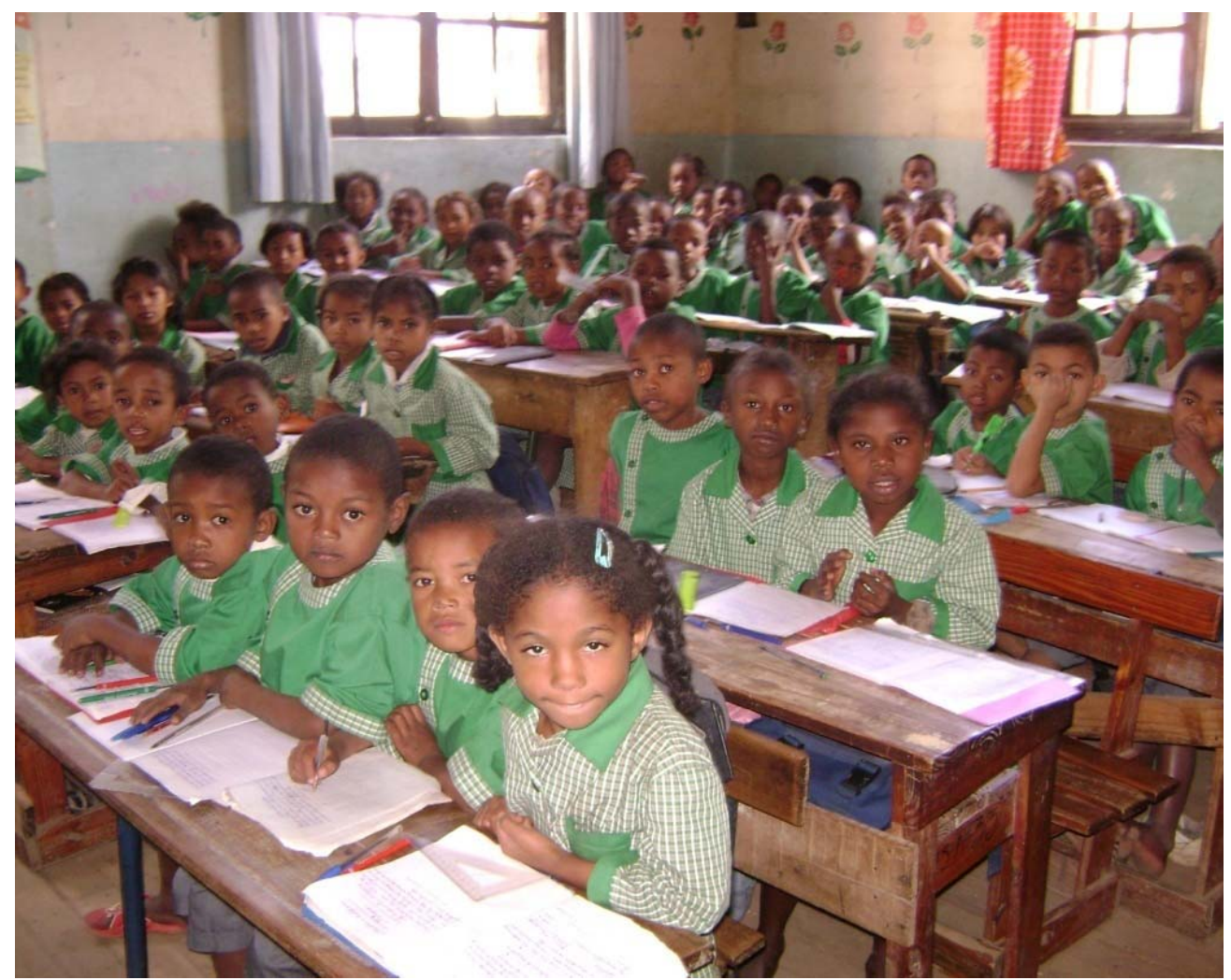

\section{Executive summary \\ Implementation of the MAP}

Situation of the Indicators related to Big Objectives.................................................

Commitment 1: Responsible Governance .......................................................

Commitment 2: Connected Infrastructures.....................................................

Commitment 3: Educational Transformation .........................................................15

Commitment 4: Rural Developpement ............................................................20

Commitment 5: Health, Family Planning, and the Fight against HIV/AIDS.............24

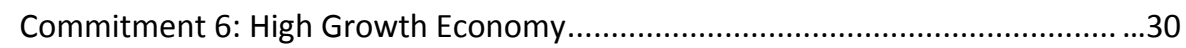

Commitment 7: Cherish the Environnement .......................................................36

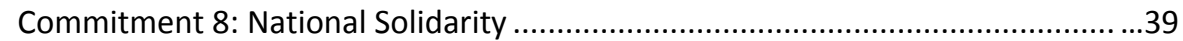

\section{Funding of the MAP}

Annex: Priority Indicators

Photo : EPP Andrefan'Ambohijanahary 




\section{ACRONYMS}

\begin{tabular}{|c|c|c|c|}
\hline$A B C$ & Agri business Center & $\mathrm{DH}$ & District Hospital \\
\hline$A D B A$ & Arab Development Bank in Africa & DHS & District Health Services \\
\hline$A F D$ & African Development Fund & DIREEF & Interregional Directorate of Environment, Water, and Forests \\
\hline$E D F$ & European Development Fund & DIRM & Interregional Directorate of Mines \\
\hline AGEPMF & Agency in charge of implementation and promotion of Microfinance & DEEM & Directorate of Economic Studies and Modeling \\
\hline AIZ & Agricultural Investment Zone & $E D B M$ & Economic Development Board of Madagascar \\
\hline $3 P$ & Public Private Partnership & EEZ & Exclusive Economic Zone \\
\hline ANDEA & National Water and Sanitation Authority & $E I G$ & Economic Interest Group \\
\hline APMF & Port and Waterways Authority & $E K A$ & Ezaka Kopia ho an’ny Ankizy \\
\hline$A P P I$ & Partnership and Investment Promotion Agreement & EONC & Emergency Obstetric and Neonatal Care \\
\hline$A R V$ & Anti Retro Viral & EPI & Expanded Program on Immunization \\
\hline ATT & Road Transport Authority & FAPBM & Foundation for Madagascar's Protected Areas and Biodiversity \\
\hline BAM & Mining management office & FIREF & Fund for Insertion and Rehabilitation to Formal Employment \\
\hline$B H C$ & Basic Health Center & GDP & Gross Domestic Product \\
\hline BIANCO & Independent anti-corruption office & IG2P & Integrated Growth Poles Project \\
\hline$B N G R C$ & National Risk and Disaster Management Office & GEFP & Group of free processing enterprises and partners \\
\hline CAC & Commune Support Center & GMIS & Geographic and Mining Information System \\
\hline CAM & Market Access Center & $\mathrm{HIPCl}$ & Heavily Indebted Poor Countries Initiative \\
\hline CAP & Educational Support Center & ICT & Information and Communication Technologies \\
\hline CAPJ & Youth Vocational Animation Center & IDA & International Development Agency \\
\hline$C D P$ & Commune Development Plan & $H D I$ & Human Development Indicator \\
\hline CGA & Approved Management Center & FDI & Foreign Direct Investment \\
\hline CIREEF & Interregional office of Environment, Water, and Forests & IEC & Information-Education-Communication \\
\hline CIRFIN & Financial Jurisdiction & $I E C / B C C$ & Information - Education - Communication for Behavioral Change \\
\hline CISCO & School District & $I E C / P F$ & Information-Education-Communication Family Planning \\
\hline CLAC & Reading and Cultural Animation Centers & $\mathrm{IMCl}$ & Integrated Management of Childhood IIInesses \\
\hline CLLS & Local AIDS Control Committee & IMF & Mutual Microfinance Institution \\
\hline COJI & Committee of the Indian Ocean Games & INSTAT & National Institute of Statistics \\
\hline COMESA & Common Market of Eastern and Southern Africa & IUCN & International Union for The Conservation of Nature \\
\hline CPAC & Anti-Corruption Penal Chain & $J I C A$ & Japan International Cooperation Agency \\
\hline \multirow[t]{2}{*}{ CREAM } & Center of Research, Studies, and support to Economic Analysis in & KASTI & Komitin'ny Ala sy ny Tontolo lainana \\
\hline & Madagascar & $L D F$ & Local Development Fund \\
\hline CRENA & Ambulatory Center for Nutritional Rehabilitation and Education & LLITN & Long Lasting Insecticide-Treated Nets \\
\hline CRENI & Intensive Nutritional Rehabilitation Center & $L M D$ & Licence Master Doctorate \\
\hline CTD & Decentralized collectivities & MAEP & Ministry of Agriculture, Livestock, and Fisheries \\
\hline$D B G M$ & Directorate of Governance in the Mining Sector & MADRES & Support to Renovating Higher Education in Madagascar \\
\hline$D E P A$ & Directorate of Safe Water and Sanitation & MAP & Madagascar Action Plan \\
\hline
\end{tabular}




\section{ACRONYMS}

$\begin{array}{ll}\text { MCA } & \text { Millennium Challenge Account } \\ \text { MDN } & \text { Ministry of National Defense } \\ \text { MENRS } & \text { Ministry of Education and Scientific Research } \\ \text { MFB } & \text { Ministry of Finances and Budget } \\ \text { MFPTLS } & \text { Ministry of Civil Service, Labor and Social Laws } \\ \text { MHT } & \text { Mobile Health Team } \\ \text { MINJUS } & \text { Ministry of Justice } \\ \text { MinSanPFPS } & \text { Ministry of Health, Family Planning and Social Protection } \\ \text { MTPM } & \text { Ministry of Public Works and Meteorology } \\ & \\ \text { MVU } & \text { Mobile Video Unit } \\ \text { UNESCO } & \text { United Nations Educational and Cultural Organization } \\ \text { UNICEF } & \text { United Nations Program for Children } \\ \text { FFW } & \text { Food for Work } \\ \text { NIMES } & \text { National Integrated Monitoring and Evaluation System } \\ \text { OMERT } & \text { Malagasy Office in charge of Studies and Regulation of } \\ \text { PFMIS } & \text { Telecommunications } \\ \text { PGDI } & \text { Public Finances Management Information System } \\ \text { PGRM } & \text { Governance and Institutional Development Project } \\ \text { PLHA } & \text { Mineral Resources Governance Project } \\ \text { PME } & \text { People Living with HIV/AIDS } \\ \text { PSDR } & \text { Planning Monitoring and Evaluation } \\ \text { PHBM } & \text { Rural Development Support Program } \\ \text { PRBM } & \text { Higher Mandrare Basin Project } \\ \text { PMTCT } & \text { Project for the Rehabilitation of Lower Mangoky } \\ \text { PMU } & \text { Prevention of Mother-to-Child Transmission } \\ \text { PNAEP } & \text { Procurement Management Unit } \\ \text { PNAN } & \text { National Program for Safe Water Supply } \\ \text { PNEOA } & \text { National Nutrition Action Plan } \\ \text { PNC } & \text { National Program for Engineering Structure Maintenance } \\ \text { PNDR } & \text { Prenatal consultation } \\ \text { PNN } & \text { National Rural Development Program } \\ \text { PNNC } & \text { National Nutrition Policy } \\ \text { PNPS } & \text { National Program of Community-based Nutrition } \\ \text { PNR } & \text { National Policy for Social Protection } \\ & \text { Primary National Road } \\ & \end{array}$

Procurement Officer

Project for Institutional Reinforcement of the Mining Sector

Project of Institutional Reinforcement for Governance

School-based Nutrition Program

Risk and Disaster Management

Regional Development Plan

Road Maintenance Fund

Regional Program for Rural Development

Program of Reform for the Administration's Efficiency

Regional Reference Hospital

Rapid Result Initiative

Southern African Development Community

Madagascar's Protected Areas System

State Secretariat in charge of Public Security

Sustainable Forest Management Site

Military Service centered on Development Actions

National Plan for Land Development

Secondary National Road

Tourist Land Reserves

Tertiary National Road

United Nations Development Program

Voluntary Counseling and Testing

Indian Ocean Commission

Vision Madagascar Naturally

Non Processed Food Commodities

Water Sanitation Hygiene

World Wildlife Fund of nature

World Food Program

World Trade Organization

Zones on Agreed Development

Agri business Center

Arab Development Bank in Africa

African Development Fund

European Development Fund

Agency in charge of implementation and promotion of Microfinance 


\section{LIST OF GRAPHS AND TABLES}

\section{List of graphs}

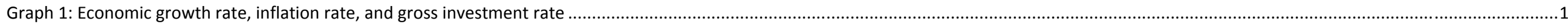

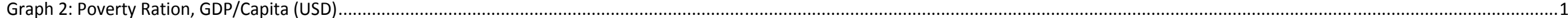

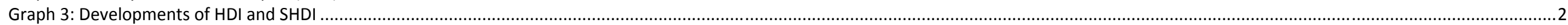

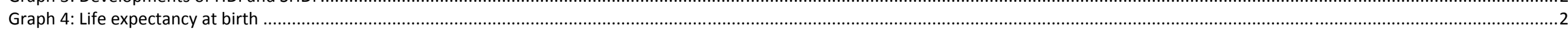

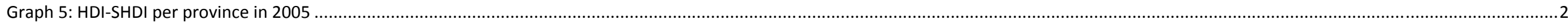

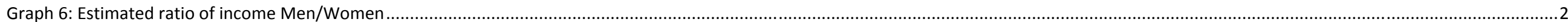

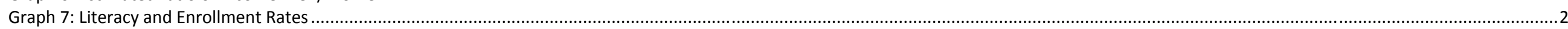

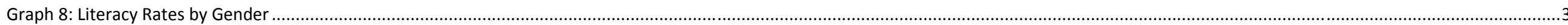

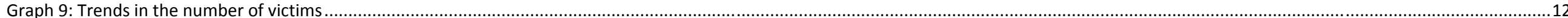

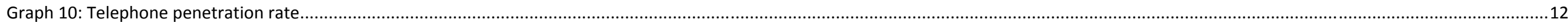

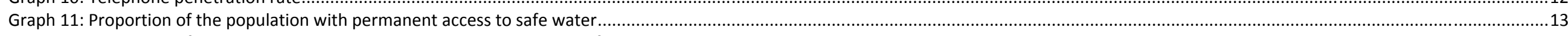

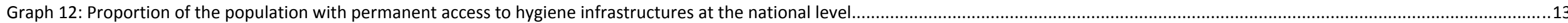

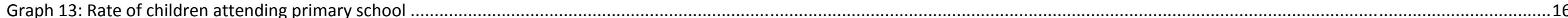

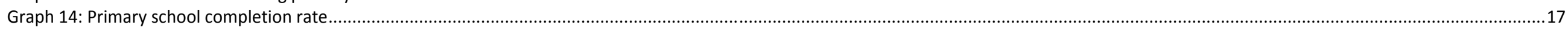

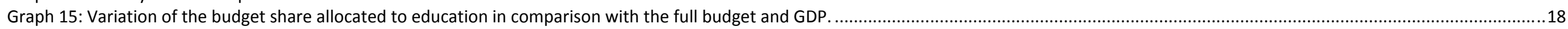

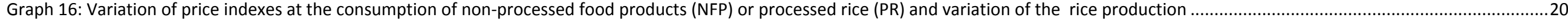

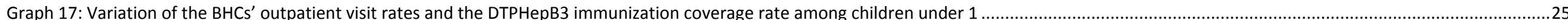

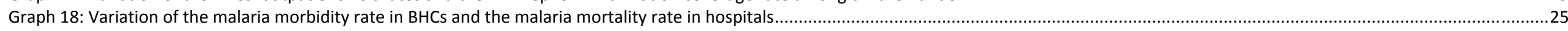

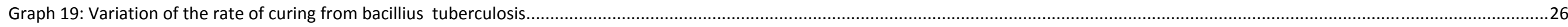

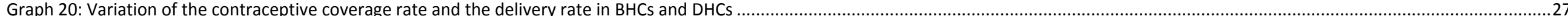

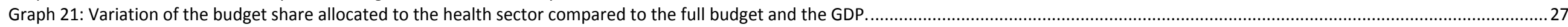

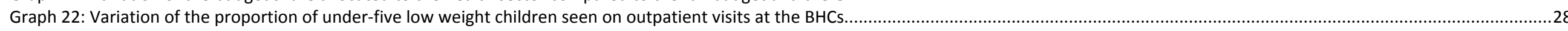

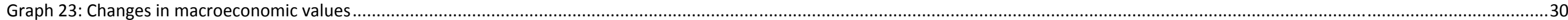

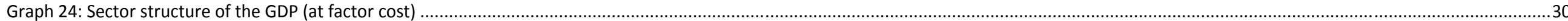

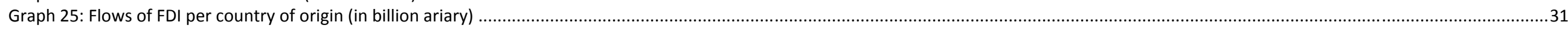

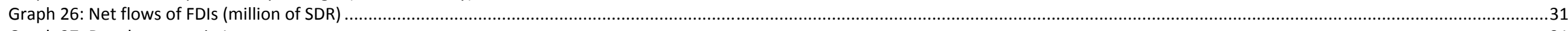

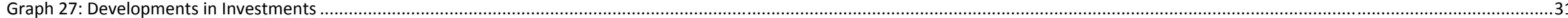

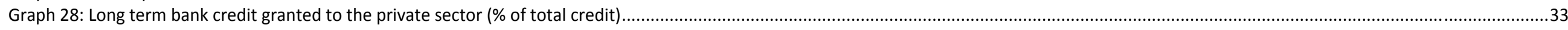

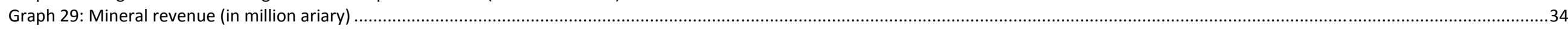

\section{List of tables}

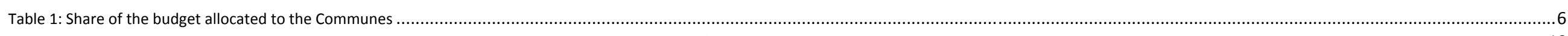

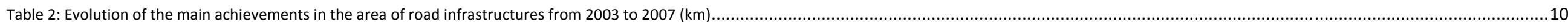

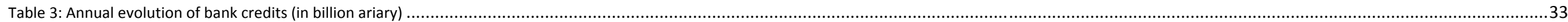

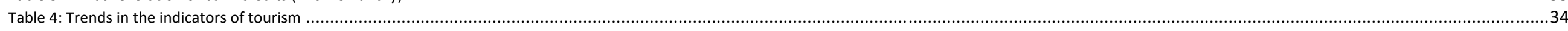

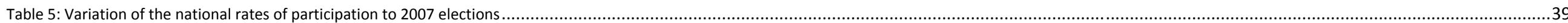

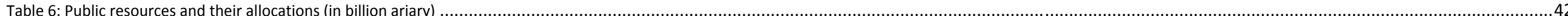

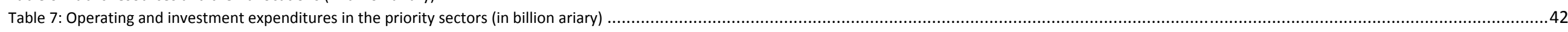

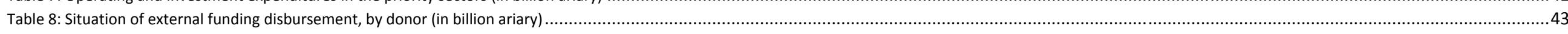

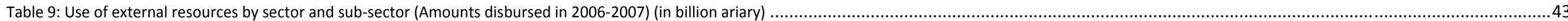




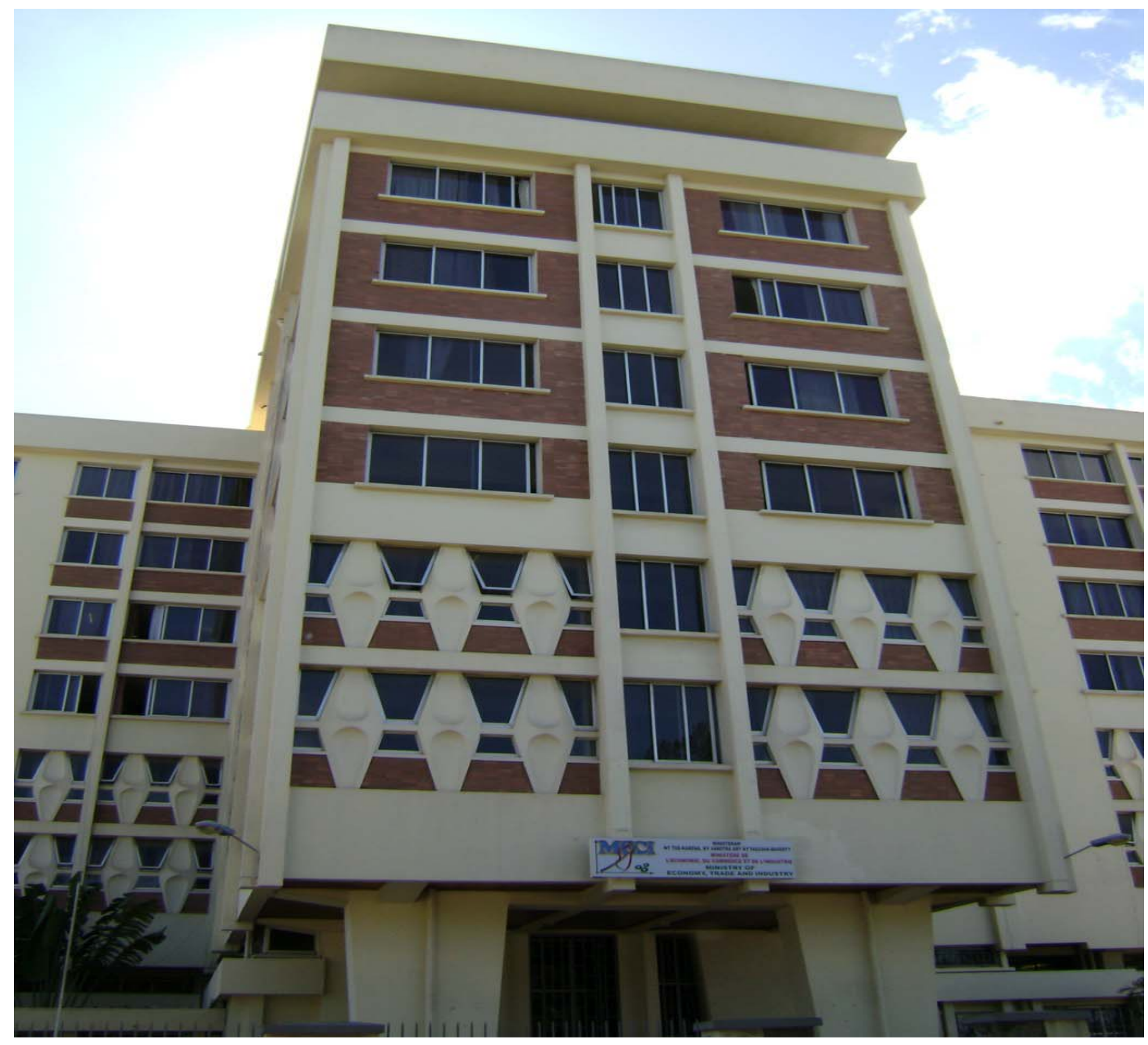




\section{PREFACE}

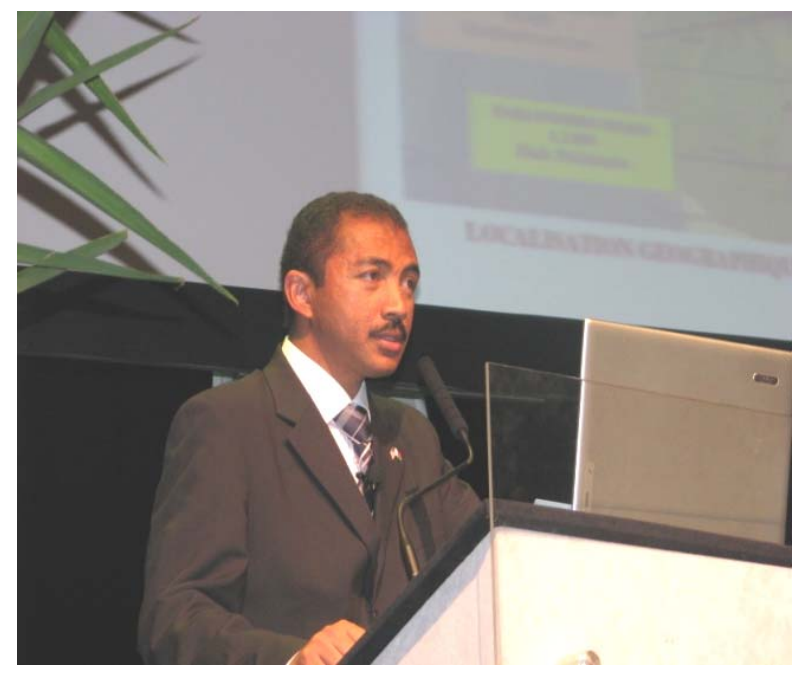

The Madagascar Action Plan (MAP) that was officially adopted in November 2006 is an ambitious while realistic action plan that serves as roadmap and defines Madagascar's priorities for the 2007-2012period. It describes commitments, strategies and actions to ensure rapid economic growth, taking into account the benefits and the challenges of globalization, based on the "Madagascar naturally" vision and the Millennium Development Goals.

Year 2007 as the first year of implementation of the MAP was characterized by the development of different management, implementation, and monitoring tools, including the Implementation Plan (IP) and the National Integrated Monitoring and Evaluation System (NIMES). The tools are based on the methodology of result-oriented management and put the emphasis on consistency and synergies among the different sectors. Various entities from the Public Administration, the Technical and Financial Partners, and the Private sectors were closely involved in the development of the referential framework through a focus group.

The present document is the first Annual Monitoring Report on the MAP Implementation. The priority indicators adopted in a participatory way as part of the NIMES were selected to reflect the level of achievement of the objectives under the MAP's eight Commitments and various Challenges. The indicators relate mainly to the Big Objectives and the immediate priorities defined in the MAP as well as to the Millennium Development Goals.

Thus, the present report offers a reference framework for decision-making on sectoral orientations as part of implementing the MAP and constitutes a tool for advocating among all Partners.

Collaboration though focus groups will be built upon as part of an ongoing process of consulting partners in order to fine-tune, at each sector's level, strategies and indicators to implement
Sectoral Programs. Harmonization activities will be conducted at the Regions' level to ensure consistency between the Sectoral Programs and the MAP's regional priorities.

We hope that there will be fruitful collaboration among all stakeholders as well as genuine partnership with all the Technical and Financial Partners of the international Community in order to make the NIMES operational starting in Year 2008 in the framework of the MAP implementation.

We would like to thank you for the mutual trust that was demonstrated and that will be further strengthened in the coming years.

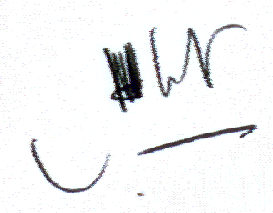

Ivohasina Fizara RAZAFIMAHEFA Minister of Economy, Trade and Industry 


\section{EXECUTIVE SUMMARY}

Over the last three years, Madagascar's economic situation has been characterized by steady growth estimated at $5.0 \%$ on average against an average annual demographic growth rate of $2.8 \%$. However, the living standard of the population as captured by the indicators related to the big objectives of the MAP has not kept up with this pace. Indeed, though the country has upgraded into a country with a medium human development with an HDI of 0.505 during this period, the index in 2005 was only 0.527 . In addition, gender-based disparities are noted though they tend to diminish over time mainly due to efforts made in the social sectors (health and education). The most significant disparities are geographic ones, with Toliara having an HDI of 0.399 and Antananarivo 0.579 .

On the other hand, the decrease in the poverty rate from $73.6 \%$ in 2003 to $66.3 \%$ in 2007 remains low and fragile especially when measured against the Millennium Development Goals (MDGs). It is also subject to significant geographic disparities: only eight (8) regions fare better than the national average and about three fourths of the poor live in rural areas.

Orientation focus to improve the situation include allocating resources based on proven priorities as well as developing and implementing a policy of appropriate redistribution.

\section{COMMITMENT 1: RESPONSIBLE GOVERNANCE}

Efforts were made to achieve the objectives under the Commitment on Responsible Governance:

- As regards security of people and property, a clear decrease was noted in the crime rate due to intensified insecurity control in the most affected Regions and Districts. However, crime is becoming increasingly violent with organized criminality and proliferation of weapons.
- As regards strengthening the rule of law, it is noted that the processing of pending cases is still very slow and that the delay for processing cases is still long.

- As regards the perception of corruption, clear improvement was noted in the related index, allowing us to hope that the objective will be achieved by 2012 .

- As regards the ongoing reform of public finances management, an increase in the fiscal pressure was noted. In the same way, the operational and organizational reforms at the customs and the tax services have been completed. The organic law on public finances, and the new code of public procurements have become effective and the reform and reorganization of the bodies in charge of controlling and auditing the use of public funds have been initiated. The Public Fund Management Information System (PFMIS) is operational at all Ministries of the central government. These reforms need to be further strengthened to support the objectives under the MAP's Immediate Priorities.

- Finally, as regards effective decentralization and Land Development, the laws and regulations have been revised to grant more power and responsibilities to Communes and Regions: the laws and regulations on budget, financial, and accounting management as well as on the collection of land tax have been published. However, to date, only 254 communes benefit from the support of the Communes Support Centers (CSC), which calls for efforts to build as soon as possible the capacities of the remaining communes so that they can carry out what is under the competency and keep up with their missions.

\section{COMMITMENT 2: CONNECTED INFRASTRUCTURES}

The following ministries were the most concerned by the actions undertaken: Public Works and Meteorology,
Transports and Tourism, Energy and Mines, and Telecommunications.

- In the public works sector, convincing results were achieved in building, rehabilitating, and ensuring regular maintenance of national roads. Conversely, the achievement rate is low as regards building rural roads mainly because of the inadequacy of credits allocated to this activity.

- In the transport sector, the improved quality of transport infrastructures has allowed for increasing the respective rates of good and passengers' transport.

- In the energy and mining sector, JIRAMA's capacity to produce electricity remains inadequate and limited due to technical issues (the dilapidated state of materials) as well as financial issues (operations in deficit). In addition, the objective for rural electrification in $\mathbf{2 0 0 7}$ is far from achieved. To make up for the low performance, an increasing number of independent energy producers and providers (private operators) have emerged, allowing for an increase of the power installed from 2006 to 2007. Finally, the households' access rate to safe water at the national level has slightly improved between 2004 and 2006. In 2006, the objective of water points set up in rural areas was largely exceeded. In the area of sanitation, no tangible change was noted between 2006 and 2007 and the objective of sanitation infrastructures set up was not achieved. However, the sector has gained new assets with the development of the National Program for Access to Safe Water and Sanitation (NPASFWS) for year 2005 to 2015 and the newly operational National Water and Sanitation Authority.

- In the area of telecommunications, significant progress is noted in terms of telephone penetration rates. 


\section{EXECUTIVE SUMMARY}

\section{COMMITMENT 3: EDUCATIONAL TRANSFORMATION}

Tangible effects have been noted in the education sector since 2004: almost all children have access to primary school (net enrollment rate), the quality and internal effectiveness of education have improved, and the shift to a seven-year fundamental cycle is gradually happening. However, pre-school and the reform of higher education remain a big challenge. Indeed, the shift to the LMD system in higher education has triggered positive response among the public and private partners and has led to deciding on methodological and institutional changes. The issue now is to build the capacities of universities (funding, materials, partnerships, etc.) in order to make concrete the implementation as well as the monitoring of the new system.

\section{COMMITMENT 4: RURAL DEVELOPMENT}

The pillars and levers for initiating the Green Revolution have been reinforced, namely:

- Promotion of market-driven activities;

- Diversification of agricultural activities by making available and distributing certified seeds;

- Setting up of Market Access Centers (MAC) and AgriBusiness Centers (ABC) in several decentralized collectivities;

- Diversification and improvement of sea products as well as building and rehabilitating infrastructures.

Conversely, the objectives for 2007 for setting up of onestop shops and land management offices as well as issuing land titles and certificates have not been achieved. Access to funding in rural areas remains a major impediment mainly because of the cost of credit.

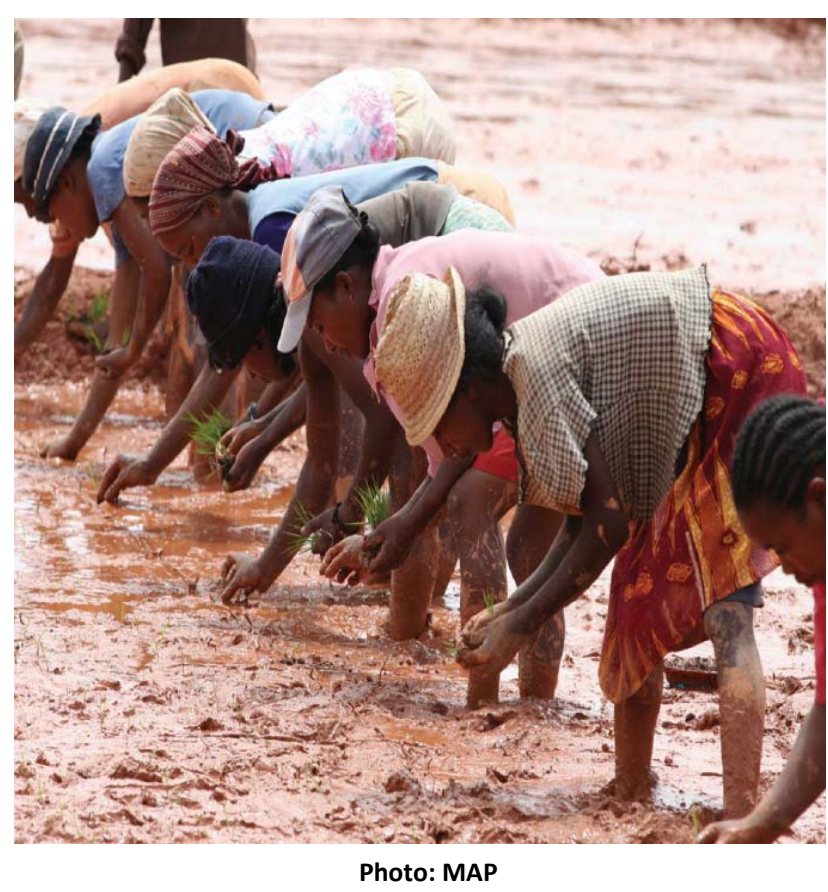

COMMITMENT 5: HEALTH, FAMILY PLANNING, AND THE FIGHT AGAINST HIV/AIDS

In the area of health, the building and rehabilitation of health centers have allowed for increasing the number of operational public BHCs as well as the ratio of population per BHC. However, the outpatient consultation rates remain low. Big efforts need to be made so that BHCs can be operational by increasing the number of staff and building the capacities of the medical staff. The good performances in the areas of immunization coverage and preventive actions under malaria control have greatly contributed to reducing the child and mortality rates. The contraceptive coverage rate has much increased, due to the availability of family planning sites as well as improved knowledge of contraception. As regards HIV/AIDS control, the HIV prevalence rates remains below $1 \%$. However, the STI prevalence among pregnant women can jeopardize the good results, calling for strengthening appropriate actions.

The results obtained in reducing low weight among children under five in BHCs and community sites are satisfactory. In order to make malnutrition control activities sustainable, efforts should be directed towards awareness-raising and capacity-building for communities.

\section{Commitment 6: High Growth Economy}

The steady growth noted these last years was mainly driven by private investments that benefit from a conducive business climate and increasingly streamlined procedures (in the area of taxation). The changes in the production structure shows that the tertiary sector has been the lever of economic growth over the last years with a significant contribution of transport, works, telecommunications (NICTs) and Tourism. However, in terms of performance, the secondary sector has made a significant leap, increasing from 3.5\% in 2006 to $9.8 \%$ in 2007.

The control of money supply growth and the enforcement of budget policy oriented on reducing deficit to $2.8 \%$ of the GDP have resulted in curbing the inflation rate at $8.2 \%$ (end of period). The fiscal pressure has improved as well, increasing to $11.4 \%$, thus exceeding the goal of $10 \%$. This performance needs to be further strengthened to support the funding of the MAP.

While the country's exports have increased by an average of $11.6 \%$ over the last three years, due to the imports induced by foreign direct investments (FDI) in 2007, the external deficit has risen to $14.1 \%$ of the GDP. The currency reserves have been maintained at 2.9 months of imports, thanks to the flow of foreign aid. 


\section{EXECUTIVE SUMMARY}

Thanks to the benefits of foreign debts relief, the ratio of debt service against exports has steadily decreased from $9.23 \%$ in 2002 to $1.7 \%$ in 2007 .

The exchange rate of the Ariary against SDR (average over the period) has become stable and has even shown appreciation.

The challenge remains to achieve a two-digit growth rate and macroeconomic stability sustained by improved structural and institutional reforms.

\section{COMMITMENT 7: CHERISH THE ENVIRONMENT}

Satisfactory results were achieved in setting up Protected Areas and constitute promising indications as regards achieving the objectives for 2012 .

Efforts have been made to maintain the surface area of forests and to promote reforestation actions.

Funds have started to be mobilized for the Foundation for Madagascar's Protected Areas and Biodiversity, involving the Government, technical and financial partners, as well as the private sector in a $3 \mathrm{P}$ system.

Environmental control systems have been strengthened.

\section{COMMITMENT 8: NATIONAL SOLIDARITY}

Mechanisms for citizens' participation are poorly developed in Madagascar. For the time being, elections seem to be the most privileged factor in the Malagasy context compared to other channels such as media and civil society organizations.

National awareness was demonstrated in the strong collaboration of decentralized services in the birth registration program or Ezaka Kopia ho an'ny Ankizy (EKA).
As regarding preserving and enhancing the value of cultural heritage, tangible results were noted especially as regards the rehabilitation and restoration of cultural sites. In addition, practice of sports among the population has improved.

High level athletes benefited from improved preparation which gave the satisfactory results obtained by Madagascar at the $7^{\text {th }}$ Games of the Indian Ocean Islands, boosting national pride.

Women's participation in the nation's economic and political life remains low. Social and cultural factors that are often detrimental to women still govern gender relationships in the areas of decision-making and responsibilities. However, actions going towards gender equality and women's empowerment have been carried out.

\section{FUNDING OF THE MAP}

In 2007, the funding of Madagascar's development, mainly through the Madagascar Action Plan, was mainly supported through:

- The mobilization of internal resources made up of to a large extent by tax revenues;

- The contributions of foreign trade as a major lever of development, though its scope remains quite limited for the time being;

- Official Development Assistance provided mainly by multilateral and bilateral partners and reinforced by foreign debt relief;

- and especially, Foreign Direct Investments that have been flourishing since 2006 thanks to the actions to promote Madagascar.

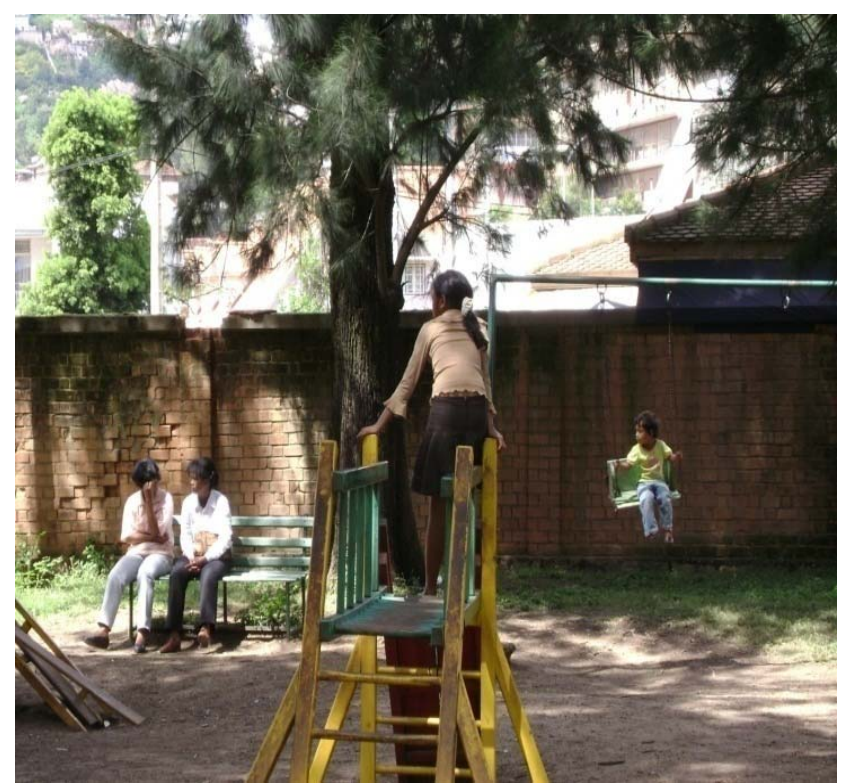




\section{IMPLEMENTATION OF THE MAP}

\section{SITUATION OF THE INDICATORS RELATED TO THE Big OBJeCtives}

Steady positive growth but slow fall of poverty and progress achieved in terms of human development

\section{Growth and poverty}

Over the last years, the country has launched specific programs in various areas and has committed additional resources obtained from the debt service relief to essential social sectors (health, education, justice, population and social protection).

The situation over the last three years has been characterized by the followings:

- An improved overall performance with a steady growth estimated at $5.0 \%$ on average, increasing from $4.6 \%$ in 2005 to $6.2 \%$ in 2007 ;

- An increase in private investments estimated at $12.3 \%$ of the GDP in 2005 and at $28.3 \%$ in 2007, which fostered an increase of the real GDP per capita;

- A significant drop in the inflation rate, from $11.5 \%$ in 2005 to $10.8 \%$ in 2006 and $8.2 \%$ in 2007 (end of period);

- An improved overall economic environment as reflected in the trends in the corruption perception index which improved from 1.7 in 2002 to 2.8 in 2005 and to 3.2 in 2007 (Transparency International);

- An increase in significant flows of foreign direct investments observed in 2006 and 2006, amounting respectively 150.5 million SDR and 652.1 million SDR despite the many constraints that are perceived by some sectors.
Graph 1: Economic growth rate, inflation rate, and gross investment rate

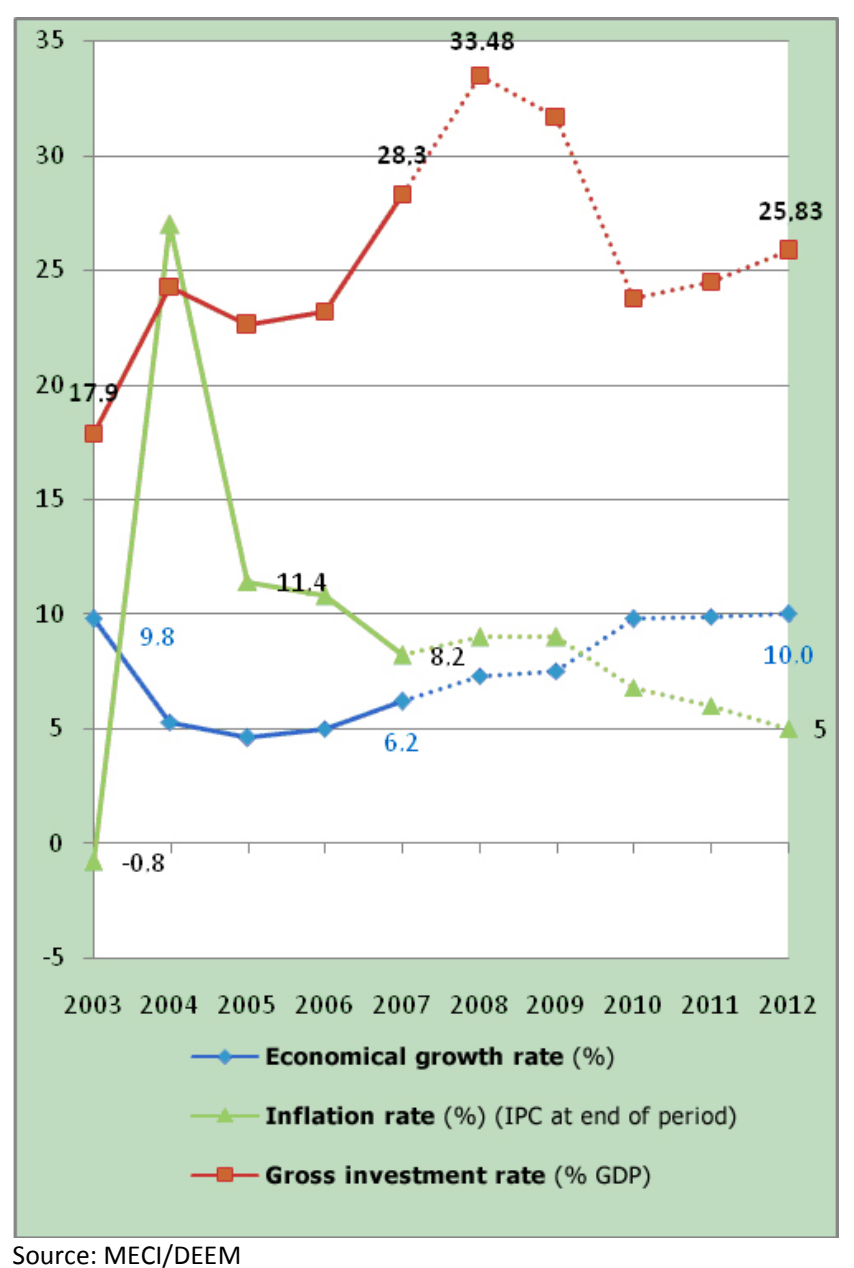

From 2001 to 2006, according to the MDGs Follow Up Report in 2007, poverty has dropped by 2.1 points of percentage, decreasing from $69.6 \%$ to $67.5 \%$. The downward trend has been maintained in 2007, and the poverty rate should drop to $66.3 \%$ according to the forecasts of the National Institute of Statistics (INSTAT).
Graph 2: Poverty Ration, GDP/Capita (USD)

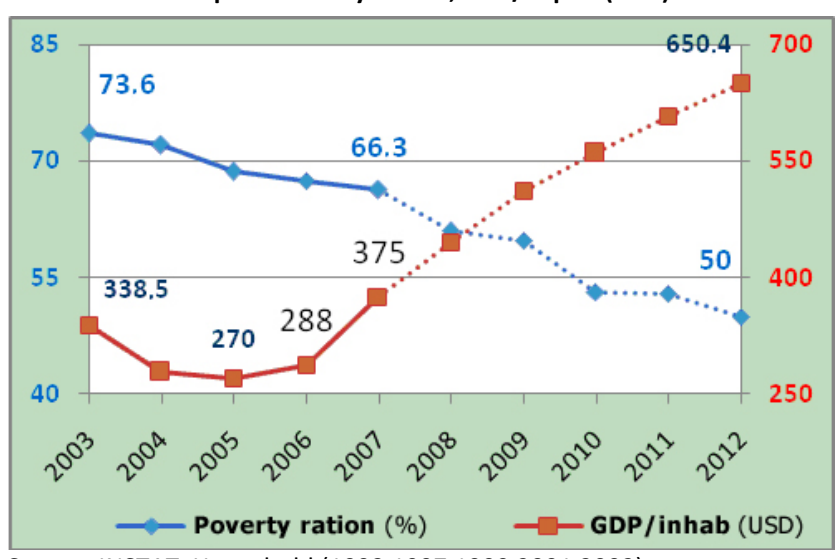

Source: INSTAT, Household (1993 199719992001 2002)

However, significant regional disparities are noted in the current situation:

- Only eight regions have a poverty rate below the national average in 2005,

- Three fourths $(3 / 4)$ of the poor are found in rural areas where $80 \%$ of the population lives.

The disparities are due to:

- The low productivity of the economic sectors;

- Acute unemployment and underemployment;

- The poor state of infrastructures;

- The effects of climate change.

In addition, urban poverty has increased by 8.1 points from 2001 to 2006 while rural poverty dropped by 3.7 points over the same period.

Unfortunately, the inequalities in resources distribution have become even more marked with the $20 \%$ of the poorest consuming $7.3 \%$ of the total consumption mass in 2005 against $6,7 \%$ in 2006.

As regards food security, the malnutrition rate as assessed through the proportion of children under five suffering from low weight seen in community sites and BHCs has tangibly decreased. However, land security, as an indirect 


\section{IMPLEMENTATION OF THE MAP}

factor, remains a big challenge in the rural world and calls for a quantum leap as only $10.4 \%$ of rural holders had a land title in 2007 while the objective by 2012 is $75 \%$.

Given the trends in growth and income per capita, the annual decrease of poverty has been only of 1.2 points on average over the last three years. Thus, poverty is decreasing slowly. If such a pace is maintained over the coming years, the objectives of cutting the proportion of the population living under the poverty line down to $50 \%$ by 2012 and down to $35 \%$ by 2015 will not be achieved.

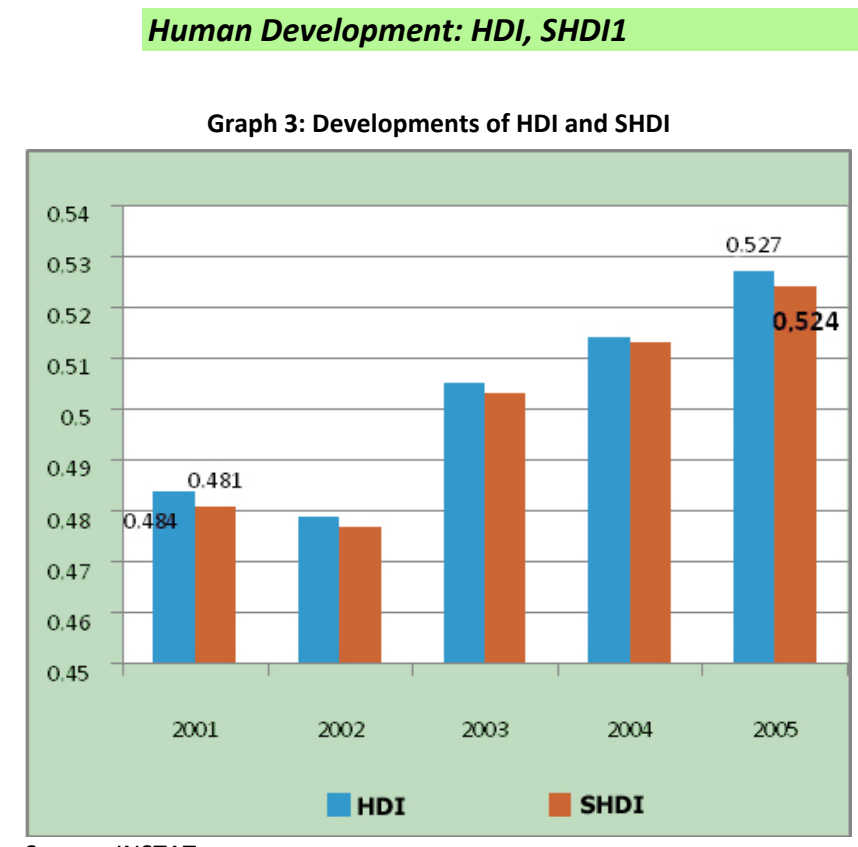

Source: INSTAT

With an national average of 0.527, Madagascar has become a country with medium human development $(0.5 \leq \mathrm{HDI}<0.8)$ since 2003 according the MDG Follow Up

\footnotetext{
${ }^{1} \mathrm{HDI}$ is calculated based on life expectancy at birth, the literacy rate
} among adults, the enrollment rate, and the GDP per capita.
Report in 2007 and the National Report on Human Development in 2006. This results from the efforts made to improve the educational system and the population's health status (enrollment rate, literacy rate, and life expectancy at birth).

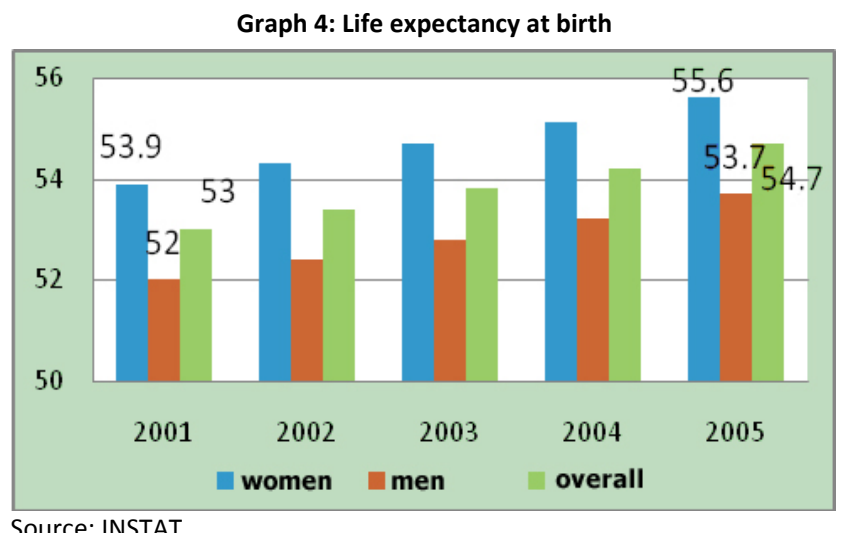

However, disparities remain and indicate that women are victims of discriminations in the economic and social processes, the SHDI being 0.524 and the HDI 0.527

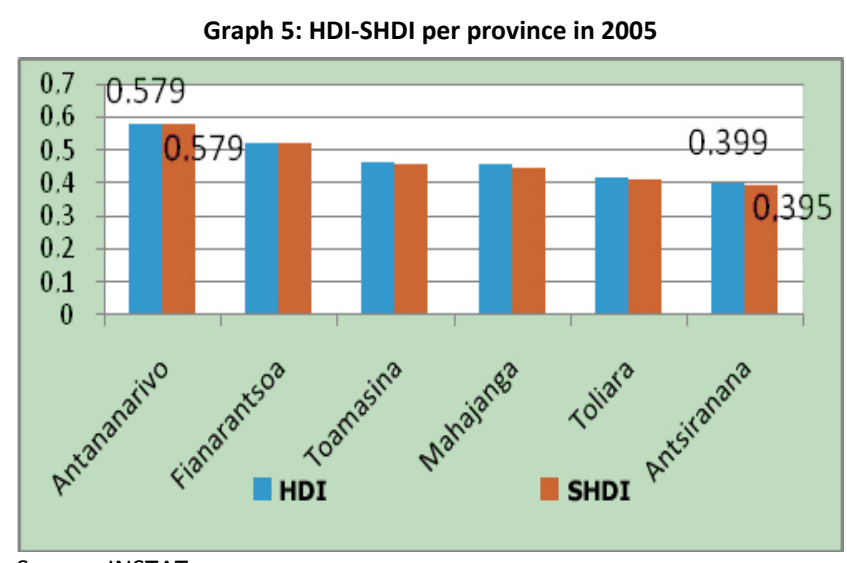

Source: INSTAT
Graph 6: Estimated ratio of income Men/Women

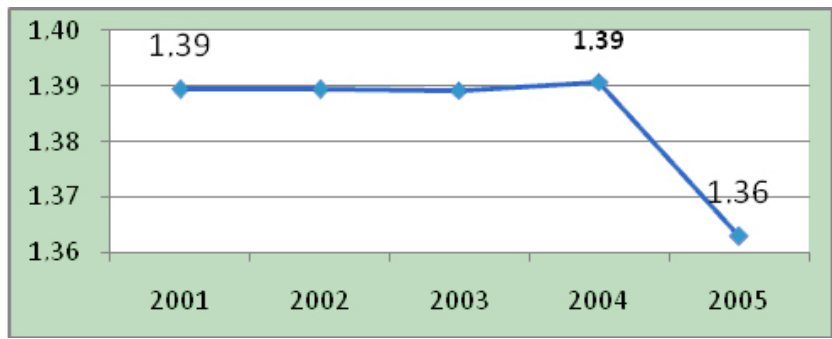

Source: INSTAT

The country is still building on the achievements made in social progress and has been sustaining and improving its performance over the last three years (2005 to 2007). The impacts of the efforts have become tangible and are reflected by the followings:

- The completion rates at the primary level, lower secondary, and higher secondary per gender as regards the educational sector;

- The improvement of the enrollment rate with the net rate becoming stable at $97 \%$ in the primary level;

- The increase of the GDP which result in a real GDP per capita of USD295 in 2005, USD288 in 2006, and USD375 in 2007.

Graph 7: Literacy and Enrollment Rates

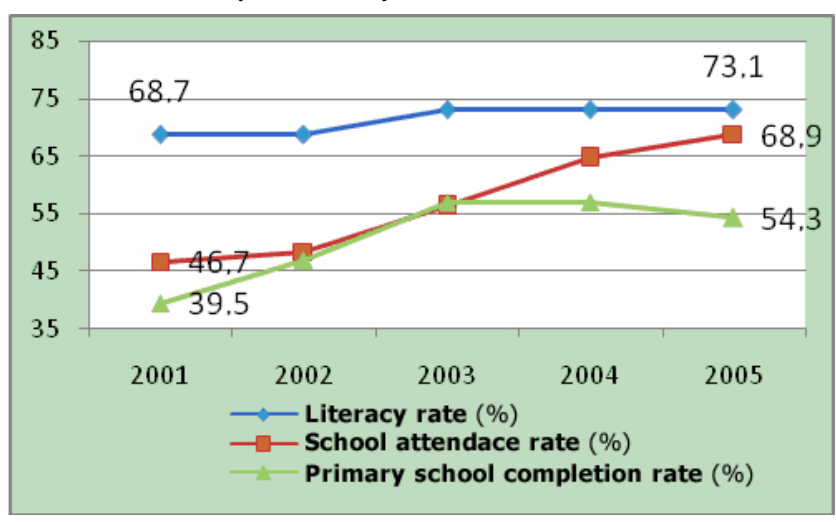

Source: INSTAT 


\section{IMPLEMENTATION OF THE MAP}

Graph 8: Literacy Rates by Gender

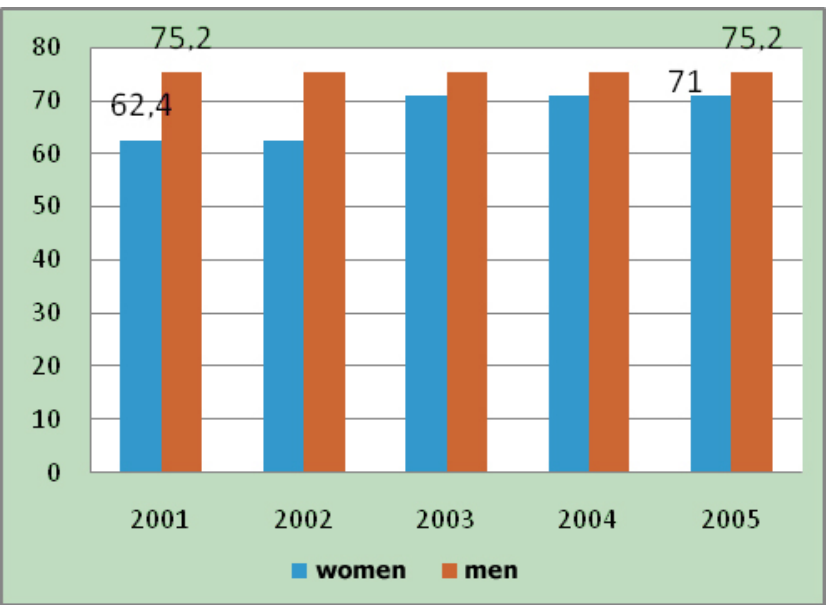

Source: INSTAT

\section{CHALLENGES}

- Reducing the poverty rate to $50 \%$ by 2012 and to $35 \%$ by 2015 means that the efforts and actions must be reinforced in order to triple the pace at which poverty is currently decreasing.

- Maintaining macroeconomic stability through a high growth rate sustained by a high investment rate especially private investment, a decrease of the inflation rate, and an increase of internal resources, namely tax revenues;

- Implementing sectoral programs, especially in high potentiality sectors in order to reinforce the economic sectors' productivity and competitiveness so as to induce higher growth based on diverse job-generating economic activities;

- Keeping on improving the investment climate as well as the business environment.

\section{RECOMMENDATIONS}

In order to support the recent performances of the Malagasy economy and to improve the living conditions of the population, the following recommendations are made:

- Reinforce institutional reforms in process to improve the economic environment through efficient governance, motivation of public servants, facilitation of access to basic infrastructures and resources (energy, telecommunication, land property, industrial zone), and expanding access to public procurements to SMEs;

- Increase rural productivity in order to ensure food security through technical support to producers, improving rural productive infrastructures and use of modern farming techniques, improved land security, and access to funding;

- Privilege the "employment" approach in major works to redistribute income and promote entrepreneurship;

- Reinforce support for micro and small enterprises by setting up and making operational support and promotion centers at the regional level and by facilitating access to funding and partnership:

- Make operational the National Strategy for Social Protection, targeting more specifically the vulnerable groups;

- Ensure optimal allocation of resources to the social sectors, in order to ensure redistribution of resources towards the vulnerable groups.

The country will be faced with the major challenge of implementing the National Integrated Monitoring and Evaluation System (NIMES) at the national and regional levels in 2008. The success of the system relies on making operational organizational and institutional frameworks, specifically the information systems, as its main pillars.

The INSTAT will proved special support to improve the information system at the national and regional levels, namely to fine tune indicators, consolidate administrative data, and producing statistical information.

In addition, special efforts will be made to improve the availability, the quality, and the reliability of administrative statistics.

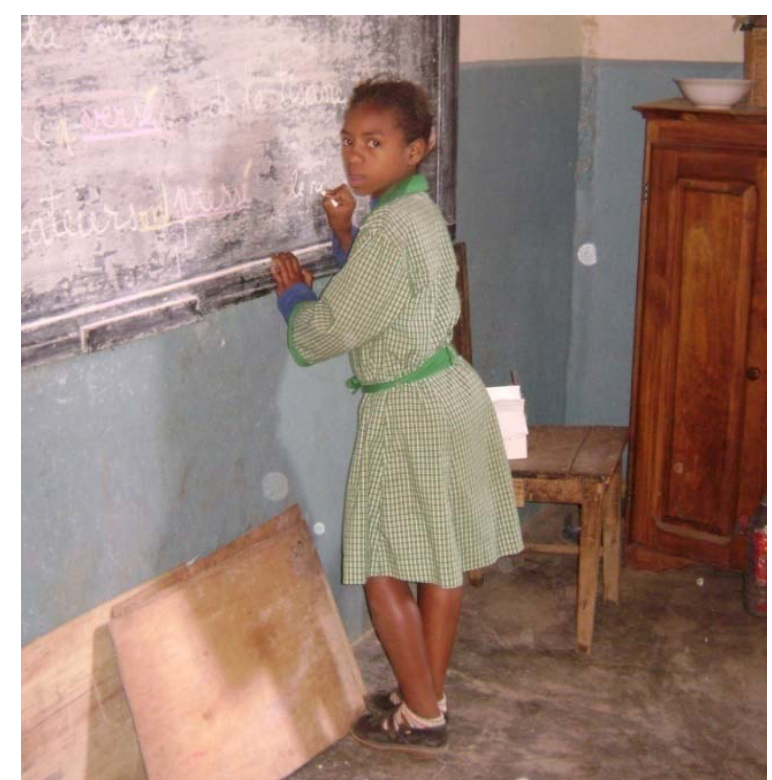

Photo : EPP Andrefan'Ambohijanahary 


\section{IMPLEMENTATION OF THE MAP}

\section{COMMITMENT 1: RESPONSIBLE GOVERNANCE}

We will have a government that every citizen and the international community can trust and have confidence in. This government and the civil service will demonstrate integrity, be efficient, and act professional in all pursuits, activities, and the provision of services. Such are the objectives under this Commitment.

\section{ANALYSIS OF THE QUANTUM LEAP}

According to the Afrobarometer survey in 2005, almost $90 \%$ of the Malagasies believe that poor governance is the reason of poverty in the country. Therefore, it is urgent to find a solution to poor governance in order to lift the country out of the difficulties it is currently faced with.

Significant progresses were made in 2007 in the following areas:

- The crime rate was reduced to 1.8 per 1,000 in 2007;

- The corruption perception index has been tangibly improving;

- The public finances management is more efficient;

- Laws and regulations on decentralization have been promulgated; the laws on the functioning of the Decentralized Collectivities have been developed and should be submitted to the Parliament at its next session.

\section{ANALYSIS OF PRIORITY INDICATORS}

Crime rate reduced at 1.8 per 1,000 inhabitants and 12 hot spots cleaned up

- Significant results were achieved in the area of people and property's security though there remain uncontrolled pockets of insecurity due to the lack of resources. In 2007, while the objective was 4 per 1,000 , the crime rate was reduced at 1.8 per 1,000 i.e. about 2 offences per 1,000 inhabitants. However, it should be noted that crime has become increasingly violent with the actions of armed gangs;

- Twelve districts against an objective of ten were cleaned up. One hundred and seventy nine (179) Autonomous Security Detachments have been standardized, the rural security operations and the general police patrols have been reinforced and the system of proximity police has been revitalized. It is more and more demonstrated that the actions of the fokonolona, the administration, and the police force complement each other and such complementarity is improving.

The reported cases of cattle thefts decreased by $38 \%$, mainly due to the recommended actions of repression and intensive checking of marketing documents.

\section{Improved Coverage of the Exclusive Economic Zone}

Covering the Exclusive Economic Zone means ensuring the surveillance of the marine zone where the country draws marine and oil resources.

The collaboration between the Civil Protection Body from the Ministry of National Defense and the National Office for Risk and Disaster Management (BNGRC) allowed for strengthening and improving the coverage of the EEZ compared to what was done in 2006. Indeed, the teams performed 133 days of outings on the sea, 626 hours and 25 minutes of flying over the Malagasy aerial space, and 120 hours of outing on fast boasts on the sea against objectives of 136 hours of outings on the sea, 300 hours of flying over, and 100 hours of outings on fast boats.
In the same way, the land surveillance actions carried out by the State Secretariat of Public Security have increased by $47.4 \%$ from 2006 to 2007.

Slow decrease of the average time for trials and processing of pending cases

A big delay was noted in the actions aimed at building the capacities of $11 \%$ of the jurisdictions in the area of standards of service in 2007. The average time for trials has not improved: the average time for simple criminal cases has remained at 120 days against an objective of 90 days, and the average time for complex criminal cases at 450 days against an objective of 365 days.

In the same way, the actions to improve the processing of pending cases were not significant enough:

- At the Supreme Court level:

- in criminal matters, $79 \%$ of the pending cases processed for judgments delivered and $65 \%$ for judgments under appeal.

- In civil matters, $63 \%$ of the pending cases processed for judgments delivered and $73 \%$ for judgments under appeal.

- At the Courts of Appeal: $94 \mathrm{M}$ of the pending cases for judgment delivered, $56 \%$ for the judgments under appeal, and $48 \%$ for case papers.

Actions were also carried out to improve the respect of human rights in prisons, namely an increase to MGA341 in the daily expenditures per prisoner against an objective of MGA120.

\section{Improved corruption perception index}

Appreciable progresses were made in the anti-corruption efforts. The actions to reinforce laws and regulations and the setting up of the Higher Council of Integrity and the 


\section{IMPLEMENTATION OF THE MAP}

Independent Anti-Corruption Office (BIANCO) have been yielding early results:

- The corruption perception index of Transparency International has improved from 1.7 (base 10) in 2002 to 3.2 in 2007. Keeping with such a pace, the objective of 5.0 by 2012 should be achieved.

- $86 \%$ of the cases processed by BIANCO have been transferred to the court and $95 \%$ of the investigated cases have been processed. However, the private sector is not fully involved in the implementation of the anti-corruption actions and the proximity actions are not yet effective due to delays in setting up branches throughout the country.

The sustainability of the overall anti-corruption system is dependent on how well the efforts are disseminated into all sectors and all segments of the society as well as the ownership of the fight against this plague by the population.

\section{Reform of public finances management}

Madagascar has conducted big efforts to improve its public finances management over the last period:

- Budgetary procedures clearly improved;

- High-performance organization of financial forth accounts;

- Consolidated expenditure chain: better transmission of information, end of the abusive application of emergency procedures;

- Coordinated efforts on the preparation of the laws relating to payments;

- Budget implementation reports produced within the year by the Ministries;
- Improved management of Treasury

However, the operational implementation of the reforms is still faced with some inadequacies that affect the effectiveness and the reliability of the overall mechanism. The budget nomenclature is still somehow complex, which results into difficulties in developing and implementing the budget.

\section{Improved fiscal pressure}

Coordinated efforts were carried out to establish an improved method for tax collection. This involved operational and organizational reforms in the customs and tax services, including:

- Extending the use of Sydonia ++ to the customs offices of Mahajanga, and making operational the automated management of DTI payments at the Toamasina Port's offices;

- Developing partnership to expand the setting up of Approved Management Centers (AMC) to the regional level.

- The tax revenues have increased by $24.7 \%$ compared to 2006. The fiscal pressure rate increased by 0.7 point compared to the rate of $10.7 \%$ in 2006 . The budget deficit, cash base, has clearly improved from $4.3 \%$ of the GDP in 2005 to -2.8 in 2007. Year 2006 was an exceptional year with a budget surplus of $37.4 \%$ which was due to debt relief.

\section{All the Ministries are connected to the Integrated Public Finances Management System (IPFMS)}

The IPFMS is effectively operational in all the central Ministries, the Treasuries, and the Control of Expenditure Commitments. However, the network is not yet operational at intra-city and intercity level. To make up for this, six regional IT centers have been made operational for the entering budget implementation data.

Budget preparation and implementation procedures improved

The macroeconomic framing of the 2007 budget took the MAP's priorities into account. The budget was ready for implementation in early January 2007, but the late appointment of the Secondary Authorizing Officer and Activity Managers delayed its actual implementation. Nevertheless, some actions were carried out, including building the capacities of the managers at the Ministries on the procedures, streamlining the nomenclature, instituting a quarterly regulation of expenditure commitment, applied all year long. However, mastering the linkage between public expenditures and results to achieve remains a problem, i.e. the concept of resultoriented management of the budget-program.

\section{Budgetary control reform continued}

The control and verification actions were continued through strengthening the operations of the structures in charge of procurement (Procurement Officers and Procurement Management Units) in the ministries. As regards the control of expenditure commitments, a counting of authorizations per category of observation and per authorizing officer is being carried out and the related statistics should be available by late 2007 .

\section{Contracts awarded through competitive processes}

The compliance of expenditure implementation to good governance principles was ensured through the actual enforcement of the new Code of Public Procurements and the functioning of the Authority in charge of Regulating Public Procurements (ARMP).

Despite weaknesses in planning and regulation of credit, the percentage of contracts awarded through a competitive process reached $87.3 \%$ of the objectives set (67.6\% against an objective of $77.5 \%$ ). 


\section{IMPLEMENTATION OF THE MAP}

Procurement procedures compliant with the new legal and regulatory framework

The proportion of procurement procedures assessed as compliant with the new regulatory framework in a sample of public institutions deemed to be representative (Health, Education, Transport, Agriculture, and Public Works) was $93.8 \%$ of the objectives set. The Procurement Officers were appointed in the Ministries and received training on typical bidding documents, public procurement techniques, and rules provided by the Code of Public Procurements. However, some of the trainees do not yet master their work.

\section{Administrative procedures streamlined in public} services

In order to reinforce the effectiveness of public service provision, the setting up of a one-stop shop at the Ministry of Civil Service has allowed for regularizing the career files of Government employees. As a result, 893 decrees of admission to retirement, 791 decrees and decision of promotion, and 697 cases of integration were processed. Thanks to the Rapid Result Initiative (RRI), the average time for processing a file decreased from 120 to 75 days.

Users benefit form high-quality public service provision with the promotion of e-governance, made concrete through the rolling out of the Government's Intranet in all Ministries.

\section{Local tax collection rate}

The organizational and information systems at the Ministry in charge of Decentralization and Land Development at the Presidency do not yet allow for having real time data on the local tax collection at the decentralized collectivities' level. Through the data are available, the sampling made among some administrative accounts are not yet reliable enough.

However, with the available information, it is possible to identify positive developments in the collection of taxes at the commune level with an increase from MGA26,245 billion in 2005 to MGA41,376 billion in 2007, i.e. an increase of $57.7 \%$.

Actions have been carried out to improve local tax collection methods:

- Introduction to the software "HETRA" for 260 communes: census procedures, collection of land taxes, determination and possible expansion of tax base as well as of the amounts to be collected each year;

- $\quad$ Setting up of Commune Support Centers (CAC), with 300 communes covered to date;

- Publication of the law setting up the Local Development Fund whose main role is to build the communes' capacities and to fund their activities and investments.

\section{A small share of the budget allocated to the} Communes

Table 1: Share of the budget allocated to the Communes

\begin{tabular}{|l|l|l|l|}
\hline \multicolumn{1}{|c|}{ Indicator } & \multicolumn{1}{c|}{$\mathbf{2 0 0 6}$} & $\mathbf{2 0 0 7}$ & $\mathbf{2 0 0 8}$ \\
\hline $\begin{array}{l}\text { Share of the budget } \\
\text { allocated to the } \\
\begin{array}{l}\text { Communes (\% of general } \\
\text { budget) }\end{array}\end{array}$ & 1.21 & 1.48 & 2.20 \\
\hline
\end{tabular}

The proportion of the budget allocated to the communes remains low at only $1.52 \%$ of the total budget. Given that the executive officers of the communes are at the end of their terms, and given the budget framing constraints, the
Central Government acted in a prudent way in allowing funds to meet the needs of the communes because of the poor financial and administrative management capacity of mayors. Therefore, the share of the budget going to the communes was low. However, the Central Government's will to grant more autonomy is clearly seen in the promising increases in the transfers made over the previous years.

\section{Contributions of Programs and Projects}

- The Program of Reforms for the Efficiency of Administration (PREA) groups the Project of Governance and Institutional Development/IDA (PGDI), the Administrative Reform Support Project (ARA)/UNDP, the Project of Institutional Reinforcement for Governance (PRIBG)/ADB. PREA's intervention focus on promoting and enhancing the government's efficiency as part of promoting governance: presidential leadership, development of convergence and harmonization among actions supported by financial partners, a result-oriented spirit, modernization of and capacity building for the public administration, improvement of traceability of financial transactions and steering of proximity services reforms.

- The reinforcement of integrity and the reform of the business law benefited from the contributions of the Priority Solidarity Fund "Support to Consolidating the Rule of Law". On the other hand, the "Community Support for the Rule of Law" with the European Union contributes to improving human rights in the prison setting.

- The Program ACORDS/EU focuses on funding communes. 


\section{IMPLEMENTATION OF THE MAP}

- As part of local governance and support to decentralized collectivities and services, the Integrated Growth Poles Project (IG2P) contributed to building the capacities of municipalities as well as increasing their tax revenues.

\section{COMPLETION STATUS OF THE MAJOR COMMITTMENTS TAKEN DURING THE PRESIDENTIAL DIALOGUE}

\section{Immediate Actions}

- Increase by $44.2 \%$ of the operations carried out by the different bodies of the police force to establish security, including 15 fokontany supervised, which allowed for arresting 22 bandits;

- Increase by $27.3 \%$ of intelligence information obtained before, during, and after municipal elections;

- Increase by $35.5 \%$ of flash operations during the endof-year holidays;

- Bill on establishing the Higher Court of Justice submitted to the Government

- Partnership between the BIANCO and the Justice: agreement pending at the Ministry of Justice on regular communication of the results of cases referred to the courts;

- Production and wide dissemination of a 2008 calendar for all the communes of Madagascar, stressing the responsibilities of and what is expected from elected officials and administrative authorities as well as the institutional aspect of decentralization;
- Dissemination and distribution of the software "HETRA" for direct and rapid application: the data of 260 communes were entered and the actions will be continued in order to cover all the communes of Madagascar;

- Setting up of CACs in 300 communes in order to provide technical support.

\section{Actions in $\mathbf{3}$ months}

- $\quad$ Setting up an information and data processing system that is up-to-date, modern, and standardized installation of two HF posts in Betafo and Mahanoro, 10 central directorates, and 7 central services connected to the Government's intranet.

- Anti-corruption penal chain installed in 3 provincial capitals: Court of First Instance of Mahajanga, Fianarantsoa, Toamasina; actors sensitized;

- Reinforcing mobilization of civil society organizations as a relay for public information and education;

- Transfer of competency and power to decentralized collectivities: development of a report going towards a set of bills on decentralized collectivities that will be presented to the first session of the Parliament in May 2008;

- Making operational the Local Development Fund (LDF): recruiting the first staff. This had to wait for the two chambers of the Parliament to vote the regulations on the organization and the functioning of the LDF

\section{Ongoing actions}

- Gradual application of the computerized management of weapons and ammunition through the entering of data at the service in charge of controlling weapons at the National Police (central and inter-regional levels);

- Multiplying preventive measures in urban setting increase by $98.9 \%$ in terms of intelligence information; 98.9\% for patrols, and $8.1 \%$ for TPG;

- Fight against corruption: training of 46 investigators as peer educators, i.e. an increase in number of $58.6 \%$;

- Seventy-five (75) police cordons on roads with a decrease by 44.6 of traffic accidents;

- Increase by $62.1 \%$ of the permanent guardians for the protection institutions;

- Asset declaration form distributed to all magistrates;

- Bill on the Higher Council of Magistrates adopted by the Parliament;

- Information shops operational in 15 magistrates' courts and 4 courts of appeal;

- Twenty-two (22) checks on compliance with the rules of ethics and deontology conducted by the magistrates and the jurisdictions' staff;

- Implementation of the process to establish the standard of minimum service;

- Awareness raising and developing the sense of responsibility among administrative authorities;

- Involving decentralized collectivities in protecting national sovereignty

- Transferring competencies and power to the decentralized collectivities: actions limited to 260 


\section{IMPLEMENTATION OF THE MAP}

communes due to the delay in allocating the MPRDAT's operating budget in 2007. More efforts will be made in order to cover the remaining communes.

\section{Challenges and Outlooks}

- Implementation of all actions in the area of public security included in the RRI by March 31st, 2008 at the latest;

- Continuing the reforms, projects, and activities initiated in 2007, namely those related to transforming the judiciary system, including the Trade Court, or changing laws, namely those related to the revision of the Higher Council of Magistrates, custody, and the law on the Supreme Court;

- Developing RRI in the target jurisdictions: processing the pending cases and improving imprisonment conditions in the penitentiary institutions;

- Continuing the revitalization of penal camps;

- Development of partnership among the different anticorruption units: BIANCO, ZP, CSI, Anti-corruption Penal Chain;

- Strengthening ownership of Anti-corruption Efforts (ACE) by regional officers: implementation of a regional ACE policy;

- Improving the quality and the transparency of public services (front office): establishing and implementing the standards of minimum service;

- Strengthening the performance of the BIANCO in processing cases investigated;

- Setting up and making operational the institutional frameworks at the regional levels for reinforcing the management and the transparency of public finances: CDE, ARMP, Treasury, Budget
- Promoting the population's participation in democratic life by building on and using e-governance tools;

- Aligning the National Policy for Decentralization and Devolution to the MAP: part of its contents will be updated and harmonized with the challenges related to effective decentralization of the Administration;

- Setting up as an urgent action Commune Support Centers for a group of given communes (for instance, one CAC for every 10 to 15 communes) by December 2008;

- Developing a sense of responsibility to CAC to coach commune officers to accomplish their mission of sending information upward (namely, the administrative accounts and regular reports: only $25 \%$ sent their accounts of 2006);

- Reinforcing mass communication to raise awareness not only among leaders and administrative authorities but among citizens living in the communes as well;

- Building the capacities of communes through the Local Development Fund in order to achieve a high level of tax collection, which warrants the success of large scale social and economic actions to the benefit of the local population.

\section{RECOMMENDATIONS}

- Recruit 1,000 policemen and policewomen per year, subject to financial support and the government's authorization;

- Achieve the maximal coverage of 119 districts in order to avoid distance management of security, through timely operations, including patrols of the general police;

- Institute Behavioral Change Communication (BCC);
- Intensify the awareness-raising campaign corruption;

- Increase the number of session on civics;

- Reinforce effective collaboration between the partners of the Justice, such as BIANCO, CSI, bailiffs, lawyers, namely to accelerate the processing of cases;

- Increase the share of budget allocated to decentralized collectivities (budget transfer) to allow for :

- increasing the staff at the CAC, at the Central Directorate for processing, analyzing, and using data and producing results;

- $\quad$ reinforcing the teams of each region by recruiting officers to be in charge of the Monitoring and Evaluation Units and the Information System establishing the remaining CACs, which depends on two decisive factors: the communes' will to set up associations of communes and the contribution of technical and financial partners; - $\quad$ ensuring proximity monitoring and evaluation of actions conducted by each commune as part of implementing the MAP;

- Make operational the Local Development Fund as soon as possible in order to build the communes' capacities: control, inspection, monitoring, and evaluation of activities;

- Reinforce the application of the Code of Public Procurement by training the concerned entities at the central and regional levels on the typical bidding documents, on public procurements techniques, and on the rules provided. 


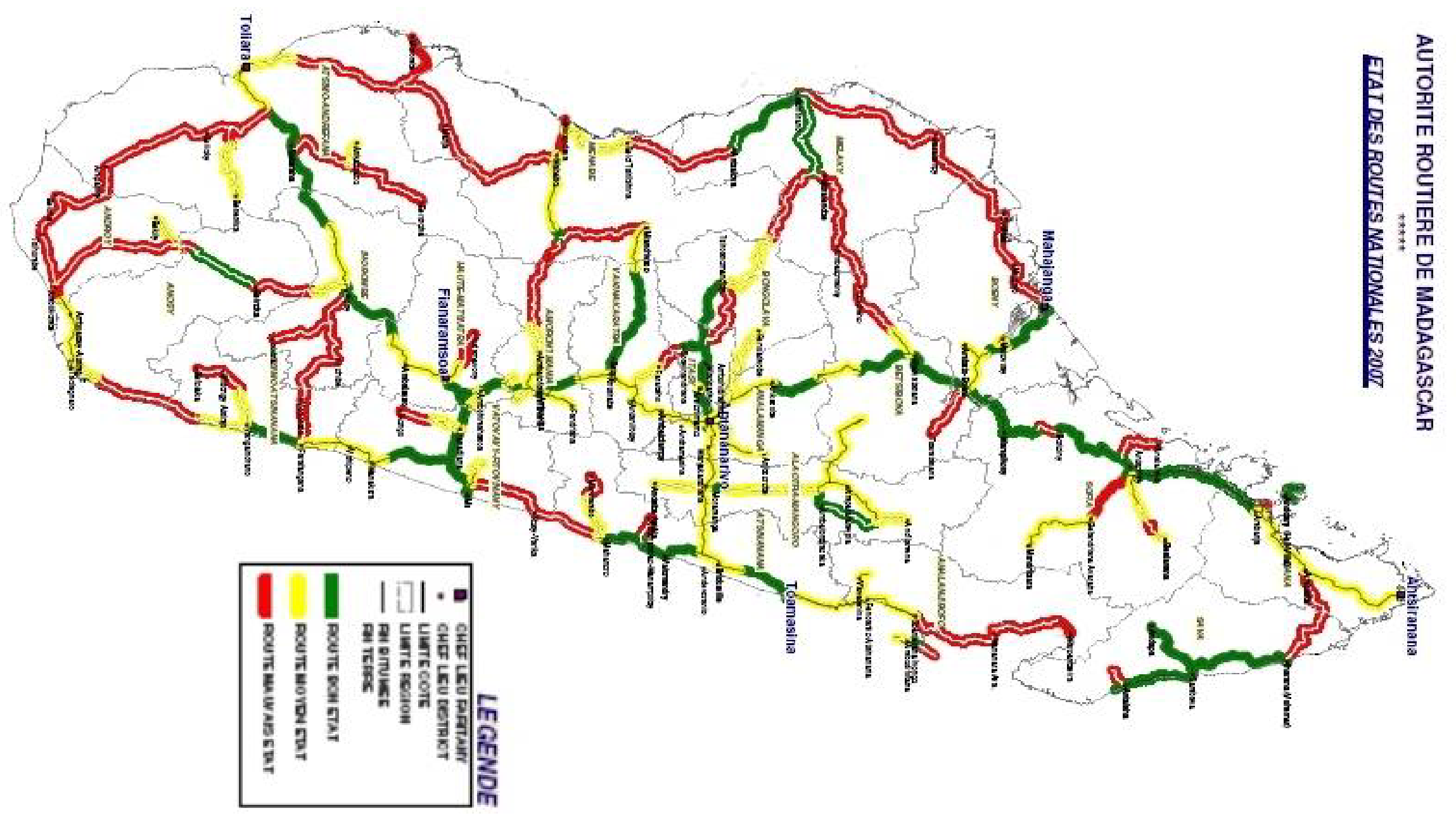




\section{IMPLEMENTATION OF THE MAP}

\section{COMMITMENT 2: CONNECTED}

\section{INFRASTRUCTURES}

The main objective under Commitment 2 is to have a connected Nation. The building of quality roads, railways, ports, and airports, the increased production of energy, the setting up of information technology systems throughout the country, the reliability of meteorological forecasts, the supply of safe water and sanitation all support the economic development process. As such, Commitment 2 provides logistical support to the other Commitments and has a cross-cutting character.

\section{ANALYSIS OF THE QUANTUM LEAP}

The following changes resulting from the implementation of Commitment 2: Connected Infrastructures were noted:

- In 2007, the Road Authority of Madagascar (ARM) became operational as part of the institutional reforms within the Ministry of Public Works and Meteorology;

- $1,382 \mathrm{~km}$ of national roads were built or rehabilitated or benefited from regular maintenance works;

- $8,251 \mathrm{~km}$ of national roads benefited from current maintenance works;

- The transport sector expanded in 2007 with an increase of $17.3 \%$ for the transport of goods and $13.3 \%$ for the transport of passengers.

- JIRAMA had poor capacity in terms of energy production due to technical as well as financial problems;

- The amounts of power installed in the form of renewable energy clearly increased thanks to the coming of independent electricity producers (private operators);
- The population's access to telephone has significantly improved;

- Households' access to safe water has slightly improved at the national level.

\section{ANALYSIS OF PRIORITY INDICATORS}

National tar or dirt roads maintained in good/fair condition

Table 2. Evolution of the main achievements in the area of road infrastructures from 2003 to $2007(\mathrm{~km})$

\begin{tabular}{|l|c|c|c|c|c|c|}
\hline Program/ Projects & $\mathbf{2 0 0 3}$ & $\mathbf{2 0 0 4}$ & $\mathbf{2 0 0 5}$ & $\mathbf{2 0 0 6}$ & \multicolumn{2}{|c|}{2007} \\
\cline { 4 - 7 } $\begin{array}{l}\text { Construction, } \\
\text { rehabilitation, and } \\
\text { regular } \\
\text { maintenance of } \\
\text { national roads }\end{array}$ & 105 & 1,504 & 805 & 2,429 & 1,229 & 1,382 \\
$\begin{array}{l}\text { Construction, } \\
\text { rehabilitation, and } \\
\text { regular } \\
\text { maintenance of } \\
\text { rural roads }\end{array}$ & 93 & 711 & 977 & 3,326 & 1,663 & 205 \\
$\begin{array}{l}\text { Current } \\
\text { maintenance of } \\
\text { national roads }\end{array}$ & NA & 6,819 & $\begin{array}{c}7,20 \\
0\end{array}$ & $\begin{array}{c}11,00 \\
0\end{array}$ & 10,900 & 8,251 \\
\hline $\begin{array}{l}\text { TOTAL } \\
\text { nOTA }\end{array}$ & 198 & 9,034 & $\begin{array}{c}8,98 \\
2\end{array}$ & $\begin{array}{c}16,75 \\
5\end{array}$ & 13,792 & 9,838 \\
\hline
\end{tabular}

Source: MTPM

A clear increase was noted in the achievements in terms of road infrastructures from 2004 to 2006 with a total of $9,034 \mathrm{~km}$ in 2004 and 16,755km in 2006. A slight decrease occurred in 2007 due to the closing out or suspension of funding. The current maintenance of national roads has a large place in the operations.

Year 2007 was a transition year for the Public Works department as the main programs were coming to their end. Results achieved in 2007 are summarized as follows: $48 \%$ of the paved roads have been maintained in good condition and $41 \%$ in fair condition. As regards dirt national roads, $10 \%$ have been maintained in good condition and $19 \%$ in fair condition. Forty percent $(40 \%)$ of the communes can be accessed by road all year long. The objectives set for 2007 were achieved but the results are quite mixed as not even half of the infrastructures existing at the national level were covered.

The following projects/programs contributed to the results: the National Road Maintenance Program (PNER/ European Union Phase II, the National Engineering Structure Maintenance Program (PNEOA)/ European Union Phase II, The regular and current maintenance program funded by FER/RPI, the Project of investments in transport infrastructures (APL3) and the Integrated Growth Pole Projects (IG2P) on a funding from the World Bank, and Projects funded by the ADB and the BADEA. While the Ministry of Public Works and Meteorology made special efforts, $70 \%$ of dirt national roads and rural roads that connect $60 \%$ of the remote communes still suffer from the lack of maintenance.

\section{Decrease in the average cost of good transport}

This primary indicator was not available from the transport sector for 2007. However, a clear improvement of the sector's performance was noted, with an increase of $17.3 \%$ for the transport of goods, and $13.3 \%$ for the transport of passengers 2 . These results are due mainly to the improved quality of infrastructures, and the efforts made since 2004 in the area of transport infrastructures. They reflect also the positive trends in imports and the coming of foreign tourists.

The main Projects that contribute to the sector's performance include the Projects for Investment in Transport Infrastructures (APL3) and the Integrated Growth Poles Project funded by the World Bank.

${ }^{2}$ According to the economic situation note prepared in 2007 by the directorate of Economic studies and Modeling (DEEM) at the Ministry of Economy, Trade, and Industry. 


\section{IMPLEMENTATION OF THE MAP}

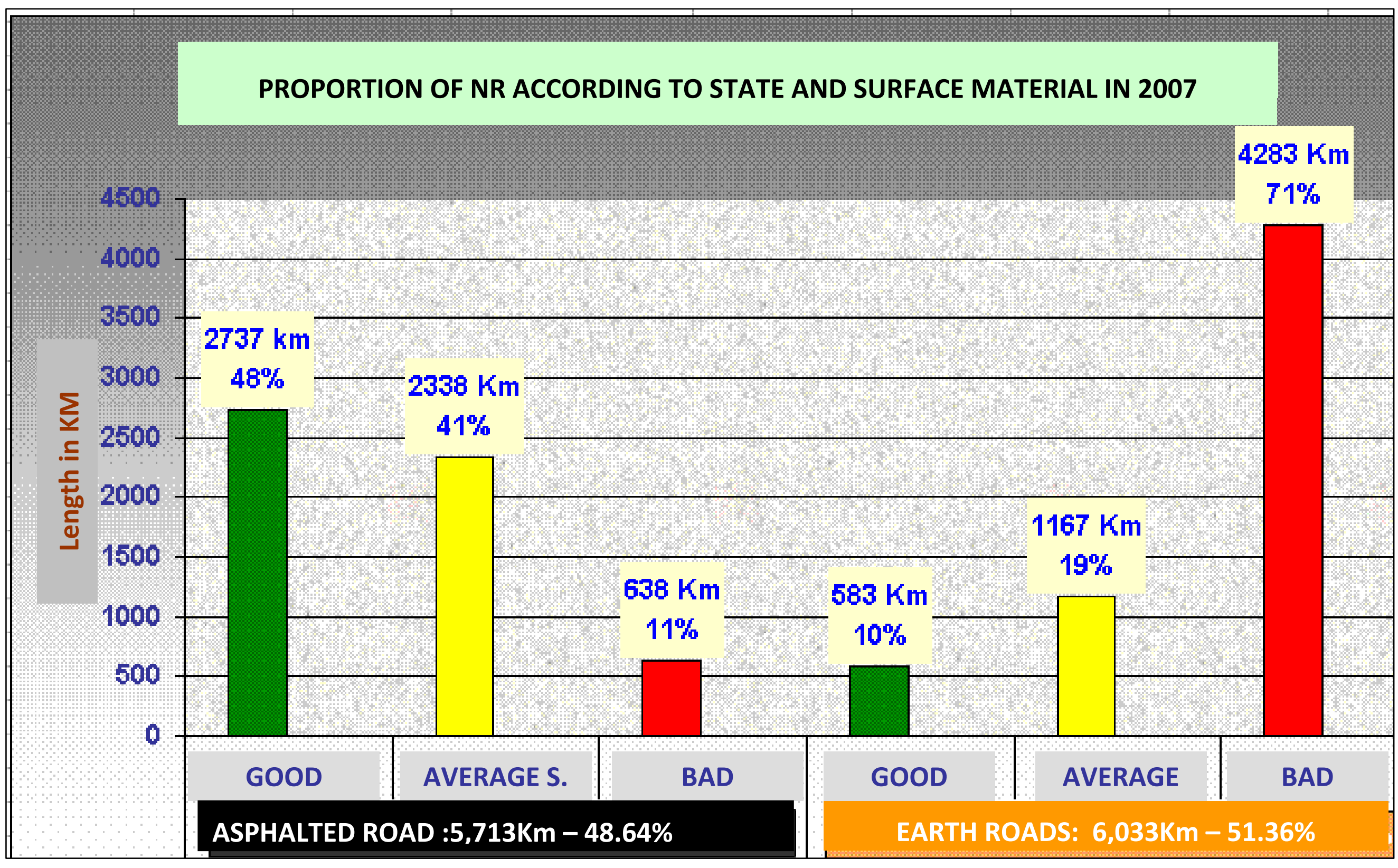




\section{IMPLEMENTATION OF THE MAP}

Decrease in the number of victims of road traffic accidents

Graph 9: Trends in the number of victims

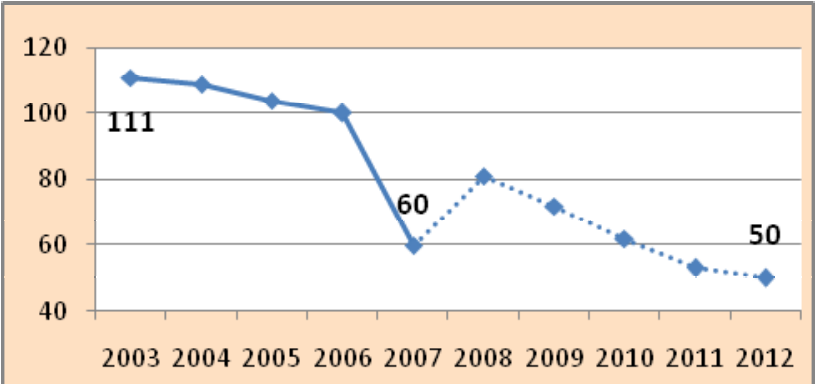

ource: MT and SNISE (Base $100=2006$ )

The evolution index of the number of victims, base 100 in 2006, decreased from to 111 in 2003 to 60 in 2007 against an objective of 91 . The result is mainly due to the measures taken by the different authorities in charge of road traffic security.

\section{Reliability of meteorological forecasts}

The meteorological forecasts' reliability rate of $65 \%$ planned for 2007 was achieved. The National Office for Disaster and Risk Management (BNGRC) has improved its timely interventions pursuant to the last cyclones and this has improved good and people's security, as well as economic activities' security in general.

\section{Households' access to electricity in rural and urban} areas

Households' access to electricity at the national level remains low, stagnating at about 45\% in 2006 and 2007. This is mainly due to the suspension of new connections because of JIRAMA's technical and financial situation (low productive capacity and non renewal of investments). This poor capacity is confirmed by the results obtained as regards rural electrification in 2007: out of the 100 localities planned, only 37 (i.e. $37 \%$ ) received electricity.
The poor performance is due to the freezing of the 2007 budget since July because of certain procedures and measures related to the decree setting up the ADER. The funding allocated from internal resources and the HIPC resources to rural electrification were transferred to the National Fund for Electricity. At this pace, the objectives set in the MAP as regards electrification, especially in rura areas, will not be achieved by 2012, which call for special actions.

As regards the evolution of cost of the electricity $\mathrm{KWH}$ from JIRAMA, tangible increases have been noted, namely $21 \%$ in $2005,56 \%$ in 2006, and $6.3 \%$ in 2007 due to JIRAMA's operating costs.

However, power installed in the form of renewable energy by independent electricity producers has increased from $88 \mathrm{MW}$ in 2006 to $91 \mathrm{MW}$ in 2007 . The increase is mainly due to the coming of several private operators such as Henri Fraise, HYDELEC, ENELEC, and EDM.

The IG2P also contributed to making up for the failure of several power-generating units of JIRAMA.

\section{Increased telephone penetration rate}

Graph 10: Telephone penetration rat

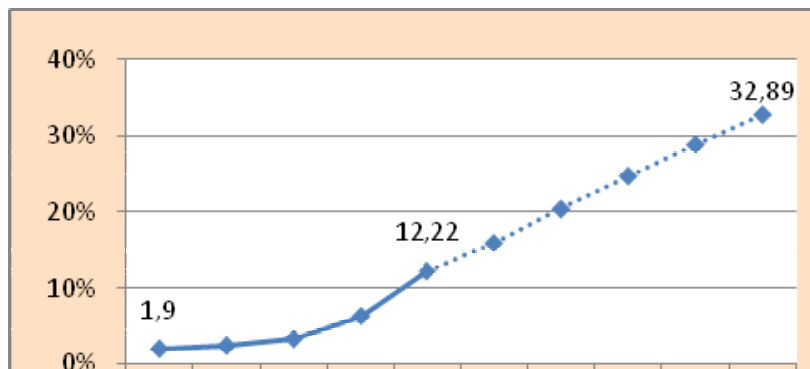

2003200420052006200720082009201020112012

Sources: MPTC et SNISE

The objective of $11.4 \%$ as regards the telephone penetration rate in 2007 has been exceeded. Indeed, the rate increased from $1.9 \%$ in 2003 , to $6.3 \%$ in 2006 and
$12.22 \%$ in 207 . The sector has been flourishing and the population's access to this service has clearly improved. The institutional reform, the sector's liberalization, and the development of competition in terms of quality of networks and services offered have largely contributed to these results.

The private sector's participation through the extension of the National Backbone project for the Northern Part in microwave beam, for Toamasina-AntananarivoFianarantsoa line in optical fiber, and operation of the Toliara-Taolagnaro-Mananjary-Vangaindrano has contributed to the good performance despite financial problems among operators.

On the other hand, the evolution of telecommunications and ICTs has allowed for the emergence of small enterprises and new economic activities that have generated employments, thus contributing to reducing poverty (repair of cell phones, taxiphones, sales of phone cards, etc.)

However, according to the MDG Follow Up Report in 2006, the coverage rate is still low compared to the country's total population on one hand and to the situation of other countries in the IOC, COMESA and SADC on the other hand.

\section{Communes' coverage with radio improved}

The commune's radio coverage rate increased from $28 \%$ in 2006 to $49 \%$ in 2007 . The result was obtained through the actions taken to lift regions faced with disaster risks out of remoteness. The French Cooperation provided special assistance by setting up 90 satellite reception antennas (Band $\mathrm{KU}$ ), 30 TV transmitters, and $35 \mathrm{FM}$ radio transmitters.

Improved access to safe water and hygiene

The water and sanitation sector has now its National Program for Access to Safe Water and Sanitation (PNAEPA) covering the period running from 2005 to 2015. 


\section{IMPLEMENTATION OF THE MAP}

The National Water and Sanitation Authority (ANDEA) created in 2004 is now operational. Its mission consists in setting up an operation framework for consultation and a regulatory framework for the use of water resources.

Graph 11: Proportion of the population with permanent access to safe wate

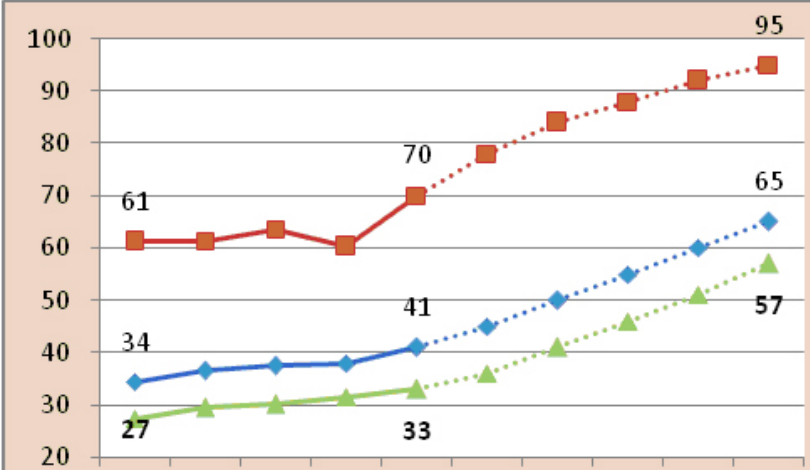

2003200420052006200720082009201020112012

at the national level (\%) - $\longrightarrow$ in urban areas (\%) in rural areas $(\%)$

Source: MEM/DEPA/MPTC and SNISE

It should be noted that the indicators published by the INSTAT on safe water supply and hygiene infrastructures under the MGDs are different from those of the Ministry in charge of Energy and Mines/ Directorate of Safe Water and Sanitation due to differences in the definition of their indicators and their basis for calculations.

According to the MDGs Follow Up Report, in 2006, the proportion of the population who had access to safe water improved from $24 \%$ in 2003 to $29.5 \%$ in 2004 and to $39.6 \%$ in 2005. According to the data from the Ministry in charge Energy and Mines, the proportion increased from $36.48 \%$ in 2004 to $37.45 \%$ in 2005 and to $38 \%$ in 2006 . The information for 2007 is not yet available. At this pace, the objective of $62 \%$ of the population having access to safe water by 2015 , as part of the MDGs, will be achieved by 2012.
It should be noted that while the objective was to build 650 water points in rural areas, the actual result was of 1,345, including 539 built by various partners (Caritas, WaterAid, CARE Fihamy, SAF/FJKM, CRS, etc.) and 806 by the Ministry in charge of Energy and Mines in collaboration with UNICEF and the DSF. The IG2P developed the water networks in Nosy Be and Taolagnaro. In urban areas, the freezing of private connections and connections for public standpipes has impeded the water supply activities.

\section{Graph 12: Proportion of the population with permanent access to} hygiene infrastructures at the national level

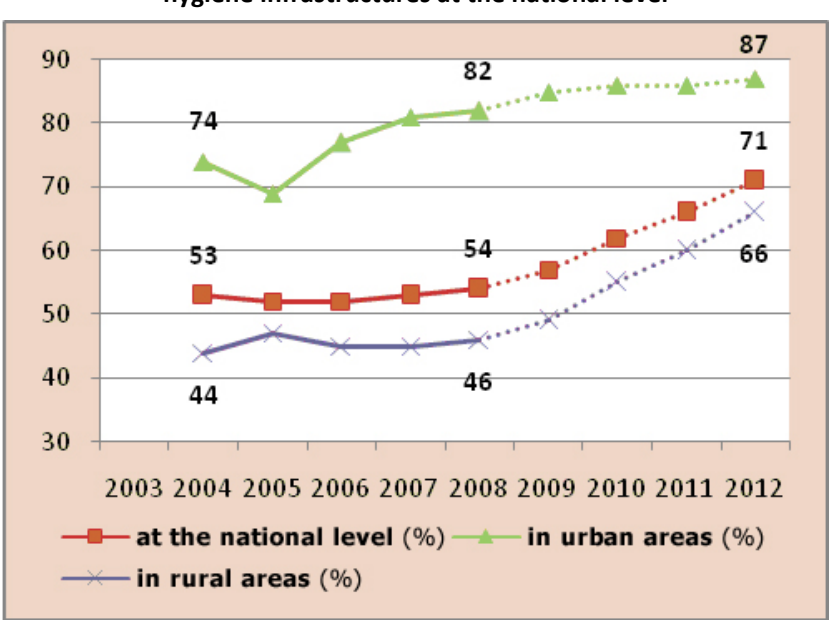

Source: MEM/DEPA/MPTC and SNISE

As regards sanitation, according to the MDGs Follow Up Report in 2006, the proportion of the population having access to an improved sanitation system increased from $44 \%$ in 2004 , to $44.8 \%$ in 2008 and to $48 \%$ in 2006 . The proportion of the population having latrines has slightly increased from 50\% in 2004 to 51.5\% in 2005 and 2006. In accordance with the information provided by the Ministry in charge of Energy and Mines, the proportion of the population with permanent access to hygiene infrastructures was of 53\% in 2004, and 52\% in 2005 and 2006. Achievements in 2007 include building 4,000 latrines against an objective of 5,000. Out of these, 3,935 were built by technical and financial partners on funding other than the PIP, and the remaining on a funding from the PIP/UNICEF.

In order to achieve the objectives set for 2012, efforts must be made, especially in the area of mobilizing funding, at the local, national, and international levels.

\section{Completion Status of Commitments TAKEn}

\section{During the Presidential Dialogue}

\section{Ongoing actions:}

- A planning to pay the arrears of the Ministry of Public Works and Meteorology has been established based on the credit allocated as internal resources and VAT. However, the lack of credit remains an obstacle.

- The economical operation approaches (laborintensive, local materials) have been integrated in the strategies and actions plans of the Ministry of Public Works and Meteorology.

- Land has been made available to promoters in the sector of Energy.

- The process for integrated management of safe water resources has been integrated in the National Program for Safe Water Supply and Sanitation for the period running from 2008 to 2012

Immediate actions:

- As regards the financial gap at the Ministry of Public Works and Meteorology, a funding by the European Union as part of the $10^{\text {th }}$ EDF was signed and the credits APL2 and APL3 from IDA have been extended.

- The Inter-regional directorate of Public Works in the region of Atsimo-Andrefana has been effectively reinforced in order to provide technical support to the regions. 


\section{IMPLEMENTATION OF THE MAP}

- Negotiations are in process for the effective application of weighing bridges as part of respecting and protecting public property;

- The repression of perpetrators of serious bodily accidents in the transport sector has become effective.

- The Electricity Sector Policy Note is developed.

\section{Actions in three months}

- The Sector Policy Note that was prepared addressed the issue of consistency and harmonization among transport sector policies.

- The thermal plants of Mandroseza (40MW), Mahajanga (13MW), and Toamasina (7.5MW) are operating.

- The feasibility study on interconnection of the electric lines between Antsirabe and Ambositra and the feasibility study on the hydraulic plant of Valobe are completed.

- The Administrative Secretariat of the PICOM Project is set in December 2007.

- The Diorano Wash charter is approved by the Government.

- The approval of the National Sanitation Policy and Strategy is in process.

\section{Challenges}

- For the Ministry of Public Works and Meteorology: repairing as an urgent action the damages caused by cyclones Fame and Ivan as they have seriously affected road infrastructures;

- Optimizing the operation of the $40 \mathrm{MW}$ thermal plant in Mandroseza;
- Finalizing the development works for the hydroelectric site of Sahanivotry, which is on track;

- Developing the national telecommunication backbone;

- Accelerating international connections through a submarine optical fiber connecting Madagascar to Eastern Africa and completing the study on the project of connection with La Réunion;

- Setting up ICT technopolis in partnership with the private sector;

- Ensuring national coverage with radio and TV;

- As regards national access to safe water, providing safe water to an additional group of 7.2 million people at least by 2012 , i.e. achieving an increase from $38 \%$ in 2006 to $65 \%$ in 2012;

- As regards national access to basic sanitation infrastructures (latrines), achieve an increase from $52 \%$ in 2006 to $71 \%$ by 2012 , allowing an additional group of 6 million people to have access to latrines by 2012.

\section{ReCommendations}

- Develop the cross-sector linkages between Public works and Transports in order to achieve the expected results;

- Based on the indicators defined in the NIMES, standardize the indicators of the sectors of Transports, Energy, Water \& Sanitation in close collaboration with the INSTAT in order to ensure the reliability of the statistical information generated;

- Provide for operational mechanisms at the OMERT to facilitate coordination of information between the administration and the private sector as regards ICTs.;

- Reinforce the institutional framework in charge of coordinating, planning, and ensuring monitoring and evaluation in order to discuss and negotiate with and mobilize technical and financial partners for additional funding for the water and sanitation sector;

- Build the capacities of the private and public sectors to provide water and sanitation, especially at the regional level

- Disseminate the National Sanitation Policy and Strategy and raise awareness among the population as regards its implementation.

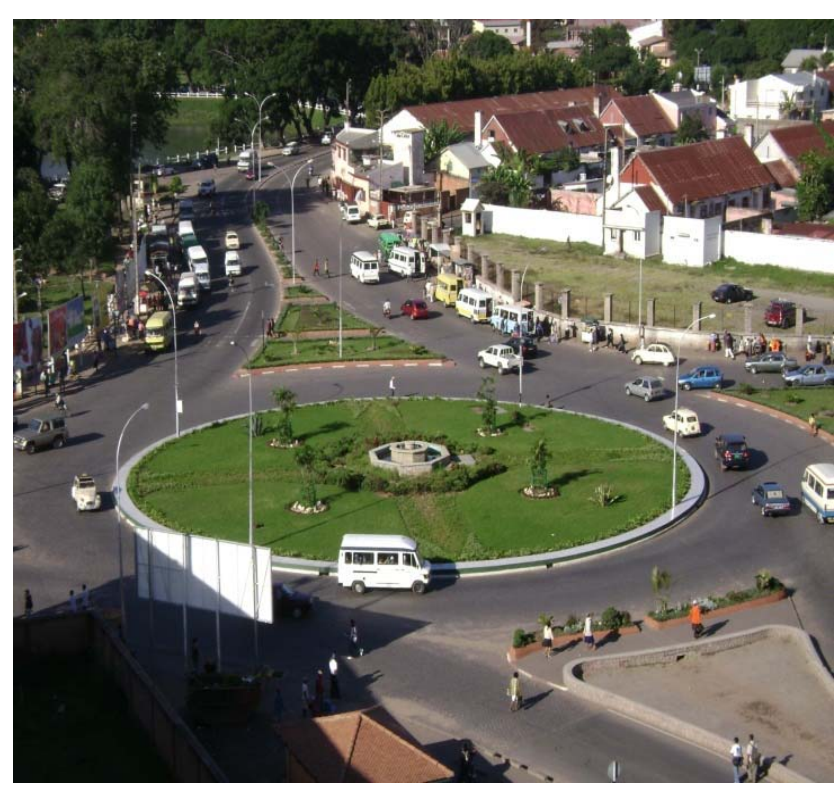




\section{IMPLEMENTATION OF THE MAP}

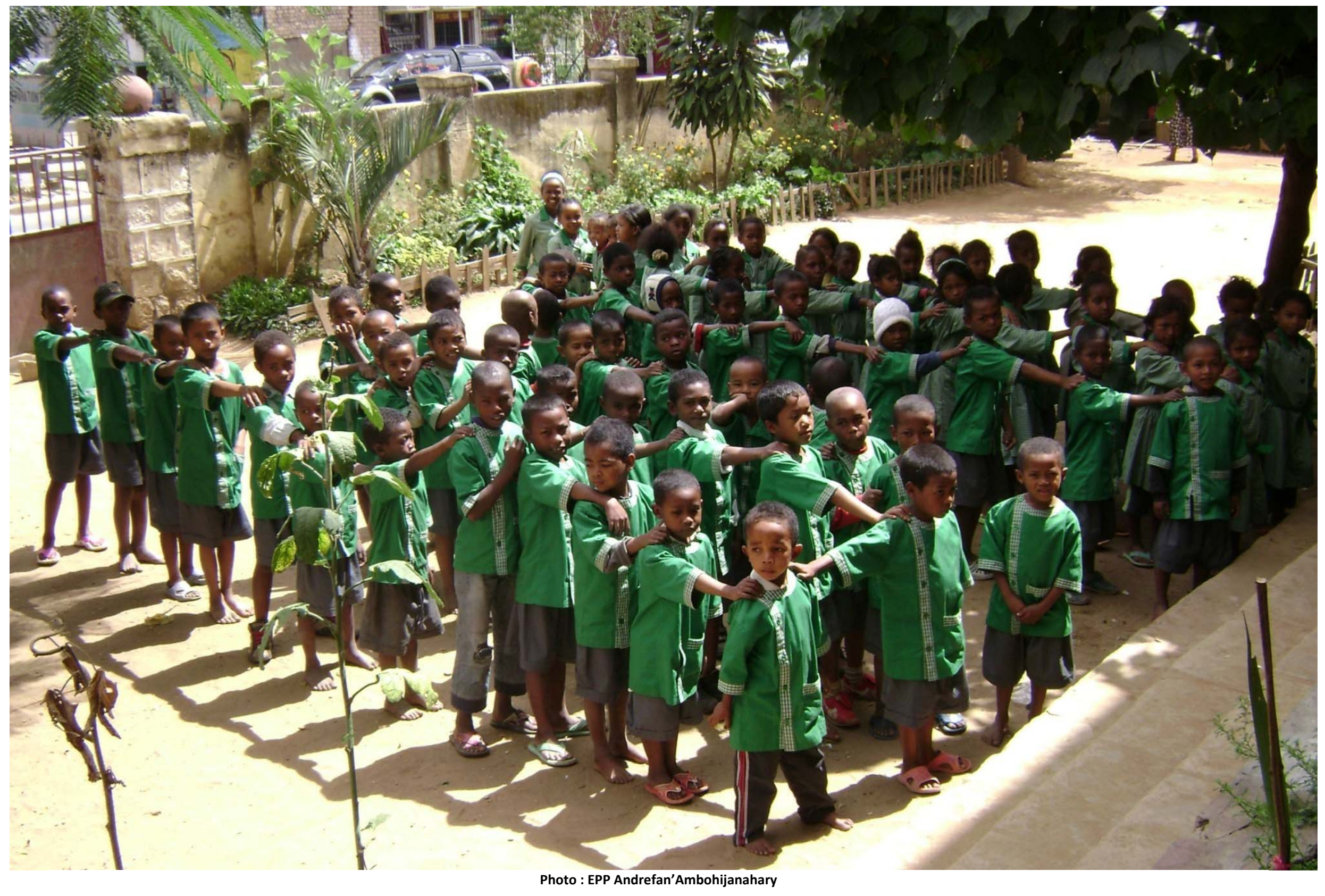




\section{IMPLEMENTATION OF THE MAP}

\section{COMMITMENT 3: EDUCATIONAL TRANSFORMATION}

The objective for 2012 is to ensure that all children have access to quality fundamental education, to develop a long-term vision for youth, and to provide the latter with the knowledge they need to thrive.

\section{ANALYSIS OF THE QUANTUM LEAP}

The educational system will be transformed to comply with world-class quality and effectiveness standards. Such a system would stimulate creativity, help students make their dreams come true, and provide Madagascar with the human resources needed to become a competitive nation and a successful player in the world economy. The transformation is expressed through:

- an institutional change (strategy and legal frame) of pre-school education, which is in progress;

- the reorganization of the primary fundamental education into 7 years;

- the establishment of the LMD system in higher education.

\section{ANALYSIS OF PRIORITY INDICATORS}

\section{Slight improvement of the pre-school coverage rate in} 2007

Pre-school education is generally focused on preparing children to enter primary school.

The pre-school coverage rate reached $7.1 \%$, when the objective set was $7 \%$. However, the attention granted to pre-school education is still insufficient. In most cases, it is only the privileged children, whose majority live in urban areas, where the cost of access is high, that benefit from the current system. There is also great need for human resources and trained staff.

Furthermore, the absence of a financial strategy for the implementation of the community centres development plan is a major impediment. In the past years, the Preschool Activity Centers (PAC) created by the State with support from UNICEF, as well as the pre-school structures set up at the rural level, with support from the local communities, have for instance stopped operating.

It is planned to develop programs that are appropriate to pre-school and are consistent with those of the first year of the Preparatory Course. To fill out human resources, 530 educators received training, out of the 3,500 that are planned to be trained.

\section{Improvement of the rate of children attending schoo at all levels \\ Primary education}

According to the 2006 MDG monitoring report, the net rate of children attending primary school increased from $93.3 \%$ in 2004 to $96.8 \%$ in 2005 , to go back to $96.2 \%$ in 2006. This trend suggests that the MDG objective of $100 \%$ of children attending primary school in 2015 will probably be achieved. Besides, up to 2007, the performance has steadied around $97 \%$.

As part of the creation of a successful primary education system, the gross rate of children attending school has clearly fallen during the 04 last school years (2004-2007); the net and gross rates of children attending school are in fact expected to draw closer to each other, since the objective is to reduce the difference between the two rates, as much as possible $\mathrm{A}$ good performance was recorded in year 2007 , with a gross rate of $122 \%$ against an expected rate of $126.6 \%$ and a net rate of children attending school keeping steady around 97\%. Generally speaking, a slight disparity was noted between boys and girls, with a percentage of $123 \%$ among boys and $120.8 \%$ among girls. The following account for the progress made:

- availability of the grades 1 to 7 matrices, of the 7th year graduation profile, and of the curricula's draft;

- standardization of entries in first year;

- building of new schools and rehabilitation of closed schools (upon funding from AFD, OPEP, BADEA, JICA, BAD) ;

- recruitment and training of teachers for the implementation of the 7 years primary education reform (FTI, AFD);

- continuation of the allocation of school kits and textbooks (KFW, BAD);

- granting of subsidies to alleviate parental contribution in registration fees;

- subsidizing of teachers (Parents' Associations);

- equipment of teachers with pedagogical guides (BAD, JICA).

The variations of the gross and net rates of children attending primary school during the 2004-2007 period are presented in the following Graph.

Graph 13: Rate of children attending primary school

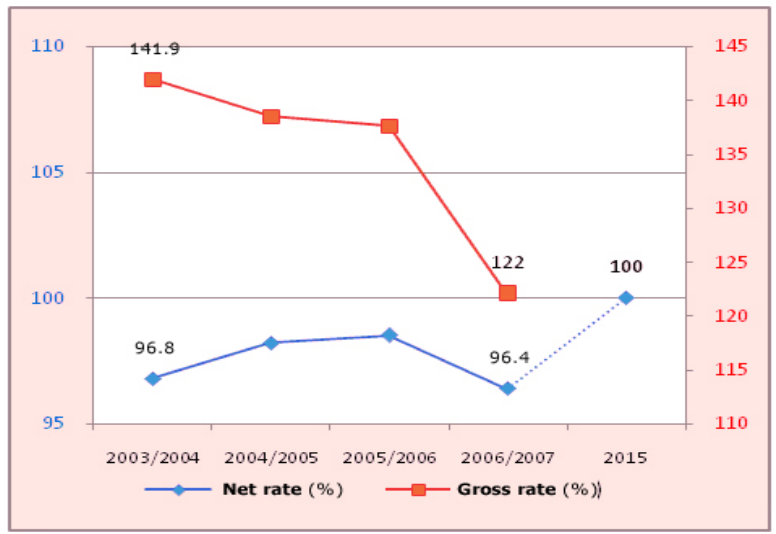

Sources: MENRS, REF 2007 and SNISE, and MDG 2006 


\section{IMPLEMENTATION OF THE MAP}

\section{Secondary education}

The rate of students attending secondary school depends on the primary school completion rate, which has been high during the past years. As such, a gross rate of students attending secondary school of $32.9 \%$ was recorded in 2007, exceeding the objective of $31 \%$. In secondary schools, no discrimination relating to sex has been noted (the rate of students attending secondary school is of $32.8 \%$ among boys and $33 \%$ among girls). The improvement particularly owes to:

- the increase of the number of first year students from 103,380 in school year $2005 / 2006$ to 223,940 in school year 2006/2007;

- the increase and improvement of the schools' capacity through the building and allocation of new classrooms, upon funding from BADEA and the OPEP;

- the granting of subsidies to teachers.

\section{At the upper secondary level}

The rate of students attending upper secondary school highly depends on the lower secondary completion rate. In year 2007, the gross rate of students attending upper secondary school reached $10.3 \%$ for an objective set at $8.4 \%$. Several factors contributed to this performance:

- the number of students in first year increased from 39,600 in 2006 to 49,800 in 2007;

- several rural upper secondary schools were re-opened with support from the BADEA (63 rooms built in 5 upper secondary schools);

- the upper secondary teachers' capacities were built, in partnership with AFIDES and WWF;

- the strategy for the ongoing training of upper secondary teachers was developed and the relating structure was implemented in partnership with TISSA/UNESCO.

\section{Education completion rate at all levels}

\section{Primary Education}

According to the 2006 MDG monitoring report, the primary school completion rate increased from $47 \%$ in 2004 to stick around 57\% in 2005 and 2006, and then fell back to $54.3 \%$ in 2007 . This rate has thus fluctuated a lot, without communicating a clear trend. The situation showed a lower internal effectiveness among boys, where the primary school completion rate amounted to $52.7 \%$ against $56 \%$ among girls.

Nevertheless, the rate of pupils repeating class has improved in the past years, decreasing from $29.9 \%$ in 2004 , to $19.7 \%$ in 2006, and finally $17.5 \%$ in 2007 . Given the situation, continuous efforts need to be provided to attain the completion rate of $85 \%$ by 2012 .

Several partners contributed to the improvement of internal effectiveness through:

- the recruitment and training of teachers (FTI, AFD) ;

- the equipment of teachers with pedagogical guidebooks (BAD, JICA) ;

- the creation of school feeding activities in vulnerable zones (PAM, NORWAY, FTI);

- the distribution of Approach By Skills (ABS) Tools.

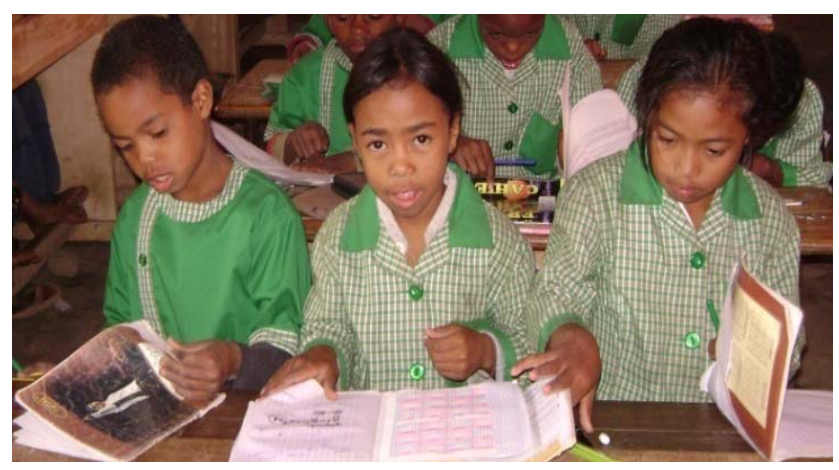

Graph 14: Primary school completion rate

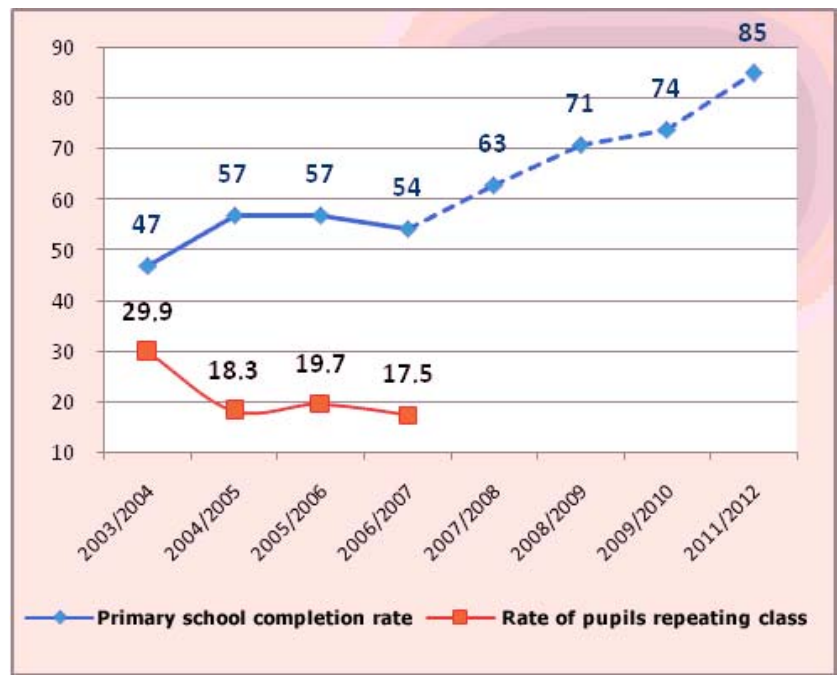

Sources: MENRS, REF 2007, and SNISE

\section{Secondary education}

In 2007, the secondary school completion rate amounted to $20.7 \%$ for an objective set at $21 \%$. The high rate of students repeating class in rural secondary schools, resulting from the lack of skilled teachers for certain subjects, accounts for the difference between the actual rate and the objective. As part of the intensification of secondary education, the disparity between sexes is in the stage of disappearing $(20.7 \%$ among boys and $20.8 \%$ among girls).

It must be noted that efforts were provided to train new teachers.

\section{At the upper secondary school level}

While the objective was set at $8.1 \%$, the upper secondary school completion rate recorded in 2007 amounted to $8.3 \%$. This result has been achieved owing mainly to the training of teachers, the recruitment of new teachers, and 


\section{IMPLEMENTATION OF THE MAP}

the improvement of the students' setting of work (allocation of scientific and technical equipment).

\section{Slight increase of the number of students per 100,000} inhabitants and rise of the number of annual Higher Education graduates

Facing the limited capacity of absorption (infrastructures, supervision, etc.) of public higher education, the situation was globally improved through the enhancement of the capacity of higher education private institutions. The number of students per 100,000 inhabitants increased from 286 in 2006 to 292 in 2007. An increase by 6 students per 100,000 inhabitants was therefore recorded, but the objective of 309 was not attained.

As of year 2007, the number of higher education graduates reached 6,568 for an objective set at 5,625, owing particularly to a more striking increase of the number of graduates from private higher education institutions. However, the proportion of female graduates (48\%) remains lower than that of male graduates (52\%). At the public university's level, the following account for the results obtained:

- the establishment of virtual libraries in the 6 universities and 2 Research Centers (CIDST, FOFIFA);

- the recruitment of lecturers in the 6 Universities (32 new associate professors in different Human Medicine specializations and 47 new lecturers);

- the signing of the Funding convention of the Madagascar Support to the Higher Education Reform Project (MSHER, upon funding from FSP).

- the establishment of the LMD system in higher education: methodological and institutional changes have been drawn up. However, in order to successfully implement the changes, the challenge is to materialize the building of the human as well as physical capacities of the teaching staff and faculties, as well as monitoring and partnership.

\section{Low levels of newly literate people}

According to the MDG report, the literacy rate of people aged 15 and on increased from $59.2 \%$ in 2004 to $62.9 \%$ in 2009. Information is not available for year 2007, due to the periodicity of the Household survey.

For year 2007, the partial results obtained on the literacy education of adolescents/youth who are out-of-school and/or dropped out of school early, using the ASAMA and AFI-D method are still poor. The objective of 36,700 newly literate people is only achieved at $40 \%$. Among the 14,350 newly literate people, 13,040 are adults and 1,310 are children.

It must be noted that 1,010 literacy teachers and animators out of the 1,400 planned, received training in 2007 and 12,150 reading and arithmetic books were produced.

\section{Budget allocated to the Education Sector}

The share of the full budget that is allocated to Education decreased between 2004 and 2006, falling from $23.41 \%$ in 2004 to $21.28 \%$ in 2005 , and to $17.4 \%$ in 2006 . In 2007, the budget portion increased to $22.7 \%$, for an objective set at $21.65 \%$. Although the budget increased in 2007 , when compared to the GDP, the budget portion allocated to the MENRS (Ministry of National Education and Scientific Research) slightly decreased between 2005 and 2007, from $3.9 \%$ in 2005 to $3.8 \%$ in 2006 , and $2.8 \%$ in 2007.

It must be noted that the MNESR has a poor capacity of absorption (internal funding in investment and operation - $76.17 \%$ with $30.75 \%$ of investment expenses particularly. This poor capacity is associated with delays of budget implementation at the Ministry's level and with the expenses regulation effect. In addition, there is slowness of implementation of some Projects, for instance the Primary and secondary education (OPEP), Education III
(FAD Group), School rebuilding, Support to general teaching (BADEA).

The limited resources allocated by the State to public education may not create sufficient impetus to improve the coverage and internal effectiveness of the educational system.

Graph 15: Variation of the budget share allocated to education in comparison with the full budget and GDP.

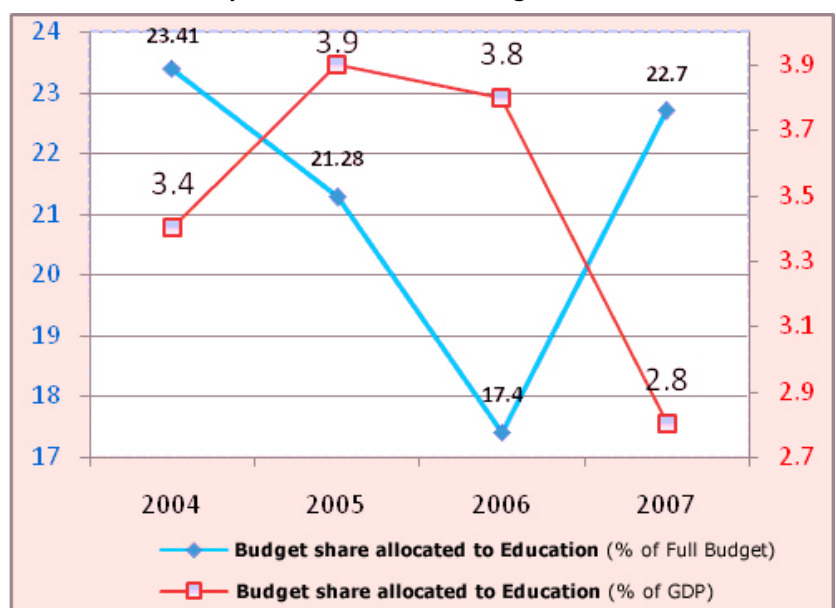

Sources: MENRS, MFB/PARP, and DSRP 2006

\section{COMPLETION STATUS OF THE MAJOR}

COMMITTMENTS TAKEN DURING THE

\section{PRESIDENTIAL DIALOGUE}

\section{Immediate actions :}

- Proposals on the design of the directions and instructions for carrying out the end-of-primary certificate constituted and ready to be handed over with the funds, to the 10 experimental RDNEs;

- Making the decentralized organizations and the partners of Vocational and Technical Training 


\section{IMPLEMENTATION OF THE MAP}

responsible, through the adoption of a decree on the establishment of Regional Groups of Vocational Training and Technical Education Institutions (GVTTEI);

- Rehabilitation of certain facilities that were affected by cyclones.

\section{Actions in $\mathbf{3}$ months :}

- Development of model examination papers for the CEPE;

- Computerization/Awareness-raising of Regional Organization Committees (COR) in the 10 experimental RDNEs;

- Finalization of the document on setting up and making the National Training Agency operational.

\section{Ongoing actions :}

- Documentary research, processing and analysis of the collected information, establishment of the terms of reference for holding a workshop on the future of official examinations (CEPE, BEPC, CAP/EP);

- Development of the "teacher evaluation guide";

- Organization of the CEPE, CAP/EP/BEPC examinations;

- Recruitment of 250 official teachers for upper secondary schools, of 2,000 official teachers and 5,000 non-official teachers of the primary cycle;

- Selection of 2,800 semi-specialized teachers for the establishment of the 7-year primary education;

- Decentralization of some of the duties at the level of the 22 RDNEs and 111 CISCOs: career management (promotion, integration, contract renewal, and others);

- Establishment of the local commissions in charge of recruiting contractual teachers for upper secondary schools at the RDNE level;

- Capacity building of RDNEs' agents along with the installation of the career management software;
- Awareness-raising of the population of the importance of literacy education for quality of life;

- Census of illiterate people within communities and forwarding of statistics to relevant authorities;

- Capacity building of decentralized services and collectivities as regards literacy to achieve sustainability.

\section{ChALLENGES AND OUTLOOKS}

- Innovate content (analysis of examination papers) and organize (device) official examinations relevant to CEXAM;

- Modernize the MENRS' Human Resources Management;

- Recruit teachers for the lower and upper secondary levels, based on needs expressed;

- Establish 5 pilot facilities, based on demand;

- Answer the skill needs of great projects;

- Reconvert some Vocational Training Centers according to the needs of the regional markets (match training to job offers);

- Develop training references on farming, hotel trade and catering and make trainings with professionals operational;

- Establish national strategies to take literacy education to scale;

- Establish a support fund to literacy education;

- Modernize the management of universities through computerization;

- Improve the quality of training to comply with international standards through gradual transition to the LMD system;

- Develop Strategic Plans at the level of each university and research institution
- Turn some universities and/or research institutions into centres of excellence.

\section{RECOMMENDATIONS}

- Perform a stabilization of the staff budgeted for at the MENRS;

- Build the capacities of the MENRS (physical, human, and financial);

- Accelerate the releasing speed of the staff budgeted for by the MFB;

- Appoint 2,800 new semi-specialized teachers as early as the start of school year 2008-2009 for the reorganization of primary education into 7 years.

- Build the capacities of teachers in evaluation for certification, based on the ABS in Grades 2 and 3, by equipping them with tools for asset evaluation;

- Respect and enforce the evaluation reforms required by all relevant entities, at all levels;

- Improve the diversification of innovative pedagogical methods and facilitate access to the methods through Distance Open Training (DOT);

- Improve supervision at the universities' level through the recruitment of new researcher teachers. 


\section{IMPLEMENTATION OF THE MAP}

COMMITMENT $4:$ RURAL
DEVELOPMENT

Dynamic rural development and effective alleviation of poverty are at the core of the Government's endeavours. Rural areas will thrive and prosper through a green revolution that will substantially increase agricultural production. Agri-business centers will be established in each and every region to assist in training and in the provision of farming resources such as irrigation, seeds, fertilizer, and storage facilities.

\section{ANALYSIS OF THE QUANTUM LEAP}

According to the 2006 Millenium Development Goals (MDG) monitoring report, about $3 / 4$ of the poor live in rural areas, where approximately $80 \%$ of the Malagasy population also lives. However, rural poverty decreased from $77.2 \%$ in 2001 to $73.5 \%$ in 2005 that is, a significant fall of 3.7 points over the period. The dynamics of the Malagasy economy's structural transition has indeed benefited to the rural world: the increase of farm gate prices during the mentioned period has generated significant advantages for the rural people.

Graph 16: Variation of price indexes at the consumption of nonprocessed food products (NFP) or processed rice (PR) and variation of the rice production

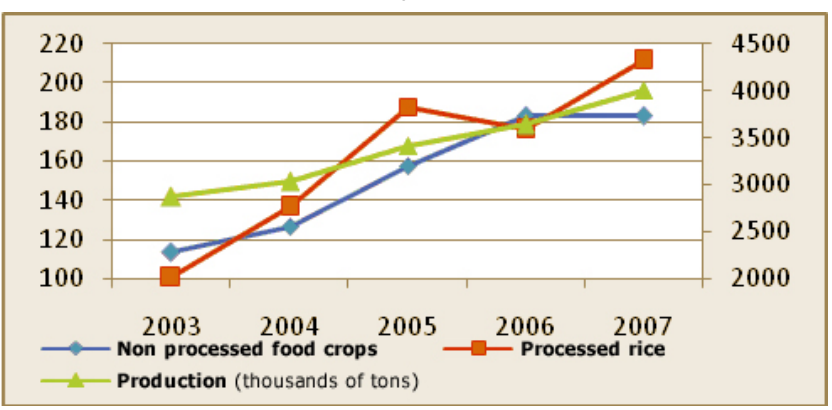

Sources: BCM statistical information report
Because information on farm gate prices were lacking, we instead tried to analyze the price indexes at the consumption of non-processed food products (NFP), processed rice, and the variation of the rice production.

The primary sector's growth is still precarious and has practically not changed over the past three years. While the average growth of the population amounts to $2.8 \%$ the primary sector's growth rate amounted to $2.5 \%$ in $2005,2.1 \%$ in 2006 , and $2.2 \%$ in 2007 . A slight increase was noted in the agriculture sector, 2.6\% in 2006 and $2.9 \%$ in 2007, but on the other hand, the breeding and fisheries' growth rate decreased from $1.9 \%$ in 2006 to $1.7 \%$ in 2007.

To remedy to the slowness of poverty alleviation in rural areas, priority has been given to the reinforcement of the mainstays and levers for launching the «Green Revolution ", particularly:

- The promotion of market-oriented activities, diversification of agricultural activities by making certified seeds available and by distributing them, establishment of Market Access Centers (MAC), AgriBusiness Centers ( $A B C$ );

- The diversification and improvement of the fishery production as well as the rehabilitation and building of exploitation infrastructures;

- The improvement of land security, in the rural world more particularly, through the establishment of onestop-shop and land offices and the attribution of land titles and certificates.

No change worthy of note was observed towards improving life conditions in rural areas. This essentially results from the poorness of the agricultural production, the poor state of the hydro-agricultural infrastructures, and the effects of climate change.
The close linkages that should exist between $A B C s$ and farmers (grouped into associations), remain vague and are not materialized. The results are indeed mitigated, insofar as:

- associations and/or "medium farmers" are long to emerge to supply "big farmers" in the chain value pattern of specific promising sectors (fruit and vegetables, milk, paddy, etc.);

- the awareness-raising and mobilization of rural actors regarding the constitution of associations, have not yet reached cruising speed;

- access to rural funding is still a major impediment, due essentially to the cost of credit;

- besides climate hazards, insecurity in the rural world may reduce to nothing the efforts undertaken and calls for drastic and rigorous measures.

\section{ANALYSIS OF PRIORITY INDICATORS}

The green revolution will allow for improving the nonproductive areas of the farming world and the levels of income.

Slight increase of the proportion of rural operators holding land titles or certificates

In spite of the performance recorded at the end of the period, the rhythm of increase of the percentage of rural operators holding land titles or certificates, increased from $10 \%$ in 2008 to $10.24 \%$ in 2006 , and 10.42 in 2007 (for an objective of $10 \%$ ). However, compared to the objective of $75 \%$ set for 2012 , this is very slow. Fortyseven (47) Communal land offices were indeed established as planned and 1,100 people received training on land management. As such, land security remains a big challenge. 


\section{IMPLEMENTATION OF THE MAP}

Also, the cost of access to certification, which is unaffordable for some social strata, is the main barrier to the delivery of established land titles.

\section{Clear increase of the rice production}

The mainstays of the Green Revolution are reinforced. Concerning the rice production, in spite of the drought that occurred at the beginning of the campaign, the production of paddy, estimated at 4,010,189t, increased by $10.2 \%$ in 2007 , compared to $6.4 \%$ in 2006 . This increase essentially owes to:

- An intensification of the use of agricultural inputs: the amount of fertilizer distributed increased from 7,357 tons in 2006 to 36,000 tons in 2007 and the seeds used, from 483 tons in 2006 to 2,650 tons in 2007;

- The acquisition of 4,884 small agricultural equipment;

- The development of a surface area of $100,660 \mathrm{Ha}$ for an objective set at $100,000 \mathrm{Ha}$; the surface area suitable for cultivation is currently estimated at 1,300,000Ha;

- The water mastery of $12,000 \mathrm{Ha}$ of rice fields;

- The establishment of 58 demonstration showcases at the Communes' level, to improve cultivation techniques.

The levers of the Green Revolution are also set and ready:

- The National Chamber of Agriculture, the 22 Regional Chambers, the 32 Departmental Chambers, and the 70 Communal Chambers are operational;

- The capacity building of farmers' organizations is intensified;

- The activities relating to the Agricultural Investment Zones (ZIA) have started.

\section{Rise of the penetration rate of financial institutions}

During the past three years, significant results have been obtained regarding the growth and development of Microfinance Institutions' (MFI):

- In terms of market penetration, in 2007, approximately $8.51 \%$ of Malagasy families are beneficiaries of the financial services offered by MFIs, compared to $6 \%$ in 2005 . The coverage rate of Districts having operational financial institutions amounts to $70.43 \%$.

- On June 30, 2007, mutual and non-mutual MFIs had more than 317,281 members, including $38 \%$ of women.

- The mutuals' outstanding savings reached 33 billion Ariary and outstanding credit, more than 44 billion Ariary.

Yet, considering the scope of the role that the rural world is expected to play in the achievement of the MAP's objectives, further efforts must be provided, because this penetration rate is still low. Besides, the establishment of the Agricultural Development Fund is not effective.

\section{Diversification of the rural households' sources} of income

The present circumstances are calling for the diversification of productions. As such, specific actions have been taken to:

- encourage farming operators to enhance the value of Malagasy quality and of added-value, export products. The volume of agricultural exports increased from 560 billion Ariary in 2006 to 636.7 billion Ariary in 2007;

- prompt the farming population to take up dairy breeding and beekeeping, which can both be significant sources of income: the annual growth rate of the dairy production reached $8.04 \%$ in 2007 and 40 modern breeding farms, 36 of which own more that 10 cows, are now established;

- increase the number of sectors that may be exported and will be a complementary source of income for the rural population: lima beans, chilli, cassava, fruits and vegetables;

- support the emergence of a number of sectors that set the economy at promoting independence in energy and the diversification of agricultural export products: sugarcane, jatropha, bio ethanol, chilli, fruits and vegetables;

- rationally manage productive spaces: the value of $10,880 \mathrm{Ha}$ of new areas of tanety was enhanced through arboriculture, food crops, pastureland, while the objective was set at $10,000 \mathrm{Ha}$ and $1,725 \mathrm{Ha}$ of catchment areas were developed instead of the $835 \mathrm{Ha}$ planned;

- make 06 "AgriBusiness Centers » $(A B C), 07$ Market Access Centers (MAC), and 13 Agricultural Service Centers operational, to improve the organizational environment of producers. In this respect, the development of quality standards is a big challenge.

The average growth of the "fisheries and breeding «division remained slightly below 2\% from 2005 to 2007. The same applies to the honey production, which reached $1.02 \%$ over the said period.

\section{CONTRIBUTION OF PROGRAMS AND PROJECTS}

- The National Land Program (NLP) and the Millenium Challenge Account (MCA) made significant achievements in auditing land files and supporting land administration;

- The Agency for the Implementation and Promotion of Microfinance (AGIPMF) opened and re-opened several 


\section{IMPLEMENTATION OF THE MAP}

cashes to achieve the objective of establishing proximity financial services that answer the needs of members, in spite of the fact that some networks were impedimentped by the poor drain of savings;

- The National Coordination of Microfinance, funded by UNDP, conducted actions for the revision of the legal and regulatory framework, the supervision and control of sectors, and the capacity building of MFls in particular;

- The FIFAMANOR Support Project (dairy triangle) mainly reinforced the producers' capacities at improving production techniques - dairy production more specifically;

- The coverage rate of the Rural Development Support Project (RDSP) reached $71 \%$ of rural communes. The contributions of RDSP, of the Mandrare Upper Basin Project (MUBP), of the Irrigated Catchment Areas Perimeters Project, and the Rehabilitation of Lower Mangoky Project (RLMP) improved the support to productive investments, agricultural research, and the capacity building of farmers' associations;

- The Erosion Control Project, located in Marovoay, contributed to enhancing the value of tanetys, controlling bush fires, and developing catchment areas.

\section{COMPLETION STATUS OF THE MAJOR} COMMITMENTS TAKEN DURING THE PRESIDENTIAL DIALOGUE

\section{Immediate actions :}

- As part of the Green Revolution: participation of 30 agents of the MAEP in the popularization of rice production intensification and expansion techniques;
- Importation of goats of meat and wool of higher quality;

- Awareness-raising of butchers on hygiene standards in slaughterhouses and meat stalls;

- Training of meat inspectors in the regions of Vakinankaratra, Analamanga, Upper Matsiatra, and Atsimo Andrefana ;

- Preparation of the fish farming development strategy

- Expansion of and training on pond, cage, or enclosure breeding of fish.

\section{Actions in $\mathbf{3}$ months :}

- Delivery of 658 permissions for the importation of animal food products (AFP):

- Improvement of the hygiene standards control on animal food products (AFP) and animal production;

- Making legislative texts on animal health consistent.

\section{Ongoing actions :}

- Development of the surveillance protocol of emerging diseases;

- Locking up control of bovidae under transaction;

- Technical orientation on the new sectors' requirements;

- Awareness-raising of operators on cage breeding of alevins, until processing;

- Contact of financial (MCA, AMPA, FAO, etc.) and technical (task force for the development of cage breeding) partners;

- Development of the steering plan 2008-2012;

- Creation of fishers' and fish farmers' associations;
- Establishment of MFIs in non-covered zones, defined through consultation between all stakeholders;

- Research for fund donors and strategic partners.

\section{Challenges and Outlooks}

- On the macro-economic plan, reduce the rural areas' poverty rate by improving the resource allocation to this sector and by increasing the sector's growth and share in the GDP;

- Double to triple the food production, especially rice production;

- Reinforce land security;

- Develop and enforce a surveillance protocol of emerging diseases;

- Provide technical orientation on the new sectors' requirements;

- See to it that farmers internalize the necessity of using inputs in their culture;

- Develop the cage breeding and production of alevins.

\section{RECOMMENDATIONS}

- Review and set higher all expectations relating to the priority indicators of the MAP's implementation monitoring;

- Promote the emergence of young rural entrepreneurs (medium farmers);

- Actively research funding with financial partners to build the capacities of the MAEP; 


\section{IMPLEMENTATION OF THE MAP}

- Train trainers on hygiene standards, legislative texts on animal health, regulatory texts on cage and enclosure breeding, and the strategy for the development of fish farming;

- Facilitate the establishment of associations of: fishers, fish farmers, breeders, farmers, etc.

- Facilitate the acquisition of the equipment necessary to the establishment of cage and enclosure breeding and the creation of traditional fishers' or small and medium fish farmers' associations;

- Raise the butchers' awareness on hygiene standards in slaughterhouses and in meat stalls;

- Reinforce the improvement of the availability, quality, and reliability of agricultural statistics, in partnership with the INSTAT particularly: farm gate prices, production, number of associations, etc.;

- Make the data relating to the number of research products available for the needs of the regional sector, to indicate the speculative specificities of each region of Madagascar (emphasis on the "chain value" principle).
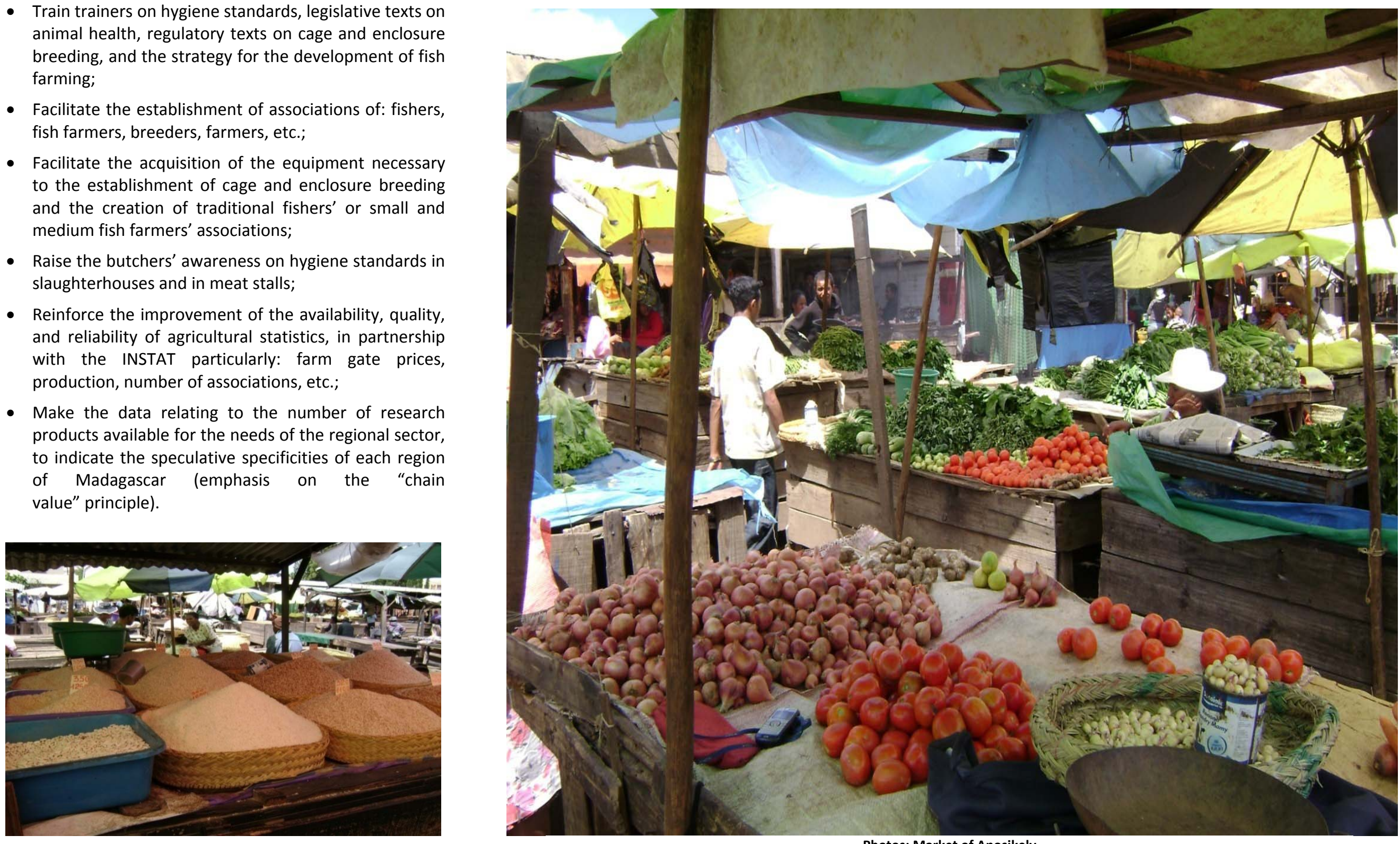

Photos: Market of Anosikely 


\section{IMPLEMENTATION OF THE MAP}

\section{COMmitMent 5: Health, Family Planning, and the Fight against HIV/AIDS}

The main objectives of Commitment 5 are to promote maternal and child health by improving the population's access to quality services, intensify the control of infectious diseases, fight HIV/AIDS, intensify the family planning strategy, and improve nutrition. Besides, by adopting the Millenium Declaration, Madagascar committed itself to achieve the goals of the Declaration. Three out of the eight Millenium Development Goals are directly linked to health, namely: the reduction of child mortality, the improvement of maternal health, and the fight against HIV/AIDS, malaria, and other diseases.

\section{ANALYSIS OF THE QUANTUM LEAP}

- Greater management of the populations' care through the enlargement of the care coverage;

- better health coverage in child and women's care: immunization, maternal aid, infectious diseases control;

- reduction of the morbidity and mortality rates associated to malaria;

- decline in the proportion of under-five children seen in BHCs and community sites that have a low weight;

- reinforcement of the strategic and technical coordination of the actions for fighting AIDS, through the multi-sectoral approach;

- making the equity fund operational for underprivileged people, resulting in the enlargement of the care coverage to the least privileged populations.

\section{ANALYSIS OF PRIORITY INDICATORS}

\section{Low rate of use of Outpatient Visits in BHCs}

At $35.8 \%$, for an objective set at $49 \%$, the rate of use of BHCs' Outpatient Visits remains low. The functionality of the newly built BHCs, particularly the lack of corollary staff and staff budgeted for, accounts for this poor rate. However, efforts were undertaken to improve the compliance of health facilities with standards and expectations in this area are by far exceeded by achievements: 120 BHCs were rehabilitated/built instead of 84, 05 maternity wards out of 05 were rehabilitated/built, and 96 BHCs were provided with material and equipment instead of 60 , as planned. All health facilities were provided with quality medicines and quality perfusion liquid. The programs CRESAN 2 (funded by IDA) and SANTE 2 (funded by FAD) contributed to the Public health facilities' and equipment's compliance with standards. The absorption rate of the credits allocated is however very low. This is associated with the low compensation from the Government.

\section{Satisfactory DTPHepB3 immunization coverage rates}

Immunizations are the main measures for preventing target diseases as a whole, measles and poliomyelitis more particularly. To increase the immunization coverage, the availability of vaccine was ensured in health facilities, throughout the country.

In 2007, the DTPHepB3 immunization coverage rate among children under 1 was $87.10 \%$ for an objective set at $80 \%$. Regarding other types of immunizations among children under 1 , the immunization coverage rates are respectively: $97.5 \%$ for the B.C.G. and $94.4 \%$ for the antimeasles.
Variation of the immunization coverage during the past five years:

Since 2005, the immunization coverage has remained over $90 \%$, after a significant decrease in 2004. The improvement of the child immunization coverage contributed to the substantial reduction of child and youth mortality in Madagascar. The good performances are the result of the absence of vaccine stock-outs, the implementation of outreach, and especially the awareness-raising actions undertaken. The cold chain coverage is close to $75 \%$ throughout the country. If current the trend is followed on and present efforts are maintained, the objective of $100 \%$ will be achieved by 2012.

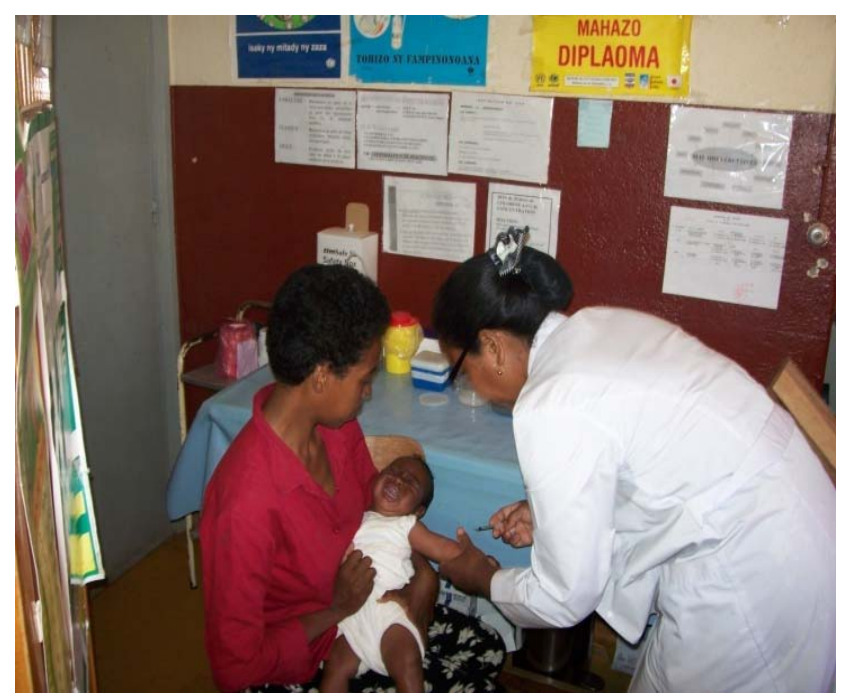

Photo : MSPFPS

Besides the State, several technical and financial partners contribute to supporting immunization by providing vaccines and cold chain equipment. These partners include: WHO, USAID, Rotary Club International, and UNICEF. 


\section{IMPLEMENTATION OF THE MAP}

Graph 17: Variation of the BHCs' outpatient visit rates and the DTPHepB3 immunization coverage rate among children under 1

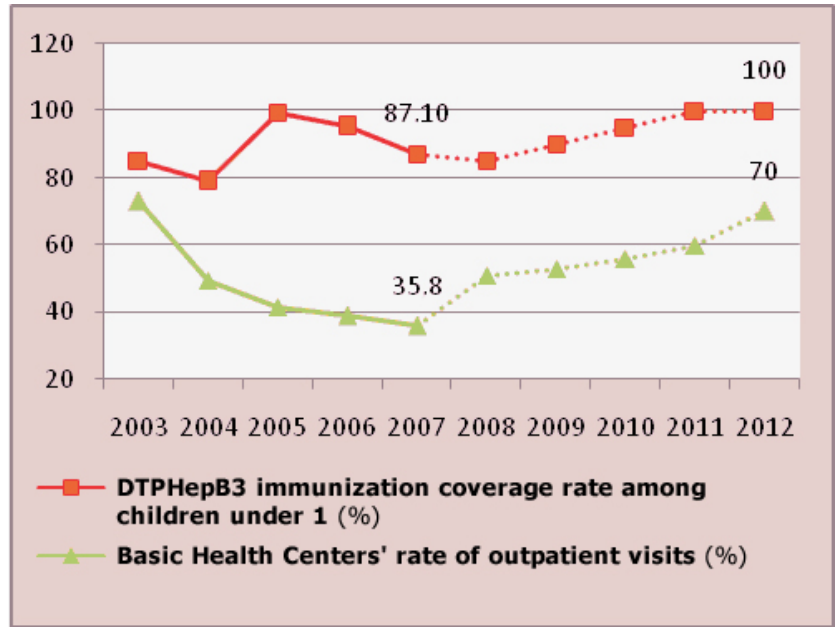

Sources: MSPFPS and SNISE

Downward trend of the child and maternal mortality rates

These two indicators reflect the impact of the actions undertaken to improve maternal and child health. Results are not available for 2007, because the evaluation of the indicators requires surveys that are spread out over five years (DHS) or two years (Household survey).

A few trends are however worthy of note: according to the $1^{\text {st }}$ national MDG monitoring report, the mortality rate among children under 5 fell from 93.4 per thousand in 1997 to 58.0 per thousand in 2004. The high performances of the immunization coverage rates and the preventive measures taken to control malaria are just as many factors that contributed to this improvement.

According to the same report, the maternal mortality rate decreased from 488 per thousand live births to 469 per thousand live births in 2004 . These figures indicate a slow progression. In spite of the rise of the contraceptive prevalence - which resulted in better birth spacing, the standardization of heath facilities, and the increase of their number, some major impediments remain, namely the low rates of deliveries at the BHCs and DHCs and the low rates of outpatient visits in BHCS, which result from the lack of medical staff.

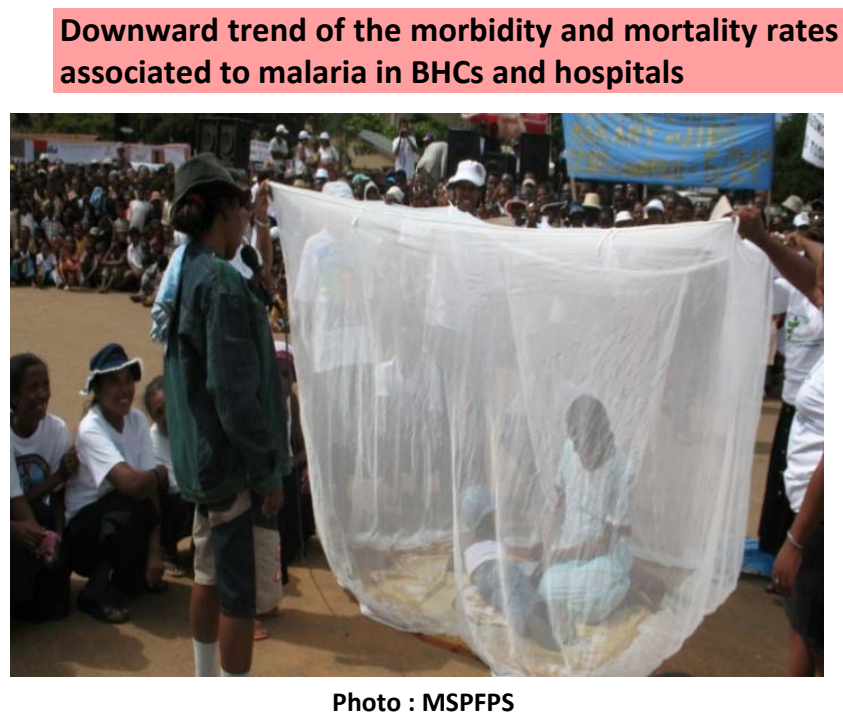

Malaria ranks second in the causes of morbidity According to the results of the Household 2001, malaria is the reason for $19.4 \%$ of outpatient visits in BHCS. The morbidity rate associated to malaria at the $\mathrm{BHC}$ level was reduced to $11.1 \%$ in 2007 for an objective of $15 \%$. During the past 5 years, this rate has tended to decrease, as shown on the following figure:

From 2003 to 2005, the morbidity rate associated with malaria in BHCs varied from $18.8 \%$ to $16 \%$, it slightly increased in 2006, and went down to $11.10 \%$ in 2007.

Regarding the mortality rate associated with malaria in hospitals, the objectives for 2007 were exceeded with a result of 15.64 against an expected rate of $15.70 \%$. During the 4 past years, this indicator remained steady, with rates varying between $16.5 \%$ and $17.5 \%$.

Graph 18: Variation of the malaria morbidity rate in BHCs and the malaria mortality rate in hospitals

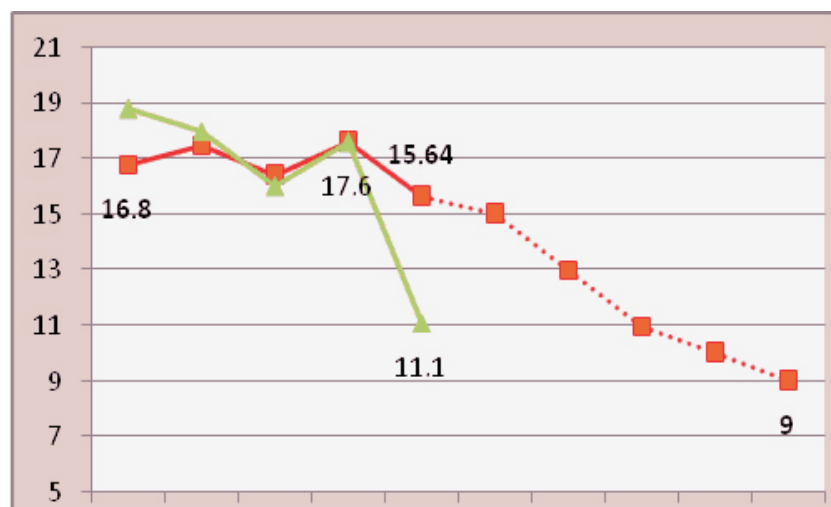

2003200420052006200720082009201020112012

$\longrightarrow$ - Malaria mortality rate in hospitals (\%)

Malaria morbidity rate at the BHC level (\%)

Sources: MSPFPS and SNISE

The promotion of insecticide-treated bednets, the improvement of the disease's management, and the improvement of the health system in collaboration with Global Fund, WHO, and CRESAN, are all factors that contributed to obtaining these results. As regards prevention, the distribution of Long-Life InsecticideTreated Nets (LITN) to pregnant women as well as their sale at affordable prices, as part of social marketing has resulted in increasing the population that has access to these bednets: 2,910,000 LITN were distributed free of charge against an objective of 2,100,000 and 2,016,436 were sold at affordable price.

Clear improvement of the rate of curing from bacillius Tuberculosis

The objective set for 2007 is largely achieved with an actual rate of $78.00 \%$ for an expected rate of $72 \%$. During 


\section{IMPLEMENTATION OF THE MAP}

the past 04 years, results indicate a positive change with the rate's increasing from $66 \%$ in 2003 to $71 \%$ in 2004 , $75 \%$ in 2005 , and $78 \%$ in 2006 . This improvement owes to the decentralization of tuberculosis control and the increase of the number of Screening and Treatment Centers.

Substantial efforts must still be provided in screening the disease and monitoring patients, because many of them are often lost of sight.

Graph 19: Variation of the rate of curing from bacillius tuberculosis

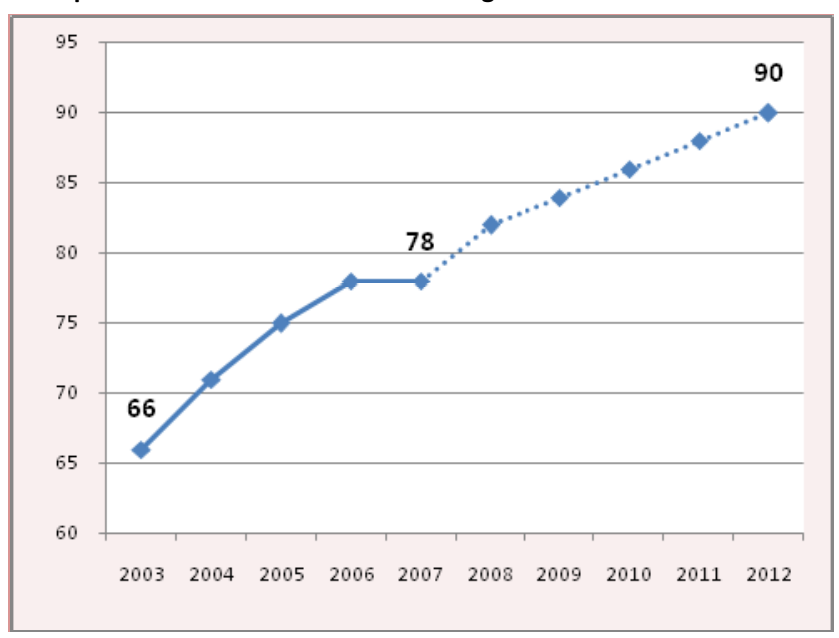

Sources: MSPFPS and SNISE

\section{HIV prevalence among pregnant women}

Sexually transmitted diseases are known to be a major factor of HIV propagation.

Since there has been no national survey, this prevalence will be assessed against partial results. The setting of objectives regarding the number of HIV-positive pregnant women and People Living with HIV (PLHIV) is based on the trends of the preceding years.

Due to the strong prevalence of syphilis among pregnant women, specific actions were taken to improve the means of preventing mother-to-child transmission. Likewise, the monitoring of people under Anti-RetroViral treatment (ARV) has been reinforced.

The strategies initiated pertained to the reinforcement of decentralization, program management for a local response to STIs and HIV/AIDS, the intensive campaign held at national scale for behavior change and society's awareness-raising, and the capacity building of physicians. The following achievements were made in improving access to and use of STI/HIV/AIDS prevention and management services:

- Prevention of Mother-to-Child Transmission (PMCT) sites were made operational;

- Allocation of laboratory reagents and medical consumables was conducted;

- HIV-positive pregnant women were managed.

The response to HIV and AIDS is strongly supported by the President and are expressed through a multi-sectoral strategic approach and a local response. Several donors are contributing to the fight through UNOAIDS, namely UNDP, UNESCO, FNUAP, WHO, the World Bank, BIT and WFP.

Although the prevalence is relatively low (less than $1 \%$ ), it may be increased by the fact that the STI prevalence is high and that the population has numerous risky sexual behaviours. Also, the HIV epidemic is classified as little active, but it shows a tendency to generalization.

\section{Percentage of people under ARV treatment who are still alive 12 months after starting the treatment}

The monitoring of this indicator, which has been newly however been conducted in this area, namely:

- the psycho-social and medical management of PLHIV;

- making PLHIV reference centers operational. introduced, is not yet mastered. Several actions have
It must be mentioned that regarding the monitoring of people under ARV treatment, some PLHIV are lost of sight or even deceased. Outlooks for 2008 consist in conducting a survey on HIV prevalence among pregnant women and a biological surveillance survey to reinforce control and prevention measures.

Challenges include:

- maintaining the HIV prevalence rate below $1 \%$

- effective decentralization of the response to HIV/AIDS;

Recommendations:

- Reinforce effective collaboration between SE/CNLS, the MSPFSP, and partners under the STI/HIV/AIDS program, in decentralizing the program's management and in conducting surveys;

- Use the National Strategic Plan as a reference for the development of regional plans for HIV/AIDS control;

- Use the monitoring-evaluation plan as a reference for monitoring responses.

- Make the accessibility of condoms and all services linked to reproductive health effective;

- Reinforce PLHIV management and psycho-social services.

- Increase the number of PLHIVs treated among people under ARV treatment.

\section{Extremely satisfactory contraceptive rate}

The partial result obtained for year 2007 (from a reporting rate of $54.85 \%$ ) is $19.30 \%$ for an objective of $19 \%$. The percentage of Family Planning (FP) services users has always satisfactorily increased.

FP use was promoted on one hand by the availability of FP services and on the other hand, by the building of knowledge on contraception. It must be noted that the 


\section{IMPLEMENTATION OF THE MAP}

access to modern contraceptive methods was improved and the number of FP sites increased.

The promotion of Family Planning is supported by the country's High Authorities. From 2003 to 2007, the contraceptive coverage rate has almost increased fourfold. Hundred percent $(100 \%)$ of functional public health facilities have become FP sites and 111 District Health and Social Affairs Services (DHSAS) are supplied with contraceptive products.

FNUAP is the main partner that supports the reproductive health program in Madagascar. The success of the program is reflected by the high outlay rate of the planned funding.

Little change of the delivery rates at the BHCs and DHCs level

A slight improvement of the situation was recorded in the past years: from $24.2 \%$ in 2003 , the indicator increased to $26.10 \%$ in 2006 after decreasing at $19.6 \%$ in 2005. In 2007, the result obtained amounts to $25.20 \%$ for an objective set at $25 \%$.

The management of deliveries is low because the community lacks knowledge on danger signs and therefore fails to resort to the services on time and there is insufficient service offer.

The Ministry of Health, with the collaboration of external partners, including FNUAP, UNICEF, WHO and GTZ provides considerable efforts to reinforce Emergency Obstetrical and Neonatal Care (EONC) services on its own budget. However, most health workers are not equipped with the skills needed for EONC. Finally, developing of a maternal and neonatal care program using a communitybased approach would be very challenging.

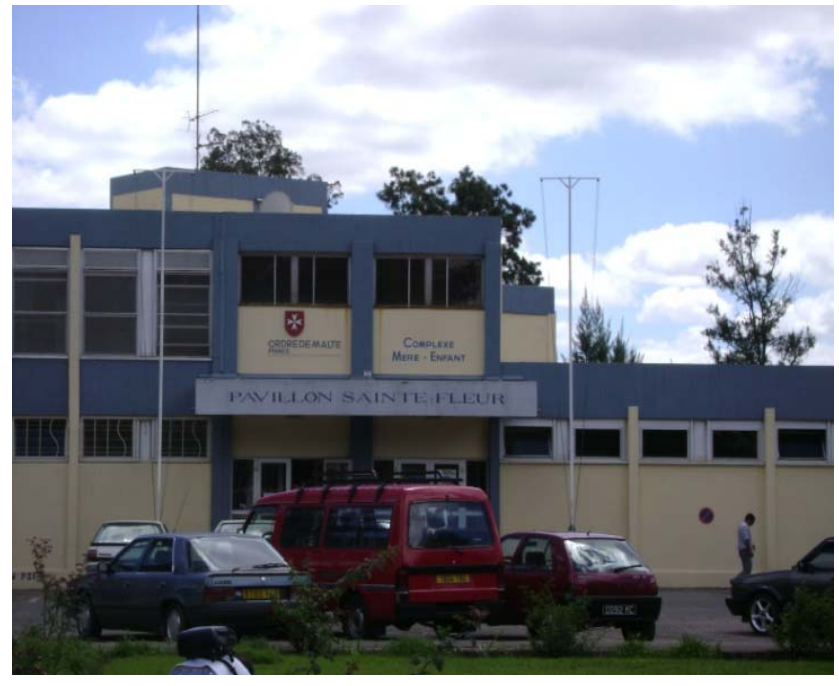

Graph 20: Variation of the contraceptive coverage rate and the delivery

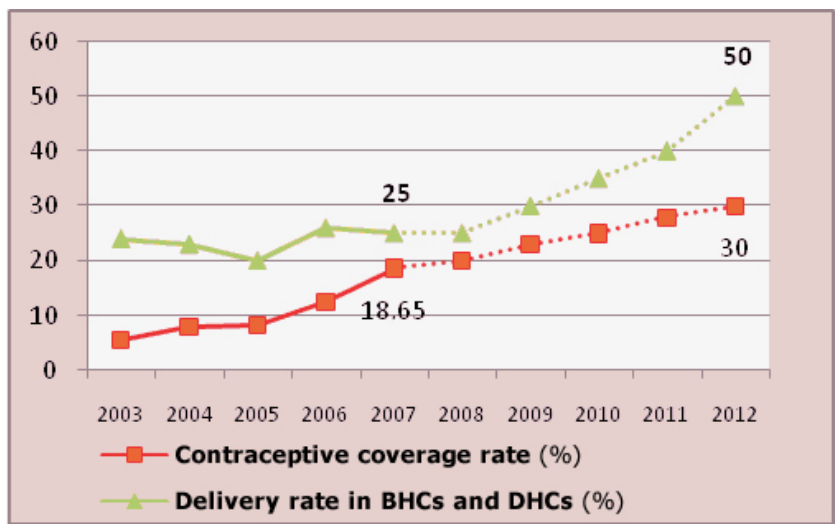

Sources: MSPFPS and SNISE

\section{Budget allocated to the Health Sector}

The share of the full budget that is allocated to the health sector has continuously decreased from 2004 to 2006, falling from $8.34 \%$ in 2004 , to $7.89 \%$ in 2005 , and $7.50 \%$ in 2006 . However, it slightly increased to $8.80 \%$ in 2007 . Taken in terms rate in BHCs and DHCS of GDP percentage, it amounted to $1.30 \%$ in 2004 , increased to $1.63 \%$ in 2006, and decreased back to $1.51 \%$ in 2007.

It must however be noted that the absorption capacity of the MSPFPS (domestic funding for operation and investment) remains average $(73.38 \%)$ with investments reaching only $51.95 \%$. This performance is linked to the lateness of budget implementation at the Ministry's level and to the expenses regulation effect. Slowness was also noted in the financial implementation of Programs/Projects such as SANTE 2, Multisectoral Program for the Prevention of AIDS, Nutrition II, CRESAN 2, Infectious Diseases Control.

Given the importance given to role of DHSs as proximity services, the budgets allocated to them continuously increased, from $54.07 \%$ of the MSPFPS budget in 2004 to $58.8 \%$ in 2007.

Graph 21: Variation of the budget share allocated to the health sector compared to the full budget and the GDP.

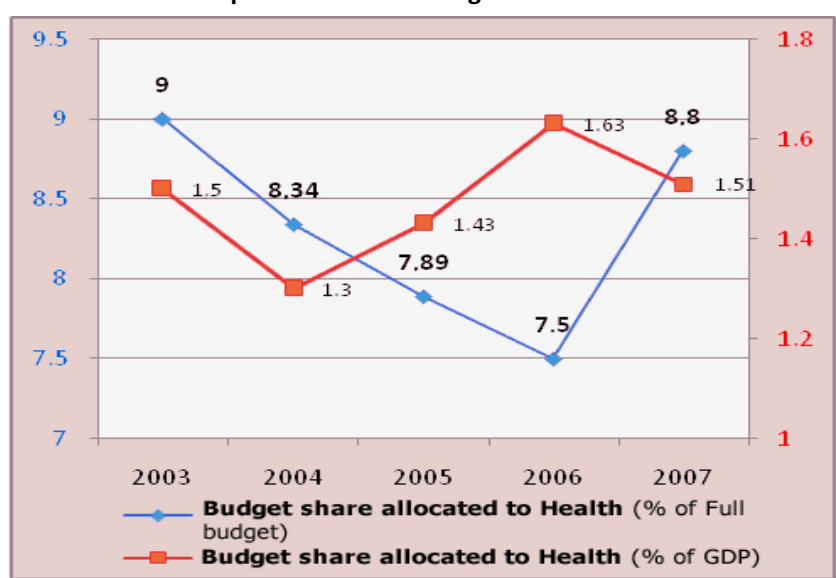

Source: MSPFPS

\section{Malnutrition rate}

Malnutrition is a public health issue and affects a great majority of the population. In 2007, information on malnutrition rates was not available, because such 


\section{IMPLEMENTATION OF THE MAP}

information is subject to a subsequent DHS survey. Malnutrition was therefore assessed using indicators on low weight among children under five.

Clear improvement of the proportion of underfive low weight children seen on outpatient visits at BHCs

The objective set for 2007 was achieved with a result of $14.07 \%$ for an expected rate of $15 \%$. Several actions contributed to this success, including:

- the reinforcement and consolidation of malnutrition control activities at the school level through food support in CISCOs;

- the creation of temporary jobs (food for work/ labor intensive) to prevent food and nutritional crises during lean periods.

Graph 22: Variation of the proportion of under-five low weight children seen on outpatient visits at the BHCS

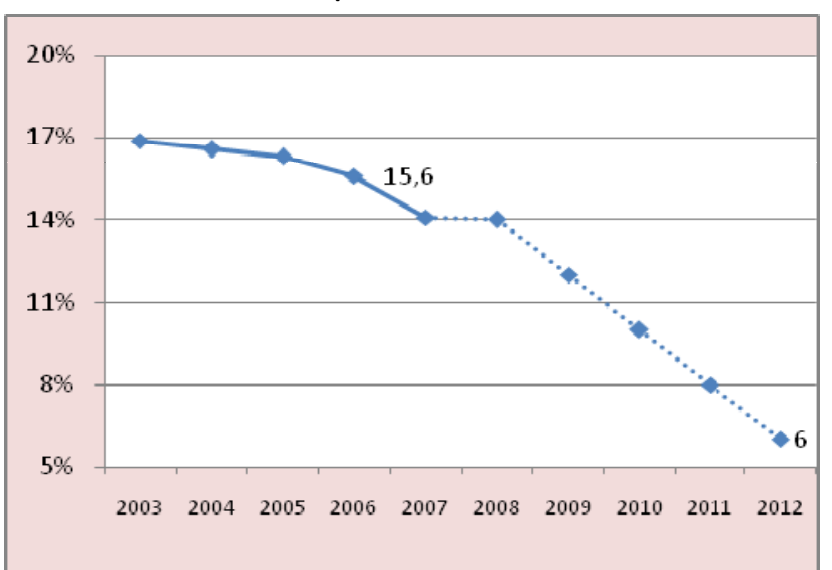

Sources: MSPFPS and SNISE

The proportion of under-five low weight children has clearly regressed in the past five years, falling from $16.90 \%$ in 2003 to $15.6 \%$ in 2006 .
Significant decrease of the proportion of underfive low weight children seen at NNO community sites

In 2007, the low weight prevalence rate among children under five in community sites reached $25.4 \%$ while the objective set was $38 \%$. The duplication of community sites is a sustainable strategy for controlling malnutrition.

Although community mobilization is critical to the program's success, the perception of malnutrition issues requires further advocacy at the decision-makers' level.

The adoption of the National Nutrition Policy (NNP) in 2004 and the establishment of the National Nutrition Office (NNO) under the supervision of the Prime Minister's Office, as the coordination body of the interventions and interveners, have allowed for capitalizing all efforts and assets for better synergy and complementarity of action.

Several programs, such as PNNC/SEECALINE and CRS among others, conducted in collaboration with Ministeria Departments contributed to the control of malnutrition by establishing community sites, deworming children, providing iron supplementation to primary school pupils, and promoting school feeding, with support from technical and financial partners (World bank, UNICEF, WFP).

\section{COMPLETION STATUS OF THE MAJOR}

\section{COMMITMENTS TAKEN DURING THE PRESIDENTIAL}

\section{DIALOGUE}

\section{Immediate and ongoing actions}

\section{Cross-cutting actions:}

- Establishment of the National Committee for Human Resources Management (NCHRM) and the Regional Committee for Human Resources Management (RCHRM) for the decentralization and management of human resources;
- Six paramedical training centers are already established in the 6 former provinces, but the availability of resource people and practicum structures complying with standards are still to be developed;

- Development of the decent behavior code at the University Hospital Center, HJRA;

- Existence of a duty tower in BHCs, to ensure access to care;

- Establishment of a monitoring committee at the DRSPFPS level to monitor the implementation of the commitments taken during the presidential dialogue at the regional level

- Use of the Malagasy language for communication;

- Establishment of competent teams at the development and negotiation stage: strategic reflection group established at the central and regional levels;

- Increase of the budget share allocated to the health sector, refer to the Budgetary conference;

- Allocation of funds only upon presentation of supporting documents to ensure that it is possible to track the funds' circuits, including their use;

- Advocacy with donors: action planned during a joint review;

- Advocacy for the creation of the budget for 3P involving NGOs in the monitoring of physical achievements;

- Beneficiaries' mastery over the donors' procedures; 


\section{IMPLEMENTATION OF THE MAP}

- Leadership in the coordination of forums and sectoral reviews ensured by the MSPFPS;

- All actors concerned are involved in and made responsible for the integrated development of health

- Distribution of the preventive and curative roles among State structures and other interveners: this is defined in the partnership convention, but the dissemination of the concerned NGOs and associations' conventions is insufficient;

- Orientation of all ORDSED and State credit managers on efficient resource management procedures;

- Elimination of major infectious diseases;

- Reinforcement of IEC on the use of ACT or antimalarial drugs; these are integrated in the performance of District community workers;

- Establishment of the Health Input Integrated Action Program (HIIAP) as part of the integration in the SALAMA circuit and the dispatching of supplies;

- Supply of BHCs according to their needs;

- HIV preventive measures and screening promoted at the corporate level as part of the company's own domestic STI/HIV/AIDS control policy, in compliance with the national strategic plan;

- Signing of the partnership convention between the MINSANPFPS and SE/CNLS for an allocation of local AIDS control committees (CLLS) and a task force;
- Establishment of a task force for HIV/AIDS control in the 22 regions: convention between the MSPFPS and SE/CNLS established;

- Signing of partnership conventions between the MSPFPS and SE/CNLS to facilitate the CBOs' animators' access and for the consideration of technical aspects (Counselling and Voluntary Tests);

- Establishment of a regional coordination unit in the 22 regions;

- 750 Health Facilities integrate HIV counselling and voluntary test in 2008, as part of improving the population's access to prevention services;

- Integration of health actions in Communal Development Programs to facilitate collaboration on planning and raising awareness on health activities, such as immunization;

- Popularization of national and international texts on women's rights in the Project's intervention sites.

\section{ChALLENGES AND OUTLOOKS}

Integrate different actors in the implementation and monitoring operational plan of the commitments taken during the presidential dialogue; mobilize resources for the implementation of the commitments within time limits.

\section{RECOMMENDATIONS}

- To officers per level: develop an implementation operational plan for the commitments taken during the presidential dialogue; ensure implementation within time limits and develop self-monitoring and self-evaluation of the commitments at each entity's level.

- Improve the quality and reliability of statistical information, through close collaboration between the INSTAT and the MSPFPS: support to the definition and calculation of indicators, etc. 


\section{IMPLEMENTATION OF THE MAP}

\section{COMMITMENT 6: HIGH GROWTH ECONOMY}

The Madagascar Action Plan counts on an economic growth of 7 to $10 \%$ until 2012, through the revitalization of the private sector in a climate conducive to investments.

\section{ANALYSIS OF THE QUANTUM LEAP}

- The Economic Development Board of Madagascar (EDBM) has become operational and subsidiaries have been established in the poles of Taolagnaro and Nosy Be.

- The reforms on public revenues and expenditures management as well as the organization of the control bodies were continued.

- The new public procurement procedures have been implemented.

- The new organic law on public finances has become effective.

- The investment act has been developed and promulgated.

\section{ANALYSIS OF INDICATORS}

\section{Steady macroeconomic stability and economic activities influenced in many ways by the developments of globalization}

Increase in economic growth and investments, including FDI

The international context for year 2007 was mainly marked by a steady though moderate growth, the sharp increase in oil price, by the depreciation of dollar against euro, and by the drop in the price of basic commodities. All of these had diverse influences on the national economy. However, overall, the trends in the big indicators have been positive.

Graph 23: Changes in macroeconomic values

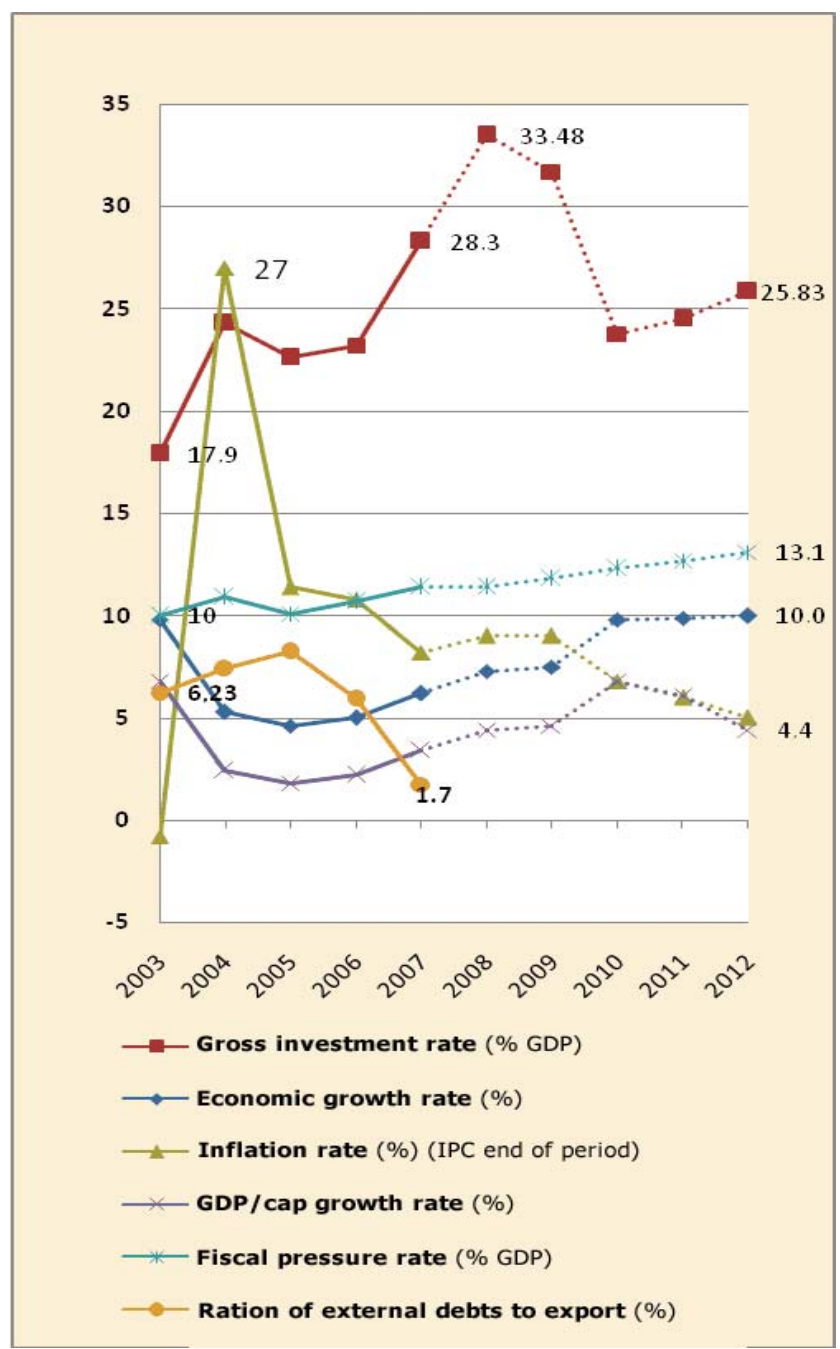

Sources: $\mathrm{MECI} / \mathrm{DEEM}$
The economic growth rate has remained above the demographic growth rate of $2.8 \%$ per year, increasing from $4.6 \%$ in 2005 to $6.2 \%$ in 2007 against an objective of $5.6 \%$ (an average of $5.0 \%$ over the last three years). This is mainly due to private investments estimated at $12.3 \%$ of the GDP in $2005,14.7 \%$ in 2006 and finally $20.7 \%$ in 2007.

The trends in economic growth has strengthened the restructuring of the economy towards the tertiary sector, with this sector's performance increasing from $7.1 \%$ in 2006 to $7.7 \%$ in 2007 , mainly because of the sub-sectors of transport, telecommunication, and tourism.

Graph 24: Sector structure of the GDP (at factor cost)
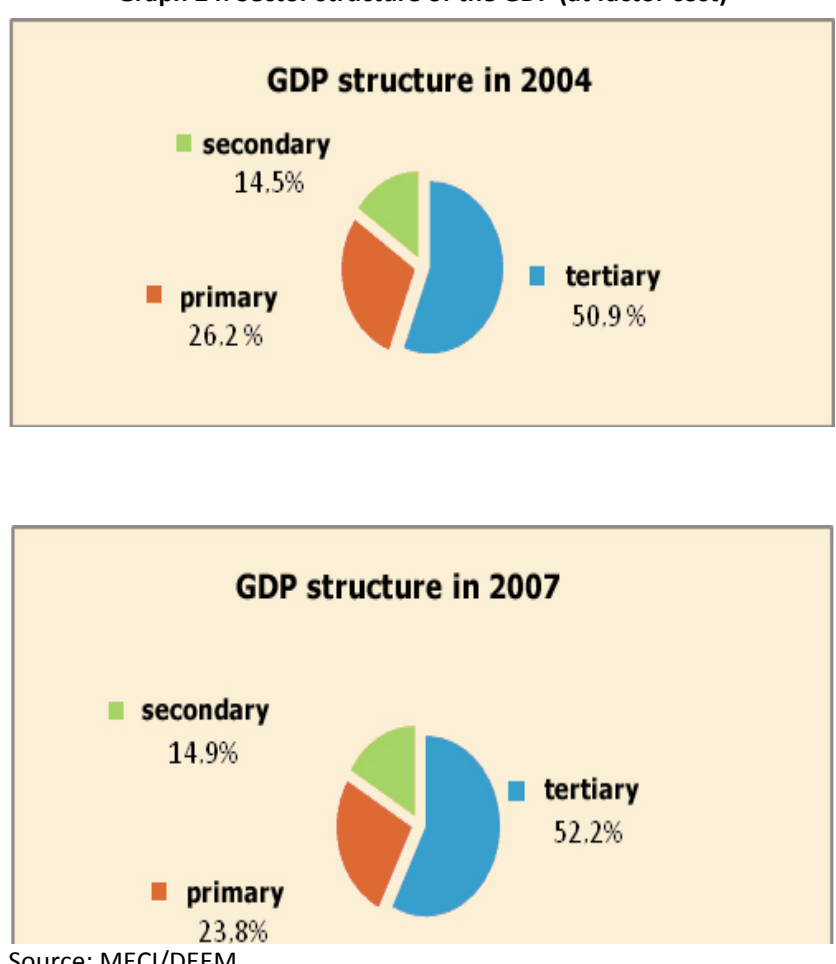


\section{IMPLEMENTATION OF THE MAP}

Despite internal as well as external shocks (cost of oil, power shortage, decrease of productivity due to competitors), the secondary sector managed to achieve a performance of $9.9 \%$ in 2007 against an average of 3.5\% during the 2005-2006 period, mainly because of the performances of the Free Export Processing Zones and food processing.

Growth in the primary sector remains low at $2.1 \%$ in 2006 and $2.2 \%$ in 2007

As regards foreign direct investments (FDI), the sector of "extractive activities" accounted for almost 95\% of the total flows of investments in 2007. Four countries rank as the main investors in this sector, namely Canada with 48.9\%, Japan with 19.3\%, South Korea with 19.3, and the USA with 8.3\%. France has lost in ranking in 2007. However, France has a special position as it is present in almost every sector. Japan and Korea's presence has been especially marked in 2007.

Graph 25: Flows of FDI per country of origin (in billion ariary)

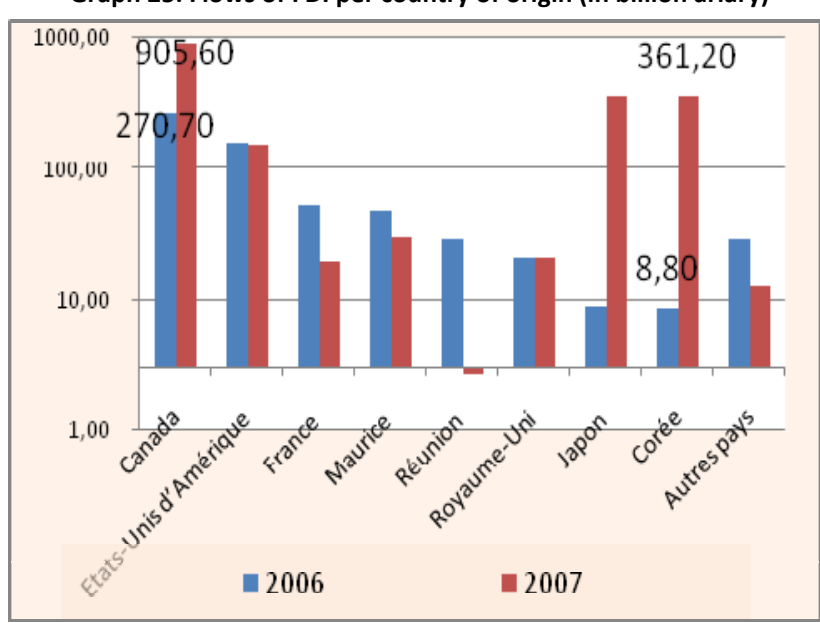

Source : BCRM
FDIs have started massively flowing in the country in 2006. This phase could keep on going and would allow for achieving the gross investment rates needed to sustain a steady growth until 2012

However, there remain some problems that may still discourage FDIs in Madagascar:

- While potentialities for investments in Madagascar are presently numerous, the flow of capital from the countries in the Southern African Development Community (SADC) and the Common Market of Eastern and Southern Africa (COMESA) remain low.

- Efforts must be made in the area of power supply in order to meet the needs of investors.

Graph 26: Net flows of FDIs (million of SDR)

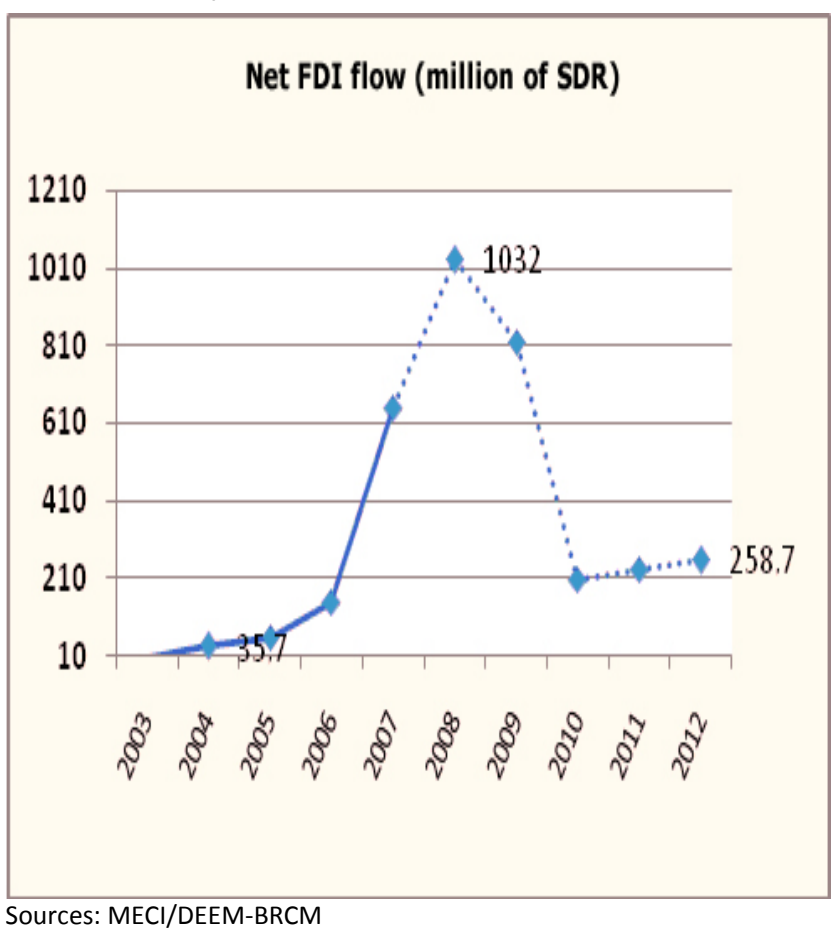

Graph 27: Developments in Investments

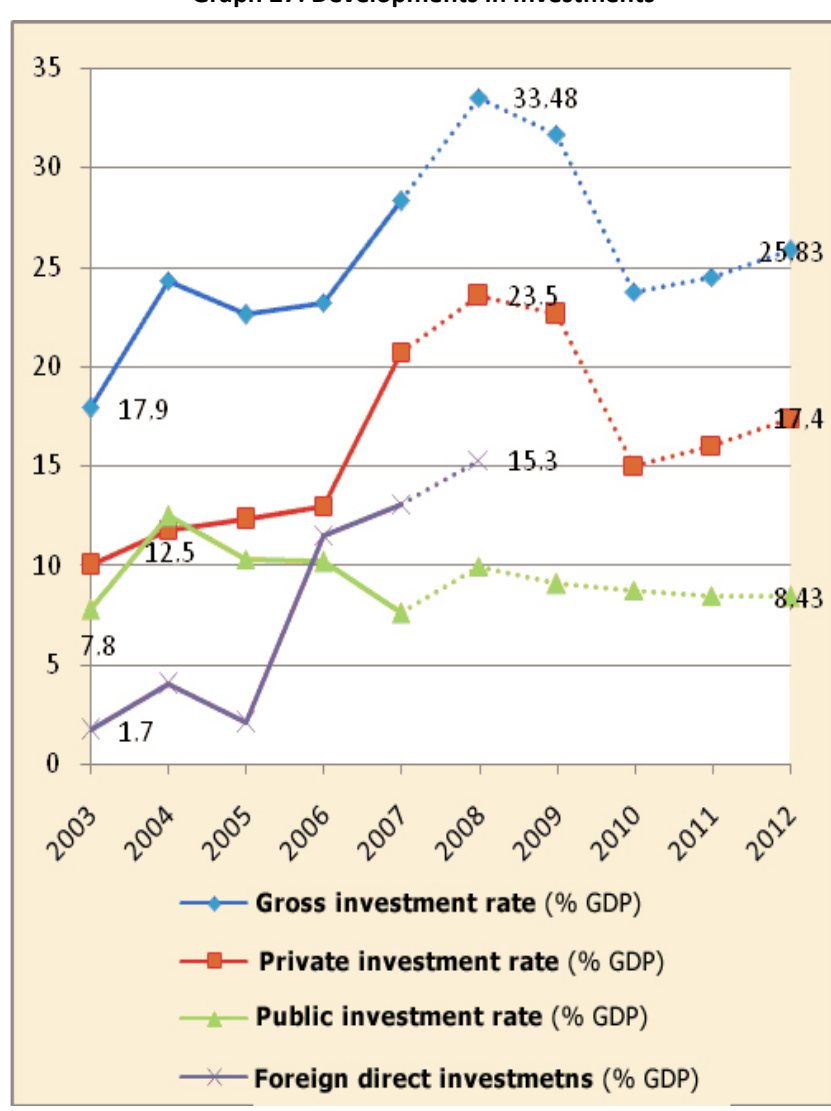

Sources: MECI/DEEM-BRCM-SNISE

\section{Control of inflation and budget deficit}

Decrease in the inflation rate

The control of money supply growth through diverse indirect regulation instruments ${ }^{3}$ as well as the enforcement of budget policy oriented on reducing deficit

${ }^{3}$ Policy of interest rate, police of money base, procurement procedures at market conditions, policy of compulsory reserves including a penalty rate in case of gaps between the required and the actual reserves, sterilization policy to control potential adverse effects of the FDIs flows. 


\section{IMPLEMENTATION OF THE MAP}

has resulted in a slow down in the internal inflation rate 4 From $11.4 \%$ in 2005, it decreased to $10.8 \%$ in 2008 and finally dropped at $8.2 \%$ in 2007 (end of period), despite the influence of unfavorable factors related to the economic situation such as the sharp increase in oil and rice price on the international market, the fluctuations of the ariary, the inadequate supply of energy, and climatic hazards. Thus, the objective of $10.1 \%$ in 2007 was overachieved.

In 2008 , the objective as regards the money policy is to maintain inflation at a one-digit rate by the end of the year despite the difficult context. Over the next three months, the banks' liquidity will be actively controlled through interventions on the money market while the rate of compulsory reserves and the reference rate will remain unchanged and the interest rates on the money market will be maintained at their current levels.

\section{Increased fiscal pressure and drop of budget deficit}

The fiscal pressure rate of $11.4 \%$ in 2007 is 0.5 point above the set objective of $10.9 \%$. This contributed to improving the budget deficit which dropped to $2.8 \%$ of the GDP against a forecasted $4.7 \%$ over the period.

This performance was due to the followings, in particular:

- a tight budget policy consisting in decreasing public expenditures of 2.7 points compared to the total expenditures in 2006 and of 2.1 points compared to the objective of 2007;

- regulation of expenditures based on tax revenues;
- improvement of public finances management by building the capacities of customs and tax departments.

Constraints on investment climate perceived in different ways by investors

Madagascar ranked 131st, 155th, and 149th country out of 175 countries respectively in 2005 and 2006 in the Doing Business ranking.

A study on a sample of 293 manufacturing enterprises conducted by the consultant firm ATW in collaboration with the World Bank in 2005 based on a comparative analysis with similar and competitive countries pointed out some assets and weaknesses in relation with the investment climate in Madagascar:

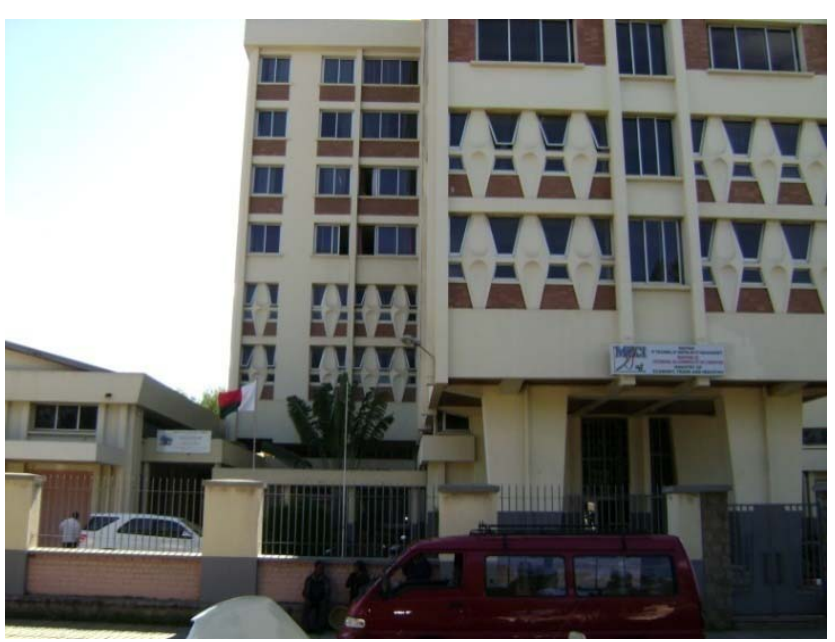

Assets:

- Competitive hand labor cost;

- Competitive average time spent on custom clearance for both imports and exports;
- More favorable access to short-term and commercial credit

\section{Weaknesses:}

- The burden of red tape and corruption (long delays in processing requests, etc.)

- Difficult access to long-term credit and high cost of security;

- Higher taxation rates that are difficult to manage;

- Higher indirect costs due to inadequate infrastructures: unreliable power supply, inadequacies in the supply chain, inadequate transport network, and sub-optimal water supply services.

The study also showed wide variations in the perception of the constraints based on the type of enterprises surveyed:

- A high percentage of free export processing enterprises, national enterprises, and non exporting enterprises consider control on prices, inflation, an macroeconomic instability as major constraints;

- Enterprises out of free export processing zones, small enterprises, and national enterprises seem to be the most affected by the cost of credit. In addition to non exporting enterprises, they are the ones that are the most concerned by the credit access issue.

- A big proportion of free export processing enterprises and very large size enterprises think that uncertainties in regulations are a major obstacle.

In addition, in reference to the assessment of business climate by Doing Business, from 2005 to 2006, there have been improvements as regards the aspects related to business creation, the tax and duty payment condition, and the transborder trade conditions. Land tenure in Madagascar is seen as one of the most difficult issues

\footnotetext{
${ }^{4}$ Measured through the changes in the consumer price index
} 


\section{IMPLEMENTATION OF THE MAP}

compared to other reference countries. However, it should be noted that Madagascar has undertaken major structural reforms until 2007 in order to improve the business climate, especially the investment climate, through the followings:

- Adopting the competition act as well as the law on the general guarantee for investors through the country's accession to the Mutlinational Investments Guarantee Agency;

- $\quad$ Signing the Agreement setting up the African Trade Insurance Agency;

- Setting up the one-stop shop for Investments and Enterprises (GUIDE);

- Creating the Economic Development Board of Madagascar (EDBM);

- Signing Agreements for Investments Promotion and Protection (bilateral agreements or with union of groups).

\section{Small amounts of long-term bank credit granted to} the private sector

The amounts of credit banks increased from MGA609.95 billion in 2003 (out of which MGA604.10 billion was allocated to the private sector) to MGA1,043.08 billion in 2005 (out of which MGA1,034.22 billion was allocated to the private sector) and to MGA1,431.53 billion in 2007 (out of which MGA1,406.21 billion was allocated to the private sector).

As of December 2007, the credit granted to the private sector was distributed as follows: $62 \%$ was short-term credit, $31.16 \%$ medium term, and $6.84 \%$ long-term. From 2005 to 2007, the amount of bank long-term credit received by the private sector has kept on increasing, the increase rate being 24\% from 2005 to 2006 and 64\% from 2006 to 2007 . However, the amount of this type of credit remains small compared to the total amount of credit granted by the system, thus limiting the investment capacity of local enterprises.

Table 3: Annual evolution of bank credits (in billion ariary)

\begin{tabular}{|l|c|c|c|c|c|}
\hline & $\mathbf{2 0 0 3}$ & $\mathbf{2 0 0 4}$ & $\mathbf{2 0 0 5}$ & $\mathbf{2 0 0 6}$ & $\mathbf{2 0 0 7}$ \\
\hline $\begin{array}{l}\text { Total bank credits } \\
\text { (CT+MT+LT) }\end{array}$ & 609.95 & 846.71 & $1,043.08$ & $1,225.36$ & $1,431.53$ \\
\hline $\begin{array}{l}\text { Total bank credit to } \\
\text { private sector }\end{array}$ & 604.10 & 830.57 & $1,034.22$ & $1,205.39$ & $1,406.21$ \\
\hline $\begin{array}{l}\text { \% LT credit/total credit to } \\
\text { private sector }\end{array}$ & 6.67 & 6.36 & 4.54 & 4.86 & 6.84 \\
\hline \% LT credit/total credit & 6.60 & 6.24 & 4.50 & 4.78 & 6.72 \\
\hline
\end{tabular}

Source : BCRM

Moreover, the results of the study made by the World Bank in 2005 on the investment climate pointed out to the following main difficulties in accessing credit:

- High cost of credit

- High cost of collaterals required;

- Complex loan request procedures.

Graph 28: Long term bank credit granted to the private sector (\% of total credit)

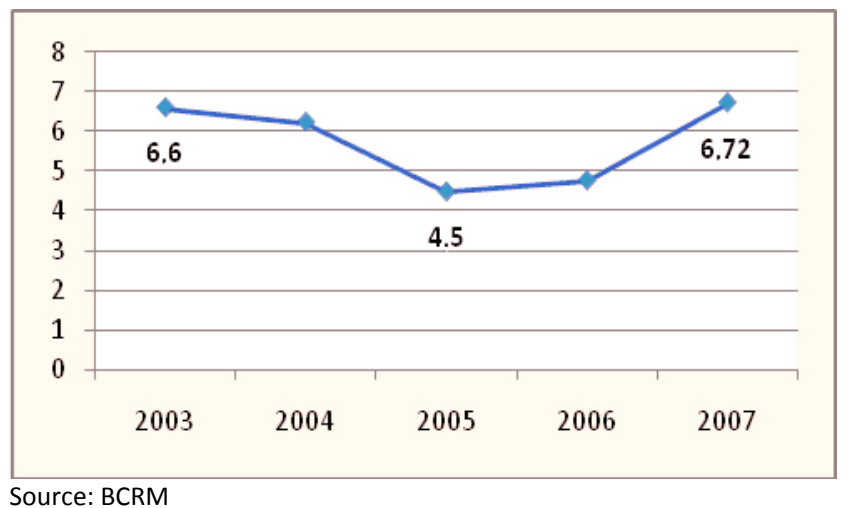

Source: BCRM
In addition, the dynamics in microfinance institutions - a source of potential funding to support small private enterprises' initiatives, has improved only in the last years with a use rate of $1 \%$ before $1990,6 \%$ in 2005 , and $8.51 \%$ in 2007.

\section{External situation controlled}

Increase in goods exports, external deficit, stabilization of exchange rate and currency reserves

On average, the country's export over the last three years increased by $11.6 \%$. This is due more to the expansion to regional markets for traditional products with comparative advantages than to the extension of outlets for non traditional products. In terms of face value, they increased from 673.2 million SDR in 2008 to 808 million SDR in 2007.

Nevertheless, the trend towards a deterioration of the trade balance remains an impediment, the trade balance deteriorating from $-1,0 \%$ in 2006 to $-2.4 \%$ in 2007 :

- Decrease of $1.2 \%$ of export price in terms of foreign currency;

- Increase of $9.9 \%$ of import price due to the sharp increase in oil price;

- Increase of $16.7 \%$ in equipment goods price and $8.6 \%$ in raw materials' price.

The deficit of the external current account, including grants, increased from $-8.7 \%$ of the GDP in 2006 to $-14.1 \%$ in 2007 due to the sharp increase in imports (equipment goods pursuant to investments, especially in the mining sector). 


\section{IMPLEMENTATION OF THE MAP}

The flow of external aid in various forms - direct budget aid, aid through project, debt cancellation as part of the Initiative for Multilateral Debt Relief, has allowed for reconstituting currency reserves at a level of 2.9 months of goods and services imports in December 2007.

The big fluctuations of the Ariary in 2004-2005 are now past history. The exchange rate for ariary against SDR (average over the period) has become stable, and the ariary has even started appreciating in 2007. The appreciation was especially marked against the US dollar $(10 \%)$ and more moderate against the euro (5.0\%).

\section{A downward trend as regards the ratio of} foreign debt service against exports

Over the last four years, Madagascar foreign debt service has been on a downward trend, decreasing from 49 million SDR in 2004 to 13.99 million SDR in 2007 (including 6.59 million SDR of principal and 7.4 million SDR of interest). The trends results from the increasingly significant amounts of debt relief received over the periods, the most important ones coming from multilateral and bilateral donors. In the same way, the ratio of debt service against exports has kept on decreasing from $9.23 \%$ in 2002 to $1.7 \%$ in 2007 .

\section{Regression in mineral duty collection}

\section{Low rate of mineral duty collection}

In 2007, the mineral duty collected amounted MGA252.5 billion against MGA289.1million in 2006 and MGA339.8 million in 2005, which gives decrease rates of $12.7 \%$ from 2006 to 2007 and $25.7 \%$ from 2005 to 2006 . This may be due to the late collection of data at the lower levels, on one hand and to the decrease in the price of precious stones such as sapphire or rubies on the international market since 2006, on the other hand. It should be noted that there is a lack of organizational mechanisms to improve governance in this sector.

As the sector's performance is mainly assessed by the increase of FDIs, and given that the current investments of QMM-Rio Tinto in ilmenite in Taolagnaro and Sherrit in nickel and cobalt in Ambatovy are still in the investment phase, the expected social and economic impacts are not yet tangible.

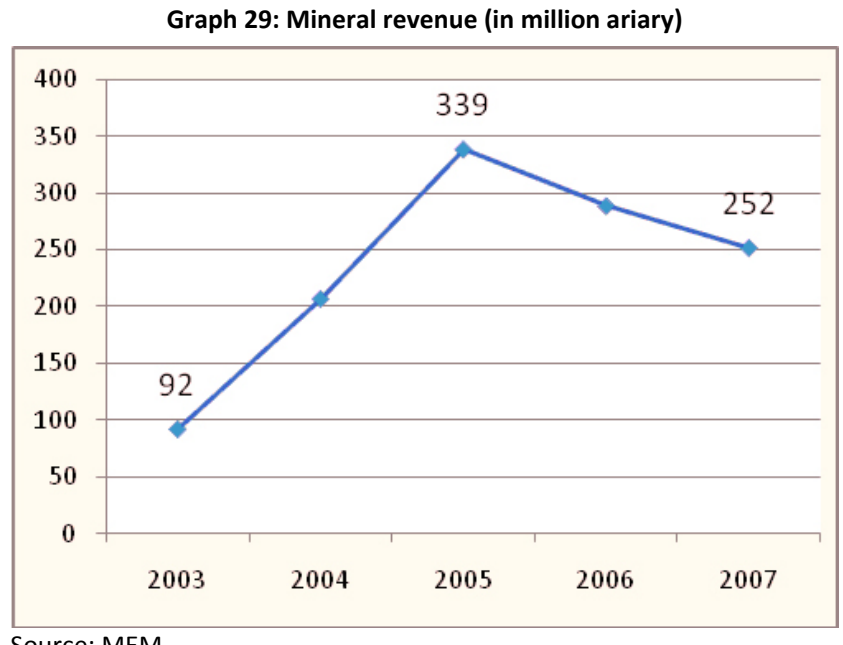

Source: MEM

\section{Improved performance of the tourism sector}

\section{Increase in tourism revenues, number of tourists} and direct employments generated

The sector of tourism constitutes a lever for the country's development. In 2007, according to the economic situation note (Division of Economic Studies and Modeling/MECl), the tourism's performance was good: a clear increase of the number of non resident visitors was noted, from 227,052 in 2005 to 311,730 in 2006 and 344,348 in 2007; the income generated increased from 124.0 million SDR in 2005 to 157.7 million SDR in 2006 and 211 million SDR in 2007; in addition 1,956 new employments were created. These results were obtained thanks to an increase in the accommodation capacity: with 164 new tourist enterprises and 1,409 new hotel rooms.

Table 4: Trends in the indicators of tourism
\begin{tabular}{|l|c|c|c|c|c|}
\hline \multicolumn{1}{|c|}{ Indicators } & Unit & $\mathbf{2 0 0 4}$ & $\mathbf{2 0 0 5}$ & $\mathbf{2 0 0 6}$ & $\mathbf{2 0 0 7}$ \\
\hline $\begin{array}{l}\text { Incoming non } \\
\text { resident visitors }\end{array}$ & Number & 228784 & 277052 & 311730 & 344348 \\
\hline $\begin{array}{l}\text { Revenues of } \\
\text { international } \\
\text { tourism }\end{array}$ & $\begin{array}{l}\text { Million } \\
\text { SDR }\end{array}$ & 104,3 & 124,0 & 157,7 & 211,0 \\
\hline Hotels & Number & 853 & 937 & 1015 & 1179 \\
\hline Rooms & Number & 10230 & 10879 & 11872 & 13281 \\
\hline $\begin{array}{l}\text { Enterprises } \\
\text { working on tours } \\
\text { and tourist } \\
\text { animation }\end{array}$ & Number & 589 & 709 & 755 & 816 \\
\hline $\begin{array}{l}\text { Employment } \\
\text { created by travel } \\
\text { enterprises }\end{array}$ & Number & 3939 & 4310 & 4527 & 4710 \\
\hline $\begin{array}{l}\text { Total of } \\
\text { emplyoyments } \\
\text { created }\end{array}$ & Number & 19845 & 21167 & 22409 & 24365 \\
\hline
\end{tabular} Source : MEEFT

\section{Contribution of the Main Projects}

The USD12.5 million guarantee fund set up by the Integrated Growth Pole Project (IG2P) and the International Finance Corporation in September 2006 to guarantee up to $50 \%$ the credits granted by BNI-CA and BFV-SG to Micro, Small, and Medium Enterprises (MSME) has allowed the two banks to grant USD14.6 million to 


\section{IMPLEMENTATION OF THE MAP}

enterprises as of December 2007, thus exceeding the set objectives. The amount is made up of 848 credits, with 568 granted by BNI-CA and 280 by BFV-SG.

In addition to the support to banks, IG2P also contributed to the performance of other sectors, namely:

- Implementing training programs for MSMEs to build the private sector's capacity and the intensive capacity-building programs in local governance;

- Rehabilitating infrastructures and equipment to improve public services and the living conditions of the local population;

- Building major infrastructures that have a structuring effect on economic growth:

- Rehabilitating of safe water supply networks and solving power supply problems;

- Providing operational and strategic support;

- Providing support to the tourism sector.

Two major projects contribute to the development of the mining sector:

- As regards the Project for the Mining Sector's Institutional Reinforcement (PRISM), the results are fairly satisfactory. The main activities - building the mining administration competence and updating geological and mining information, were completed but the activities to support the private sector in processing mining products and in extractive activities were not done.

- As regards the Mining Resources Governance Project (PRGM), the setting up of regional environmental units was a significant achievement. Conversely, the actions to support the decentralized management of mineral resources were not satisfactory.

\section{Completion Status of the Commitments}

TAKen DURING the Presidential Dialogue

\section{Ongoing actions:}

- 244 enterprises were controlled as regards the payment of the tourist duty.

\section{Immediate actions:}

- Measures were taken to facilitate investments in building hotels of a standard of at least 3 stars.

- The members of the 12 Chamber of Commerce and Industry were elected.

\section{Short-term actions:}

- The Tourism Code has been effectively revised in collaboration with the World Bank.

- Official launching of Success Stories (entrepreneurs' competition): Business Plan SAHIA 2008

\section{Challenges AND OUTLOOKS}

\section{Investment climate}

- As regards taxation, the tax exemption and relief granted to free export processing enterprises could be rebalanced in order stimulate new investments;

- As regards regulations, they should be streamlined in order to reduce opportunities for corruption;

- As regards infrastructures, the high indirect costs due to inadequate infrastructures (public utilities, supply chain, and transport especially) are to be decreased.

- As regards finances, access to credit is to be expanded and the cost of accessing credit reduced.

\section{Foreign Direct Investments}

- Increase the amounts of FDIs with high value added and giving more importance to employmentgeneration.

\section{RECOMMENDATIONS}

Mines

- Implement the new system for collecting data on mineral duties at the lower levels;

- Strengthen support to the private sector in processing mining products and in extractive activities;

- Implement the actions to support the decentralized management of mineral resources;

- Reinforce the effective implementation of mining governance;

- Accelerate the progress towards the exploitation phase of the major mining projects while respecting local communities and environment.

\section{Foreign Direct Investments}

- Promote and orient FDIs towards the exploitation of resources other than mineral ones in order to develop the other sectors and strengthen competition.

- Build the capacity of the Center for Research, Studies, and Support to Economic Analysis in Madagascar (CREAM) to conduct an assessment of trends and the multiplier effects of FDIs.

\section{Tourism}

- Rehabilitate, as an urgent action, the hotel facilities destroyed by cyclones Fame and Ivan in order to be ready for the next tourist season.

- Initiate discussions to reinforce linkages of tourism with other sectors, especially Public Works and Transport, Environment, Telecommunications and Communications. 


\section{IMPLEMENTATION OF THE MAP}

\section{COMMITMENT 7: CHERISH THE ENVIRONMENT}

As part of implementing the "Madagascar naturally" vision, the State decided to:

- increase the surface area of protected areas from $1,700,000 \mathrm{Ha}$ to $6,000,000 \mathrm{Ha}$ that is, by more than $250 \%$.

- keep its $9,000,000 \mathrm{Ha}$ of forest and wetland areas for the conservation of its natural riches and the use of its forest, lake, marine, and coastal resources;

- increase the reforested surface area from $360,000 \mathrm{Ha}$ to $540,000 \mathrm{Ha}$ that is, by $50 \%$.

According to the MDGs, the following conditions must be met to ensure the sustainability of the environment:

- the principle of sustainable development needs to be integrated in national policies;

- the current trend that would lead to the loss of environmental resources needs to be reversed.

\section{ANALYSIS OF THE QUANTUM LEAP}

Environment is currently integrated in the larger vision of sustainable development and poverty alleviation policy.

Overall, significant results were obtained and are materialized by:

- The increase of the proportion of Protected Areas (PA) from $2.9 \%$ in 2004 to $8.2 \%$ in 2007 .

- The combined efforts for maintaining the forest's surface area and promoting reforestation actions;

- The mobilization of funds for the Protected Areas and Biodiversity Foundation of Madagascar (PABFM);

- The reinforcement of environmental control systems.

Nevertheless, the MDGs monitoring report indicates that the proportion of forest area has stagnated around $22.6 \%$ between 2004 and 2006. In the nineties, the deforestation rate in Madagascar amounted to $0.82 \%$ per year. This rate fell back to $0.55 \%$ per year from 2000 to 2005 . The regions holding the highest deforestation rate are Itasy and Vakinankaratra.

\section{ANALYSIS OF PRIORITY INDICATORS}

Perceptible increase of the Protected Areas' (PA) surface area in 2007

In $2007,876,623 \mathrm{Ha}$ of PA were created that is, an increase by $28.4 \%$ compared to 2006 . The temporary status was attributed to $850,588 \mathrm{Ha}$ while $26,035 \mathrm{Ha}$ received the final status. When the PA creation achievements are cumulated, it appears that the objectives set for 2012 in PA creation are achieved at $77 \%$. Awareness-raising was conducted in 271 Fokontanys and communal consultations were performed in 12 sites.

Regarding delineation, development schemes, and management modes, 07 PAs have been delineated and 07 Development and Management Schemes developed in 06 Regions, namely: Atsimo Andrefana, Menabe, Vakinankaratra, Diana, Alaotra Mangoro, and Atsinanana.

The number of tourists who visited the PAs reached 113,875 .

As regards ecological monitoring and the enforcement of measures for the conservation of land and water ecosystems, the PAs' overall index of effectiveness reached $59 \%$ for an objective set at $63 \%$.

\section{Increase of the reforested and restored surface area}

A surface area of $18,379 \mathrm{Ha}$ was reforested, which amounts to $73.5 \%$ of the objective set. With the production of $9,642,993$ seedlings, objectives were achieved at $80.4 \%$. Several restrictions account for the fact that objectives were not achieved and include the high cost of reforestation and technical problems, among others.
Eighty (80) Land Reserves for Reforestation (LRR) of a surface area of 44,544 have been identified in 16 Communes.

As for the pilot sites for carbon absorption and sequestration, $10 \mathrm{Ha}$ of land have been restored.

\section{Objective for the reduction of the burnt surface area} almost achieved

The objective set in 2007 is that the burnt surface area will be inferior to $450,000 \mathrm{Ha}$ that is, a reduction rate of $34 \%$ compared to the 2002 level $(680,000 \mathrm{Ha})$. This rate was almost attained in the course of the year with an actual rate of $33 \%$, amounting to $455,816 \mathrm{Ha}$ of burnt areas. Control efforts are provided by the Forest Administration in combination with those supplied as part of the bush fires control, including the enforcement of incentive and eradication measures. The highest rate of clearing has always been recorded in Toamasina, of all the Faritanys of Madagascar. It must be noted that the annual amount of burnt areas always increases significantly when elections are held that year.

A hundred (100) Communes were awarded prizes for the prevention of uncontrolled fires.

Funds mobilized for the Protected Areas and

Biodiversity Foundation of Madagascar

The amount mobilized for the PABFM reached USD $33,162,586$ and is distributed as follows:

- Malagasy State

- WWF

- $\mathrm{Cl}$

- KFW

- AFD

- FFEM

- IDA

- GEF

USD $2,555,801$
USD $1,000,000$
USD $1,000,000$
USD $6,664,071$
USD $2,961,809$
USD $1,480,905$
USD $7,500,000$
USD $10,000,000$

The environmental forest receipts amounted to $200 \%$ of the objectives set that is, 3,029 billion Ariary, including 


\section{IMPLEMENTATION OF THE MAP}

2,367 billion Ariary of entry fees in Protected Areas and 662 million Ariary from the National Forest Fund.

A process is underway to develop 03 instruments for sustainable funding (carbon, green tax, levy on environmental services, and biodiversity offset).

To increase funding from the private sector, the policy of concession of ecotouristic services and lands in National Parks/ANGAP to the private sector is being studied.

\section{Increased implementation of the Environmental}

\section{Education Policy}

As part of the training on environmental education, the environmental curriculum is adopted in:

- $100 \%$ of primary schools;

- $90 \%$ of secondary schools;

- $25 \%$ of technical and vocational schools;

- 06 Universities.

Trainers are established and pedagogical kits are developed. The activities will be gradually conducted at the Regions' level.

\section{Reinforced forest control}

Regarding policing, control, and the forest regulation frame:

- 04 control units have been established in 04 Regions and also in large airports;

- 02 environmental regulation and control tools have been developed;

- 24 controls have been performed;

- 27 misdemeanors have been established and more than 20,000 pieces of illegal wood seized.

\section{CONTRIBUTION OF PROGRAMS AND PROJECTS}

The results of the Environmental Program 3 funded by IDA, CI, USAID, the UE, and UNDP are materialized by the development of "Trust Fund" specific instruments of financial sustainability for the PABFM and the improvement of the institutional device.

The Sustainable Management of Natural Resources Program (RFA), the pilot Project for Protecting and Enhancing the Value of Biodiversity (AFD), and the Study of Rural Development and Catchment Areas Development in Southwestern Alaotra (JICA), all contributed to the sector's performance.

Efforts must nevertheless be provided regarding the Development of National Actions to Adjust to Climate Change Project (IDA) and the Seeds Harvesting and Conservation Project (Royal Botanic Gardens).

\section{COMPLETION StATUS OF THE MAJOR \\ COMMITMENTS TAKEN DURING THE PRESIDENTIAL DIALOgue}

- Conciliation of agricultural development and forest conservation through the promotion of consultation and the establishment of consultation structures between the sectors concerned, in the different processes: zoning, management transfer, development and management scheme of catchment areas or wide areas of agricultural production, creation of protected areas with consideration of preservation actions, commune development plans, etc.

- Trial funding of FATANOL stoves production;

- Communication packages are developed, networks and media are animated and sensitized (posters, TV programs, website, exhibitions, participation in official celebrations). Pedagogical kits are developed and trainer teachers are trained. Vintsy magazines are disseminated and clubs are set up in schools;

- Environmental cells are established and reinforced for the environmental integration in 11 sectors;
- Joint design of the CIREEFs' AWPs with the Regions, with technical and financial supervision from donors as well as involvement, according their zones of intervention;

- Management of environmental dashboards (TBE) at the national and regional levels;

- Establishment of the Regional Directorates of Environment, Water and Forest, and Tourism (RDEWFT) in the 22 Regions.

\section{Challenges and Outlooks}

- Ensure the fluidity of information between decentralized services;

- Reinforce linkages with the Regions: technical supervision, communication of information;

- Equip the 22 Regions with their own regional control service.

\section{RECOMMENDATIONS}

- Involve all interveners, sectoral Ministries, decentralized territorial collectivities, the forces of law and order, and the local population, so that control efforts may be combined at all levels;

- As for ANGAP, one site should have just one donor

- Each Protected Area should have a fire management plan including preventive as well as active control. 


\section{IMPLEMENTATION OF THE MAP}

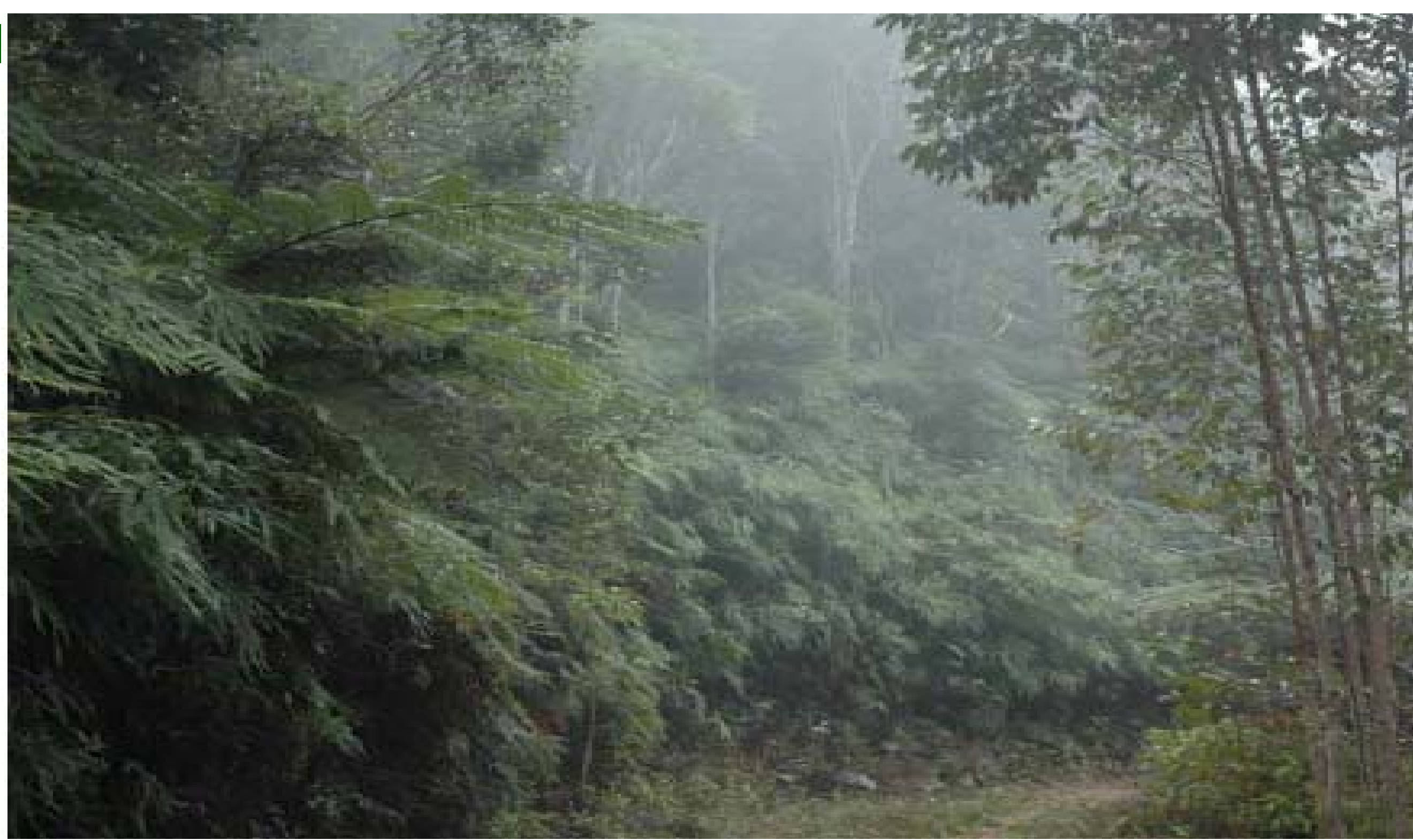




\section{IMPLEMENTATION OF THE MAP}

\section{COMMITMENT \\ 8: \\ NATIONAL \\ SOLIDARITY}

The objective of Commitment 8 is to conjure up a national identity and to honor and preserve our heritage and cultural traditions. The citizens' participation in all aspects of the social, cultural, and political lives will be promoted to contribute to the country's development.

\section{ANALYSIS OF THE QUANTUM LEAP}

- The democratization process is doing well in Madagascar, resulting for instance, in the multiplicity of political parties and the proliferation of media (radio, television, newspaper, etc., which are mostly private).

- The elections, to which several candidates from political parties or not presented themselves, were judged as free and open.

- Conclusive sustained results supported by national awareness were obtained in birth registration.

- Concrete results were obtained regarding the preservation of cultural heritage.

- The preparation of athletes to international competitions was improved owing to the support provided to the practice of high level sports.

\section{ANALYSIS OF PRIORITY INDICATORS}

Mechanisms of citizen participation are developed but little in Madagascar. For the moment, elections seem to be the most determining factor in the Malagasy setting, compared to other channels, such as media and civil society organizations. The main issues of citizen participation are: i) difficulties of access to information; ii) lack of organization of the civil society, iii) poor participation of women; iv) perfectibility of the electoral process; v) poorness of local governance.

Mitigated results regarding the national rate of participation to elections

The Afrobarometer survey 2005 (source: Integrity National Observatory $\#^{\circ} 3$ of July-August 2006) indicated an important participation rate to the 2002 legislative elections, with $77 \%$ of Malagasy people reporting participation to these elections. In 2007, the national rate of participation to the three elections organized are mitigated, as shown on the following table and compared to the objective set of $60 \%$.

Table 5: Variation of the national rates of participation to 2007 elections

\begin{tabular}{|l|c|c|c|}
\hline \multicolumn{1}{|c|}{ Type of election } & Registered & Voted & Rate of participation \\
\hline Referendum & 7416433 & 3247018 & $43.78 \%$ \\
\hline Legislative & 7502905 & 3452683 & $46.02 \%$ \\
\hline Communal & 7111343 & 4499482 & $49.21 \%$ \\
\hline
\end{tabular}

Source: National Board of Elections

Several factors account for the level of the population's participation described in the previous table:

- the development of electoral registers by organizers;

- awareness-raising of electors on participation;

- the organization of civil societies, which can provide linkages between citizens and the party in power;

- the high level of illiteracy;

- the electoral college's lack of political maturity.

Decrease of the percentage of youth and children having no birth certificate

Although accurate figures are not available, experience shows that many children are not registered at birth. In such cases, they are deprived from their most elementary rights.

In 2007, the proportion of children and youth under 18 that had no birth certificate amounted to $31.2 \%$ while the objective was set at $33.2 \%$.

In spite of the situation, there is community dynamism and strong collaboration between decentralized services; the populations of the different localities organize themselves with court services and proximity authorities, including municipal services, to hold open hearings with parental participation and local funding.

However, there are still issues such as the unavailability of magistrates for the open hearings due to their responsibilities and lack of knowledge of the newly appointed the Heads of Fokontanys on procedures. It is also clear that funds are lacking.

UNICEF contributes to the National Program of Rehabilitation of Birth Registration or Ezaka Kopia ho an'ny Ankizy (EKA) Program.

\section{Number of national cultural heritages (physical or non physical) preserved}

In 2007, seven cultural heritages underwent rehabilitation and restoration works instead of three, as planned. Caution must nevertheless be taken in interpreting the results, as most works are just being started

Problems encountered include emergencies relating to the unexpected changes of the sites' conservation state that often appear during the work. The lack of standardized infrastructures and potential donors intervening in the sector are also serious impediments to cultural development.

The main programs and projects that contributed to the achievements are: 


\section{IMPLEMENTATION OF THE MAP}

- UNESCO: technical and financial support;

- Support of the Coopération Française to ART MADA;

- Support of the United States of America to the preservation and promotion of traditional dance and music.

\section{Number of athletes participating in international} competitions

Year 2007 was marked by the selection of 393 athletes for competitions such as the $7^{\text {th }}$ Indian Ocean Island Games. Although this figure amounts only to $79 \%$ of the objective set, the high number of medals obtained has shown the quality and high level of the selected sportspeople, and national pride was reinforced.

The 3P collaboration in this area had great importance, as it widely contributed to the achievement of the results. However, the lack of proximity sports infrastructures is still a major impediment to the development of sports for all.

Main contribution of programs and projects

- Technical and financial support to sports activities and youth initiatives by the Support Program to Sport and Youth Initiatives (SPSYI):

- Technical and financial support of athletes by the CONFEJES in training and participation to great games;

- Fight against the propagation of HIV/AIDS among young sportspeople aged 12 to 18 in Madagascar, by the Project Increased use of health services and products, component of SantéNet funded by USAID.

\section{Promotion of gender equality and women's autonomy}

Malagasy women are beginning to hold decision-making positions, although they are still represented in lesser number in the society's activity sectors: in 2007, the proportion of women in the National Assembly amounted to $7.9 \% ; 10 \%$ in the Senate; $15.8 \%$ in the Government; $13.6 \%$ at the Regions' level (as Head of the Region), and $4.2 \%$ at the Communes' level (as Mayors).

Several actions were undertaken to take up the challenge set:

- Reinforcement of the structures in charge of promoting the participation, promotion, and protection of women through the establishment of a national observatory in charge of gender-related changes in partnership with the Sehatra Ivohizana Mira Lenta NGO (SIMIRALENTA); Promotion of women's participation in economic and civic affairs through the establishment of a female leaders' network in every Region;

- Training of 3,250 women from the 22 Regions on leadership, upon the President's initiative;

- Training of focal points on advocacy, in partnership with CARE and SAHA;

- Establishment of 6 listening and legal counselling centers to support women in distress;

- Training of 200 women on political matters in partnership with Norway as part of Promoting Credible Elections and Democratic Governance in Africa.

\section{Completion Status of the Major}

\section{Commitments taken duRING The PREsidential}

\section{Dialogue}

\section{Immediate actions:}

- As part of promoting citizen participation, the civi society is currently undertaking several education and awareness-raising actions.
- Adoption and issuing of Law 2007-040 of 14-01-08, to facilitate the obtaining of birth certificates. This Law confers the competency of open hearings to the Head of District and his/her Deputy;

- Awareness-raising of parents on declaring births;

- Promotion of the participation of head of fokontanys in birth declaration;

- Validation of the National Sports Policy, which awaits the parliamentary session;

- Enhancement of the value of the Malagasy language and cultural identity: text proposal for the Linguistic Policy in the process of finalization;

- Celebration of the Vezo culture in Toliara and the "Jerijery" event in Vavatenina as part of laying emphasis on the Malagasy ways and customs;

- Education and awareness-raising of the population on ways and customs;

- Mobilization of all sectors on the gender approach: a gender cell is created and made operational at the level of each Ministerial Department in partnership with FNUAP

- Dissemination of knowledge on laws pertaining to women and women's rights: laws and texts are already gathered, the translation of the CEDAW Convention is finalized; the dissemination, planned for 2008 is awaiting funding;

- National awareness-raising on gender: awarenessraising on women's rights and on gender during thematic days such as on Women's day on March 08, Rural Women's day, Population's day, Violence Control day, or open day on tourism;

- Awareness-raising of the population on changing and adopting ways and customs, based on the strong points provided for in the MAP: raise awareness and 


\section{IMPLEMENTATION OF THE MAP}

advocate with traditional leaders in Southwestern Madagascar;

- Training of 307 animators on the gender approach, for parental education.

\section{Ongoing actions :}

- Coordination between the MENRS and the MSCL to prevent dual systems of school sports management;

- Reinforcement, improvement, and increase of the number of cultural centers: laying of the foundations of the future House of Culture in Fénérive Est.

\section{Challenges and outlooks}

- Integrate the cultural aspirations and trends of the various local communities concerned in the social and economic development;

- Perform the inventory, collection, analysis, and dissemination of information on the Malagasy culture and values, to optimize their management and exploitation for development:

- Professionalize cultural actors and operators;

- Develop and build the capacities of Decentralized Territorial Collectivities in registering births;

- Ensure the availability of sports infrastructures at the local, regional, and national levels;

- Develop a sports for all program to maximize participation in sports activities;

- Develop an insurance scheme for all participants in sports programs;

- Conduct advocacy with technical and financial partners for investments in the sports and youth area.

- Popularize the national and international texts on women's rights in the Project's intervention sites.

\section{RECOMMENDATIONS}

- Expand EKA activities to other Communes already defined in the action plan 2008.

- Increase the budget of the EKA program, especially in RPI and mobilize other donors, because UNICEF is currently the only donor.

- Research financial partners and potential investors for the development of the cultural sector.

- Incite decentralized collectivities to integrate the youth and sports component (especially the building of sports infrastructures) in their development program;

- Mobilize resources for the training of sportspeople to improve performances.

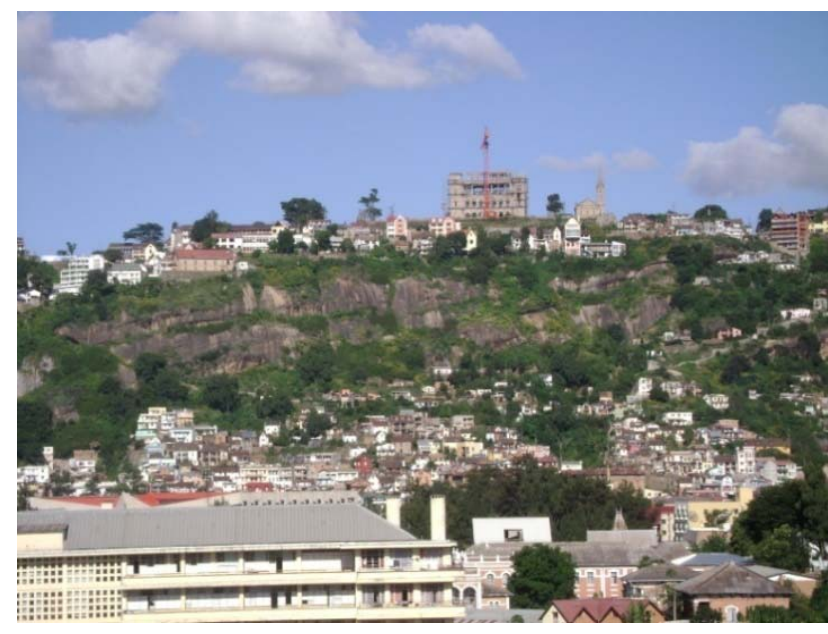

41
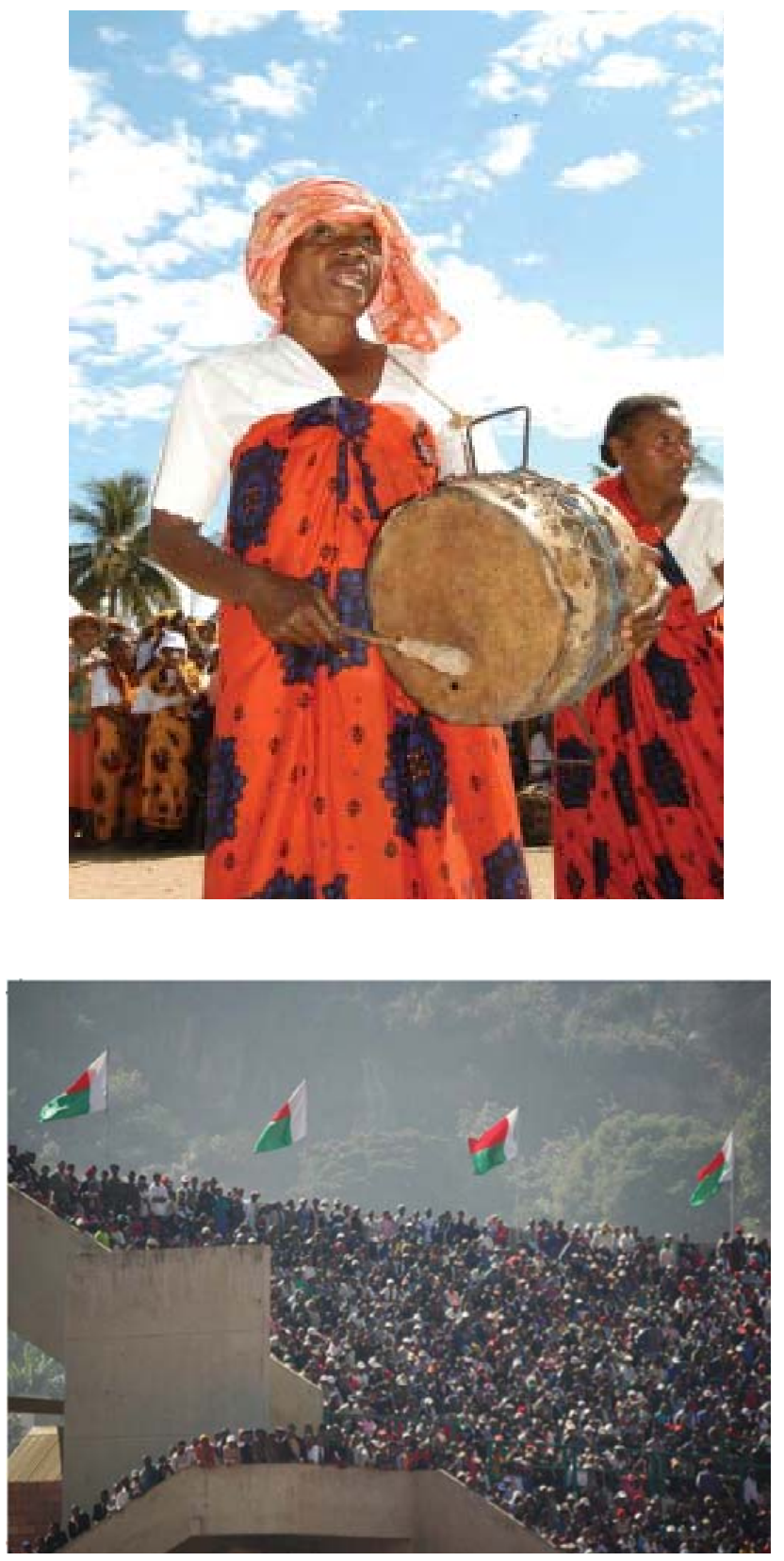

Photos MAP 


\section{FUNDING OF THE MAP}

Overall Situation of Financings/
Disbursements

To implement the MAP, public resources, internal as well as external, must be strongly mobilized and used in an optimal way. In 2007, the first implementation year, the budget execution showed that the $65.3 \%$ of the total resources came from internal resources (i.e. MGA1,693 billions) and 34.7\% form external resources (i.e. MGA901 billion).

\subsection{EXTERNAL FUNDINGS}

Table 5 shows that in 2007, tax revenues representing $52 \%$ of the total public resources constituted the most important part of the Government's resources in implementing the MAP. Efforts were made to mobilize internal resources. Thus, the tax revenues amounted MGA1, 493 billion with a fiscal pressure rate of $10.9 \%$. External resources, namely external grants and funding, represented $44 \%$ of total resources.

As regards the allocation of the resources, $20 \%$ of the internal resources (i.e. MGA327 billion) were mobilized to fund investment expenditures that amounted MGA1, 298 billion and represented $45 \%$ of the total resources. The rest was allocated to personnel expenditures $(23.8 \%)$, to operating expenses (16.5\%) and to other expenditures (14\%).
Table 6: Public resources and their allocations (in billion ariary)

\begin{tabular}{|c|c|c|c|}
\hline & $\begin{array}{c}2006 \\
\text { Achieved } \\
\end{array}$ & $\begin{array}{c}2007 \\
\text { Achieved } \\
\end{array}$ & $\begin{array}{r}2008 \\
\text { Planned } \\
\end{array}$ \\
\hline Total resources & $\underline{2564}$ & $\underline{2594}$ & $\underline{3414}$ \\
\hline Internal resources & 1042 & 1693 & 2045 \\
\hline Includ. Tax revenues & 1261 & 1573 & 1943 \\
\hline Non tax revenues & 62 & 35 & 35 \\
\hline $\begin{array}{l}\text { Internal financing } \\
\text { (net) }\end{array}$ & -286 & 83 & 67 \\
\hline $\begin{array}{l}\text { Revenues of } \\
\text { Privatization fund }\end{array}$ & 5 & 2 & 0 \\
\hline External resources & 1522 & 901 & 1369 \\
\hline Grants & 5655 & 593 & 788 \\
\hline Net external funding & -4133 & 308 & 581 \\
\hline Total Expenditures & $\underline{2564}$ & $\underline{2594}$ & $\underline{3414}$ \\
\hline Personnel expenditures & 590 & 711,2 & 810,6 \\
\hline $\begin{array}{l}\text { Expenditures on good and } \\
\text { services }\end{array}$ & 381 & 432,4 & 695,9 \\
\hline Investment expenditures & 1209 & 1049,9 & 1578,8 \\
\hline Internal financing & 286 & 314,9 & 426,8 \\
\hline External financing & 923 & 735 & 1152 \\
\hline $\begin{array}{l}\text { Other expenditures } \\
\text { Including interests on } \\
\text { debt }\end{array}$ & 385 & $\begin{array}{r}400,3 \\
155,6\end{array}$ & 328,3 \\
\hline
\end{tabular}

Source : MFB/DGB

During budget year 2007, a big share of public expenditures ( $46 \%$ of the total budget, all categories taken together) was allocated to the social sector, namely education, infrastructures, and health. Their respective share in the budget was of $22.7 \%$ for education, $8.3 \%$ for infrastructures, and $8.8 \%$ for health.
Table 7: Operating and investment expenditures in the priority sectors (in billion ariary)

\begin{tabular}{|c|c|c|c|c|c|c|}
\hline \multirow{4}{*}{$\begin{array}{l}\text { Total all } \\
\text { institutions } \\
\text { and ministries }\end{array}$} & \multicolumn{2}{|c|}{2007} & \multirow{3}{*}{$\begin{array}{c}2008 \\
\text { LF } \\
\end{array}$} & \multicolumn{2}{|c|}{2007} & \multirow{3}{*}{$\begin{aligned} 2008 \\
\text { LF }\end{aligned}$} \\
\hline & Plan. & Achi & & Plan & Ach & \\
\hline & \multicolumn{2}{|c|}{$\begin{array}{l}\text { en milliards } \\
\text { d'Ariary }\end{array}$} & & \multicolumn{2}{|c|}{ en $\%$ du total } & \\
\hline & & & & & & \\
\hline Total & $2,631.4$ & $1,726.1$ & $2,907.7$ & 100 & 100 & 100 \\
\hline $\begin{array}{l}\text { Personnel } \\
\text { Without } \\
\text { personnel }\end{array}$ & 552.1 & 527.9 & 638.4 & , & , & \\
\hline Investment & $1,439.7$ & 561.9 & $1,512.1$ & , & , & \\
\hline Health & 207.4 & 152.2 & 256.0 & 7.9 & 8.8 & 8,8 \\
\hline Personnel & 53.1 & 52.6 & 67.7 & & , & \\
\hline Without perso. & 46.9 & 43.8 & 49.7 & . & ， & \\
\hline Investment & 107.4 & 55.8 & 138.7 & . & , & \\
\hline Education & 514.9 & 392.2 & 570.5 & 19.6 & 22.7 & 19,6 \\
\hline Personnel & 233.6 & 231.5 & 278.4 & & , & \\
\hline Without perso. & 114.8 & 109.4 & 121.7 & , & , & \\
\hline Investment & 166.5 & 51.2 & 170.4 & & , & \\
\hline Agriculture & 207.5 & 63.3 & 263.8 & 7.9 & 3.7 & 9,1 \\
\hline Personnel & 13.2 & 13.1 & 17.3 & & & \\
\hline Without perso. & 11.9 & 11.2 & 20.8 & , & , & \\
\hline $\begin{array}{l}\text { Investment } \\
\text { Water and }\end{array}$ & 182.4 & 39.0 & 225.8 & & & \\
\hline Forest & 60.6 & 15.2 & 70.8 & 2.3 & 0.9 & 2,4 \\
\hline Personnel & 2.6 & 2.6 & 5.1 & , & & \\
\hline Without perso. & 1.5 & 1.0 & 3.0 & ' & , & \\
\hline Investment & 56.5 & 11.6 & 62.7 & & & \\
\hline$\underline{\text { Justice }}$ & 45.4 & 43.6 & 61.8 & 1.7 & 2.5 & 2,1 \\
\hline Personnel & 23.7 & 23.7 & 30.8 & , & & \\
\hline Without perso. & 17.2 & 16.5 & 22.3 & , & & \\
\hline $\begin{array}{l}\text { Investment } \\
\text { Public }\end{array}$ & 4.4 & 3.4 & 8.7 & & & \\
\hline Works & 381.2 & 142.5 & 354.0 & 14.5 & 8.3 & 12,2 \\
\hline Personnel & 6.8 & 6.8 & 8.4 & & , & \\
\hline Without perso. & 1.6 & 1.4 & 9.9 & & & \\
\hline Investment & 372.8 & 134.3 & 335.6 & & , & \\
\hline
\end{tabular}




\section{FUNDING OF THE MAP}

Generally speaking, the absorption capacity of $65.59 \%$ (investment and operation) in 2007 is a low performance (39.02\% being investment). The low performance is noted especially in the priority sectors such as Agriculture, Water \& Forest, Public Works, Education, and Health and I s due to delays in budget implementation at the Ministries, poor mastery of the software ORACLE, the negative effects of expenditures regulation resulting in slow financial implementation of certain Program/projects, or even the lack of financial incentives.

\subsection{EXTERNAL FUNDING}

Table 8: Situation of external funding disbursement, by donor (in billion ariary)

\begin{tabular}{|c|c|c|c|}
\hline Donors & 2006 & 2007 & $\begin{array}{c}2008 \\
\text { (Programming) }\end{array}$ \\
\hline Multilatéraux & 830.4 & 655.0 & 846.8 \\
\hline - IDA & 312.4 & 310.0 & 279.9 \\
\hline - FAD- ADB & 68.6 & 39.0 & 106.6 \\
\hline - EU-EIB & 348.3 & 219.6 & 232.3 \\
\hline - UNDP & 12.8 & 11.4 & 18.6 \\
\hline - UNICEF & 30.8 & 46.6 & 31.3 \\
\hline - UNFPA & 3.1 & 3.9 & 2.7 \\
\hline - BADEA & 15.6 & 14.0 & 45.5 \\
\hline - OPEP &, & ,- & 61.5 \\
\hline - OTHERS & 39.0 & 10.5 & 68.4 \\
\hline Bilatéraux & 194.7 & 203.3 & 310.6 \\
\hline - France (AFD) & 29.1 & 33.6 & 68.7 \\
\hline - USA & 86.8 & 86.7 & 32.9 \\
\hline - Japan & 36.3 & 14.4 & 30.3 \\
\hline - Germany & 15.5 & 17.7 & 13.8 \\
\hline - China & & & 91.4 \\
\hline - Norway & & - & 13.6 \\
\hline - Others & 27.0 & 50.9 & 60.1 \\
\hline Othe raid & 0.2 & 1.2 & 5.1 \\
\hline Total & $1,025.4$ & 859.5 & $1,162.5$ \\
\hline
\end{tabular}

Source : MFB/DGB
The total amount of disbursements on external funding in 2007 was MGA859.5 billion, distributed as follows:

- Multilateral funding: MGA655 billion

- Bilateral funding: MGA203.3 billion

Table 9: Use of external resources by sector and sub-sector (Amounts disbursed in 2006-2007) (in billion ariary)

\begin{tabular}{|l|r|r|}
\hline \multicolumn{1}{|c|}{ Allocated to } & \multicolumn{1}{|c|}{$\mathbf{2 0 0 6}$} & \multicolumn{1}{c|}{$\mathbf{2 0 0 7}$} \\
\hline Productive sector & $\mathbf{1 4 4 . 0}$ & $\mathbf{1 4 4 . 4}$ \\
\hline Agricuture/livestock/fisheries/forestry & 80.1 & 77.4 \\
Industries and crafts & 0.0 & 0.0 \\
Mines & 21.0 & 13.8 \\
Tourism & 0.0 & 0.0 \\
Environment & 43.0 & 53.3 \\
\hline Infrastructures & $\mathbf{5 4 5 . 2}$ & $\mathbf{3 9 5 . 6}$ \\
\hline Transports & 494.6 & 310.2 \\
Energy & 4.5 & 7.1 \\
Water sanitation & 16.8 & 8.1 \\
Urban and land development & 29.2 & 70.2 \\
Telecommunications & 0.0 & 0.0 \\
\hline Social & $\mathbf{2 4 1 . 3}$ & $\mathbf{2 3 7 . 2}$ \\
\hline Education and training & 61.3 & 40.8 \\
Health & 152.9 & 59.9 \\
Social action & 27.0 & 136.4 \\
\hline Administrative & $\mathbf{9 4 . 8}$ & $\mathbf{8 2 . 3}$ \\
\hline Public authorities & 21.0 & 22.8 \\
Economy and Finances & 73.6 & 58.1 \\
General administration & 0.0 & 0.4 \\
Sovereignty & 0.2 & 1.0 \\
\hline Overall total & $\mathbf{1 , 0 2 5 . 4}$ & $\mathbf{8 5 9 . 5}$ \\
\hline Source : MFB/DGB & &
\end{tabular}

Table 8 shows that the external resources were allocated based on the MAP's priorities, which reflects donors' commitment to support the government's effort to achieve the MAP's ambitious objectives. Indeed, in 2007, a big share of the resources allocated by donors (MGA395.6 billion, i.e. 46\%) was allocated to the funding of infrastructures, including the transport sub-sector that benefited from MGA310.2 billion. The respective shares of the social and productive sectors were of MGA237.2 billion (27.5\%) and MGA144.4 billion (16.8\%). The remaining MGA82.3 billion were allocated to the administrative sector.

\subsection{Contribution OF Foreign Trade}

In order to own international mechanisms and systems to develop foreign trade, Madagascar has developed its relations at the regional level through the IOC, the COMESA, the SADC, the African Growth Opportunity Act (AGOA), The Association of Countries Riparian to the Indian Ocean, and the African Caribbean and Pacific (ACP)countries under the Cotonou agreement. At the global level, the country has accessed the World Trade Organization (WTO).

Madagascar's exports increased by 13.7\% from 2006 to 2007, compared to $9.0 \%$ from 2005 to 2006 . However, it must be noted that the situation results more from an expanded market for existing products than an expansion of outlets for non traditional products. It reflects the benefits of developing regional cooperation: indeed, Madagascar took profit of its comparative advantages related to its geographical proximity with certain countries members of regional organizations (SADC, COMESA). Over three years, Madagascar's exports towards nearby countries such as South Africa and Mauritius have made up $34 \%$ of the total foreign trade on average.

However, imports also increased by 29.3\% between 2006 and 2007, compared to $1 \%$ between 2005 and 2006 . Imports of energy, equipment goods, and raw materials accounted respectively $18.6 \%, 12.6 \%$ and $15.3 \%$ of the total imports. The increase in the imports of equipment goods was exceptionally high in 2007 due to the investments in the mining sectors. 


\section{FUNDING OF THE MAP}

A refocusing of the trade policy is planned, taking into account the standard and quality aspects, in order to better face competition.

In addition, the balance trade has kept on deteriorating, from $-1.0 \%$ in 2006 to $-2.4 \%$ in 2007.

The deficit of the external current account was funded by the flow of external aid in various forms - direct budget aid, aid through project, debt cancellation as part of the Initiative for Multilateral Debt Relief, which allowed for reconstituting foreign currency reserve at a level of 2.9 months of goods and services imports in December 2007.

\subsection{Contribution OF Foreign Direct INVESTMENTS (FDIS)}

The investment efforts in the private sector have strongly contributed to achieving the growth rates observed in the different sectors over the last two years. Foreign investments have been of special importance in sustaining economic growth. Indeed, the amount of FDIs increased from 58.0 million SDR in 2005 to 150.5 million SDR in 2006 and 652.1 million SDR in 2007 (forecast), according to the 2006-2007 Economic and Financial Report of the MECl. The target sectors include the extractive activities followed by financial activities, oil distribution, and telecommunication.

As regards actions to promote Madagascar, they included participation in international fairs, and the development of bilateral agreements to promote and protect investments.

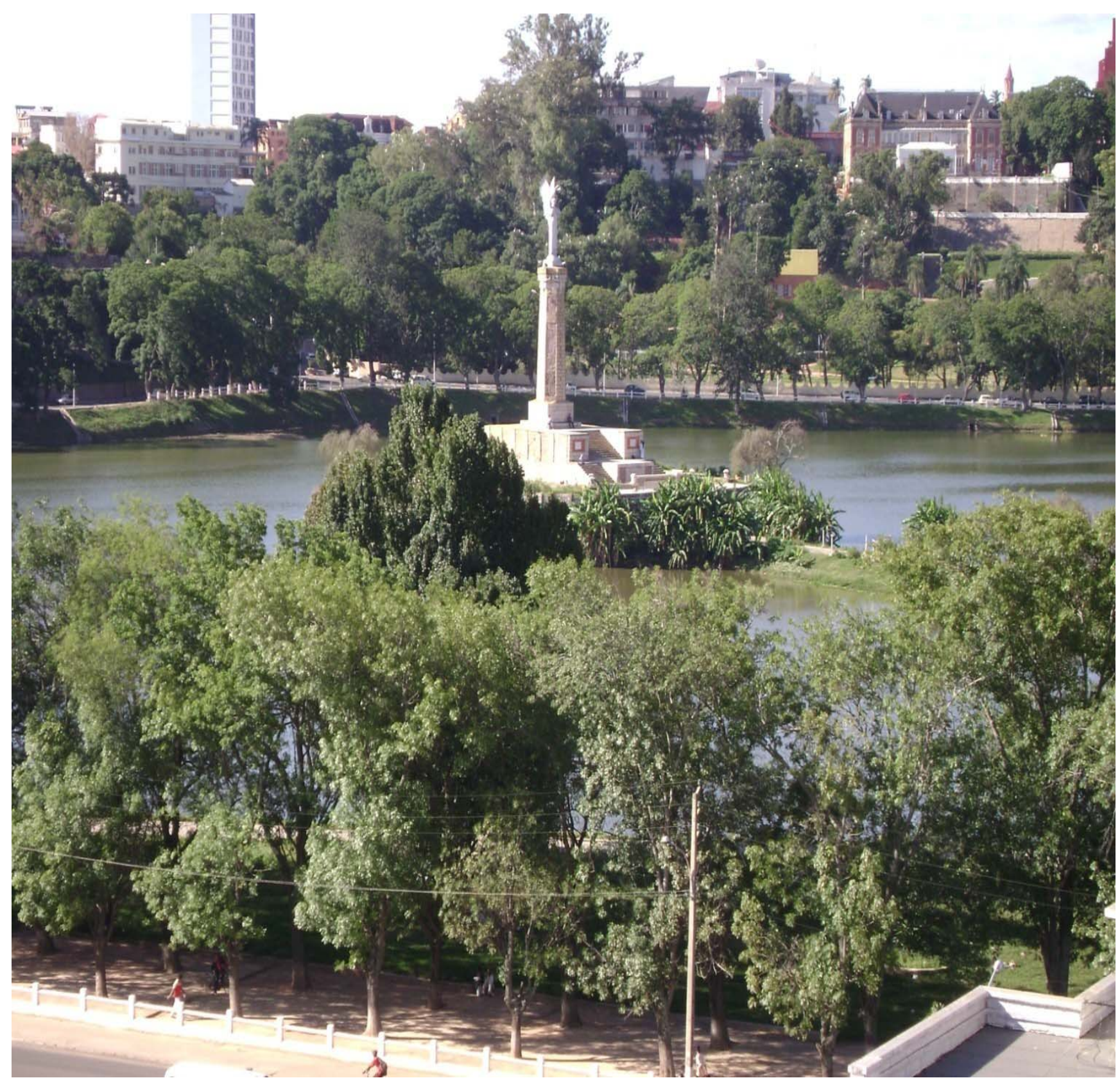

44 
ANNEX

PRIORITY INDICATORS 

INDICATORS OF THE BIG OBJECTIVES

\begin{tabular}{|c|c|c|c|c|c|c|c|c|c|c|c|}
\hline \multirow[b]{2}{*}{ INDICATORS } & \multirow[b]{2}{*}{2003} & \multirow[b]{2}{*}{2004} & \multirow[b]{2}{*}{2005} & \multirow[b]{2}{*}{2006} & \multicolumn{2}{|c|}{2007} & \multirow{2}{*}{$\begin{array}{c}2012 \\
\begin{array}{c}\text { NIMES } \\
\text { objective }\end{array}\end{array}$} & \multirow{2}{*}{$\begin{array}{c}2015 \\
\text { MDG } \\
\text { Objective }\end{array}$} & \multirow[b]{2}{*}{ Periodicity } & \multirow[b]{2}{*}{ Verification source } & \multirow[b]{2}{*}{ Observations } \\
\hline & & & & & Objective & Achieved & & & & & \\
\hline Economic growth rate & 9,8 & 5,3 & 4,6 & 5 & 5,6 & 6,3 & 7 à 10 & & yearly & MECI/DEEM & \\
\hline Life expectancy at birth & 53,8 & 54,2 & 54,7 & - & - & - & - & - & every 10 years & RGPH/INSTAT & $\begin{array}{l}\text { Intermediate } \\
\text { framework as } \\
\text { estimated by INSTAT }\end{array}$ \\
\hline Literacy rate (\%) & - & 73,1 & 73,1 & 73,1 & - & - & - & 100 & & INSTAT & \\
\hline Net primary enrollment rate (\%) & 82,2 & 96,8 & 98,2 & 98,5 & 97 & 96,4 & 98,7 & 100 & yearly & MENRS & \\
\hline Gross enrollment rate (all levels) (\%) & 56,3 & 64,65 & 68,95 & & & & & & & INSTAT & \\
\hline Estimated men/women's income & 1,39 & 1,39 & 1,36 & - & - & - & - & - & & INSTAT & \\
\hline HDI & 0,505 & 0,514 & 0,527 & - & - & - & - & - & & INSTAT & \\
\hline SHDI & 0,503 & 0,513 & 0,524 & - & - & - & - & - & & INSTAT & \\
\hline Women's life expectancy & 54,7 & 55,1 & 55,6 & - & - & - & - & - & & INSTAT & \\
\hline Men's life expectancy & 52,8 & 53,2 & 53,7 & - & - & - & - & - & & INSTAT & \\
\hline \begin{tabular}{|l|l|} 
Primary school completion rate (\%) \\
\end{tabular} & - & 47 & 57 & 57 & 53 & 54,3 & 85 & 100 & yearly & MENRS & \\
\hline Literacy rate among adults (men) (\%) & 75,2 & 75,2 & 75,2 & - & - & - & - & 100 & & INSTAT & \\
\hline Ranking in investment climate (World Bank) & - & - & $131 / 155$ & $149 / 175$ & - & 149 & 80 & - & & MAP/Doing & \\
\hline $\begin{array}{l}\text { Transparency International's corruption perception index } \\
\text { (base 10) }\end{array}$ & - & - & 2,8 & - & 3,3 & 3,2 & 5 & - & yearly & BIANCO & \\
\hline Percentage of rural holders with land titles or certificates (\%) & - & - & 10 & 10 & 15 & 10,42 & 75 & - & quarterly & MAEP & \\
\hline Net FDI flows (million SDR) & 9,1 & 35,7 & 58 & 150,5 & - & 652,1 & - & - & yearly & BCRM & \\
\hline POVERTY RATIO & 73,6 & 72,1 & 68,7 & 67,5 & - & 66,3 & 50 & 35 & $\begin{array}{l}\text { HHS every } 3 \text { years } \\
\text { MDG every } 2 \text { years }\end{array}$ & INSTAT & \\
\hline Share of the poorest quintile in consumtion (\%) & & 6,4 & 7,3 & 6,7 & & & - & - & every 2 years & OMD & \\
\hline
\end{tabular}


COMMITMENT 1: RESPONSIBLE GOVERNANCE

\begin{tabular}{|c|c|c|c|c|c|c|c|c|c|c|c|}
\hline \multirow[b]{2}{*}{ INDICATORS } & \multirow[b]{2}{*}{2003} & \multirow[b]{2}{*}{2004} & \multirow[b]{2}{*}{2005} & \multirow[b]{2}{*}{$\begin{array}{l}\text { Base line } \\
2006\end{array}$} & \multicolumn{2}{|c|}{2007} & \multirow{2}{*}{\begin{tabular}{c|c|}
2012 \\
NIMES \\
object.
\end{tabular}} & \multirow{2}{*}{$\begin{aligned} 2015 \\
\text { MDG } \\
\text { object. }\end{aligned}$} & \multirow[b]{2}{*}{ Periodicity } & \multirow[b]{2}{*}{ Verification Source } & \multirow[b]{2}{*}{ Observations } \\
\hline & & & & & Objective & $\begin{array}{c}\text { Achievemen } \\
\mathrm{t}\end{array}$ & & & & & \\
\hline Annual crime rate per 1,000 citizens & - & - & 4,2 & - & 4 & 1,8 & 2,6 & - & Annual & MDN/SESP & \multirow{3}{*}{$\begin{array}{l}\text { New indicator adopted in } \\
\text { NIMES }\end{array}$} \\
\hline Number of red districts cleaned up & - & - & & - & 10 & 12 & 61 & - & Annual & MDN/SESP & \\
\hline Economic exclusive zone coverage (\%) & - & - & 17 & - & 17 & 18 & 40 & - & Annual & MDN/SESP & \\
\hline Rule of law indicator by the World Bank & - & - & 45 & - & 48 & - & 60 & - & Every 2 years & World Bank & $\begin{array}{l}\text { World Bank study every } 2 \\
\text { years }\end{array}$ \\
\hline Average time for processing cases: simple criminal case (in days) & - & - & - & - & 90 & 120 & - & - & Annual & MINJUS & \multirow{3}{*}{$\begin{array}{l}\text { New indicator adopted in } \\
\text { NIMES }\end{array}$} \\
\hline Average time for processing cases: complex criminal case (in days) & - & - & - & 360 & 360 & 450 & 180 & - & & & \\
\hline Transparency International (base 10) corruption perception index & - & - & 2,8 & & 3,3 & 3,2 & 5 & - & Annual & BIANCO & \\
\hline \begin{tabular}{|l} 
National index of anti-corruption percpetion: \\
- by civil servants
\end{tabular} & - & - & - & - & $\begin{array}{c}\text { increase } \\
\text { of } 5 \%\end{array}$ & - & - & - & Annual & CSI & \multirow{3}{*}{ To be discussed with CSI } \\
\hline FFrequency of bribery to obtain linceses and permits in the city of Antananarivo (\%) & - & - & - & 57 & - & - & - & - & Annual & CSI & \\
\hline $\begin{array}{l}\text { MAmount paid by households in bribery to obtain access to public services (in percentage } \\
\text { of total expense) }\end{array}$ & - & - & 3,6 & 3,1 & - & - & - & - & Annual & CSI & \\
\hline \begin{tabular}{|l|} 
Percentage of cases processed by BIANCO referred to courts (\%) \\
\end{tabular} & - & - & - & - & 36 & 86 & 55 & - & Annual & BIANCO & \multirow{3}{*}{$\begin{array}{l}\text { New indicator adopted in } \\
\text { NIMES }\end{array}$} \\
\hline Fiscal pressure rate (\%) & - & - & 10 & & 11 & 11,4 & 13 & - & Annual & MFB & \\
\hline $\begin{array}{l}\text { Number of public institutions (central ministries) implementing their annual budget using } \\
\text { the PFMIS }\end{array}$ & - & - & - & - & 9 & All ministries & - & - & Annual & MFB & \\
\hline PEFA (Public Expenditures and Finance Accountability) & - & - & 6 & - & 8 & - & 20 & - & Every 2 years & World Bank & \multirow{3}{*}{$\begin{array}{l}\text { World Bank study every } 2 \\
\text { years }\end{array}$} \\
\hline Number of PEFA indicators ranking B or plus (general category) & - & - & - & - & 14 & - & - & - & Every 2 years & World Bank & \\
\hline $\begin{array}{l}\text { Number of PEF indicators on the prepration and implementation of the budget (Indicators } 1 \\
\text { to 7) ranking B or plus (budget preparation and implementation category) }\end{array}$ & - & - & - & - & 10 & - & - & - & Every 2 years & World Bank & \\
\hline Percentage of services using the PFMIS (\%) & - & - & - & - & 30 & 100 & 100 & - & Annual & MFB & $\begin{array}{l}\text { New indicator adopted in } \\
\text { NIMES }\end{array}$ \\
\hline $\begin{array}{l}\begin{array}{l}\text { OR number of PEFA indicators on budget monitoring (indicators } 22 \text { to 25) ranking B or plus } \\
\text { (category budget monitoring) }\end{array} \\
\end{array}$ & - & - & - & - & 1 & - & - & - & Every 2 years & World Bank & \multirow{2}{*}{$\begin{array}{l}\text { World Bank study every } 2 \\
\text { years }\end{array}$} \\
\hline $\begin{array}{l}\text { OR number of PEF indicators on the internal and external control mechanism (indicators } \\
20,12,26 \text { to } 28 \text { ) ranking higher than } B \text { (category internal and external control) }\end{array}$ & - & - & - & - & 1 & - & - & - & Every 2 years & World Bank & \\
\hline Percentage of contracts awarded through competitive process (\%) & - & - & - & - & 77,5 & 67,6 & - & - & Annual & MFB & \multirow[b]{2}{*}{$\begin{array}{l}\text { Priority indicator MAP } \\
\text { monitoring } 2007\end{array}$} \\
\hline $\begin{array}{l}\text { Percentage of procurements in a sample of representative institutions (Health, Education, } \\
\text { Transport, and Agriculture) asssessed as compliant with the new legal and regulatory } \\
\text { framework (\%) }\end{array}$ & - & - & - & - & 30 & 28,1 & - & - & Annual & MFB & \\
\hline Index of procedure delay in key units (base 100 in 2005) & - & - & 100 & - & 100 & 63 & 66 & - & Annual & MINFOPTLS & \multirow{4}{*}{$\begin{array}{l}\text { New indicator adopted in } \\
\text { NIMES }\end{array}$} \\
\hline $\begin{array}{l}\text { Indice du taux de recouvrement des taxes locales (base } 100 \text { en 2005) Index of local tax } \\
\text { collostion ratos (hase } 100 \text { in } 2005 \text { ) }\end{array}$ & - & - & 100 & - & 100 & - & 300 & - & Annual & MPRDAT & \\
\hline Part du budget alloué aux Communes (\% par rapport au budget total)) & - & - & - & - & 3 & 1,52 & - & - & Annual & MFB & \\
\hline Share of annual budget allocated to local governments (\%) & - & - & - & - & 15 & - & - & - & Annual & MFB & \\
\hline
\end{tabular}


COMMITMENT 2: CONNECTED INFRASTRUCTURES

\begin{tabular}{|c|c|c|c|c|c|c|c|c|c|c|c|}
\hline \multirow[b]{2}{*}{ Dénomination indicateurs } & \multirow[b]{2}{*}{2003} & \multirow[b]{2}{*}{2004} & \multirow[b]{2}{*}{2005} & \multirow[b]{2}{*}{$\begin{array}{l}\text { Base line } \\
2006\end{array}$} & \multicolumn{2}{|c|}{2007} & \multirow{2}{*}{$\begin{array}{c}2012 \\
\text { NIMES } \\
\text { object. }\end{array}$} & \multirow{2}{*}{$\begin{array}{c}2015 \\
\text { MDG } \\
\text { object. }\end{array}$} & \multirow[b]{2}{*}{ Periodicity } & \multirow[b]{2}{*}{ Verification Source } & \multirow[b]{2}{*}{ Observations } \\
\hline & & & & & Objective & $\begin{array}{c}\text { Achievemen } \\
\mathrm{t}\end{array}$ & & & & & \\
\hline Percentage of paved national roads in good condition (\%) & - & - & - & - & 48 & 48 & - & - & semester & MTP and CTD Activity report & \multirow{4}{*}{$\begin{array}{l}\text { New indicatosr adopted } \\
\text { in NIMES }\end{array}$} \\
\hline Percentage of paved national roads in fair condition (\%) & - & - & - & - & 41 & 41 & - & - & semester & MTP and CTD Activity report & \\
\hline Percentage of dirt national roads in good condition (\%) & - & - & - & - & 10 & 10 & - & - & semester & MTP and CTD Activity report & \\
\hline Percentage of dirt national roads in fair condition (\%) & - & - & - & - & 19 & 19 & - & - & semester & MTP and CTD Activity report & \\
\hline Index of reduction in the number of road traffic accident & 111 & 109 & 104 & 100 & 91 & 60 & 50 & - & yearly & MT/DGT/ATT & \multirow{6}{*}{$\begin{array}{l}\text { New indicatosr adopted } \\
\text { in NIMES }\end{array}$} \\
\hline $\begin{array}{l}\text { Percentage of communes with accessibility to all-season road all year long } \\
\text { (base 1,557 communes) }\end{array}$ & - & - & - & - & 40 & 40 & 64 & - & yearly & $\begin{array}{l}\text { Report and baseline survey of road } \\
\text { data }\end{array}$ & \\
\hline Reliability rate of meterological forecasts (\%) & - & - & - & - & 65 & 65 & 85 & - & yearly & METEO Activity report & \\
\hline Average cost of good transport (MGA/T/Km) & - & - & - & - & 93 & - & 80 & - & quarterly & Survey & \\
\hline Rate of access to electricity among households in urban areas (\%) & - & - & - & - & 45 & 45 & 74 & - & yearly & Statistic, Observation MEM/JIRAMA & \\
\hline Rate of access to electricity among households in rural areas (\%) & - & - & - & - & 5 & 5 & - & - & yearly & Statistic, Observation MEM/JIRAMA & \\
\hline Evolution du prix du KWH (en Ar.) & 140 & 140 & 175 & 273 & 290 & 290 & - & - & yearly & Statistic, Observation MEM/JIRAMA & \\
\hline Power installed by independent elecricity producers in MW & - & - & - & 88 & 88 & 91 & 223 & - & yearly & Statistic, Observation MEM/JIRAMA & $\begin{array}{l}\text { New indicatosr adopted } \\
\text { in NIMES }\end{array}$ \\
\hline Telephone penetration rate (\%) & 1,9 & 2,3 & 3,2 & 6,3 & 11,4 & 12,2 & 32,9 & - & yearly & MPTC/OMERT activity report & \\
\hline TV coverage rate at the national level (\%) & - & - & 23 & 23 & 36 & 41,13 & 70 & - & every 4 months & MPTC/ORTM activity report & \multirow{2}{*}{$\begin{array}{l}\text { New indicatosr adopted } \\
\text { in NIMES }\end{array}$} \\
\hline Radio coverage rate at the national level (\%) & - & - & 28 & 28 & 44 & 49 & 70 & - & & MPTC/ORTM activity report & \\
\hline $\begin{array}{l}\text { Rate of population with permanent access to safe water at the national level } \\
\text { (\%) }\end{array}$ & 34,3 & 36,5 & 37,5 & 38 & 41 & - & 65 & - & yearly & $\begin{array}{l}\text { Sector yearbook / activity report } \\
\text { MEM/EPM-INSTAT }\end{array}$ & \\
\hline Rate of population with permanent access to safe water in urban areas (\%) & 61,1 & 61,3 & 63,7 & 64,2 & 70 & 57,3 & 95 & - & yearly & $\begin{array}{l}\text { Sector yearbook / activity report } \\
\text { MEM/EPM-INSTAT }\end{array}$ & \\
\hline Rate of population with permanent access to safe water in rural areas (\%) & 27,4 & 29,5 & 30 & 31,6 & 33 & - & 57 & - & yearly & $\begin{array}{l}\text { Sector yearbook / activity report } \\
\text { MEM/EPM-INSTAT }\end{array}$ & \multirow{4}{*}{$\begin{array}{l}\text { Awaiting for calculations } \\
\text { of } 2007 \text { indicators }\end{array}$} \\
\hline $\begin{array}{l}\text { Rate of population with permanent access to hygiene infrastructures at the } \\
\text { national level (\%) }\end{array}$ & - & 53 & 52 & 52 & 56 & - & 71 & - & yearly & $\begin{array}{l}\text { Sector yearbook / activity report } \\
\text { MEM/EPM-INSTAT - MDG report }\end{array}$ & \\
\hline $\begin{array}{l}\text { Rate of population with permanent access to hygiene infrastructures in urban } \\
\text { areas (\%) }\end{array}$ & - & 73,8 & 68,7 & 77 & 81 & - & 87 & - & yearly & $\begin{array}{l}\text { Sector yearbook / activity report } \\
\text { MEM/EPM-INSTAT }\end{array}$ & \\
\hline $\begin{array}{l}\text { Rate of population with permanent access to hygiene infrastructures in rural } \\
\text { areas (\%) }\end{array}$ & - & 44,2 & 47 & 45 & 45 & - & 66 & - & yearly & $\begin{array}{l}\text { Sector yearbook / activity report } \\
\text { MEM/EPM-INSTAT }\end{array}$ & \\
\hline
\end{tabular}


COMMITMENT 3: EDUCATIONAL TRANSFORMATION

\begin{tabular}{|c|c|c|c|c|c|c|c|c|c|c|c|}
\hline \multirow[b]{2}{*}{2003} & \multirow[b]{2}{*}{2004} & \multirow[b]{2}{*}{2005} & \multirow[b]{2}{*}{$\begin{array}{c}\text { Base line } \\
2006\end{array}$} & \multicolumn{2}{|c|}{2007} & \multirow{2}{*}{\begin{tabular}{|c|}
2012 \\
NIMES object.
\end{tabular}} & \multirow{2}{*}{\begin{tabular}{|c|}
2015 \\
MDG \\
object.
\end{tabular}} & \multirow[b]{2}{*}{ Periodicity } & \multirow[b]{2}{*}{$\begin{array}{l}\text { Verification } \\
\text { Source }\end{array}$} & \multirow[b]{2}{*}{ Observations } & \multirow[b]{2}{*}{ Observations } \\
\hline & & & & Objective & $\left|\begin{array}{c}\text { Achieveme } \\
\mathrm{nt}\end{array}\right|$ & & & & & & \\
\hline Percentage of children aged 3-5 years attending pre-school & - & - & - & 5 & 7 & 7,1 & 20 & - & yearly & MENRS annual census & $\begin{array}{l}\text { New indicatosr } \\
\text { adopted in NIMES }\end{array}$ \\
\hline Gross enrollment rate at primary level & 123,1 & 141,9 & 138,5 & 137,6 & 126,6 & 122 & - & - & yearly & MENRS annual census & \\
\hline Net enrollment rate at primary level (\%) & 82,2 & 96,8 & 98,2 & 98,5 & 97 & 96,4 & 98,7 & 100 & yearly & MENRS annual census & \\
\hline Enrolment rate in lower secondary school (college) & - & - & - & - & 31 & 33 & - & - & yearly & MENRS annual census & $\begin{array}{l}\text { New indicatosr } \\
\text { adopted }\end{array}$ \\
\hline Gross enrollment rate at higher secondary (Lycée) & - & - & - & - & 8,4 & 10,3 & - & - & yearly & MENRS annual census & $\begin{array}{l}\text { New indicatosr } \\
\text { adopted }\end{array}$ \\
\hline Primary education completion rates & 45 & 47 & 57 & 57 & 53 & 54,3 & 85 & 100 & yearly & MENRS annual census & \\
\hline Completion rate for lower secondary school & - & - & - & 32 & 21 & 20,7 & 26 & - & yearly & MENRS annual census & $\begin{array}{l}\text { New indicatosr } \\
\text { adopted }\end{array}$ \\
\hline Enrolment rate in the general upper secondary school & - & - & - & 7,4 & 8,1 & 8,3 & - & - & yearly & MENRS annual census & $\begin{array}{l}\text { New indicatosr } \\
\text { adopted }\end{array}$ \\
\hline Number of students per 100,000 inhabitants & - & 252 & 263 & 286 & 309 & 292 & - & - & yearly & MENRS/University annual census & \\
\hline Annual number of university graduates & - & - & - & - & 5625 & 6568 & - & - & yearly & MENRS/University annual census & $\begin{array}{l}\text { New indicatosr } \\
\text { adopted }\end{array}$ \\
\hline Number of people becoming literate & - & - & - & - & 36700 & 14351 & 218500 & _ & yearly & MENRS annual census & \\
\hline Literacy rate among people aged 15 and more & 57 & 59,2 & 62,9 & 62,9 & - & - & 80 & 100 & - & INSTAT & $\begin{array}{l}\text { INSTAT/EPM survey } \\
\text { results }\end{array}$ \\
\hline Share of education in total buget & 20,13 & 23,41 & 21,28 & 17,4 & 21,65 & 22,7 & - & - & yearly & MENRS-MFB & \\
\hline Budget of education as a percentage GDP & - & 3,4 & 3,9 & 3,8 & 4,3 & 2,8 & - & - & yearly & MENRS-MFB & \\
\hline
\end{tabular}


COMMITMENT 4: RURAL DEVELOPMENT

\begin{tabular}{|c|c|c|c|c|c|c|c|c|c|c|c|}
\hline \multirow{2}{*}{2003} & \multirow{2}{*}{2004} & \multirow{2}{*}{2005} & \multirow{2}{*}{ Base line 2006} & \multicolumn{2}{|c|}{2007} & \multirow{2}{*}{$\begin{array}{c}2012 \\
\text { NIMES object. } \\
\end{array}$} & \multirow{2}{*}{$\begin{array}{c}2015 \\
\text { MDG object. }\end{array}$} & \multirow{2}{*}{ Periodicity } & \multirow{2}{*}{$\begin{array}{c}\text { Verification } \\
\text { Source }\end{array}$} & \multirow{2}{*}{ Observations } & \multirow{2}{*}{ Observations } \\
\hline & & & & Objective & Achievement & & & & & & \\
\hline Percentage of farmers having land titles or certificates & - & - & 10 & 10 & 15 & 10,4 & 75 & & quarterly & MAEP & \multirow{14}{*}{$\begin{array}{l}\text { New indicators } \\
\text { adopted in NIMES }\end{array}$} \\
\hline Number of land certificates delivered & - & - & & 1100 & 3500 & 2600 & 826000 & & quarterly & MAEP & \\
\hline Number of land titles produced & - & - & 13700 & 500000 & 512265 & 8843 & 953000 & & quarterly & MAEP & \\
\hline Percentage of districts with operational financial institutions (\%) & - & - & - & 6 & 65 & - & 100 & & quarterly & MAEP & \\
\hline Rate of penetration of financial institutions & - & - & 6 & 8 & 9 & 8,5 & 14 & & yearly & MAEP/IF & \\
\hline Rice productivity (mT/Ha) & - & - & & 2,8 & 2,8 & - & 6 & & yearly & MAEP & \\
\hline Rice production (mT) & - & - & 3420000 & 3640000 & 4070000 & 4010189 & 10500000 & & yearly & MAEP & \\
\hline Amounts of fertilizers used (T) & - & - & 14500 & 30000 & 33000 & 36000 & 175000 & & quarterly & MAEP & \\
\hline Amount of seeds used (T) & - & - & 187 & 1500 & 1900 & 2650 & 10000 & & quarterly & MAEP & \\
\hline Number of cattle & - & - & 9687342 & 9200000 & 9650000 & 9882000 & 12000000 & & yearly & MAEP & \\
\hline Annual increase rate of milk production (\%) & - & - & - & 0 & 4 & 8,0 & 70 & & yearly & MAEP & \\
\hline Annual increase rate of honey production (\%) & - & - & - & 0 & 2 & 1,0 & 20 & & yearly & MAEP & \\
\hline Annual production of marine products $(T)$ & - & - & 138450 & 105000 & 116750 & 151000 & 227000 & & yearly & MAEP & \\
\hline Number of cooperatives set up & - & - & - & 70 & 70 & - & 200 & & yearly & MAEP & \\
\hline
\end{tabular}


COMMITMENT 5: HEALTH, FAMILY PLANNING, AND FIGHT AGAINST HIV/AIDS

\begin{tabular}{|c|c|c|c|c|c|c|c|c|c|c|c|}
\hline \multirow[b]{2}{*}{2003} & \multirow[b]{2}{*}{2004} & \multirow[b]{2}{*}{2005} & \multirow{2}{*}{$\begin{array}{l}\text { Base } \\
\text { line } \\
2006\end{array}$} & \multicolumn{2}{|c|}{2007} & \multirow{2}{*}{\begin{tabular}{|c|}
2012 \\
NIMES object.
\end{tabular}} & \multirow{2}{*}{$\begin{array}{r}2015 \\
\text { MDG } \\
\text { object. }\end{array}$} & \multirow[b]{2}{*}{ Periodicity } & \multirow{2}{*}{$\begin{array}{l}\text { Verification } \\
\text { Source }\end{array}$} & \multirow[b]{2}{*}{ Observations } & \multirow[t]{2}{*}{ Observations } \\
\hline & & & & Objective & $\begin{array}{c}\text { Achieveme } \\
\text { nt }\end{array}$ & & & & & & \\
\hline $\begin{array}{l}\begin{array}{l}\text { Percentage of outpatient consultations using Basic Health } \\
\text { Centers }\end{array} \\
\end{array}$ & 72,9 & 49,4 & 41,6 & 38,8 & 49 & 35,8 & 70 & & yearly & $\begin{array}{l}\text { BHC activity report, MSPFPS } \\
\text { yearbook statistic }\end{array}$ & \\
\hline $\begin{array}{l}\text { Percentage of childbirth occurring in Basic Health Centers and } \\
\text { District Hospitals }\end{array}$ & 24,2 & 23,1 & 19,6 & 26,1 & 25 & 25,2 & 50 & & yearly & MSPFPS & \\
\hline \begin{tabular}{|l|l} 
Malaria morbidity rate at BHC level \\
\end{tabular} & 18,8 & 18 & 16 & 17,6 & 15 & 11,1 & - & & yearly & Health statistic unit activity report & \\
\hline Malaria mortality in hospital setting & 16,8 & 17,5 & 16,4 & 17,6 & 15,7 & 15,6 & 9 & & yearly & $\begin{array}{l}\text { Health statistic unit activity } \\
\text { report/MSPFPS }\end{array}$ & \\
\hline TB recovery rate & 66 & 71 & 75 & 78 & 78 & 78 & 90 & & yearly & $\begin{array}{l}\text { Tuberculosis control unit activity } \\
\text { report/MSPFPS }\end{array}$ & \\
\hline Prevalence of HIV among pregnant women & - & - & - & - & 0,95 & - & $<0,80$ & & $\begin{array}{l}\text { INSTAT } \\
\text { survey }\end{array}$ & $\begin{array}{l}\text { HIV prevalence survey/MSPFPS/ } \\
\text { INSTAT }\end{array}$ & Requires survey \\
\hline $\begin{array}{l}\text { Percentage of adults and children on ARV who are still alive } 12 \\
\text { months after initiation of ARV }\end{array}$ & - & - & - & - & 90 & - & 95 & & yearly & $\begin{array}{l}\text { Physicians activity report } \\
\text { /MSPFPS/IST/VIH/SIDA }\end{array}$ & New indicator adopted in NIMES \\
\hline Contraceptive coverage rate (\%) & 5,5 & 7,9 & 8,2 & 12,5 & 19 & 19,3 & 25 & & yearly & Annual report & \\
\hline $\begin{array}{l}\text { Immunization coverag rate (DTPHep B3) among children under } \\
\text { one (\%) }\end{array}$ & 85,1 & 79 & 99,5 & 95,3 & 80 & 87,1 & 100 & & yearly & MSPFPS (Immunization unit) & \\
\hline $\begin{array}{l}\text { Proportion d'enfants agés de } 1 \text { an vaccinés contre la rougeole } \\
\text { (\%) }\end{array}$ & 52,25 & - & - & - & 80 & 91,4 & 100 & & yearly & MSPFPS (Immunization unit) & DHS survey every 5 years \\
\hline Under five mortality (per 1,000 chlildren) & - & 58 & - & - & - & - & - & 31 & \begin{tabular}{|l|} 
Every 5 \\
years
\end{tabular} & EDS - INSTAT & \\
\hline Under five mortality (per 1,000 live births) & - & 94 & - & - & - & - & - & 53 & $\begin{array}{l}\text { Every } 5 \\
\text { years }\end{array}$ & EDS - INSTAT & \\
\hline Maternal mortality rate per 1000 live births & - & 469 & - & - & - & - & - & 122 & \begin{tabular}{|l|} 
Every 5 \\
years
\end{tabular} & EDS - INSTAT & \\
\hline $\begin{array}{l}\text { Proportion of children seen in outpatient consultations at BHCS } \\
\text { suffering from low weight (\%) }\end{array}$ & 16,9 & 16,6 & 16,3 & 15,6 & 38 & 14,07 & 6 & & yearly & HBC/ MSPFPS activity report & \\
\hline $\begin{array}{l}\text { Proportion of children under } 5 \text { seen in community sites (ONN) } \\
\text { suffering from low weight }\end{array}$ & - & - & - & - & 38 & 25,4 & 28 & 22 à 20 & $\begin{array}{l}\text { Every } 3 \\
\text { years }\end{array}$ & $\begin{array}{l}\text { Partners activity report, ONN } \\
\text { database }\end{array}$ & $\begin{array}{l}\text { Establishment of ONN community } \\
\text { sites since } 2006\end{array}$ \\
\hline Share of health budget against GDP (\%) & 1,5 & 1,3 & 1,43 & 1,63 & - & 1,51 & - & & yearly & MSPFPS-MFB & \\
\hline Share of health in total budget (\%) & 9 & 8,3 & 7,9 & 7,5 & 8,6 & 8,8 & - & & yearly & MSPFPS-MFB & \\
\hline
\end{tabular}


COMMITMENT 6: HIGH GROWTH ECONOMY

\begin{tabular}{|c|c|c|c|c|c|c|c|c|c|c|c|}
\hline \multirow[b]{2}{*}{2003} & \multirow[b]{2}{*}{2004} & \multirow[b]{2}{*}{2005} & \multirow[b]{2}{*}{$\begin{array}{c}\text { Base line } \\
2006\end{array}$} & \multicolumn{2}{|c|}{2007} & \multirow{2}{*}{$\begin{array}{c}2012 \\
\text { NIMES } \\
\text { object. }\end{array}$} & \multirow{2}{*}{\begin{tabular}{|c|}
2015 \\
MDG object.
\end{tabular}} & \multirow[b]{2}{*}{ Periodicity } & \multirow[b]{2}{*}{$\begin{array}{l}\text { Verification } \\
\text { Source }\end{array}$} & \multirow[b]{2}{*}{ Observations } & \multirow[b]{2}{*}{ Observations } \\
\hline & & & & Objective & Achievement & & & & & & \\
\hline Economic growth rate (\%) & 9,8 & 5,3 & 4,6 & 5 & 5,6 & 6,2 & 7 à 10 & & yearly & MECI/DEEM & \\
\hline Private investment rate (\% of GDP) & 10 & 11,8 & 12,3 & 13 & 21,7 & 20,7 & 17,4 & & yearly & MECI/DEEM & \\
\hline Public investment rate (\%of GDP) & 7,8 & 12,5 & 10,3 & 10,2 & 9,37 & 7,6 & 12,6 & & yearly & MECI/DEEM & \\
\hline Gross investment rate (\% of GDP) & 17,9 & 24,3 & 22,6 & 23,2 & 31,07 & 28,3 & 30 & & yearly & MECI/DEEM & \\
\hline Annual Inflation rate (\%) - end of period & $-0,8$ & 27 & 11,4 & 10,8 & 8,4 & 8,2 & 5 & & yearly & MECI/DEEM & \\
\hline PIB per Capita (USD) & 338,5 & 278 & 270 & 288 & 411 & 375 & 647 & & yearly & MECI/DEEM & \\
\hline PIB per capita increase rate (\%) & 6,8 & 2,4 & 1,8 & 2,2 & - & 3,4 & 4,4 & & yearly & MECI/DEEM & \\
\hline Fiscal pressure rate (\% of GDP) & 10 & 10,9 & 10,1 & 10,7 & 10,9 & 11,4 & 13,1 & & yearly & MECI/DEEM & \\
\hline Exports (million SDR) & 611,30 & 673,20 & 566,30 & 579,60 & - & 808,00 & - & & yearly & MECI/DEEM & \\
\hline External debt service (million SDR) & 38,08 & 49,69 & 46,6 & 34,34 & - & 13,99 & - & & yearly & Public debts-MFB & \\
\hline Ratio of external debt service to exports (\%) & 6,23 & 7,38 & 8,23 & 5,92 & - & 1,7 & - & & yearly & Public debts-MFB & \\
\hline Foreign currency reserves (in imports month) & 2,7 & 2,9 & 2,9 & 2,9 & 2,6 & 2,9 & 6 & & yearly & MECI/DEEM-BCRM & \\
\hline Net FDI flow (million SDR) & 9,1 & 35,7 & 58 & 150,5 & - & 652,1 & - & & yearly & BCRM & \\
\hline Long term bank credit to private sector (\% Total credit) & 6,6 & 6,24 & 4,5 & 4,78 & - & 6,72 & 8,0 & & yearly & BCRM & \\
\hline Tertiary GDP(\%) & 51,6 & 50,9 & 51,5 & 52,4 & 53,3 & 53 & 56,9 & & yearly & MECI/DEEM & \\
\hline Primary GDP (\%) & 26,8 & 26,2 & 25,8 & 25,1 & 24,2 & 24,2 & 19,1 & & yearly & MECI/DEEM & \\
\hline Secondary GDP (\%) & 14,1 & 14,5 & 14,2 & 13,9 & 13,7 & 15,2 & 14,3 & & yearly & MECI/DEEM & \\
\hline Mineral duty (in million MGA) & 92 & 207 & 339,8 & 289,1 & - & 252,5 & - & - & yearly & MEM & \\
\hline Number of tourists visiting Madagascar & - & 228784 & 277052 & 311730 & - & 344348 & 500000 & - & yearly & MEEFT & \\
\hline Revenue generated by the tourist sector (millions US\$) & - & 104,3 & 124 & 157,7 & - & 211 & 537 & - & yearly & MEEFT & \\
\hline Number of employments created by the tourism sector & - & 3939 & 4310 & 4527 & - & 4710 & 40100 & - & yearly & MEEFT & \\
\hline
\end{tabular}


COMMITMENT 7: CHERISH THE ENVIRONMENT

\begin{tabular}{|c|c|c|c|c|c|c|c|c|c|c|c|}
\hline \multirow[b]{2}{*}{2003} & \multirow[b]{2}{*}{2004} & \multirow[b]{2}{*}{2005} & \multirow[b]{2}{*}{$\begin{array}{l}\text { Base line } \\
2006\end{array}$} & \multicolumn{2}{|c|}{2007} & \multirow{2}{*}{$\begin{array}{c}2012 \\
\text { NIMES object. }\end{array}$} & \multirow{2}{*}{\begin{tabular}{|c|}
2015 \\
MDG object.
\end{tabular}} & \multirow[b]{2}{*}{ Periodicity } & \multirow[b]{2}{*}{$\begin{array}{l}\text { Verification } \\
\text { Source }\end{array}$} & \multirow[b]{2}{*}{ Observations } & \multirow[b]{2}{*}{ Observations } \\
\hline & & & & Objective & $\begin{array}{c}\text { Achievem } \\
\text { ent }\end{array}$ & & & & & & \\
\hline Surface area of protected areas created (in thousand hectare) & - & - & - & 3736 & 1000 & 876,6 & 6000 & - & yearly & MEEFT & \multirow{7}{*}{$\begin{array}{l}\text { New indicators adoptes } \\
\text { in the NIMES }\end{array}$} \\
\hline Amount of mobilized capital (in thousand USD) & - & - & - & 18000 & 33900 & 33162 & 50000 & - & semester & MEEFT/PTF & \\
\hline Burnt areas reduction rate (\%) & - & - & - & 32 & 34 & 33 & 70 & - & semester & MEEFT & \\
\hline Percentage of land covered with forest (\%) & - & - & 22,6 & 22,6 & & - & - & - & yearly & MEEFT & \\
\hline Reforested area ( $\mathrm{Ha}$ ) & - & - & - & 36000 & 25000 & 18379 & 540000 & - & quarterly & MEEFT & \\
\hline $\begin{array}{l}\text { Environmental Curriculum in primary, secondary, tertiary schools, } \\
\text { and vocational schools: adopted (\%) }\end{array}$ & - & - & - & - & 5 & $\begin{array}{c}100 \text { (primary school) } \\
90 \text { (secondary school) } \\
25 \text { (technical \& vocational school) } \\
1 \text { module in } 6 \text { universities }\end{array}$ & 90 & - & yearly & MEEFT & \\
\hline Number of forest control unit set up & - & - & - & 4 & 4 & 4 & 23 & - & yearly & MEEFT & \\
\hline
\end{tabular}


COMMITMENT 8: NATIONAL SOLIDARITY

\begin{tabular}{|c|c|c|c|c|c|c|c|c|c|c|c|}
\hline \multirow[b]{2}{*}{2003} & \multirow[b]{2}{*}{2004} & \multirow[b]{2}{*}{2005} & \multirow{2}{*}{$\begin{array}{l}\text { Base line } \\
2006\end{array}$} & \multicolumn{2}{|c|}{2007} & \multirow{2}{*}{$\begin{array}{c}2012 \\
\text { NIMES } \\
\text { object. }\end{array}$} & \multirow{2}{*}{\begin{tabular}{|c|}
2015 \\
MDG object. \\
\end{tabular}} & \multirow[b]{2}{*}{ Periodicity } & \multirow{2}{*}{$\begin{array}{c}\text { Verification } \\
\text { Source }\end{array}$} & \multirow[b]{2}{*}{ Observations } & \multirow[b]{2}{*}{ Observations } \\
\hline & & & & Objective & Achievement & & & & & & \\
\hline $\begin{array}{l}\text { Number of natinal heritage whether material or immaterial } \\
\text { preserved }\end{array}$ & - & - & - & 3 & 3 & 7 & 20 & - & yearly & Activity report/SECL & \multirow{7}{*}{$\begin{array}{l}\text { New indicators adopted in the } \\
\text { NIMES }\end{array}$} \\
\hline National participation rate to elections - referendum & - & - & - & - & 60 & 43,8 & - & - & - & CNE & \\
\hline National participation rate to legislative elections & - & - & - & - & 60 & 46 & - & - & - & CNE & \\
\hline National participation rate to municipal elections & - & - & - & - & 60 & 49,2 & - & - & - & CNE & \\
\hline Number of athletes taking part in international competitions & 279 & - & 39 & 78 & 495 & 393 & 1358 & - & yearly & $\begin{array}{l}\text { Mission report of the } \\
\text { delegations/MJS }\end{array}$ & \\
\hline Rate of children under 18 without birth registration certificates & - & - & - & - & 33,2 & 31,2 & - & - & yearly & $\left|\begin{array}{l}\text { Recensement au niveau des } \\
\text { fokontany/Ministère Intérieur }\end{array}\right|$ & \\
\hline $\begin{array}{l}\text { Proportion of member of parliaments who are women } \\
\text { Senate } \\
\text { National assembly }\end{array}$ & - & 5,0 & 5,0 & 5,0 & - & $\begin{array}{l}10 \\
7,9\end{array}$ & - & - & - & MSPFPS & \\
\hline
\end{tabular}







\section{MINISTRY OF ECONOMY, TRADE, AND INDUSTRY}

\section{SECRETARIAT GENERAL}

DIVISION OF ECONOMY

Directorate of Program Monitoring and Evaluation

Po. Box 674, Immeuble Plan, Anosy-Antananarivo

Third Floor, Door 302 ; Phone. (261) 20.22.234.03, fax : (261) 20.22.285.08 ; dcsep@yahoo.fr ou dsep@meci.gov.mg,

Siteweb :www.meci.gov.mg 





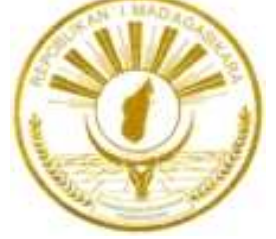

PRESIDENCE

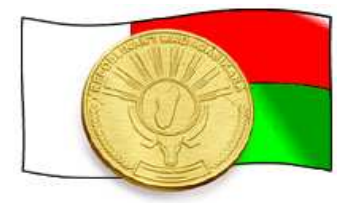

PRIMATURE

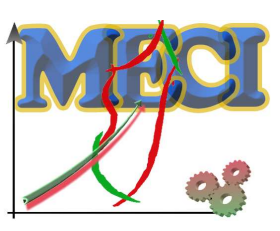

MINISTERE DE L'ECONOMIIE DU COMMERCE ET DE L'INDUSTRIE
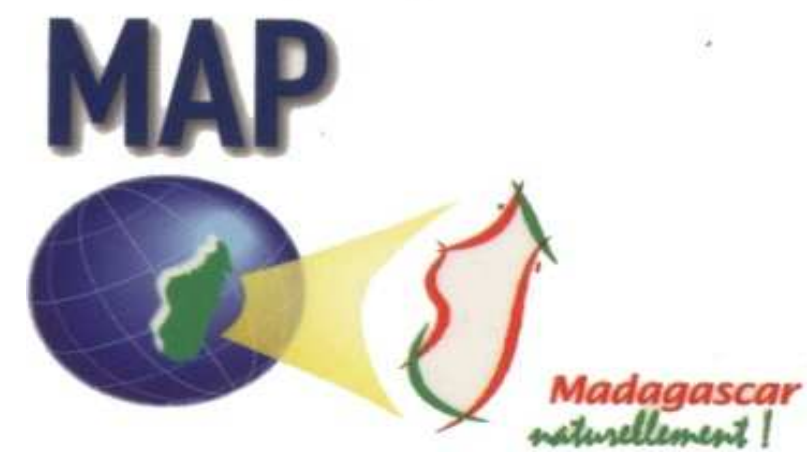

Madggascar

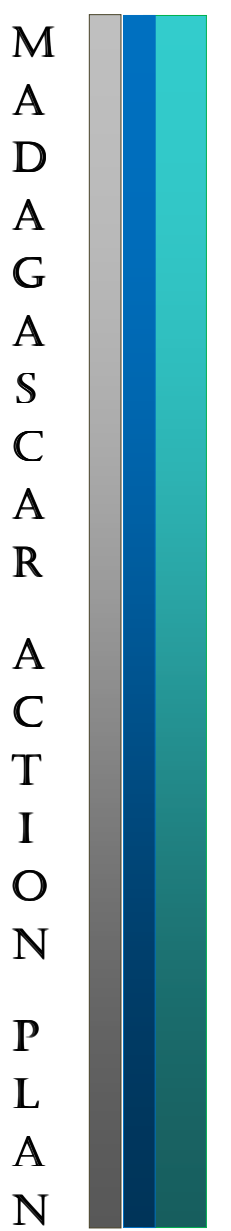

\section{Implementation of} the MAP:

\section{Progress Report}

First Semester of 2008 


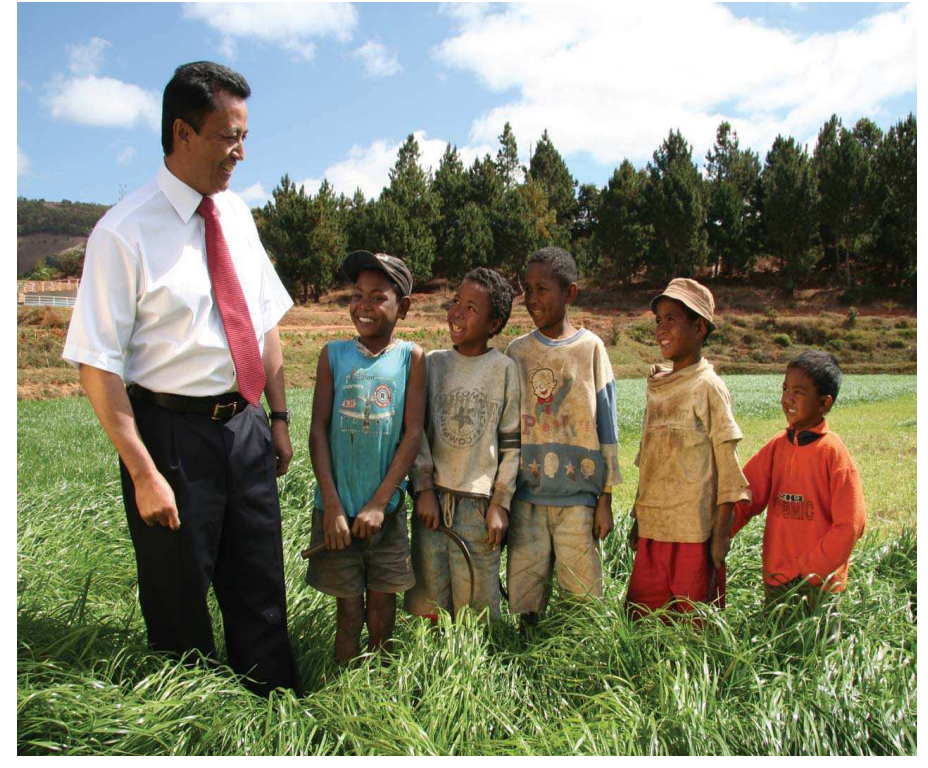

\title{
Implementation of the MAP:
}

Progress Report

\author{
First Semester of 2008
}




\section{TABLE OF CONTENTS}

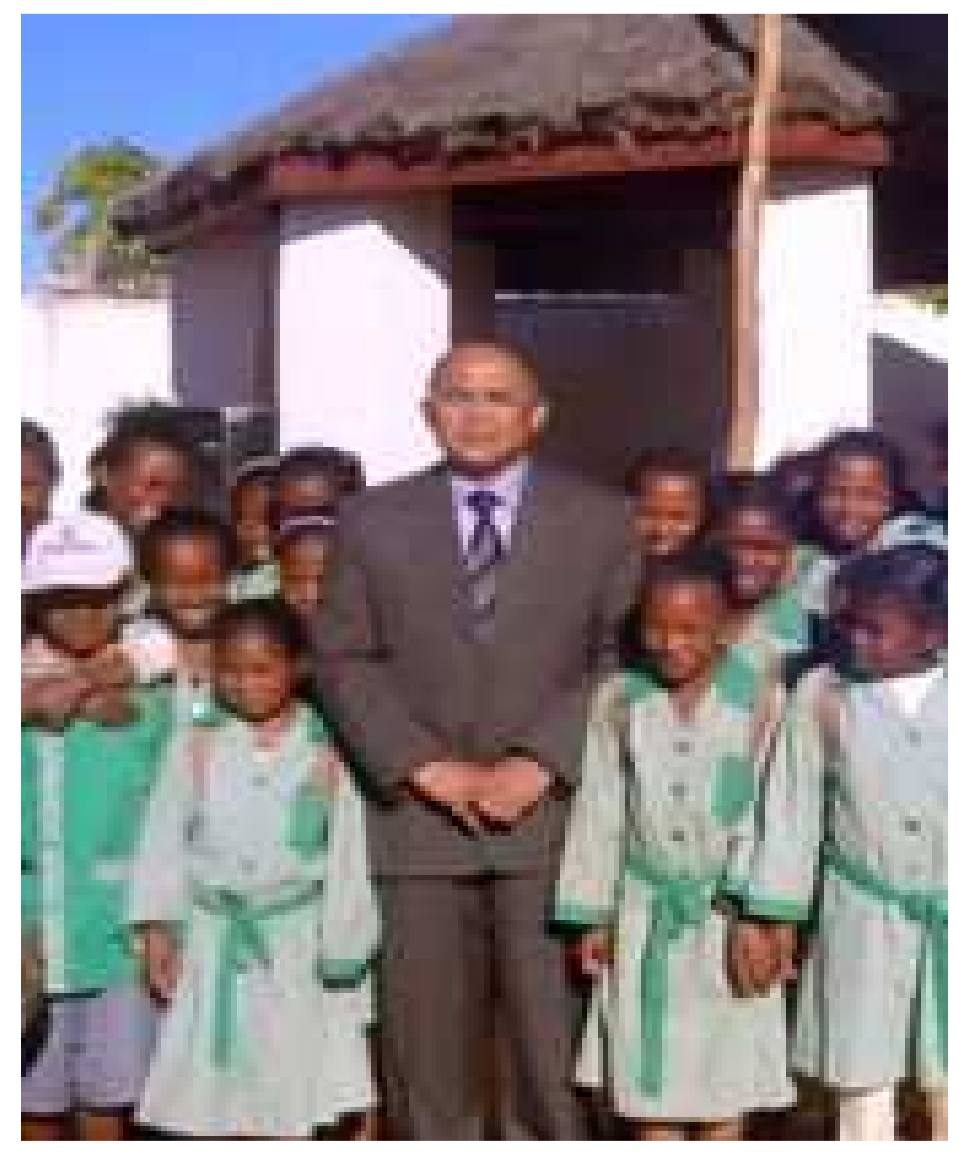

\section{Acronyms}

List of Graphs and tables

\section{Preface}

Implementation of the SNISE

Executif Summary

Implementation of the MAP

Situation of the Indicators related to the Major Objectives . ..................................

Commitment 1 : Responsible Gouvernance..........................................................2

Commitment 2 : Connected Infrastructures... .....................................................

Commitment 3 : Educational Transformation.....................................................13

Commitment 4 : Rural Development...............................................................18

Commitment 5 : Health, Family Planning, and the Fight Against HIV/SIDA..........23

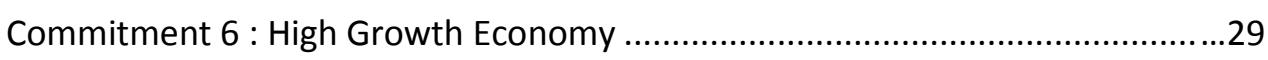

Commitment 7 : Cherish the Environment .......................................................36

Commitment 8 : National Solidarity ......................................................................

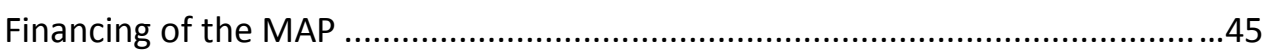

Annex

Priority Indicators

Disbursement Table 


\section{ACRONYMS}

Agri business Center

Agency in charge of Implementing and Promoting Microfinance

National Water and Sanitation Authority

Agency in charge of Port, Sea, and Rivers

Partnership and Investment Promotion Agreements

Anti Retro Virals

Land Transportation Agency

Arab Development Bank in Africa (ADBA)

Mining Management Office

Office for Madagascar Mining Cadastre

Independent Anti-corruption Office

National Risk and Disaster Management Office

Commune Support Center

Market Access Center

Educational Support Center

Youth Vocational Animation Center

Authorized Management Center

District Hospital Center

Regional Reference Hospital Cente

Interregional Office of Environment, Water, and Forests

Financial Jurisdiction

School District

Reading and Cultural Animation Centers

Local AIDS Control Committee

Committees for the Indian Ocean Games

Common Market of Eastern and Southern Africa

Anti-Corruption Penal Chain

Pre natal Consultation

Centers of Research, Studies, and Support to Economic Analysis in Madagascar

Ambulatory Center for Nutritional Rehabilitation and Education Intensive Nutritional Rehabilitation Center

Basic Health Center

Decentralized Local Governments

Voluntary Counseling and Tests

Indian Ocean Commission

Self Standing Security Secondment
$D B G M$

DEPA

DIREEF

DIRM

$D E E M$

$E D B M$

EKA

ESM

FAPBM

$F A D$

FOAD

FED

$F D L$

FER

FIREF

GEFP

GIE

$G R C$

HIMO

IDA

$I D H$

IDE

IEC

IEC/CCC

$I E C / P F$

IMF

INSTAT

IPPTE

JICA

KASTI

LMD

MAEP

MADRES

$M A P$

$M C A$

$M D N$
Directorate of Governance in the Mining Sector

Directorate of Safe Water and Sanitation

Interregional Directorate of Environment, Water, and Forests

Interregional Directorate of Mines

Directorate of Economic Studies and Modeling

Economic Development Board of Madagascar

Ezaka Kopia ho an'ny Ankizy (Effort in Children Birth Registration)

Mobile Health Team

Foundation for Madagascar's Protected Areas and Biodiversity

African Development Fund (AFD)

Distance Open Training

European Development Funds

Local Development Fund

Road Maintenance Fund (RMF)

Fund for Insertion and Rehabilitation to Formal Employment

Group of free Processing Enterprises and Partners

conomic Interest Group

Risk and disaster Management

High Labor Intensity

International Development Agency

Human Development Indicator (HDI)

Foreign direct Investment (FDI)

Information-Education-Communication

Information - Education - Communication for Behavioral Change

Information-Education-Communication Family Planning

Mutual Microfinance Institutions

National Institute of Statistics

Heavily Indebted Poor Countries Initiative (HIPCI)

Japan International Coopération Agency

Komitin'ny Ala sy ny Tontolo lainana (Committee for Forests and the Environment

Licence Master Doctorate

Ministry of Agriculture, Livestock, and Fisheries

Support to Renovating Higher Education in Madagascar

Madagascar Action Plan

Millennium Challenge Account

Ministry of National Defense 
ACRONYMS

MENRS

MFB

MFPTLS

MIID

MINJUS

MinSanPFPS Ministry of Health, Family Planning, and Social Protection

MTPM

OMERT

$O M C$

ONG

ONN

OPEP

$P A M$

PCD

PCIME

PEV

$P G D I$

PGRM

$P I B$

PIC

PNAEP

PNAN

PNEOA

$P N D R$

$P N F$

$P N N$

PNNC

PNPS

PNUD

$P R D$

PRDR

PREA

PRISM

$P R I B G$

PRMP

PSE

PSDR

Ministry of Education and Scientific Research

Ministry of Finances and Budget

Ministry of Civil Service, Labor, and Social Laws

Long Lasting Insecticide-Treated Nets (LLITN)

Ministry of Justice

Ministry of Public Works and Meteorology

Malagasy Office in charge of Studies and Regulation of

Telecommunications

World Trade Organization (WTO)

Non Government organization (NGO)

National Nutrition Office

Oil Exporting Country Organization (OECO)

World Food Program (WFP)

Commune Development Plan

Integrated Management of Childhood Illnesses (IMCI)

Enlarged Program of Immunization (EPI)

Project for Governance and Institutional Development

Mineral Resources Governance Project

Gross domestic Product (GDP)

Integrated Growth Pole

National Program for Safe Water Supply

National Nutrition Action Plan

National Program for Maintaining Construction Works

National Rural Development Program

National Land Tenure Program

National Nutrition Policy

National Program for Community based Nutrition

National Policy for Social Protection

United Nations Development Program (UNDP)

Regional Development Plan

Regional Program for Rural Development

Reform Program for Efficiency among the Administration

Project for Institutional Reinforcement of the Mining Sector

Institutional Strengthening Project for Good Governance

Public Procurement Official

Planning Monitoring and Evaluation

Programs of Support to rural Development
PHBM

PRBM

PSN

PTME

PVVIH

RFT

$R N P$

RNS

RNT

$R R I$

$S A D C$

SAPM

SESI

SESP

SGFD

SIGFP

SIGM

$S M A D$

SNAT

SNISE

SONU

SSD

TIC

UGPM

UICN

UMV

UNESCO

UNICEF

VCT/HIMO

VINA

VNT

WASH

WWF

ZAC

ZEE

ZIA

$P P P$
Higher Mandrare Basin Project

Project for the Rehabilitation of Lower Mangoky

School-based Nutrition Program

Prevention of Mother to Child Transmission

People Living with HIV/AIDS (PVVIH)

Tourist Land Reserves

Primary National Road

Secondary National Road

Tertiary National Road

Transformed rice

Rapid Result Initiative

Southern African Development Community

Madagascar's Protected Areas System

State Secretariat in charge of Internal Security

State Secretariat in charge of Public Security

Sustainable Forest Management Sites

Integrated system for Managing Public Finance

System of Geographical and Mining Information

Military Service focused on Development Actions

National Plan for Land Management

National Integrated Monitoring and Evaluation System

Emergency Obstetric and Neonatal Care

District health Service

Information and Communication Technology (ICT)

Procurement Management Unit (PMU)

International Union for Conservation of Nature (IUCN)

Mobile Video Unit

United Nations Educational Scientific and Cultural Organization

United Nations Program for Children

Food for Work /High Labor Intensity

Madagascar Naturally Vision

Non transformed Fish Ponds

Water Sanitation Hygiene

World Wildlife Fund of Nature

Zone for Agreed Upon Consultation

Exclusive Economic zone (EEZ)

Agricultural Investment Zone

Public Private Partners 


\section{LIST OF GRAPHS AND TABLES}

\section{List of graphs}

Graph 1 : Evolution in the share of budget for Education, Health compared with the total budget, Evolution in economic growth.

Graph 2 : Evolution in the Improved Corruption Perception Index

Graph 3 : Evolution in Public Revenues - first Semesters of 2006/2007/2008.

Graph 4 : Evolution in Public Expenditures - First Semesters of 2006/2007/2008 …..................................................................................................... 4

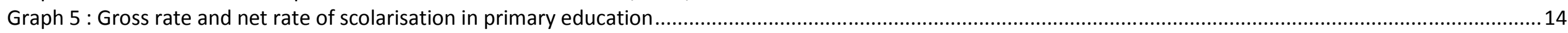

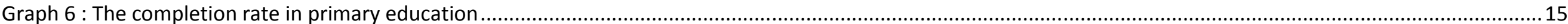

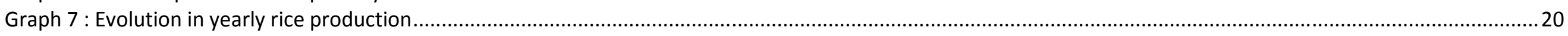

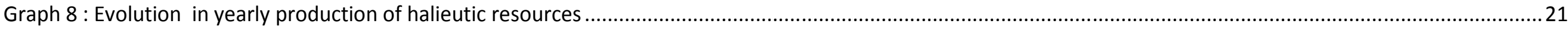

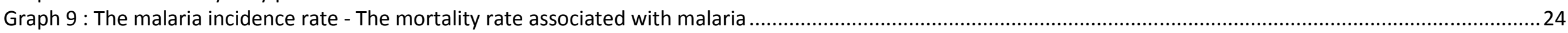

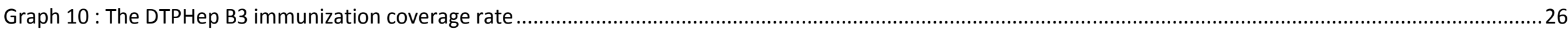

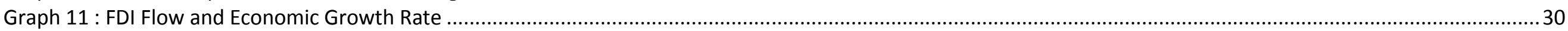

Graph 12 : Variation in Consumption Price Indices for some main products (December 2007- June 2008)............................................................................. 32

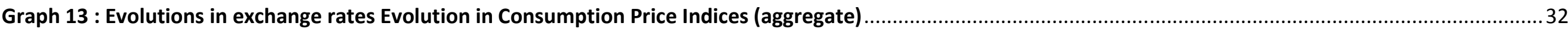

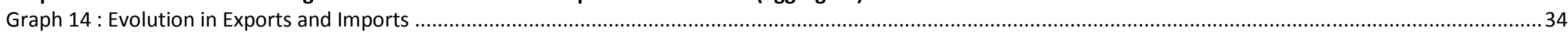

\section{List of tables}

Table 1 : Rate of Criminality

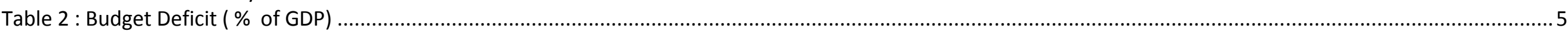

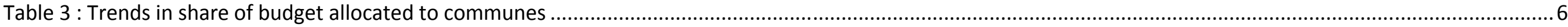

Table 4 : Table on the results of the priority indicators, from the regional Directorates as of the first semester of 2008 ........................................................................ 8

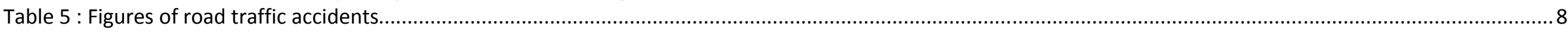

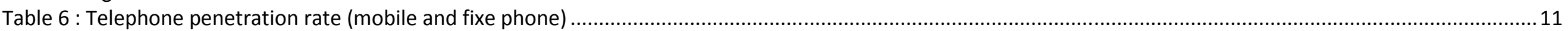

Table 7 : Percentage of the population with permanent access to safe water- national level (\%) ..................................................................................................11

Table 8 : Construction and rehabilitation of classrooms (Primairy education)

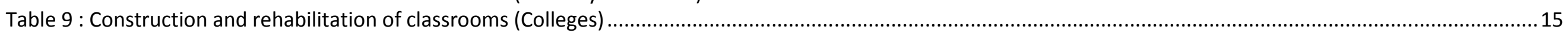

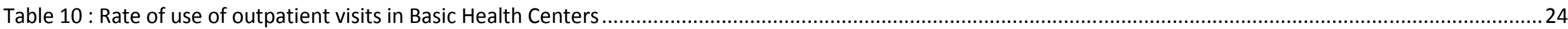

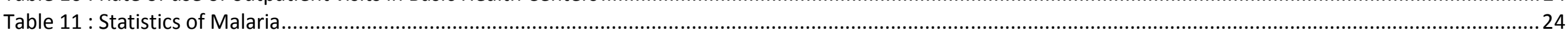

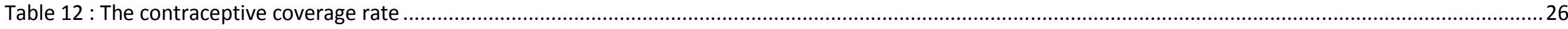

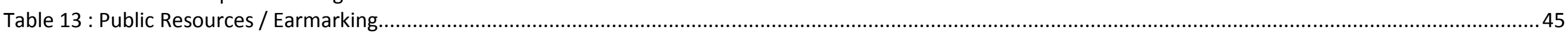

Table 14 : Operating and Investment Expenditures of Priority Sectors (in Ariary Billions) ........................................................................................................ 45

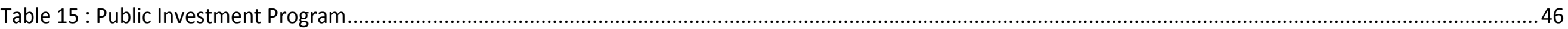

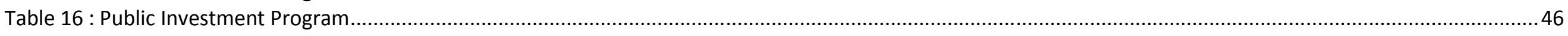

Table 17 : Status of foreign financing disbursement

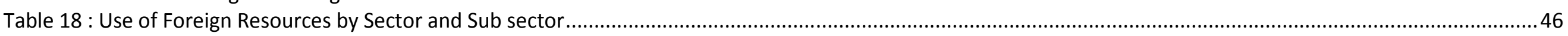




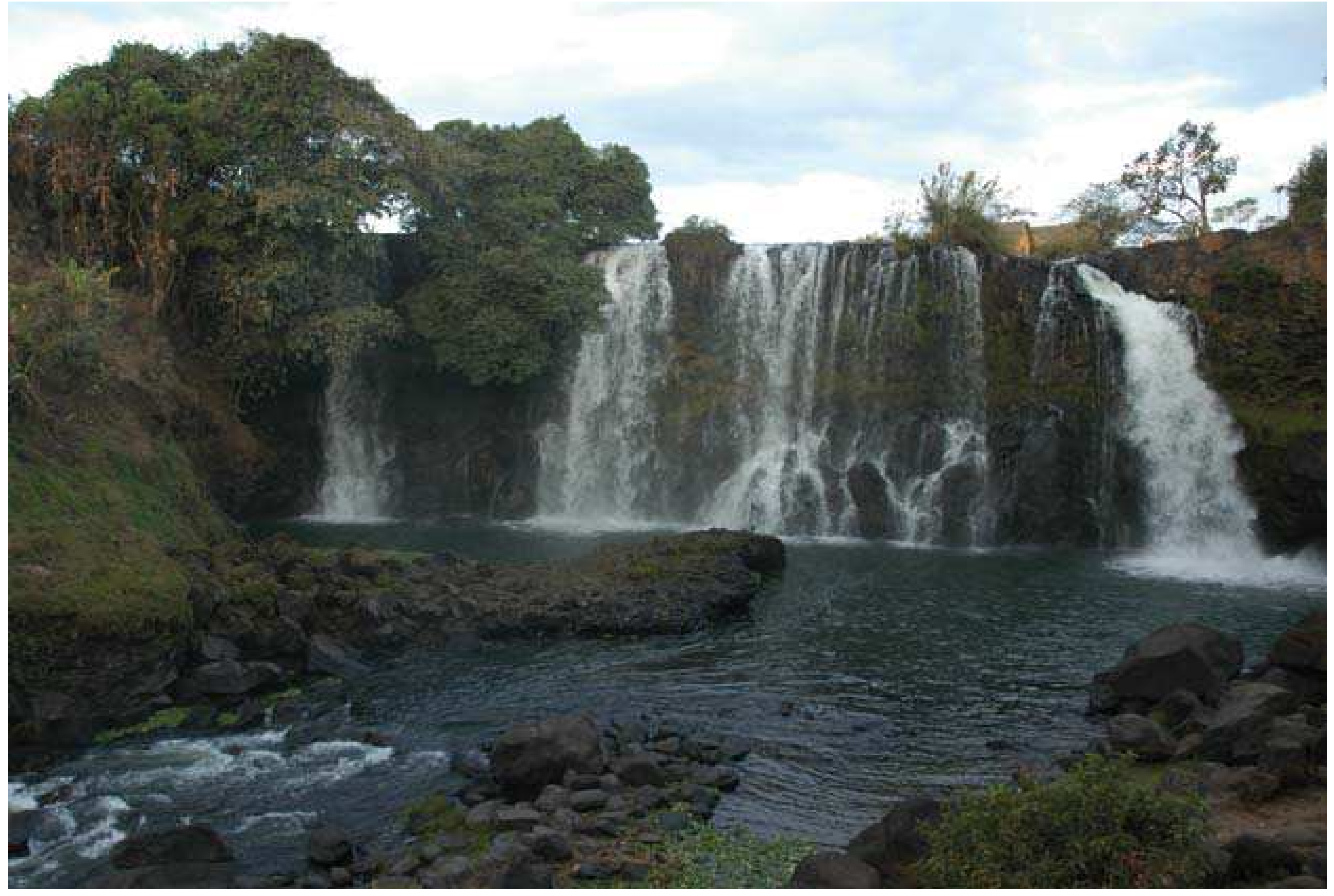




\section{PREFACE}

The efforts deployed over the last years show that Madagascar is currently moving to the gradual achievement of the Major Objectives of the Madagascar Naturally Vision and the Millennium Development Goals, which express through the materialization of the improvement in the Human development Index from 0.509 to 0.533 over the 2003-2006 period. This reflects a poverty ratio moving from $73.6 \%$ to $66.3 \%$ over the 2003 to 2007 period, and an average real growth rate of over $5 \%$ for the same period. Such performance is the more strengthened and is marked by the improvement of the implementation process over the 2008 first semester.

MAP is implemented primarily through capacity building in human foundations because the Population is at the basis of any change.

In addition, partners have been mobilized with a focus on the Government priority with especially the aim of alignment among economic and financial partners, in accordance with the Declaration of Paris. This is currently materializing through the setting up of the Partnership Framework, the essential objective of which is to strengthen the dialogue and discussions on economic development prospects and to improve aid efficiency. Moreover, the current context of the progress of Economy towards globalization urges the Government to further widen the scope of discussions on the aspects which are relevant to the economy overall in order to anticipate the harmful effects of the competition which is harsher and harsher, as well as the impacts of inflation at international scale.

In addition, particular support will be provided to improve natural resource management in the face of issues of climate change, food security, enabling environment to local private investments and Foreign Direct Investment (FDI). Besides, the Transformation Reform Initiatives of the MAP priorities are supported by audacious actions regarding the improvement of the population health status, family planning, and the implementation of the seven year reform of Basic Education at primary level.

In order to meet the challenge, developing the partnership with the International Community and the Donors, the Private Sector, and all the actors in all Regions and Communes, provides the prime conditions for achieving and materializing the MAP objectives and the Rapid and Sustainable Development by 2012 .
We hope that the mutual trust capital which is already set up between the Nation and the development actors will be strengthened in the future in order to consolidate the human development progress and the prosperity of the Nation.

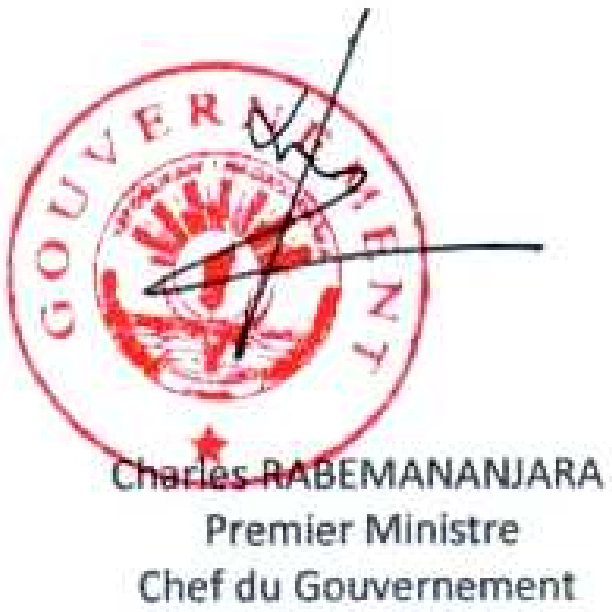




\section{IMPLEMENTATION OF SNISE}

The progress report for the first year of implementation of MAP served as a basic document for the Roundtable with the Technical and Financial Partners. Sector wide programs which facilitated the coordination and the mobilization of these partners were also developed after the implementation of the National Integrated Monitoring and Evaluation System (SNISE) this year 2008. Thus, the Government was able to raise the necessity to mobilize new financial resources for financing development and enhancing the absorption capacities of the Malagasy. As per Decree $N^{\circ}$ 2008-524 of 06 June 2008, SNISE, the scheme of which is provided below, was institutionalized.

This scheme presents the integrated responsibilities of the various entities from data collection to decision making. Any idea divergence or data inconsistency must be subject to consultation among the entities involved.

The implementation of the SNISE was conducted by the President's Office and the Prime Minister's Office. Such actions were strengthened by social mobilization and capacity building sessions at the 22 Regions.

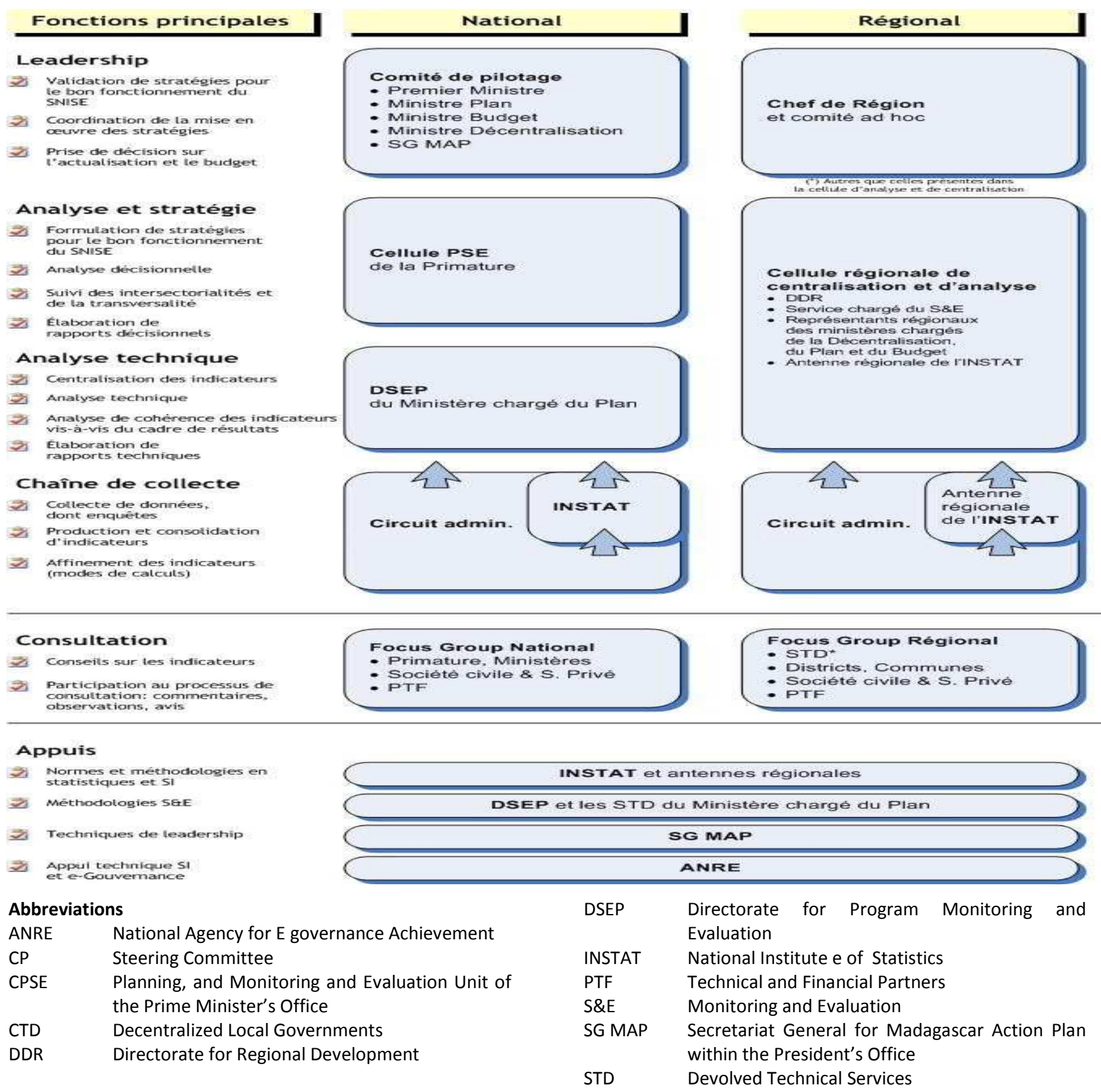

Suivi des intersectorialités et

Etaboration de

alyse techniqu

Centratisation des in

Anatyse de cohérence des

Elaboration de

collecte de donniées
dont enquêtes

Production et consotidation

Affinement des indicateurs
(mootes de calcuts)

Evaluation

Technical and Financial Partners

S\&E Monitoring and Evaluation

STD Devolved Technical Services 


\section{IMPLEMENTATION OF SNISE}

Some members of the Civil Society and some responsible in charge of the public sector were trained in multiplying actors of change and in leadership by NLIM. The Ministry of Economy, Trade, and Industry has conducted harmonizing and aligning regional interventions.

The present document is the first semester report for monitoring the MAP implementation process. It is an interim technical report, developed based on the priority indicators that were discussed and set by common agreement with INSTAT, the technical Ministries, and the Technical Partners. It serves as an element for monitoring and helping decision making after consultation of the Focus Group that is made up, among others, by Representatives of Technical and Financial Partners and by the Civil Society.

Furthermore, pending the implementation of the Actions Plans of the National Strategy for Developing Statistics (SNDS), capacity building has been conducted by INSTAT in order to enhance the administrative statistics, based on the needs of the sector wide Ministries and the Regions.

- Supply of Monitoring and Evaluation:

Information collection and processing, and production of two technical and decision making reports which are decision making tools.

- Use of Monitoring and Evaluation Information:

How monitoring and evaluation data will help in decision making and in adjusting development policies.

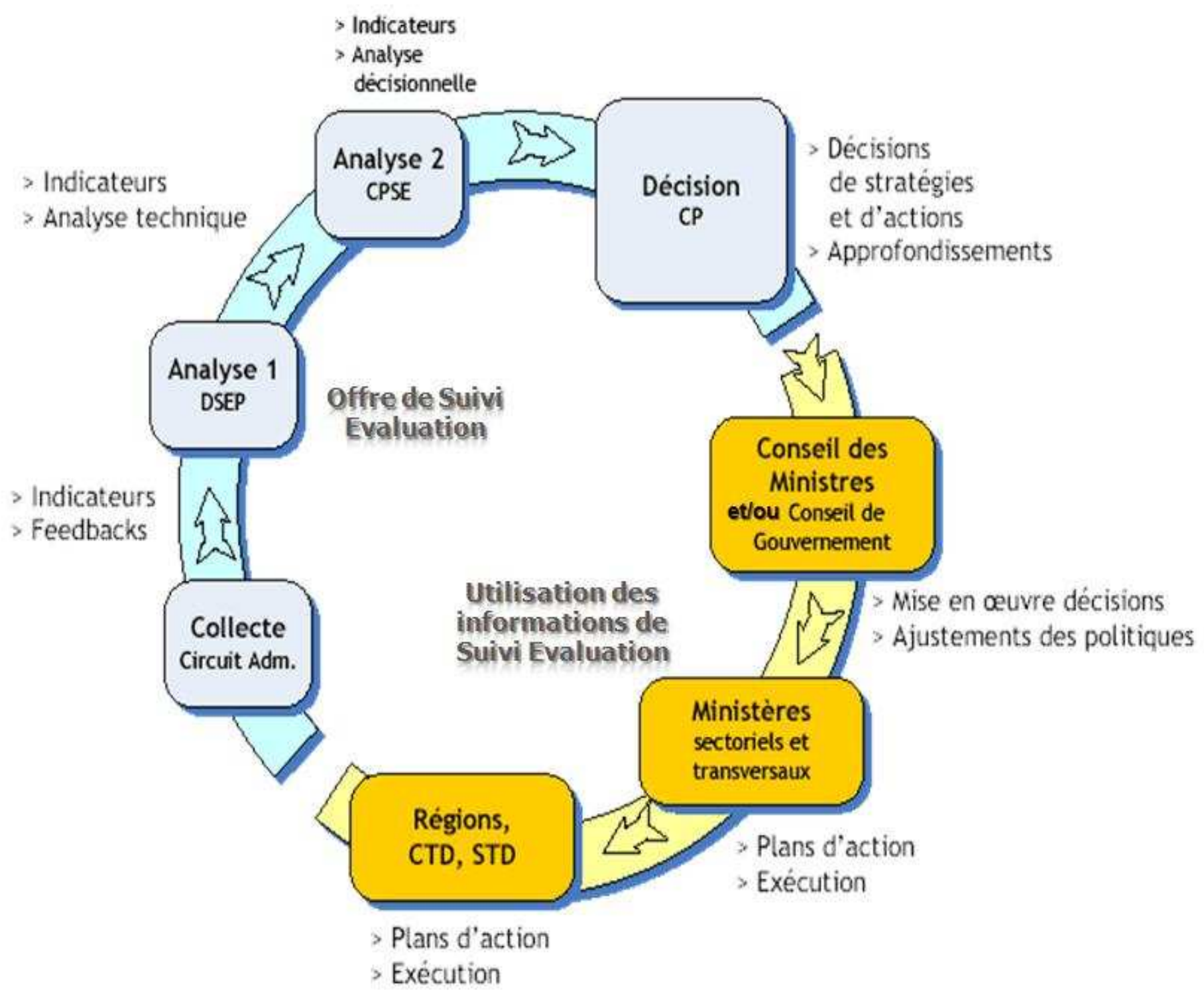




\section{EXECUTIVE SUMMARY}

\section{MAJOR OBJECTIVES}

The annual $7.3 \%$ economic growth programming is currently revised to $7.1 \%$ following mainly a priori the increasing prices of major oil and food products at the international level.

However, over the last six months, the performance recorded among some indicators of the country major objectives will contribute to enhance such trend of the national production:

- Tax revenue performance : Ariary Billion 527.3 of taxes collected and Ariary 494 Billion of customs revenues since January, i.e., $127 \%$ and $97 \%$ of semester programming respectively;

- The performance of the Foreign Direct Investment flow that exceeds actual annual forecast

- Improvement in the Corruption Perception Index in 2008 ;

- The objective in the area of literacy for people aged 15 and more has been achieved at $65 \%$ with 11,120 adults enrolled in literacy program against a forecast of 17,000 . This good performance is mainly due to effective partnership with NGOs in promoting literacy.

- The objective in the number of land titles issued has been achieved at $64 \%$ with 5,674 titles issued.

\section{COMMITMENT 1: RESPONSIBLE GOVERNANCE}

Several efforts have been undertaken to ensure good governance:

- As regards security of people and property, the crime rate has decreased to 0.75 per one thousand against an objective of less than 1.9 per one thousand. Four "red" districts out of the thirteen planned have been cleaned from crime. The effectiveness rate as regards repression of cattle thefts by the armed forces has improved to $84.6 \%$. Five regions and 29 districts have now their Plan for Community Security.
- As regards strengthening the rule of law, the program to process $100 \%$ of pending cases in 2008 (i.e. 16,686 ruling with publication delayed and 16,186 case papers delayed) has been already initiated in the Courts of First Instance [Tribunal de Première Instance (TPI)] of Antalaha, Morondava, and Morombe.

- Regarding corruption perception, the Corruption Perception Index moved from 3.2 in 2007 to 3.4 in 2008. As an illustration to this performance, significant results were noticed regarding the increased number of complaints received through the mobilization of the public to denounce corruption cases and the processing of corruption files.

- With regard to the ongoing reform of public finances management, coordinated efforts were undertaken to establish an improved method for tax collection through operational and organizational reforms of the customs and tax services. The PFMIS is operational in all central ministries and institutions as well as in the financial districts. Regarding the evaluation of the Public Finances Management System's performance, significant efforts were made to improve the management of public finances. The results of the ongoing reforms are however mixed.

- In order to reinforce the effectiveness of public services provision, the delay for processing applications or cases decreased from 63 days in late 2007 to 61 days in 2008 first semester.

Finally, with regard to effective decentralization, all the communes are currently conducting a fiscal census and are entering the data in the regional IT centers. A bill on Decentralized Territorial Collectivities is being finalized. The constitutive laws for the Local Development Fund, the main role of which is to build the communes' capacities and fund their activities and investment, have been published.

\section{COMMITMENT 2: CONNECTED INFRASTRUCTURES}

- Significant results have been achieved against the objective set for the year regarding the building, maintenance, and rehabilitation of roads in general:

- National highways: $48 \%$ in good state, $41 \%$ in fair state, i.e., $78 \%$ and $136 \%$ of the annual objectives respectively;

- Rural roads: $11 \%$ in good state and 19 in fair state, i.e., $110 \%$ and $100 \%$ of the annual objectives respectively.

The current rate for communes' connection to the national network is $53 \%$ at the national level.

- During the first semester, in comparison with statistics from year 2007, a more important number in casualties and accidents were recorded in road and sea transportations. For rail and air transportations, no significant incident and accident was recorded. Decisions on safety actions have been made.

- Achievements in electricity connections in rural and urban areas have been quite limited: 200 new connections against 1,500 planned in urban areas and 15 villages against an objective of 35 in rural areas.

- Very significant results were recorded regarding telephony penetration: $84.77 \%$ of the objective was achieved as of the first semester.

- Results are also limited as regards access to safe water: 342 new connections were completed against the 1,000 planned by the JIRAMA, i.e., an achievement rate of $34.2 \%$. In the zones not serviced by JIRAMA, 356 water points have been built against an objective of 1,200 , i.e., an achievement rate of $29.67 \%$. The situation is similar as regards hygiene promotion actions: 938 latrines and public bathhouses were built against an objective of 7,000 , i.e., a $13.40 \%$ achievement rate for the first semester of 2008. 


\section{EXECUTIVE SUMMARY}

COMMITMENT 3:

TRANSFORMATION

EDUCATIONAL

The data on enrolment and school completion are available only at year-end. In primary, lower, and upper secondary schools, as well as in vocational training, improved performance is dependent on actions to build/rehabilitate classrooms, to recruit and train teachers, to provide school kits, to establish school feeding programs in the primary schools, and to contribute to reduction of charges among parents through equipment in school kits and school funds, as well as the school feeding set up in Public Primary Schools (EPP).

Generally speaking, the building/rehabilitation activities were still under way during the first semester of 2008. However, good results were noted as regards the recruitment of teachers and the establishment of school feeding programs.

In the area of higher education and scientific research, the objectives set in terms of number of students per 100,000 inhabitants are exceeded. The rate this year is largely above that of the previous academic year. Good performances were also achieved as regards the number of students graduating

In the area of higher education and scientific research, the objectives set in terms of number of students per 100,000 inhabitants are exceeded. The rate this year is largely above that of the previous academic year. Good performances were also achieved as regards the number of students graduating.

As regards literacy, the developing partnership with NGOs gives rise to hope of success.

\section{COMMITMENT 4: RURAL DEVELOPMENT}

Significant results have been achieved in the area of land security (surface area made secure, issuance of land certificates, modernization of land services) despite the lean period that affected the communes hit by cyclones and which, as a result, reduced the applicants' capacity to pay for the certificates, as well as the election of new mayors which caused delays in formalizing the commune authority needed for signing and issuing land certificates.

The penetration rate of microfinance is promising given the geographical coverage and the development of Microfinance Institutions' network: the rate is currently $9.25 \%$ against an objective of $10 \%$, i.e., an achievement rate of $92.5 \%$. The coverage rate is $70.43 \%$ over the country (81 districts reached out of 115).

The Green Revolution has been reinforced, mainly through the intensified use of agricultural inputs, the development of hydro-agricultural works, the promotion of market-driven activities, the diversification of agricultural activities, the establishment of Market Access Centers (MAC), Agribusiness Centers (ABC), and Agricultural Service Centers (ASC) in several decentralized local governments.

However, sea-fishing production was low due to cyclones in the first semester.

\section{COMMITMENT 5: HEALTH, FAMILY PLANNING, AND THE FIGHT AGAINST HIV/AIDS}

Overall, the results obtained during the first semester of 2008 are satisfactory. The indicators have exceeded half the objectives set for the year though some indicators are available only at year-end or through surveys.

- The objective as regards the outpatient consultation rate at CSBs has been achieved at $59.4 \%$ thanks to the building/rehabilitation and equipment of CSBs, the establishment of a monitoring system, the recruitment and dispatching of medical staff, and the provision of quality drugs and supplies.

- As regards the elimination of communicable diseases such as malaria and tuberculosis, tangible results were achieved. Similar results were noted as regards the elimination and the control of other endemic/epidemic diseases.

- The DTPHep B3, BCG, and measles immunization coverage rates have been satisfactory.

- The objectives as regards delivery with qualified assistance at a BHC or a DHC and the prenatal consultations have been achieved at $68.01 \%$ and $72.03 \%$ respectively. .

\section{COMMITMENT 6: HIGH GROWTH ECONOMY}

Frequent and ongoing price increase in main oil products at the international level over these first six months affected Madagascar annual economic growth forecast. As it was initially planned at $7.3 \%$, it is estimated at $7.1 \%$. However, actions taken by the country in monetary, budgetary management and in agricultural production diversification and increase mitigated the impact of such inflationist pressure on the variation of local prices.

For the whole year, the overall price level increase is revised to $9.4 \%$ versus an initial plan of $8 \%$ (average CPI of the periods). On he whole, the consumption price index increased by $2.6 \%$ between December 2007 and June 2008.

Nevertheless, the main performances recorded are reflected by:

- The increase in production of some activity branches, namely in Buildings and Civil Works (BTP), construction materials and communication.

- The dynamics in tax revenues that contributed to curb the budget deficit at $4.4 \%$ over an initial $4.9 \%$ programming and, in parallel, the estimation of tax pressure rate at $11.9 \%$ which was initially planned at $11 \%$

- exceeded annual forecasts as regards foreign direct investments; 


\section{EXECUTIVE SUMMARY}

- growth of long-term credit granted to the private sector as well as the improvement of the penetration rate of micro-finance;

- Publication of the application decree for the Companies' Act, which abrogates the minimal capital for limited liability companies (SARL) and sole proprietorship limited liability companies (EURL).

\section{... will contribute to enhance national production}

In addition, the laws on exports and public-private partnership that will be soon published will also go towards improving the investment climate

Furthermore, In order to be able to face the global food crisis that will surely have impacts on the Malagasy economy, there is a strong need to further boost the production in primary sector, in particular performance in agriculture sub-sector.. Among other safety measures, it would be most indispensable to practice off season crops in order to increase national production.

\section{Commitment 7: Cherish the Environment}

The actions to create Protected Areas have been satisfactory with the objectives achieved at $93.90 \%$. The objectives have all been achieved as regards the global effectiveness index for protected areas, the rate of representation of habitats in the system, and the increase in the reforested surface area.

Special efforts have been undertaken to mobilize funds for the Madagascar's Protected Area and Biodiversity Foundation (FABMP), and the objective has been achieved at $154 \%$.

The forest and environmental incomes have constituted $470.67 \%$ of the line ministry's operational and investment budget. However, this is due to the sale of seized wood, a one-off event, for a total amount of Ariary $9,993,657,129.86$.
With the twenty-two Regional Inspection and Control Services (RICS) becoming operational and the establishment of a Regional Platform for Planning, Monitoring, and Evaluation, order maintenance, control and regularization in forests have improved in the regions.

\section{COMMITMENT 8: NATIONAL SOLIDARITY}

Achievements under this commitment during the first semester are quite limited.

Good performances were recorded in the areas of preserving national cultural heritage (material or immaterial), promoting gender equality and women's empowerment, and promoting access to basic social services for vulnerable groups. Conversely, the performances have been very poor as regards the program for registering children having no birth certificates and the preparation of athletes to international competitions (given the implementation of selection criteria and the schedule).

In keeping with leadership capacity building among civil society members and public sector officials, training was provided at both central and decentralized levels, as well multiplication of agents of change at regional and national levels

With regard to safety net, efforts were undertaken by the Government in order to secure access to basic commodities (nutritional support), foster income generating activities and employment creation. Furthermore actions were taken to develop off season cropping.

Regarding post disaster emergency responses, interventions consist mainly in cleaning some villages that were victimized by such disasters, in remitting donations to BNGRC and in assessing damages and losses.

Overall, much effort needs to be made to sustain some of the performances achieved in the year 2007.

\section{FINANCING OF THE MAP}

During the first semester, the total resources recorded are Ariary 1271.1 Billion of which Ariary 880.5 Billion are internal resources and Ariary 390.6 Billion external resources.

These total resources are made up at $80 \%$ by Tax Revenues as internal resources. The external resources disbursed are made up at $55 \%$ by subsidies.

Running $37 \%$ of these total resources were spent in investment, $28 \%$ in personal expenditures, $22 \%$ in functioning and $11 \%$ allocated to other expenditures.

Export revenues remain low and are equivalent to $42 \%$ of import. However, the flow of FDI has contributed to maintain the balance of payments. Our currency reserves in import months are estimated at 2.3 versus an achieved 3 Months in the first semester of 2007. 


\section{IMPLEMENTATION OF THE MAP: MAJOR OBJECTIVES}

\section{SITUATION OF THE INDICATORS \\ RELATED TO THE MAJOR OBJECTIVES}

\section{Economic Growth}

The economic growth forecast that was initially $7.3 \%$ has been revised downward to $7.1 \%$ following the increase in main oil and food products prices on the international markets.

Graph 1 : Evolution in the share of budget for Education Health compared with the total budget, Evolution in economic growth.

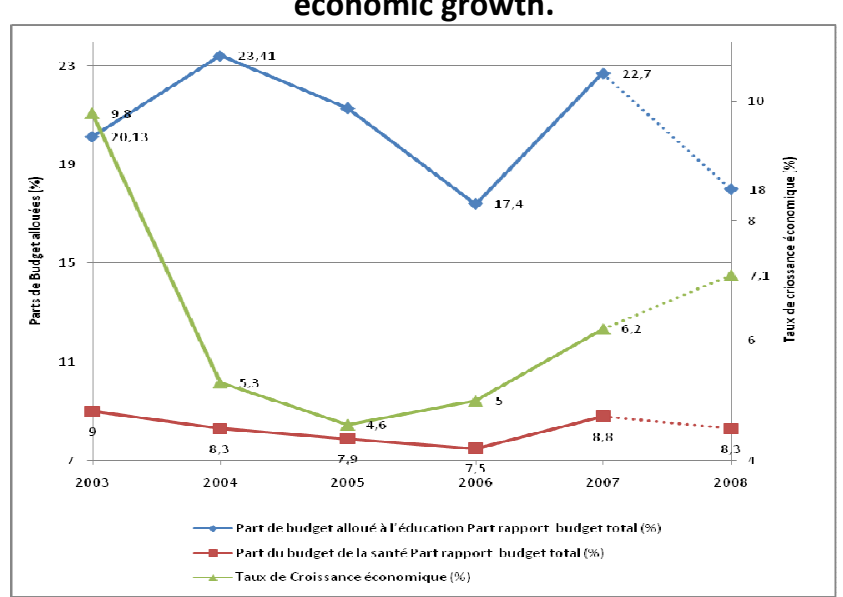

Sources: MENRS-MECI

Against this backdrop, the main production sectors forecast increases in their productions, respectively by $3.1 \%$ for the primary sector, of which livestock and fisheries by $2 \%$, by $8.8 \%$ for the secondary sector, of which extractive industries by $12 \%$ and by $9.3 \%$ for the tertiary sector, of which Civil Works by $20 \%$. The production dynamics of the main activity branches in communication, BTP and construction materials, and chemical industries will essentially contribute to enhance national production for this first semester.

\section{Foreign Direct Investments}

The net flow of foreign direct investments is estimated at SDR 441.5 million against an annual forecast of SDR 439 million, which means the objective for 2008 is achieved at more than $100 \%$ at mid-year. Further analysis will be conducted as soon as information on the structure of the investments is available.

\section{Reduced Corruption}

Tangible progress was made in controlling corruption. The actions mainly pertain to informing the general public on the progress of anti-corruption efforts in the country through the updating of the different sections in the Bureau's site. In addition, the following progress was noted:

- The number of complaints received was 3,776, which represents $50 \%$ of the objective set;

- The number of complaints that call for investigation is 525 , which represents $53 \%$ of the objectives set;

- $33 \%$ of the cases processed by BIANCO are forwarded to the legal jurisdiction against a $38 \%$ objective, and 343 cases were processed, which represents $41 \%$ of the objectives set.

\section{Schooling and Illiteracy Reduction}

In support of improving schooling and illiteracy elimination:

- 2,000 teachers formerly paid by the Parents' Associations (FRAM) were recruited, i.e., $100 \%$ of the annual objective;

- 272 primary schools against an objective of 200 are equipped with a school feeding program.

The literacy program for people aged more than 15 with poor reading abilities has had good performance by achieving $65 \%$ of the annual objective in semester 1 , i.e., 11,120 adults enrolled in literacy programs out of the 17,000 planned.

\section{Land Security}

As regards the issuance of land titles and certificates: 3,937 land certificates established versus an objective of 5060 certificates, i.e., 78\%; MAEP forecast 30000 certificates; 5,647 out of the 10,000 planned were issued, i.e., $64 \%$ of the objective.

Indeed, an 8,403 ha surface area has been secured out of a 13,156 ha objective, i.e., $64 \%$, under the implementation of the National Land Tenure Program (PNF).

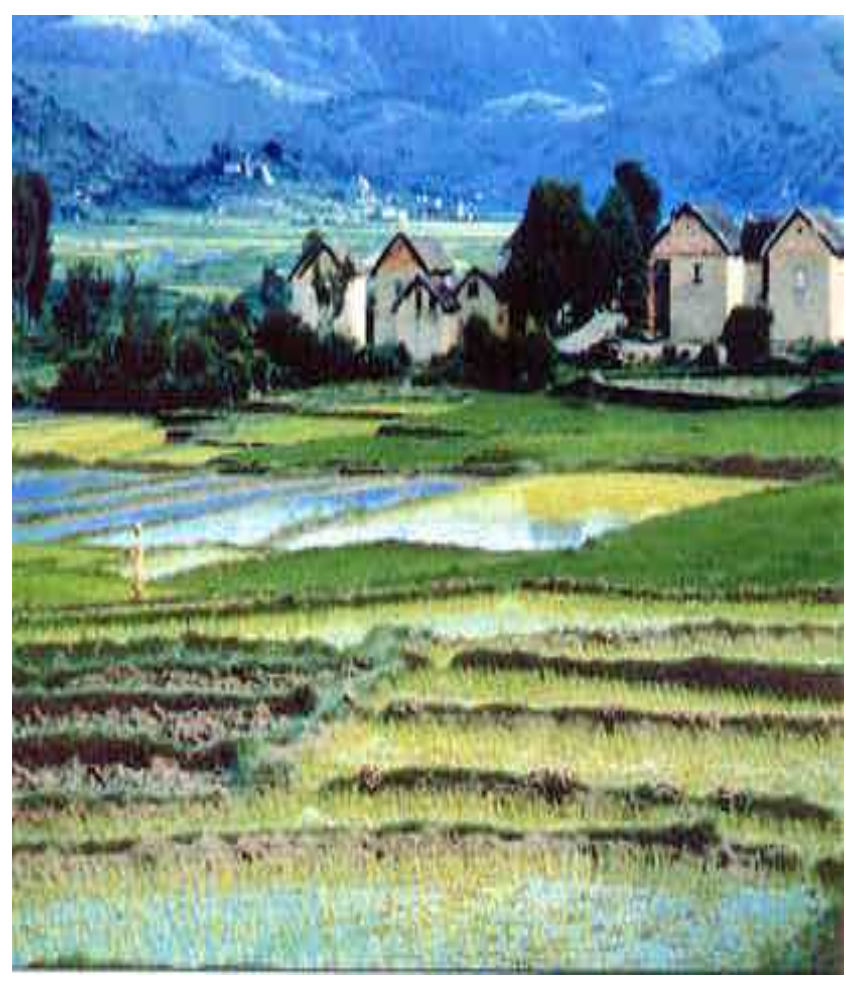




\section{IMPLEMENTATION OF THE MAP: MAJOR OBJECTIVES}

\section{COMMITMENT 1: ReSPONSIBLE GOVERNANCE}

\section{FOLLOW UP OF RECOMMENDATIONS IN 2007}

\begin{tabular}{|c|c|c|}
\hline Recommendations in 2007 & Progress status in first semester 2008 & Observations \\
\hline $\begin{array}{l}\text { Recruit } 1,000 \text { policemen and policewomen per year, subject to financial } \\
\text { support and the government's authorization; }\end{array}$ & $\begin{array}{l}\text { Technical study and draft decrees and orders finalized. } \\
\text { Recruitment postponed since } 2007 \text { independently from the State Secretariat on Home Security } \\
\text { (SESI). As a consequence, the people in charge chose to revise the PGE } 2008 \text { at mid-term and } \\
\text { provide substitution activities such as in-service training and modular training. }\end{array}$ & \\
\hline $\begin{array}{l}\text { Achieve the maximum coverage of } 119 \text { districts in order to avoid distance } \\
\text { management of security, through timely operations, including patrols of the } \\
\text { general police }\end{array}$ & $\begin{array}{l}84 \text { districts were covered in } 2007 . \text { In } 2008,2 \text { police stations out of the } 7 \text { were established, i.e., } \\
28.5 \% \text { of the objective set. }\end{array}$ & \\
\hline Institute Behavioral Change Communication (BCC); & In process with the meeting of the National Higher Council on Defense and Home Security. & \\
\hline Intensify the awareness-raising campaign on corruption & $\begin{array}{l}\text { Combined efforts as regards informing the general public. Good performance as regards the } \\
\text { increase in the number of complaints received thanks to the mobilization of the general public to } \\
\text { report cases of corruption. However, there is not yet enough mobilization in remote areas. }\end{array}$ & \\
\hline Increase the number of session on civics & Information not available & \\
\hline $\begin{array}{l}\text { Reinforce effective collaboration between the partners of the Justice, such } \\
\text { as BIANCO, CSI, bailiffs, lawyers, namely to accelerate the processing of } \\
\text { cases }\end{array}$ & $\begin{array}{l}3 \text { meetings organized on } 5 \text { topics (problems in issuing sentence implementation orders, problems } \\
\text { of assessors at the commercial court, consequence of the administration keeping quiet, justice } \\
\text { auxiliaries, lecture on the actions relating to Commitment } 6 \text { of the MAP }\end{array}$ & \\
\hline $\begin{array}{l}\text { Increase the share of budget allocated to decentralized collectivities (budget } \\
\text { transfer) }\end{array}$ & The percentage of the budget allocated to communes increased from $1.48 \%$ in 2007 to $3 \%$ in 2008 & \\
\hline $\begin{array}{l}\text { Make operational the Local Development Fund as soon as possible in order } \\
\text { to build the communes' capacities }\end{array}$ & $\begin{array}{l}\text { Publication of constitutive laws and regulations of the local development fund, manual of } \\
\text { procedures being developed, ministerial structure established (Director General, and } \\
\text { Administrative and Financial Directors appointed for EPA/FDL, members of the board appointed) }\end{array}$ & \\
\hline $\begin{array}{l}\text { Reinforce the application of the Code of Public Procurement by training the } \\
\text { concerned entities at the central and regional levels on the typical bidding } \\
\text { documents, on public procurements techniques, and on the rules provided. }\end{array}$ & Ongoing action & \\
\hline
\end{tabular}




\section{IMPLEMENTATION OF THE MAP: RESPONSIBLE GOVERNANCE}

\section{ANALYSIS OF PRIORITY INDICATORS}

\begin{tabular}{|c|c|c|c|c|c|}
\hline \multicolumn{6}{|c|}{$\begin{array}{l}\text { Reducing the crime rate and securing the red } \\
\text { zones }\end{array}$} \\
\hline \multirow[b]{2}{*}{$\begin{array}{l}\text { Indicator } \\
\text { Name }\end{array}$} & \multirow[b]{2}{*}{2006} & \multirow[b]{2}{*}{2007} & \multicolumn{2}{|c|}{2008} & \multirow{2}{*}{\begin{tabular}{|c|}
2012 \\
SNISE \\
$\begin{array}{c}\text { Objectiv } \\
\text { e }\end{array}$
\end{tabular}} \\
\hline & & & Objective & $\begin{array}{l}\text { Achieveme } \\
\text { nt 1st } \\
\text { semester }\end{array}$ & \\
\hline $\begin{array}{l}\text { rime rate } \\
\text { wer than } \\
\text { r equal to } \\
.8 \text { for } 1,000\end{array}$ & 4 & 1.8 & $<3.8$ & 0.75 & 2.6 \\
\hline
\end{tabular}

- Significant results were achieved in the area of people and property's security though there remain uncontrolled pockets of insecurity due to lack of resources. The setting up of the Special Intervention Force for the National Police, the National Gendarmerie, and the Coast Patrols and the distribution of elements according to demand has resulted in clear improvement of security in the operation zones.

- As of the first semester of 2008, the crime rate reduced to 0.75 per 1,000 against an objective of less than 1.9. As regards security operations, 35,759 were conducted in urban areas against the 37,175 planned, i.e., $96.1 \%$ of the objective; 6 Rural Security Maneuvers were conducted (50\% of the objectives); 26 Rural Security Operations were conducted out of the 300 planned, (i.e., 8.75); 68 community based police stations have been established against the 76 planned.

- Four red districts out of the 13 planned have been secured, namely Ambatofinandrahana, Ikalamavony, lakora, and Vangaindrano ; 610 Kizo guards have been created; 04 autonomous security detachments (DAS) have been established; 03 new groups have been established in Androy, Betsiboka, and Bongolava, and 02 brigades are operational ; 613 general policy patrols were conducted at the Ministry of National Defense against the 3,000 planned (i.e., $20.4 \%$ of the objective set), and 3,432 general police patrols were conducted by the SESI out of 3,750 planned $(91.5 \%$ of the objective set).

- The effectiveness rate of the armed forces in repressing cattle thefts has increased to $84.6 \%$.

- 49 cases of cattle thefts were reported against a forecast of 178 by SESI and 641 by the Ministry of National Defense. Out of the 9,572 cattle stolen, 6,175 were handed back. As regards marketing pipeline, 31,035 were made compliant by controlling markets, slaughterhouses, convoys, shops, and marketing documents.

- Five regions and 29 districts have a Social Security Plan.

Improved Coverage of the Exclusive Economic

\section{Zone}

Covering the Exclusive Economic Zone means ensuring the surveillance of the marine zone where the country draws marine and oil resources: 3,500 police operations were conducted as part of territorial surveillance, including 946 on the economic zones.

Twenty-one days of outings in the sea were conducted against an objective of 150 days, 54 hours of flying over the Malagasy territory against the 330 hours planned, and 25 hours and 25 minutes of outings on fast boats on the sea for river surveillance.

The low performance is mainly due to the lack of material and financial means (fuel and spare parts).

\section{Decreased Average Time for Trials and Processing of Pending Cases}

Awareness-raising and training sessions on standards of service were conducted for magistrates in the Court of Appeal of Antananarivo, Toliary, Mahajanga, Toamasina, and Fianarantsoa. Criminal records are now computerized in the pilot courts of Antsirabe and Ambatolampy. The cal for applications for the recruitment of 50 magistrates, 100 court clerks, and 200 penitentiary managers and agents has been sent out to increase the staff as part of adopting a more rational human resources policy.

The program for processing pending cases at $100 \%$ for 2008 has already started in the Court of First Instance of Antalaha, Morondava, and Morombe and will concern 16,686 ruling with delayed publication and 16,186 case papers.

Actions were conducted to improve human rights in prisons. The ratio of convicted/defendant is now 53/47 against an annual objective of 51/49. As regards overpopulated prisons and as part of the application of the RRI approach, 3,900 pending cases were processed at the Court of Miarinarivo and the ratio of convicted/defendant improved from $40 / 60$ to $65 / 35$. In the Court of Moramanga, 871 pending cases were processed in 60 days and the ratio convicted/defendant improved from $48 / 52$ to $92 / 8$.

The new Law on Juvenile Justice is in process, including the establishment of the educational reinsertion system.

\section{Improved Corruption Perception Index}

Tangible progress was noted as regards anti-corruption efforts. The Corruption Perception Index moved from 3.2 in 2007 to 3.4 in 2008, the objective is 5 for 2012. Actions have been conducted in informing the public on the on the progress of corruption control in the country through updates in the different sections of the Bureau's site. Good performances were observed as regards the increase of the number of complaints obtained through the mobilization of the general public to report cases of corruption, the improvement of the processing of corruption cases through capacity building of the staff in charge of investigation and through increase in the staffing, the improvement of relationship with users through the implementation of the recommendations 


\section{IMPLEMENTATION OF THE MAP: RESPONSIBLE GOVERNANCE}

coming out of the review and analysis of the target entities' systems and procedures, and community based actions, namely the establishment of a branch in Mahajanga. Indeed

- Despite poor mobilization of the public in remote areas to report corruption and despite poor understanding of what makes up a corruption offence among plaintiffs, it should be noted that 3,776 complaints were filed (i.e., $50 \%$ of the objectives set), and 525 complaints currently call for investigation, (i.e. $53 \%$, of the objective set).

- $33 \%$ of the cases processed by BIANCO are referred to the legal jurisdiction, against an annual objective of $38 \%$, and 343 cases are processed (i.e., $41 \%$ of the objectives set). Decree $\mathrm{N}^{\circ} 2007-510$ on June 5, 2008 on the establishment of the Financial Intelligence Unit (SAMIFIN) was adopted in the Council of Government. The Committee for Preserving Integrity (CSI) was in charge of establishing this entity so that it is operational.

Graph 2 : Evolution in the Improved Corruption Perception Index

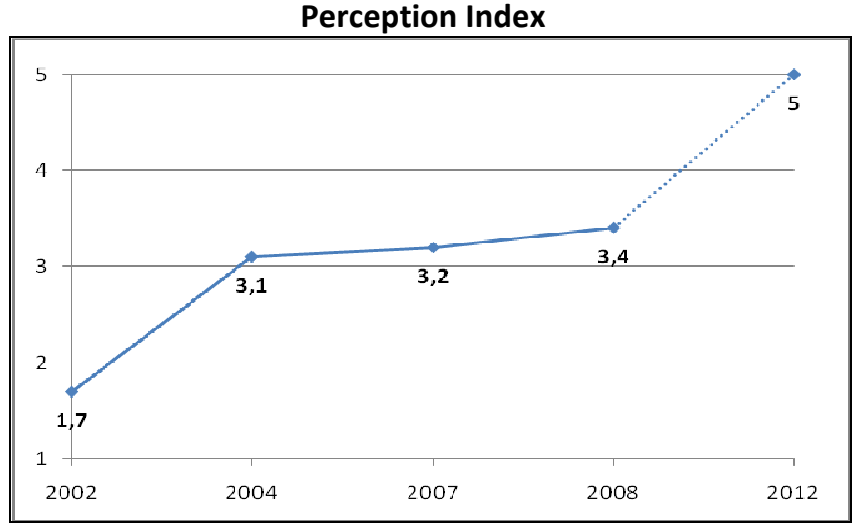

Source : Banque Mondiale

Decree $\mathrm{N}^{\circ} 2007-510$ on June 5, 2008 on the establishment of the Financial Intelligence Unit (SAMIFIN) was adopted in the Council of Government. The Committee for
Preserving Integrity (CSI) was in charge of establishing this entity so that it is operational.

\section{Reform of public finances management}

Graph 3 : Evolution in Public Revenues - first Semesters of $2006 / 2007 / 2008$

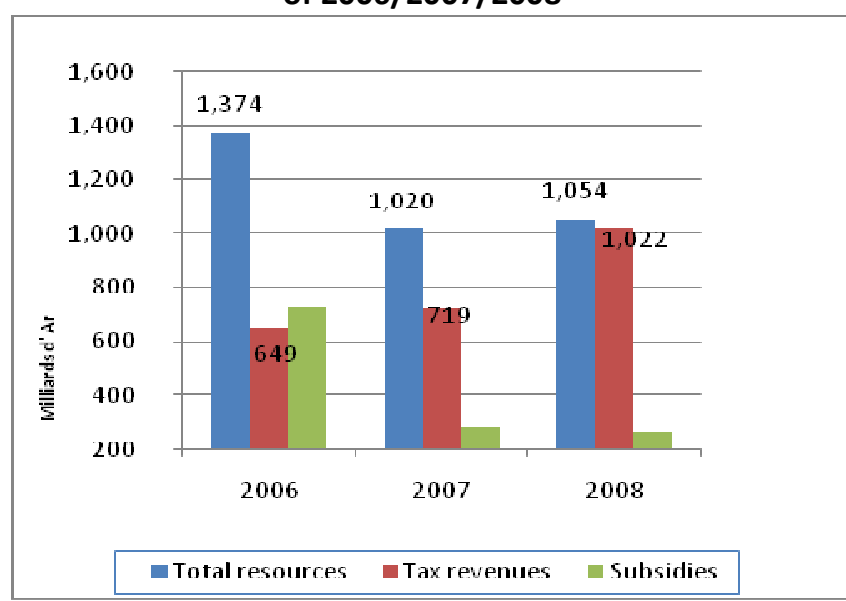

Source: OGT-MFB/DGT

\section{Improved Tax Pressure Rate}

Coordinated efforts were carried out to establish an improved method for tax collection. This involved operational and organizational reforms in the customs and tax services, including:

- Establishing three TRADENET platforms that concern Toamasina, Antananarivo, Mahajanga, Antsiranana, and Toliary, i.e., 08 customs offices, and making available all the means and resources needed for this purpose;

- Having 6 operational Approved Management Centers; establishing partnership for extending Approved Management Centers to the regional level;

Identifying 1,933 tax payers; 2 regional services for businesses adopt the procedure of wire transfer payment.
Graph 4 : Evolution in Public Expenditures - First Semesters of 2006/2007/2008

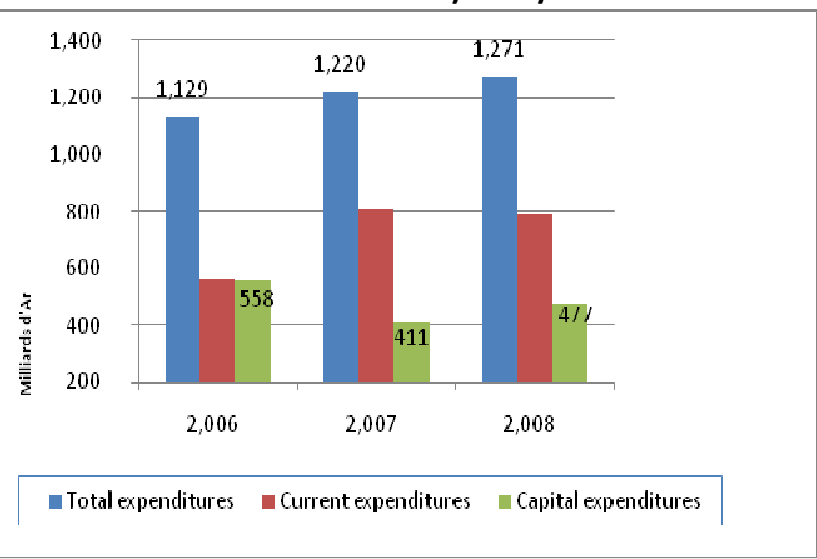

Source: OGT-MFB/DGT

Following the improvement of the tax collection system and the different reforms of the tax and custom administration, the fiscal pressure rate increased by 0.4 point against the objective of $11.6 \%$ for the year. The budget deficit, cash basis, was of $4.4 \%$ of the GDP against an objective of $4.9 \%$. The decrease is due to the compression of some expenditures lines and the increase in resources. The implementation of expenditures was somehow impeded by failures in the expenditure chain and in delays in the appointment of managers. The total expenditures amounted to Ariary 1,322.5 billion against an objective of Ariary 3,422.4 billion, i.e., $38.6 \%$ of the objectives set.

All the Ministries are connected to the Integrated Public Finances Management System (SIGFP)

The IPFMPS is now operational in ministries and institutions at the central level as well as in the Financial Districts. The central ORDSECs have been trained on the use of the SIGFP. 
IMPLEMENTATION OF THE MAP: RESPONSIBLE GOVERNANCE

Table 2 : Budget Deficit ( \% of GDP)

\begin{tabular}{|c|r|r|r|r|r|}
\hline $\begin{array}{c}\text { Priority } \\
\text { Indicator } \\
\text { Name }\end{array}$ & 2006 & 2007 & \multicolumn{2}{|c|}{2008} & 2012 \\
\cline { 3 - 6 } & & Objective & $\begin{array}{c}\text { Achievemen } \\
\text { ts 1st } \\
\text { semester or } \\
\text { revised } \\
\text { initial } \\
\text { programmin } \\
\text { g }\end{array}$ & $\begin{array}{c}\text { SNISE } \\
\text { Objective }\end{array}$ \\
\hline $\begin{array}{l}\text { Budget Deficit } \\
\text { (in \% of GDP) }\end{array}$ & 4.3 & 2.8 & 4.9 & 4.4 & 0.37 \\
\hline
\end{tabular}

\section{PEFA (Public Expenditure and Finance} Accountability)

PEFA aims at assessing the performance of the public finance management systems. Under PEFA, the first 28 indicators (the last 3 ones pertaining to donors) are distributed over six key dimensions of a public finances management system:

- Credibility of budget: 4 indicators

- Exhaustiveness and transparency: 6 indicators

- Budgeting based on national polices: 2 indicators

- Predictability and control of budget implementation: 9 indicators

- Accounting, information recording, and financial reporting: 4 indicators

- Internal surveillance and verification: 3 indicators

A draft report on the performance of public finances management in Madagascar is being prepared by the World Bank and the African Development Bank.

Madagascar has recently made significant efforts to improve public finances management. The results of the reforms are still coming, however they look quite limited:

- Eleven PEFA indicators are graded B or more, against an objective of 31 , (I.e., $36 \%$ of the objective). The main weaknesses in the current public finance system relate to the reliability of information, poor mastery of the budget concepts by the ministries, the reporting system, financial control, and external controls;

- No indicator relating to internal and external control was grade B and was more than 3 . This is due to weaknesses in procedures and responsibility assignment. Reforms are initiated for year 2008;

- Despite the lack of budget documents and the information requested in the previous fiscal years, 2 indicators on budget preparation achieved the expected grade (against an objective of 4 indicators) as well as 1 indicator on budget monitoring (against an annual objective of 2).

\section{Continued Budgetary control reform}

The control and verification actions were continued through strengthening the operations of the structures in charge of procurement (Procurement Officers and Procurement Management Units) in the ministries.

\section{Procurement procedures compliant with the} new legal and regulatory framework

About $29.1 \%$ of procurements in the pilot ministries (Health, Education, Public Works, Transportation, and Agriculture) were assessed as compliant to the procedures of the legal and regulatory framework compared to the objectives set. It should be noted that the Road Maintenance Fund also uses the new Law after receiving training on the new legislation in force.

\section{Streamlined Administrative Procedures in Public Services}

In order to reinforce the effectiveness of public service provision, the delay for processing files and applications decreased from 63 days in late 2007 to 61 days in the first semester of 2008, against an annual objective of 60 days, thanks to the RRI approach.
The text on the Ethics Committee was adopted and the Committee is now operational at the central level. However, no standard of service has been yet established.

In order to reinforce the effectiveness of public service provision, the delay for processing files and applications decreased from 63 days in late 2007 to 61 days in the first semester of 2008, against an annual objective of 60 days, thanks to the RRI approach.

The text on the Ethics Committee was adopted and the Committee is now operational at the central level. However, no standard of service has been yet established.

\section{Collection Rate on Local Taxes}

The organizational and information systems at the Ministry in charge of Decentralization and Land Development at the Presidency do not yet allow for having real time data on the local tax collection at the decentralized collectivities' level. However, all the communes are conducting a fiscal census and are entering the data in the regional IT centers. Survey forms are being developed.

- 260 communes have been receiving support on tax collection and/or fiscal census since the beginning of the year against an annual objective of 150 communes;

- A draft Code of Decentralized Territorial Collectivities is being finalized

- Seven new Commune Support Centers (CSC) out of the 10 planned are being established. Out of these, 2 are supported by the Swiss Cooperation, 4 by the French Cooperation, and 1 by IRCOD. Funding is being sought for the remaining three ones.

The constitutive laws and regulations on the Local Development Funds have been published. The main responsibilities of the LDF are to build the communes' capacities and to fund their activities and investments. 


\section{IMPLEMENTATION OF THE MAP: RESPONSIBLE GOVERNANCE}

The manual of procedures is being developed and the structure at the ministry's level is being set up (the director general and the administrative and financial directors have been recruited, and the members of the board appointed).

3,239 elected officials and managers were trained against an objective of 3,500 , and 494 fokontany offices were built, i.e., $82 \%$ of the objectives set.

\section{Share of budget allocated to communes}

Table 3 : Trends in share of budget allocated to communes

\begin{tabular}{|c|c|c|c|}
\hline \multicolumn{1}{|c|}{ Indicator } & $\mathbf{2 0 0 6}$ & $\mathbf{2 0 0 7}$ & $\begin{array}{c}\text { 1st semester } \\
\text { of } \mathbf{2 0 0 8}\end{array}$ \\
\hline $\begin{array}{l}\text { Share of budget allocated } \\
\text { to communes (as a \% of } \\
\text { general budget) }\end{array}$ & 1.21 & 1.48 & 3 \\
\hline \multicolumn{2}{|c|}{ Source: MID } & & \\
\hline
\end{tabular}

The percentage of the budget allocated to communes increased from $1.48 \%$ in 2007 to $3 \%$ in 2008 with Ariary 51 billion transferred to communes.

Two new Regional Schemes for Land Management (SRAT)] have been developed.

\section{Contribution of Programs and Projects}

- The Project of Governance and Institutional Development (PGDI)/IDA contributes to the coordination, monitoring and evaluation of the government's policy, to improving public services, to transparency and economic governance (public finances management), to strengthening the internal and external control mechanisms, to supporting the budgeting process, to strengthening the capacities of the State's General Inspectorate, the Financial Control, and the Parliament, to reforming public procurement, to supporting CSI, BIANCO, the Ministry of Justice, and the Mediator's office, to improving local tax systems, to intensifying local governance and citizens' involvement, to supporting ENAM, ENMG, CNFA, and NLIM;

- The Project for Institutional Strengthening For Governance/ ADB supports the Government in building the capacities for public finances management, in building the capacities of the Public Procurement Regulatory Body (ARMP), and in establishing public-private partnerships (PPP);

- The project for Support to Public Administration (AMAP)/ UNDP focuses on reforming the management of the government's workers;

- During the first semester of 2008, the ACORDS/EU program contributed to funding 267 communes to the benefit of a 4.5 million population: the activities focused on communes' social infrastructures and equipment (projects relating to education, health, safe water, and basic sanitation), on productive infrastructures, on infrastructures connecting the communes to the national network (markets, rural roads, and other community based economic development infrastructures);

- The interventions of the Integrated Growth Poles Project (IG2P) focused on building communes' capacities and improving their tax revenues;

- The performances of the projects on corruption control, in line with the sector program, focused on or are reflected by :

informing the public of progress in corruption control in Madagascar through updates on the different sections of the Bureau's site;

- increase in the number of complaints filed thanks to the mobilization of the public to report cases of corruption;

improving the processing of corruption cases by strengthening the capacities of the investigation staff and by increasing the staff number; improving the users' treatment by implementing the recommendations coming out of the review and analysis of the target entities systems and procedures;

Community based action, namely the setting up of a branch in Mahajanga.

\section{Challenges, Outlooks,}

AND

\section{RECOMMENDATIONS}

- Conducting sessions in regions to develop ownership towards the anti-corruption effort ;

- Building the sense of ownership as regards the establishment process and applying a minimum standard of service; developing responsibility among public services in this regard;

- Increasing the budget allocated to building the capacity of the investigation staff to process cases;

- The achievements of the sector program depend on the means available to the sector. Improving the effectiveness and the efficiency of the sector requires improving its staff capacity through refresher trainings, trainings adapted to the current context, the procurement of adequate materials (light but operational). To develop in security requires the contribution of each Malagasy citizen. Thus we need to have a new vision for defense and security, a vision under which the army develops with its human resources, its materials, and its structures in order to be up-to-date;

- Improving the effectiveness of the judicial system in enforcing laws in order to improve the effectiveness of the anti-corruption chain;

- Strengthen ownership of the anti-corruption effort by the public sector and by regional officers and engage them in implementing the anti-corruption program. 


\section{IMPLEMENTATION OF THE MAP: CONNECTED INFRASTRUCTURES}

\section{COMMITMENT 2: CONNECTED INFRASTRUCTURES}

\section{FOLLOW UP OF RECOMMENDATIONS MADE IN 2007}

\begin{tabular}{|c|c|c|}
\hline Recommendations in 2007 & Progress status as of the first semester of 2008 & Observations \\
\hline $\begin{array}{l}\text { Develop the cross-sector linkages between Public works and Transports in order to achieve the } \\
\text { expected results }\end{array}$ & $\begin{array}{l}\text { The two ministries have already worked together to develop the } \\
\text { Transport Sector Program }\end{array}$ & \\
\hline \multicolumn{3}{|l|}{$\begin{array}{l}\text { Based on the indicators defined in the NIMES, standardize the indicators of the sectors of } \\
\text { Transports, Energy, Water \& Sanitation in close collaboration with the INSTAT in order to ensure the } \\
\text { reliability of the statistical information generated; }\end{array}$} \\
\hline $\begin{array}{l}\text { Provide for operational mechanisms at the OMERT to facilitate coordination of information between } \\
\text { the administration and the private sector as regards ICTs }\end{array}$ & ARTEC will be set up after the work of an ad hoc committee & \\
\hline $\begin{array}{l}\text { Reinforce the institutional framework in charge of coordinating, planning, and ensuring monitoring } \\
\text { and evaluation in order to discuss and negotiate with and mobilize technical and financial partners } \\
\text { for additional funding for the water and sanitation sector }\end{array}$ & The Ministry of Water has been established and is operational & \\
\hline $\begin{array}{l}\text { Build the capacities of the private and public sectors to provide water and sanitation, especially at } \\
\text { the regional level }\end{array}$ & In process & \\
\hline $\begin{array}{l}\text { Disseminate the National Sanitation Policy and Strategy and raise awareness among the population } \\
\text { as regards its implementation. }\end{array}$ & In process & \\
\hline
\end{tabular}




\section{IMPLEMENTATION OF THE MAP: CONNECTED INFRASTRUCTURES}

\section{ANALYSIS OF PRIORITY INDICATORS}

\section{National tar or dirt roads maintained in} good/fair condition

The results of the building, rehabilitation, regular maintenance, and current maintenance of the tar or dirt National Roads as well as the Rural Roads are as of the first semester of 2008 as follows:

Table 4 : Table on the results of the priority indicators, from the regional Directorates as of the first semester of

\begin{tabular}{|l|c|c|c|}
\hline \multicolumn{1}{|c|}{ Indicators } & $\begin{array}{c}\text { Objectives } \\
\mathbf{2 0 0 8}\end{array}$ & $\begin{array}{c}\text { Achievement } \\
\text { s in 1st } \\
\text { semester } \\
\text { 2008 }\end{array}$ & $\begin{array}{c}\text { Achievement } \\
\text { rate (\%) }\end{array}$ \\
\hline $\begin{array}{l}\text { Percentage of communes } \\
\text { that can be accessed by } \\
\text { road all year long (\%) }\end{array}$ & 45 & 53 & 117 \\
\hline $\begin{array}{l}\text { Percentage of the } \\
\text { National Highways' } \\
\text { network (tarred) that is : } \\
\text { - In good condition (\%) }\end{array}$ & 61 & 48 & 78 \\
- In fair condition (\%) & 30 & 41 & 136 \\
\hline $\begin{array}{l}\text { Percentage of the } \\
\text { National Highways' } \\
\text { network (dirt) that is : } \\
\text { - In good condition (\%) } \\
\text { - In fair condition (\%) }\end{array}$ & 10 & 11 & 110 \\
\hline
\end{tabular}

Source: MTPM

The figures provided in the tables reflect the consolidated results of the actions undertaken by all stakeholders in the Regions.

The results relating to the road projects are only provisional as of the first semester of 2008. Generally speaking, they are significant though they do not cover half the infrastructures available at the national level. In $2007,48 \%$ of the tarred national highways were in good condition and $41 \%$ in fair condition; $10 \%$ of the dirt national highways were in good condition and $19 \%$ in fair condition.

On average, $40 \%$ of the communes could be accessed by road in 2007 . The rate is $53 \%$ in the first semester of 2008 . The rate varies among regions, ranging from 17\% for Vatovavy Fitovinany, 23\% for Betsiboka, 33\% for Haute Matsiatra, and $83 \%$ for Analamanga, 93\% for Amoron'l Mania, and 96\% for Vakinankaratra. All the development actors, whether public or private, have contributed to achieving these results.

As regards the activity program of the Ministry of Public Works and Meteorology (MPWM), the Ministry, through organizations under its leadership and technical partners, has accepted $52 \mathrm{~km}$ of building, rehabilitation, and regular maintenance of national roads $(7 \%)$ and $732 \mathrm{~km}$ are ongoing work against an objective of $742 \mathrm{~km}$. The program for National Highways in 2008 is limited to the remaining projects that fall at the end of the main programs funded by donors.

As regards Rural Roads, $270 \mathrm{~km}$ have been accepted (18\%) and $128 \mathrm{~km}$ are ongoing works against an objective of $1,500 \mathrm{~km}$. The lack or the absence of funding is a major impediment for the Rural Road activities.

As regards current maintenance works, $2,562 \mathrm{~km}$ of National Roads benefited from this activity against an objective of $8,000 \mathrm{~km}$ (i.e., $32 \%$ ) and $781 \mathrm{~km}$ of Rural Roads against an objective of $2,663 \mathrm{~km}$ (i.e., $29 \%$ ). The MPWM has anticipated and improved the preparatory steps for the road maintenance campaigns. However, due to problems in applying the new procurement procedures at the RMF, the initiation of the works was delayed, accounting for the poor achievement rate.
As regards infrastructures such as bridges and ferries, 23 new ferries were procured or built in 2008, against an objective of 23 (i.e., 100\%)

The European Union funded programs/projects : RNS 1|Antananarivo (Analavory-Carrefour RN1) and RNS1Bis|Antananarivo (Analavory-Fanjakamandroso) were checked and signed on a temporary basis. Similarly, on BAD/ FAD funding: RNS-12|Fianarantsoa (IrondroNamorona) was also checked and signed on a temporary basis. The World Bank, the ADB/ADF, the ABDEA, under the responsibility of the Malagasy Road Authority (MRA), ensure the implementation of the works on primary and secondary National Highways in collaboration with the technical partners (China Railway, SOGEA, COLAS, SMATP and ELTER SA)

The Directorate of Roads ensure the implementation of development works on black points, regular and emergency maintenance, emergency works, and reopening works under funding by the FER.

Rates of victims (injuries and deaths) of road

traffic accidents

Table 5 : Figures of road traffic accidents

\begin{tabular}{|c|c|c|c|c|c|}
\hline Year & $\begin{array}{c}\text { Number } \\
\text { of } \\
\text { accidents }\end{array}$ & $\begin{array}{c}\text { Number } \\
\text { of } \\
\text { injuries }\end{array}$ & $\begin{array}{c}\text { \% injuries/ } \\
\text { accidents }\end{array}$ & $\begin{array}{c}\text { Number } \\
\text { of deaths }\end{array}$ & $\begin{array}{c}\% \\
\text { deaths/ } \\
\text { accidents }\end{array}$ \\
\hline 2007 & 1,186 & 1,176 & 99 & 308 & 26 \\
\hline 2008 & 719 & 955 & 133 & 206 & 29 \\
\hline
\end{tabular}

The number of accidents and casualties has increased: in the first semester of 2008, the percentage of injuries against the number of accidents was of $133 \%$ against $99 \%$ in 2007 . The percentage of deaths against the number of accidents is $29 \%$ against $26 \%$ in 2007 . Given the worsening situation, resolutions were made during the meeting on road insecurity meeting convened by the Ministry of Transportation on May 22, 2008 


\section{IMPLEMENTATION OF THE MAP: CONNECTED INFRASTRUCTURES}

Immediate Actions

1. Awareness-raising campaign (organization of platform)

2. Training and refresher training for the police in charge of traffic;

3. Repressive actions: strict enforcement of laws and regulation (breathalyzer test, withdrawal of driver license, arrest, withdrawal of public transportation license, impounding, etc.)

4. Establishing control units at the road stations;

5. Technical control on the road and surprise controls on roads;

6. Better coordination of the actions of the National Gendarmerie/Police: making available communication means (black points, control zones, etc.);

7. Establishing a Monitoring Committee: evaluation, field control, monitoring, results indicators, reorientation, information, communication, etc. ;

8. Developing pounds at the collectivities' level;

9. Issuance of special authorizations limited to the Agency of Land Transportation and to the InterRegional Directorate of Transportations.

\section{Short-term actions}

1. Increasing the scale of fines;

2. Approval of bus stops in sub-urban areas by the Regional Directorates of the MPWM;

3. Increasing the frequency of technical controls;

4. Involving the CTDs in the implementation of immediate and short-term actions;

5. Holding a meeting for the five regions (former provincial capitals) and Antsirabe;

6. Standardization of road signs and markings over the whole country;
7. Involving CTDs in the surveillance of abusive boards and buildings along the roads.

Medium-term actions

1. In-depth revision of the Code of Road

2. Establishing a toll-free hotline.

Out of an objective of two road stations built/rehabilitated in 2008, 2 buildings for ticket desks have been built in Ambatondrazaka and one building for ticket desks and 6 travelers' shelters have been built in Tsiroanomandidy.

1,741 public transportation licenses at national level have been delivered from January to July 2008 against a total of 2,222 licenses in 2008.

\section{Rate of damages caused by sea navigation} accidents/incidents

As of the first semester of 2008, three sea accidents/incidents were recorded. Out of the 64 passengers concerned, 18 were killed, 33 survived or were safe, and 13 are reported missing. Given the seriousness of the accidents and the emergency of situation, the Sea and River Port Agency published a note for the enforcement of reinforcement measures on all the territory on July 30,2008 :

- Transportation of passengers by vessels intended for the transportation of goods is strictly prohibited;

- All vessels must undergo a new technical inspection despite the validity of the regular inspection they have undergone. Valid navigation permits can therefore be suspended or withdrawn.

- All departures from a Malagasy port must be approved expressly and in written either by the Port Authority, the Sea Authority or the National Gendarmerie pursuant to control and inspection of equipment for navigation, communication, survival, ship stability, based on the distance to travel and the meteorological conditions at the time of departure and the meteorological forecasts for the duration of the trip.

- A Permanent Watch Center will be soon set up to receive potential distress calls, and launch immediate rescue and assistance procedure. To this end, the Sea and River Port Authority may requisition any means belonging to private operators deemed needed for the rescue and assistance operations.

- The main achievements in Semester I include:

- Rehabilitation at $100 \%$ of the port of Mahajanga;

- Sending out the call for bids for the rehabilitation of the warehouses of the port of Mananjary;

- Study contract extended for the port of Morondava;

- Rehabilitation at $30 \%$ of the port of Antsiranana;

- In-depth revision of the Code of Sea

- Study for extending the Port of Toamasina conducted by the Japanese partners;

- Delegation of the management of the autonomous port of Toamasina completed at $100 \%$.

- $30 \%$ of the Channel of Pangalanes was rehabilitated (dredged).

\section{Number of air accidents per million of flights}

As of the first semester of 2008, 6 accidents were recorded.

The main achievements during semester I include:

- Telecommunication and meteorological equipments were installed in 9 airports: Ambatondrazaka, Antalaha, Antsohihy, Farafangana, Maintirano, 


\section{IMPLEMENTATION OF THE MAP: CONNECTED INFRASTRUCTURES}

Manakara, North Mananara, Maroantsetra, and Vohémar.

- The airports of Toamasina and Morondava have been fenced at $100 \%$.

- The new agreement on social flights has been finalized.

- The draft contract for the development of the airport of Antsirabe is being developed and the formalities for the payment of expropriation indemnifications are in process.

- The summary design for the extension of the airport of Ivato has been communicated to donors.

As part of the Open Sky policy, 10 foreign airlines are flying regularly to Madagascar (Air France, Corsair, Air Italy, Blue Panorama, NEOS, Air Austral, Air Mauritius, Airlink Regional, Comores Aviation, and Royal Aviation) and 10 Malagasy airlines provide flights on demand (Air Madagascar, Aéromarine, Air Hotel, HFF Travel Airways, Services et Transports Aériens, Sun and Sea, Madagascar Helicopter, Trans Ocean Airways, Madagascar Trans Air, and Insolite Travel Fly). Air Madagascar is the only domestic company ensuring regular flights.

\section{Number of Derailments (Railway Transportation)}

As of the first semester of 2008, 195 derailments were recorded on the main ways versus 253 in 2007. Traffic was interrupted due to railway development work.

The main achievements were as follows:

Northern Network:

- Five engines were procured and put to work;

- The railways have been renewed at $90 \%$;

- A resettlement plan has been implemented;

- The transportation of passengers resumed between Toamasina and Moramanga starting in March 2008.
Southern network

- The railways have been cleared;

- Spare parts are being procured for the vehicles;

The following should be noted as regards the contribution of projects in the Transport sector:

Funding from the French Agency for Development (AFD):

- Project for the rehabilitation of the port of Antsiranana: achievement rate $30 \%$;

- Project for the rehabilitation of the port of Morondava: monitoring of the coast's erosion performed.

Funding from the World Bank

- Project for the rehabilitation of the northern railway network: increase in traffic (goods and passengers), improved security and safety of traffic;

- Project for Rural Transportation, Component MTM (PTR): credits being reallocated;

- Project of multisector infrastructures: no achievement recorded in the first semester of 2008.

\section{Reliability of meteorological forecasts}

Under the meteorology component, it was planned for 2008 to rehabilitate and modernize the meteorological stations and the connection of observation networks and information systems. Thus, achievements in the first semester pertain mainly to communications on an essential tool to disseminate information on climatic changes.

\section{Household access to electricity in rural and} urban areas

In 2007, household access to electricity was $45 \%$ in urban areas and $5 \%$ in rural areas.

For year 2008, the objective in terms of households' access to electricity is $50 \%$ in urban areas, and $5.2 \%$ in rural areas. Two-hundred (200) new connections were made in the first semester of 2008 against an objective of 1,500 (i.e., an achievement rate of $13 \%)$. Several problems occurred, including time lost on providing refresher training to technical staff assigned to other activities (the last connections made date back to 2003), or on sorting of clients with those who already received their estimates being prioritized, or on finding clients who have moved. The new connections started only in May 2008. However, the main problem remains JIRAMA poor capacity to produce energy due to obsolete power generators.

The installation of the Sahanivotry $15 \mathrm{MW}$ hydroelectric plant, which is planned for the end of the year, may accelerate the achievement of the objective set, in electricity connection, at the beginning of the year, as well as new connections to be made for the coming year.

As regards rural electrification, ADER has set the objective of bringing electricity to 100 new villages per year. However, for year 2008, the objective has been revised down to 35 villages due to problems encountered in 2007 that are related to procedures and provisions of the constitutive decree and the transfer of the funding on internal resources and resources from the HIPC to the National Fund for Electricity. Two villages have received electricity under the decentralized mode and 13 through extension work. Thus the achievement rate in the first semester of 2008 is $40 \%$

The development of independent energy producers such as the companies Henri Fraise, HYDELEC, ENELEC, and EDM should also be noted.

Major projects that contribute to the sector's development include the hydroelectric power plant of Sahanivotry with HYDELEC, which should be operational by the end of the year; the project for new thermal power plants throughout the country, achieved at 70\% (49 power generators distributed in 36 centers, including 34 power 


\section{IMPLEMENTATION OF THE MAP: CONNECTED INFRASTRUCTURES}

generators operating since April 2008, 13 power generators being installed, and 2 generators that should be soon delivered); and the rural electrification project with ADER.

\section{Increased telephone penetration rate}

Table 6 : Telephone penetration rate (mobile and fixe$$
\text { phone) }
$$

\begin{tabular}{|l|r|r|r|r|r|}
\hline Indicator Name & 2006 & 2007 & $\begin{array}{c}\text { 0bjective } \\
2008\end{array}$ & $\begin{array}{c}\text { Achievement } \\
1 \text { st } \\
\text { semester } \\
2008\end{array}$ & $\begin{array}{l}\text { Objective } \\
2012\end{array}$ \\
\hline $\begin{array}{l}\text { Fixed and } \\
\text { mobile } \\
\text { telephony } \\
\text { penetration rate }\end{array}$ & 6.3 & 12.2 & 19.70 & 16.70 & 25 \\
\hline
\end{tabular}

In 2007, the telephone penetration rate was $12.2 \%$. The objective set for this year is 19.70 for line and cell phones. The rate increased to $16.70 \%$ during the first semester of 2008, which gives an achievement rate of $84.77 \%$. Regarding the number of subscriptions to mobile telephony (for 100,000 inhabitants), the 15,255 objective for this year 2008 is already achieved even though we are still in the first semester, with a recorded number of 15,472 , i.e., an achievement rate of $101 \%$. If MAP objective for 2012 is 22,500 mobile telephone subscriptions (for 100,000 inhabitants), we would certainly have such result if the pace is kept. On the other hand, the number of the population having a mobile telephone is $16 \%$ in the course of this first semester. This translates into an $88 \%$ achievement rate because the objective to be achieved for this year 2008 is $18 \%$. Finally, $1.9 \%$ population is using the Internet for this first semester. A 90\% rate was therefore achieved because the objective set for this year is $2.1 \%$.

The liberalization of the sector and the resulting harsh competition among operators in terms of range of services and competitiveness of prices, on the one hand, and the involvement of the private sector for the extension of the National Backbone for the Northern Part in microwave beam, for Toamasina-AntananarivoFianarantsoa line in optical fiber, and operation of the Toliara-Taolagnaro-Mananjary-Vangaindrano) on the other hand, contributed to these results. Conversely, the installation of phones in rural areas and the development of access to telecommunications including ICTs and the Internet are somehow delayed. Nevertheless, new ICT centers have been established in rural areas, namely in Antanifotsy and Fenoarivobe.

As regards connection to the international network (optical fiber), the work to install the two submarine optical cables from Toliara (EASSY with TELMA) and Toamasina (LION with Orange) started in the first semester of 2008.

\section{Access to safe water and hygiene}

Table 7 : Percentage of the population with permanent access to safe water- national level (\%)

\begin{tabular}{|l|r|r|r|r|r|}
\hline \multicolumn{1}{|c|}{$\begin{array}{c}\text { Indicator } \\
\text { name }\end{array}$} & 2006 & 2007 & $\begin{array}{c}2008 \\
\text { Objective }\end{array}$ & $\begin{array}{r}2008 \text { 1st } \\
\text { semester } \\
\text { Achievement }\end{array}$ & $\begin{array}{r}2008 \\
\text { Objective }\end{array}$ \\
\hline $\begin{array}{l}\text { Rate of } \\
\text { population } \\
\text { permanently } \\
\text { having access } \\
\text { to drinking } \\
\text { water at } \\
\text { national level } \\
\text { (\%) }\end{array}$ & 38 & $\begin{array}{r}\text { Not } \\
\text { available }\end{array}$ & 45 & $\begin{array}{r}\text { Not } \\
\text { available }\end{array}$ & 65 \\
\hline Urban (\%) & 64.2 & 57.3 & 78 & $\begin{array}{r}\text { Not } \\
\text { available }\end{array}$ & \\
\hline Rural (\%) & 31.6 & $\begin{array}{r}\text { Not } \\
\text { available }\end{array}$ & 36 & $\begin{array}{r}\text { Not } \\
\text { available }\end{array}$ & 57 \\
\hline Source : MTPC & \multicolumn{4}{|r}{} & \\
\hline
\end{tabular}

The water and sanitation sector has now its National Program for Access to Safe Water and Sanitation (PNAEPA) covering the period running from 2005 to 2015.
In 2008, the percentage of the population with permanent access to safe water was estimated at $45 \%$ at the national level, $78 \%$ in urban areas, and $36 \%$ in rural areas. During the first semester of 2008, 342 new water connections were recorded against the 1,000 planned by JIRAMA, i.e., an achievement rate of $34.2 \%$. In areas not covered by JIRAMA, 356 water points were installed against an objective of 1,200 , i.e., an achievement rate of $\mathbf{2 9 . 6 7 \%} \%$

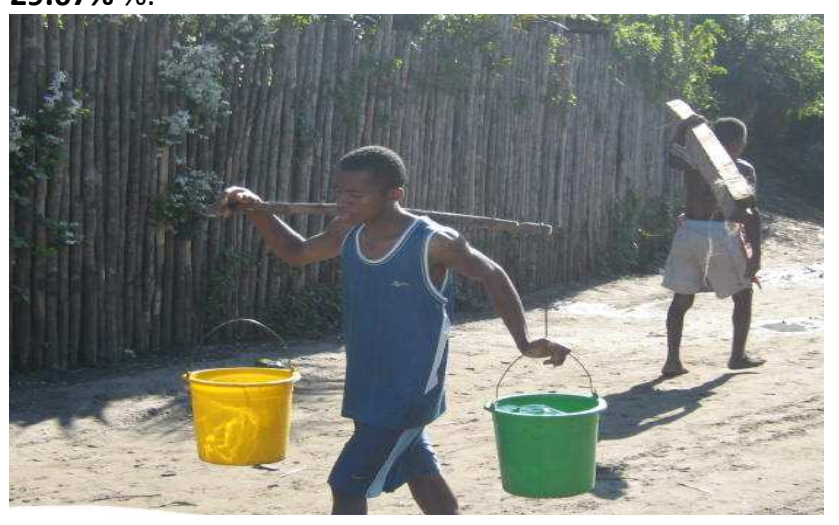

The objective in the areas of sanitation and hygiene is to have $59 \%$ of the national population, $82 \%$ of the population in urban areas, and $46 \%$ of the population in rural areas with permanent access to hygiene infrastructures. Achievements include 938 latrines and bathhouses built against an objective of 7,000 , i.e., an achievement rate of $13.40 \%$ for the first semester of 2008 .

The Water and Sanitation sector has had poor performance due to delays in freeing the budget. Thus, little results have been recorded given that operational projects/programs are in the phases of study, development of tendering documents, procurement or start up of service provision.

In urban areas: 


\section{IMPLEMENTATION OF THE MAP: CONNECTED INFRASTRUCTURES}

- Project "Safe water and Sanitation for Ambalavao and Manjakandriana": no positive achievement was recorded;

- Project "Extension of the safe water supply system for the city of Antananarivo", including improving service provision in the zones of Itaosy and lavoloha: no positive achievement was recorded.

In rural areas:

- Project "Safe water supply and sanitation for the Larger South": 69 man-powered pumps were installed, i.e., an achievement rate of $36 \%$;

- Project "Safe water supply and sanitation": 90 water points, including 50 in schools and 40 in communities, have been set against an objective of 400 , i.e., an achievement rate of 23M;

- Program for Safe Water Supply and Sanitation in rural areas (PAEAR): 167 trainers were certified on capacity building for the Regional Directorates of Health, Family Planning, and Social Protection in 8 regions and 540 districts.

As regards sanitation:

- Project "Safe water supply and sanitation": 140 latrines were built against on objective of 480 , i.e., an achievement rate of $30 \%$;

- Project out of the Public Investment Program (PIP): 316 water points and 938 latrines were built under public-private partnerships.

Issue: Non availability of information enabling to appraise coverage in access to water and sanitation, in particular in rural areas

\section{Main issues raised by Ministries:}

- Frequent change of the ministry in charge of water and sanitation sector (Ministry of Energy and Mining in January 2007, Ministry of Energy in February 2007,
Ministry of Energy and Mining in November 2007, and Ministry of Water in July 2008)

- Late appointment of GAC and SOE in June 2008 insufficient number of staff qualified for procurement (just one Person in charge of Public Procurement (PRMP) for MEM and Min Eau)

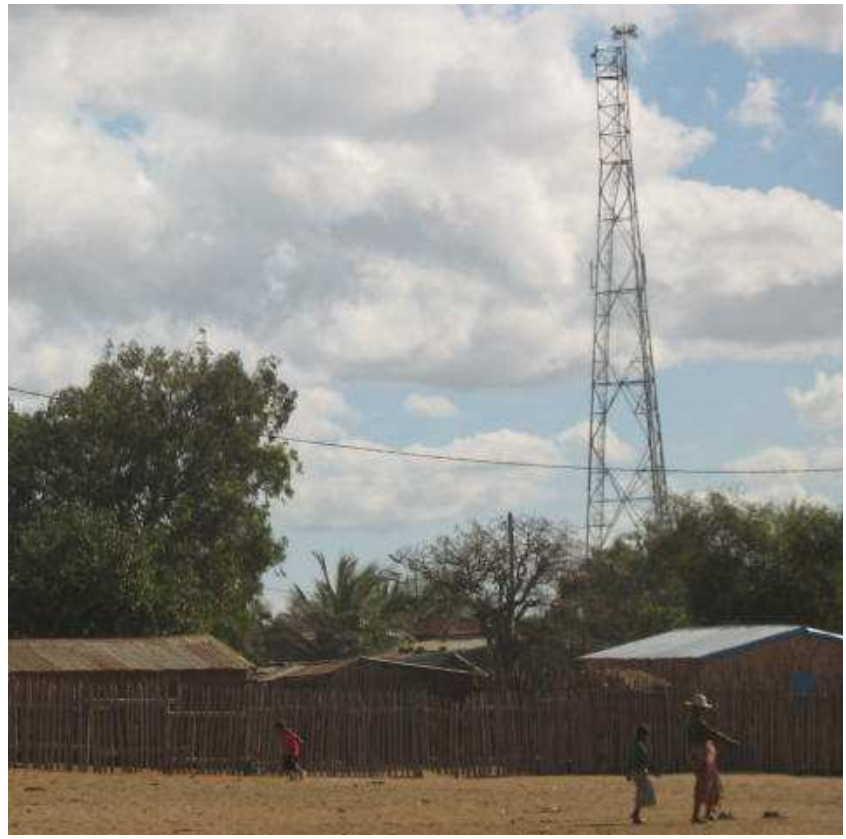

- Posting of the whole 2004-2008 whole budget of ANDEA on the 2008 budget

- Confusion in budgetary posting of the SMAD project

- The JAPAN funded EAU SUD OUEST Project is planned to start up end of September 2008

- UNDP financing is posted again while it is a project completed in 2007.

Actions have been undertaken regarding these issues:

- Appointment of a PRMP and of members of CAO

- Activation of recruitment of 60 executives
- Activation of competitive bidding document processing

\section{RECOMMENDATIONS}

As part of working towards effectiveness and efficiency in projects, the following recommendations are given:

- As regards principles and key concepts: the effectiveness of principles of program budgeting and results-driven management could be strengthened by synergy among coordination bodies and convergence of the budget monitoring systems on the one hand and the MAP monitoring systems on the other hand;

- As regards budget implementation: the regular reconciliations between the DPPI (MPWM) and the DGB (MFB) should be better formalized in order to ensure better linkages between commitments and budget regularizations;

- As regards FER procedures: the recommendations by stakeholders must become effective as soon as possible in order to avoid delaying the road maintenance campaigns;

- Develop public-private partnership in building and managing safe water supply systems;

- On the by-laws and budgeting of the Malagasy Road Authority: given that the design of the MRA was more or less taken after the operating principles of the RMF and AGETIPA for effectiveness purposes, it would be a good thing to make its status of commercial agency more coherent by specifying its modalities of funding and by solving the issue of the accountant. The funds should be rapidly made available;

- Accelerate the establishment of the 60 managers in order to strengthen the Central Administration in charge of Water and Sanitation and move on to devolution of services. 


\section{IMPLEMENTATION OF THE MAP: EDUCATIONAL TRANSFORMATION}

\section{COMMITMENT 3: EDUCATIONAL TRANSFORMATION}

Follow Up OF the ReCOMmEndations MAdE In 2007

\begin{tabular}{|c|c|c|}
\hline Recommendations made in 2007 & Progress status during $1^{\text {st }}$ semester of 2008 & Observations \\
\hline \multirow[t]{2}{*}{ Build the capacities of the MENRS (physical, human, and financial) } & $\begin{array}{l}\text { Management of MEN Human Resources modernized through the acquisition of } \\
7,000 \text { PCs for Central Services and } 22 \text { DREN }\end{array}$ & \\
\hline & MEN WEB site and database updated & \\
\hline Perform a stabilization of the staff budgeted for at the MENRS & 70,000 new MEN agents counted & \\
\hline $\begin{array}{l}\text { Appoint } 2,800 \text { new semi-specialized teachers as early as the start of school } \\
\text { year 2008-2009 for the reorganization of primary education into } 7 \text { years }\end{array}$ & $\begin{array}{l}\text { 2,800 new Semi-Specialized Teachers (SST) being trained for the start of school } \\
\text { year 2008-2009 }\end{array}$ & \\
\hline $\begin{array}{l}\text { Recruit teachers at the lower and upper secondary education levels based on } \\
\text { needs expressed }\end{array}$ & $\begin{array}{l}250 \text { teachers for upper secondary general education and } 50 \text { teachers for upper } \\
\text { secondary technical education recruited }\end{array}$ & \\
\hline Establish national strategies to take literacy education to scale & Draft national strategy to take literacy education to scale developed & \\
\hline Modernize the management of universities through computerization & Under way & \\
\hline $\begin{array}{l}\text { Improve supervision at universities' level through the recruitment of new } \\
\text { researcher teachers }\end{array}$ & $\begin{array}{l}47 \text { Lecturers and } 5 \text { Assistants recruited } \\
\text { Training of Researcher Teachers and high-ranking technicians completed }\end{array}$ & \\
\hline $\begin{array}{l}\text { Improve the diversification of innovative pedagogical methods and facilitate } \\
\text { access to the methods through Distance Open Training (DOT) }\end{array}$ & DOT is not yet in the phase of initiation & \\
\hline
\end{tabular}




\section{IMPLEMENTATION OF THE MAP: EDUCATIONAL TRANSFORMATION}

\section{ANALYSIS OF PRIORITY INDICATORS}

\section{Pre-school Education}

\section{Pre-school coverage rate}

The objective of the pre-school educational system for school year 2008-2009 is to achieve a coverage rate of $8 \%$. Efforts are made in extending the system in order to achieve the annual objective. It includes community awareness-raising and finalization of the CISCOs and communities training scheme. Activities towards the creation of community pre-school centers are under way.

Activities for establishing pre school community centers are under way in the course of this first semester.

The number of children enrolled in Pre School has been from 8,745 in 2007 to 10,321 in 2008. This year, there are 222 operational public and community pre school centers, having 362 teachers inventoried, versus 195 operational pre school centers and 254 teachers inventoried in 2007.

\section{Primary Education}

Rate of children attending primary school / Completion rate

The 2008 objective is to stabilize the gross rate around $122 \%$, and to increase the net rate to $86,8 \%$. For the time being, a $124 \%$ gross rate and an $86 \%$ net rate are recorded.

As for completion rate it was $54.3 \%$ in 2007 . The objective is to increase it to $63 \%$ for the year 2008 . These rates are available only on an annual basis

The number of pupils in the primary school has moved from 3,104,521 in 2007 to 3,263,066 in 2008. Such performance is dependent on building of classrooms, recruitment and training of teachers, relieving parents
Graph 5 : Gross rate and net rate of scolarisation in primary education

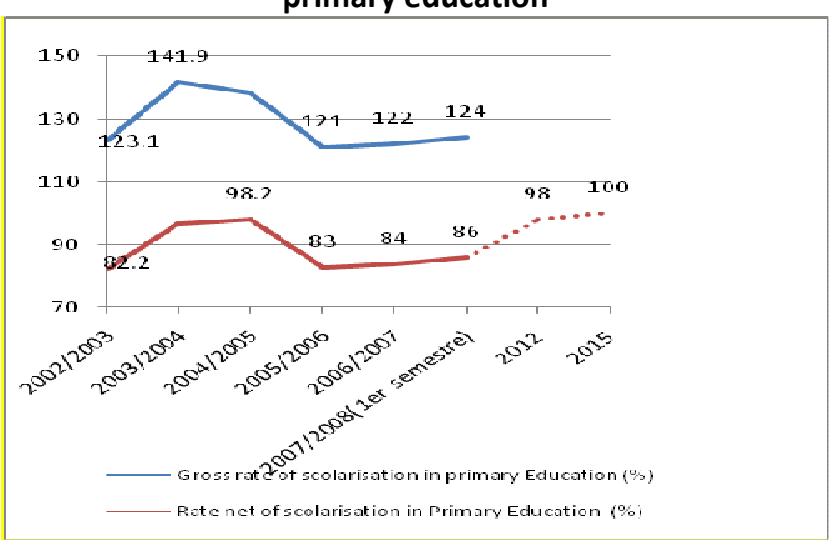

Source: MENRS

from some charges through equipment in school funds. The results obtained are:

\section{Building/rehabilitation of classrooms:}

For the year 2008, the capacity in primary education has increased. There were 53,513 operational classrooms in 2007 versus 58,005 in 2008 .

The objective for 2008 e is to build and rehabilitate 2, 000 new classrooms for the upcoming school year start so as to manage to provide each Fokontany with a full-cycle school:

- 588 classrooms are newly built, 29 classrooms are rehabilitated, calls for bids have been launched (BADEA, OPEP, BIT, JICA, FID IV).

- Contracts for other construction work have been signed. The herein after table reflects the contributions of main partners.
Table 8 : Construction and rehabilitation of classrooms (Primairy education)

\begin{tabular}{|l|l|l|l|l|}
\hline \multicolumn{5}{|c}{ (Primairy education) } \\
\hline Donors & Construction & \multicolumn{2}{l|}{ Rehabilitation } \\
\hline ADB & 468 & & & \\
\hline OPEP & 532 & 10 & 175 & 29 \\
\hline BADEA & 63 & 17 & & \\
\hline AFD & 61 & & & \\
\hline BIT & 238 & 202 & & \\
\hline JICA & 228 & 164 & & \\
\hline FID IV & 302 & 195 & & \\
\hline Total & 1,892 & 588 & 175 & 29 \\
\hline
\end{tabular}

Recruitment of Teachers:

- 2,000 Parents' Association teachers are recruited. The objective is achieved at $100 \%$ and this is owed to the fact that STDs were made responsible. However, lack of qualification is noted among candidates recruited and a 5 to 6 month delay affects the payment of their salary in some Regions.

\section{Training of Teachers:}

- The objective is to train 15,000 Parents' Associations teachers (ENF). The training will be held during the longest holidays; 43 CISCOs are sensitized; 1,170 trainers and 3,486 facilitators are trained;

- Regarding the training of Semi-Specialized Teachers (SST): 2,800 are being trained; 19 trainers are recruited in CRINFP.

It is to be noted that the ABM/MADERE, financed by AFD, provided equipment to the training and pedagogical supervision centers.

Number of subsidized FRAM teachers

As part of the development and the implementation of professionalization plan of non civil servant teachers, 28,562 among them are subsidized. 


\section{IMPLEMENTATION OF THE MAP: EDUCATIONAL TRANSFORMATION}

\section{Allocation of school kits:}

- Relevant actions deserve to be noted: 941,318 newcomers in grade one received brown school kits, which amounts to $100 \%$ of the objective.

\section{Setting up of school canteens:}

- To give further priority to the schooling of children from needy families or attending schools where food insecurity prevails, 272 Public Primary Schools (PPS),

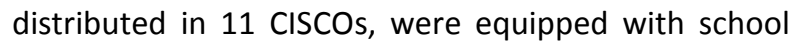
canteens against an objective of 200, thanks to WFP collaboration. 776 PPSs, distributed in 5 CISCOs, are being equipped with school canteens for the start of school year 2008-2009.

Equipment in school funds

- In order to relieve parents from some charges allocated to education, 24,387 schools have been equipped with funds out of the planned 23,052 i.e., $95 \%$.

- Distribution of educational inputs

- For better compliance with the new curricula, $3,500,000$ pedagogical inputs have been distributed to pupils.

\section{Lower secondary education}

\section{Rate of pupils attending lower secondary school} / Completion rate

For the year 2008, the objective consists in increasing the gross enrolment rate at lower secondary level to $34 \%$. $36 \%$ has been achieved.

This year, the pupil number at lower secondary school level has increased. It has grown from 420,153 in 2007 to 468,866 in 2008 . The same applies to the number of operational classrooms and the number of teachers
The completion rate objective is $24 \%$ for 2008 . Such rate is available only at the end of the school year.

The lack of qualified teachers in rural lower secondary schools is a major hindrance to achieving the desired performance.

Graph 6 : The completion rate in primary education

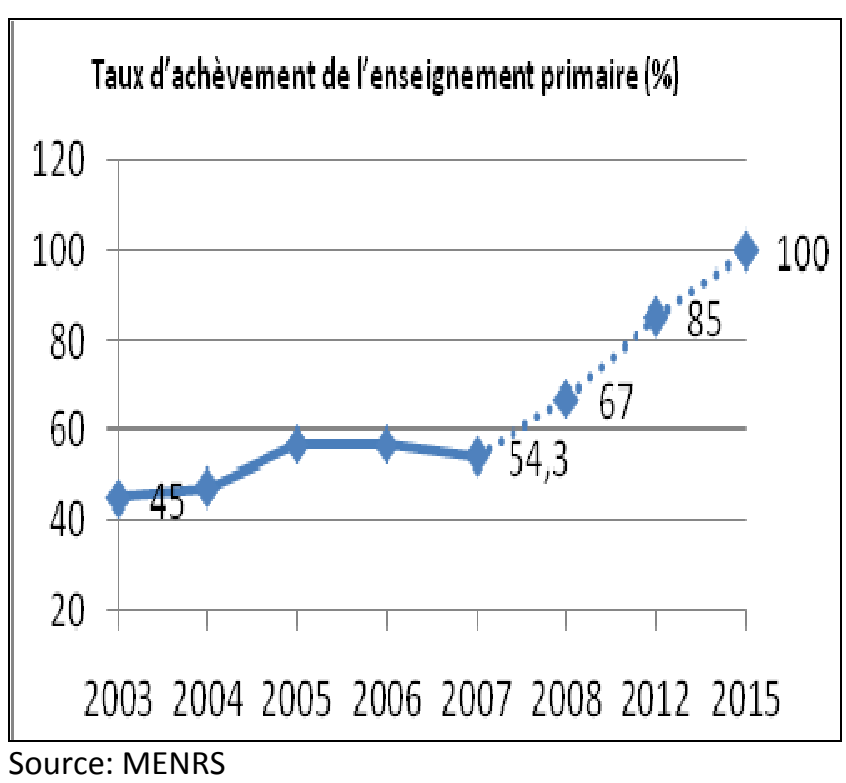

ource: MENRS

Activities undertaken during the first term 2008 to achieve the objectives include:

Building of classrooms:

The number of operational classrooms for the year 2008 is in increase, growing from 7,181 in 2007 to 7,929 in 2008.

The 2008 objective is still to build 400 classrooms for the upcoming school year, with a view to increasing capacity in lower secondary schools. 146 new classrooms have been built; 6 classrooms have been rehabilitated, calls for bids have been boosted/ boosted again (OPEP, BADEA, FID IV).
Contributions by partners are shown below:

Table 9 : Construction and rehabilitation of classrooms (Colleges)

\begin{tabular}{|l|r|r|r|r|}
\hline & \multicolumn{2}{|l|}{ Construction } & \multicolumn{2}{l|}{ Rehabilitation } \\
\hline Donors & Planned & Achieved & Planned & Achieved \\
\hline OPEP & 81 & & 23 & 6 \\
\hline BADEA & 50 & 9 & & \\
\hline FID IV & 233 & 137 & & \\
\hline Total & 364 & 146 & 23 & 6 \\
\hline
\end{tabular}

Training of teachers:

- The objective is to train 1,500 lower secondary teachers. The training is planned for the major vacation period.

Upper Secondary Education and Vocational Training

Rate of students attending upper secondary school/ Completion rate

The gross enrolment for the year 2008 is $11.6 \%$ versus the $11 \%$. Objective

The cycle completion rate in 2007 is $8.3 \%$. This year, such rate should be $9.3 \%$. The secondary school completion rate was supposed to reach $9.3 \%$. The corresponding rates for the first term 2007-2008 are not yet available. So as to achieve the objective, priority was given to the reinforcement of the accommodation capacity of upper secondary schools and the training of teachers.

Building of classrooms:

Capacity in upper secondary schools has been increased: 1,459 classrooms are operational in 2008 versus 1,280 in 2007. For the 2008 to 2009 school year, the construction of 200 classrooms is still posted as an objective.

- 67 classrooms are checked and signed for and 115 are being built, against an objective of 200 . The Call for 


\section{IMPLEMENTATION OF THE MAP: EDUCATIONAL TRANSFORMATION}

Bids relating to 62 classrooms (with funding from BADEA)

- 23 upper secondary schools are equipped with scientific equipment and libraries.

\section{Training of teachers:}

- A hundred and twenty (120) upper secondary school headmasters have been trained and are introduced to the project implementation process as part of capacity building.

Concerning vocational training, specialized job-qualifying trainings are being developed:

- 137 institutions (public and private) are involved in specialized vocational training.

- 1,365 degrees/certificates of training completion have been issued.

\section{Higher Education and Research}

Number of Students per 100,000 inhabitants/ Annual graduates of Higher education

In 2007, there were 292 students per 100,000 inhabitants. In 2008, this figure increased to 350 while the objective was 323 .

In 2007, the number of higher education graduates reached 6,568 . The rate for this is not available yet for 2008

Activities were conducted in collaboration with partners during the 6 first months of year 2008. These actions include:

Shifting to the international LMD system:

- Issuance of the Decree on LMD;

- Setting up of the Cyber-U at the University of Antananarivo;

- Development of 10,000 booklets and brochures on LMD with support from MADES;
- Equipment of 02 laboratories for the Pharmacy subjects (in collaboration with the Mérieux Foundation);

- Recruitment of 47 Lecturers and 5 Assistants;

- Setting up of the accreditation system with support from PIC;

- Modernization of the management of universities through the SCOLARIX application and creation of the IT work group from the 6 universities.

Training of Researcher teachers and high-ranking technicians:

- Official graduation of 32 Veterinary Doctors and 32 Medical Associate Professors.

Rate of perception of socio-economic and cultural development actors regarding the research and innovation works

In the field of scientific research, activities are oriented so as to support rural development, nutritional research, and in situ conservation of species.

For this first term, achievements include:

- The production of 29 tons of pre-basic and basic improved seeds (rice, legumes, corn, Lima beans, etc.);

- Production of 40,000 young fish and 2,300 cuttings of cassava;

- Production of 11 series of vaccines of 3,006,968 doses;

- Training of 31 Higher Technicians on Radioprotection;

- Laboratory trials using local industrial processes, products, and materials (volcanic fertilizers, jatropha biodiesel, bio-tany, etc.) under way;

Study of 7 medicinal plants under pharmaceutical research.

Regarding the establishment of the national research policy, the inventory has been undertaken by a group of national and international experts.

\section{Number of literacy educated people}

The first draft National Strategy was developed during this first term 2008. This paper defines the national strategy to take literacy education to scale, with a procedure manual on how to conduct literacy campaigns.

The partial results obtained regarding literacy education of children who do not attend school and/or dropped out of school as part of the EPT plan using the ASAMA method are still poor (20\%). The number of targeted children who actually attended literacy education amounts to 1,250 , while the objective is set at 6,000.

Although the result obtained is poor, the development of partnerships with NGOs and public institutions, is worth mentioning, namely with the Regions, the PPRR, and the $\mathrm{BFV}$, as well as with International Organizations such as UNESCO and OIF (Organisation Internationale Francophone).

The Literacy Education Program developed for youth and adults aged 15 on having reading difficulties recorded a good performance. The actual performance during the first term amounts to $65 \%$ of the objective for the year, i.e., 11,120 adults enrolled in literacy programs out of the 17,000 planned.

\section{Budget allocated to the Education Sector}

During the first 6 months, the percentage of commitments in the education sector reached $52.5 \%$ (domestic financing for investment and operation).

Higher education received a significant percentage of commitments, after student bursaries were paid in due time. 


\section{IMPLEMENTATION OF THE MAP: EDUCATIONAL TRANSFORMATION}

As for primary and secondary education, slowness was noted in the execution of certain projects, such as the Primary and Secondary Education (OPEP), Education III (FAD Group), Support to Schools Damaged by Cyclones, Support to General Education (BADEA).

If works are started late, the impetus generated may not suffice to improve the educational system's coverage and domestic effectiveness.

\section{RECOMMENDATIONS}

- Reinforce the improvement of the availability, quality, and reliability of MEN data statistics;

- Based on the indicators defined in the SNISE, conduct work for standardizing the indicators of the education sector in close collaboration with INSTAT for the reliability of the produced statistic information;

- Equip local communities (Head of fokontany, Parents' Associations, etc.) with transportation means to control and monitor teacher attendance;

- Equip decentralized services workers with awarenessraising staff/material;

- Reinforce resources given to decentralized services (computers for data entry, servers) to facilitate data collection;

- Accelerate the setting up of General Treasuries, CIRFIN (Financial Division), Financial Controls in Regions where this has not yet been done, in order to facilitate the payment of teachers;

- Reinforce periodic monitoring of achievements at the 22 DREN level.

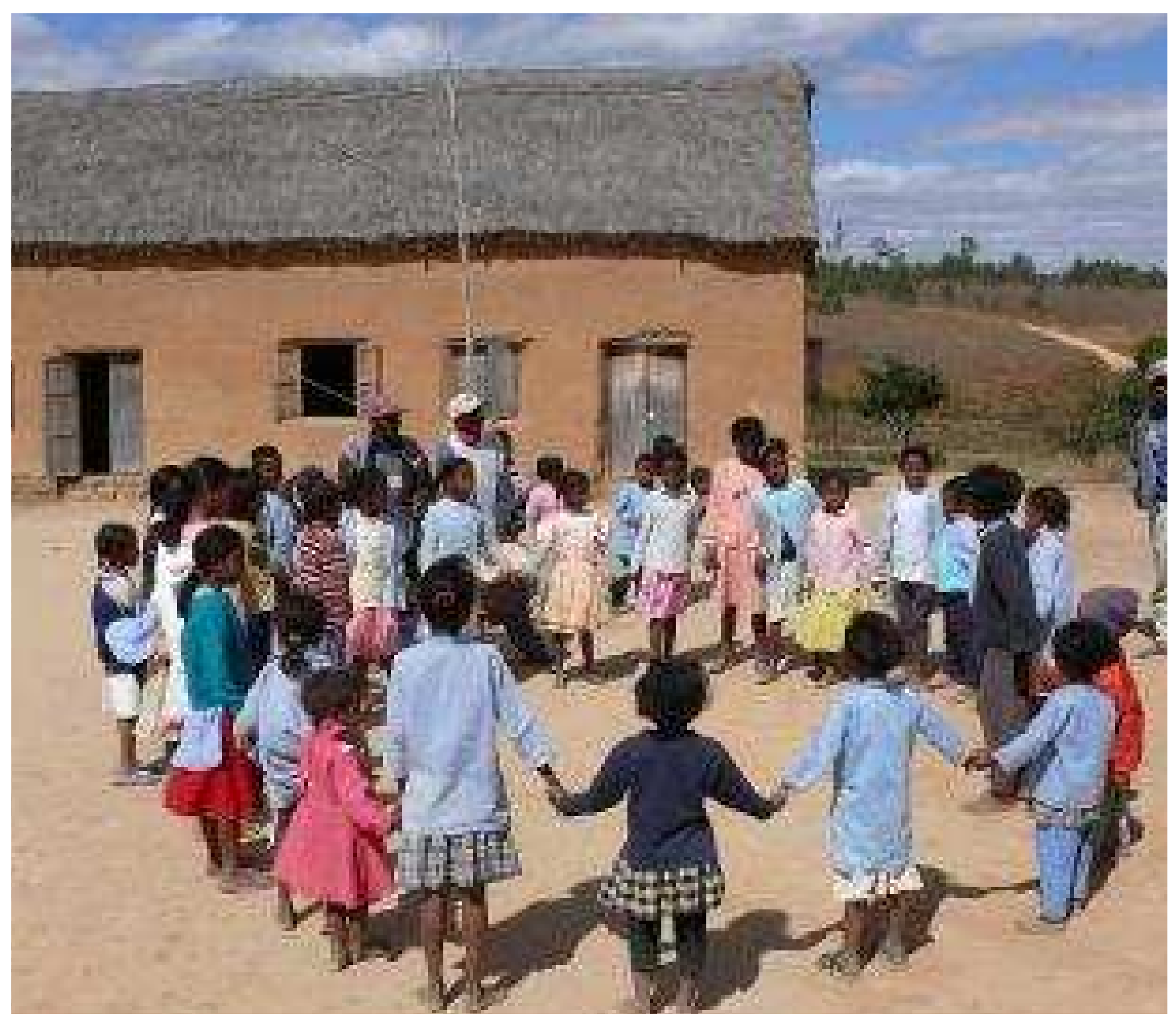




\section{IMPLEMENTATION OF THE MAP: RURAL DEVELOPMENT}

\section{COMMITMENT 4: RuRAL DeVELOPMENT}

\section{FOLLOW UP OF THE RECOMMENDATIONS MADE IN 2007}

\begin{tabular}{|c|c|c|}
\hline Recommendations made in 2007 & Progress status during $1^{\text {st }}$ semester of 2008 & Observations \\
\hline $\begin{array}{l}\text { Review and set higher all expectations relating to the priority indicators of the MAP } \\
\text { implementation monitoring }\end{array}$ & $\begin{array}{l}\text { MAEP cannot revise and set higher expectations relating to the priority indicators of } \\
\text { the MAP's implementation monitoring }\end{array}$ & \\
\hline $\begin{array}{l}\text { Train trainers on hygiene standards, legislative texts on animal health, regulatory texts on } \\
\text { cage and enclosure breeding, and the strategy for the development of fish farming }\end{array}$ & $\begin{array}{l}\text { Missions of animal health supervision and monitoring were conducted in the } 22 \\
\text { Regions; in addition, IBRSAV (Regional Office of Animal and Plant Health) were } \\
\text { sensitized on the Rift Valley fever and hygiene conditions of animal food products }\end{array}$ & \\
\hline Raise the butchers' awareness on hygiene standards in slaughterhouses and in meat stalls & $\begin{array}{l}\text { - Awareness-raising on hygiene standards in meat stalls for the } 22 \text { Regions is } \\
\text { completed }\end{array}$ & \\
\hline & $\begin{array}{l}25 \text { slaughterhouses visited and awareness-raising conducted in contaminated areas } \\
\text { to protect them from the Rift Valley fever }\end{array}$ & \\
\hline Facilitate the establishment of associations of: fishers, fish farmers, breeders, farmers, etc. & $\begin{array}{l}\text { Training on fishing techniques, security at sea, and the conservation and } \\
\text { transformation of fish products provided to fishers of Menabe, DIANA, SAVA, SOFIA, } \\
\text { and the Bay of Antongil }\end{array}$ & \\
\hline $\begin{array}{l}\text { Facilitate the acquisition of the equipment necessary to the establishment of cage and } \\
\text { enclosure breeding and the creation of traditional fishers' or small and medium fish farmers' } \\
\text { associations }\end{array}$ & $\begin{array}{l}\text { Information trainings were given to leaders of farmers' organizations, to the MAEP, } \\
\text { and to NGOs to facilitate the establishment of associations }\end{array}$ & \\
\hline
\end{tabular}

Information on the following recommendations is not available:

- Promote the emergence of young rural entrepreneurs (medium farmers);

- Actively research funding with financial partners to build the capacities of the MAEP;

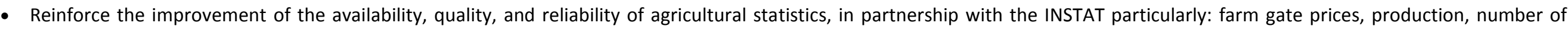
associations, etc.

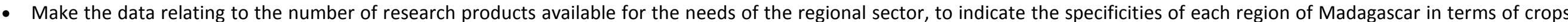
(emphasis on the "value chain" principle). 


\section{IMPLEMENTATION OF THE MAP: RURAL DEVELOPMENT}

\section{ANALYSIS OF PRIORITY INDICATORS}

The Agriculture Sector Program was developed in March 2008, and mobilizes all stakeholders, in particular the Technical and Financial Partners.

\section{Increase in the proportion of secured surface area}

The issuance of land certificates was somewhat disturbed during the first term 2008. First, the applicants' payment capacities decreased as a result of the lean period which particularly affected the Communes hit by cyclones in February. Then, the election of new mayors delayed the formalization of the authority of the commune that would sign and deliver land certificates. The following results were nevertheless obtained, as part of the implementation of Land Security activities:

- $8,403 \mathrm{Ha}$ of surface area secured against an objective of $13,156 \mathrm{Ha}$ that is, $64 \%$ of the objective

- 43 land offices (including 19 by MCA) set up and operational against the 260 ones planned, which amounts to a completion rate of $16.50 \%$

- 3,937 land certificates established by MCA NLP against an objective of 5,060, which amounts to a completion rate of $78 \%$; the MAEP plans for the establishment of 30,000 certificates

- 5,674 land titles delivered out of 10,000 planned that is, $64 \%$ of the objective

- 10 land services modernized (digitizing and restoration of land documents with allocations of equipment to land services) out of the 10 planned ones that is, $100 \%$ of the objective

- 92 PLOFs (Local Land Occupation Plan) developed against an expectation of 258 PLOFs, which amounts to a completion rate of $36 \%$ (the development of PLOFs is under way for the remaining land offices).
Increase in the penetration rate of financial
institutions

The geographical spread and development of MFI networks suggest a promising Microfinance penetration rate: the objective of $10 \%$ is $92.50 \%$ achieved with a mid-term rate reaching $9.25 \%$. Members are now 370,000 in number against an objective of 500,000 , which amounts to a completion rate of $74 \%$. Non-mutual Institutions record numerous memberships. MFIs are not yet present is some districts because of their remoteness and their lack of appropriate infrastructures for the development of MFIs. Still, the coverage rate over the national territory as a whole reaches $70.43 \%$ ( 81 districts out of 115 are covered).

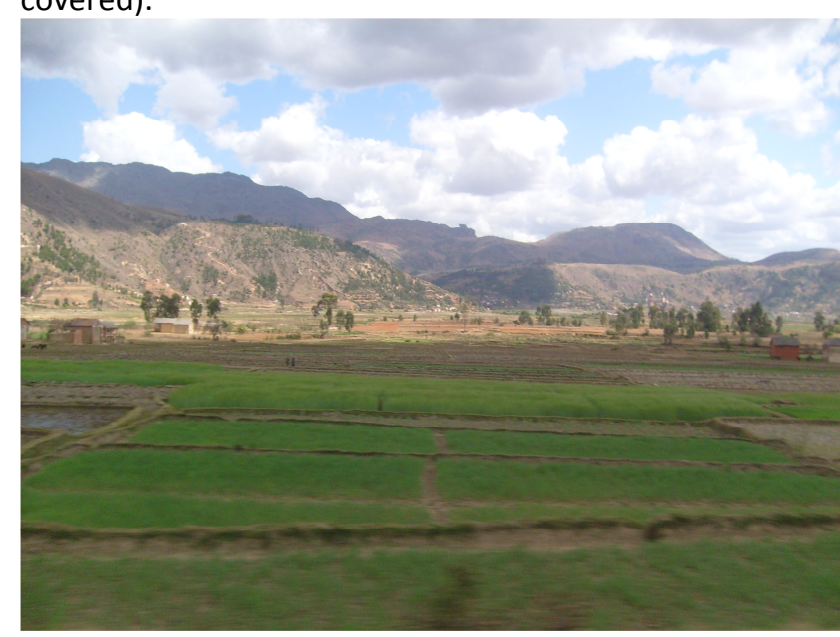

As part of the development of financial institutions in the rural world, the activities undertaken at the MAEP level include:

- An Institutional Support Fund of Ariary 1,700,000 established (OTIV Tana, OTIV Toamasina, CECAM AECA Marovoay) that is, $100 \%$ of the objective;
- A Guarantee and Refinancing Fund of USD 3 millions established by MCA, that is $100 \%$ of the objective of the MAEP amounting to Ariary $6,800,000,000$;

- 1 zone newly covered by the MFIs' network (Toamasina 2) out of the 2 planned, which amounts to a completion rate of $50 \%$;

- 6 MFIs reinforced (OTIV Tana - VakinankaratraAmoron'i Mania - Toamasina -CECAM - AECA Marovoay), the objective set is fully achieved;

- 8 new banks created out of the 8 planned, the objective is $100 \%$ achieved;

- Outstanding credit of Ariary 1,125 million invested in the agricultural sector against an objective of Ariary 1,200 million, which amounts to a completion rate of $93 \%$

\section{Use of agricultural inputs and development works}

The mainstays of the Green Revolution are reinforced by the performance of the following activities:

- Intensification of the use of agricultural inputs: the quantities of fertilizers imported amount to 13,422 tons against the objective of $19,700 \mathrm{~T}$ and the basic seeds used to 409T (off-season crops), including 26 tons of imported seeds (garden, corn, and potato) against an objective of $8000 T$;

- Training and support of 1,249 farmers' associations against plans of 910;

- Training of 13 regional inspectors to control seeds (completion rate: $100 \%$ );

- Development works which generated $17,800 \mathrm{Ha}$ of surface areas of good water mastery against plans of $120,000 \mathrm{Ha}$ that is, $14.83 \%$ of the objective; 


\section{IMPLEMENTATION OF THE MAP: RURAL DEVELOPMENT}

- Increased number of operational Water Users' Associations to 312 .

\section{Food Security}

In order to mitigate the impact of the international food crisis on the population and on account of the demand pressure and the scarcity of supply due to the stagnating crops and the moratorium to export decided by some countries, the Government has urged the intensification of off season cropping in order to diversify and increase the agricultural production. Off season cropping was launched in the Diana Region in June 2008. The objectives of the program are to double production in 2009, to triple it in 2012 , by urging farmers to change their mindset and adopt modern high yield SRI and SRA cropping and substitution cropping such as cassava, sorghum... Therefore, out of a surface area of $49,407 \mathrm{Ha}$ requested by the 22 Regional Directorates for Rural Development 30,588 Ha have been used for such cropping, and 178 tons of seeds were purchased out of the 672 ton quotas.

\section{Diversification of rural household income sources}

As regards the diversification of the agricultural production, results are as follows:

- concerning the development of innovative farming crops, 31,000 sets of banana are produced, 36,000 disseminated, and péjibaye and pineapple have been established and planted;

- the cattle vaccination rate currently amounts to $42 \%$ against an objective of $80 \%$;

- the production of fisheries resources amounts to $43,877 \mathrm{~T}$, while the objective is $150,000 \mathrm{~T}$ (the passage of cyclones during the first term did not help);

- 166 fishers out of the 200 ones planned, received training (fishing techniques, security at sea, conservation and transformation of fishing products, management of Lake Kimanomby, and rules to enforce), which amounts to a completion rate of $83 \%$;

- 404 farmer groupings out of the 461 ones planned, were set up by the ABIP-MCA Project, i.e., $87.63 \%$ of the objective;

- 7 Market Access Centers (CAM) were set up and became operational: the objective is $100 \%$ achieved (Fénérive-Est: Ampasina Maningory, Vohilengo, Ampasimbe Manantsatrana; Vavatenina: Ampasimazava, Anjahambe, Soanierana Ivongo; Manompana);

- 17 Agricultural Service Centers (CSA), 13 of which are operational, are established out of the 50 ones planned, i.e., a $34 \%$ completion rate;

- 6 ABCs out of the 12 ones planned are set up (Vakinankaratra, Amoron'i Mania, Menabe, Atsinanana, Boeny, Diana), i.e., $50 \%$ of the objective.

\section{Graph 7 : Evolution in yearly rice production}

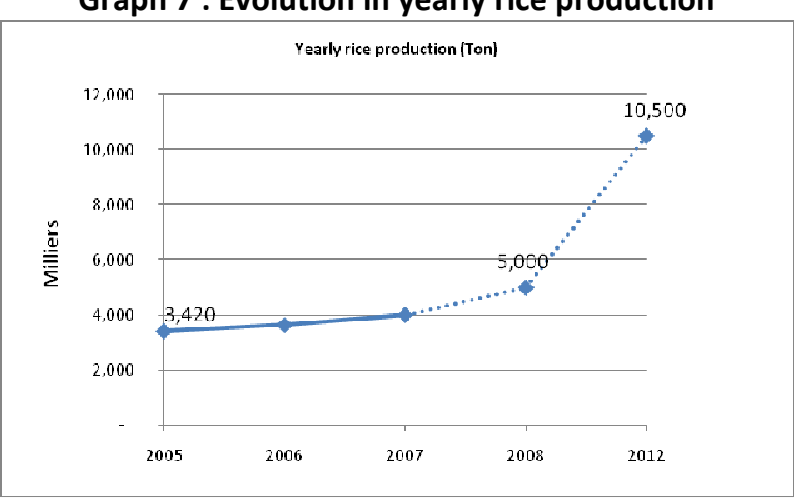

Source : MAEP

CONTRIBUTION OF PROGRAMS AND PROJECTS

National Land Program

- 43 Land Offices set up and operational,
- 5,674 land titles established,

- 3,235 land certificates established.

For MCA-Madagascar Program (Millennium Challenge Account)

- Support to land administration for the modernization of land services and the delivery of land certificates;

- $2,078 \mathrm{Ha}$ certified through the setting up of land offices;

- 5,243 agricultural farmers and companies received technical assistance;

- 83 agricultural farmers and companies use the technical assistance received;

- 1,051 Business Plans developed

- $19 \mathrm{ABC}$ clients received a bill of sale

- 4,193 saving accounts in the zones;

- Outstanding loans of USD1,869,286 of saving accounts in the zones

- Guarantee and refinancing fund established: US\$3 million ( $100 \%$ of the objective);

- 8 new funds out of the 8 planned created.

ABIP Project (MCA)

Close supervision of producer farmers by $A B C s$ regarding the respect of technical routes: Rice yield $3.47 \mathrm{Tons} / \mathrm{Ha}$, which amounts to $125 \%$ of the objective

$(2.78 \mathrm{~T} / \mathrm{Ha})$;

- Development of new value chains: 6 out of 6 , that is $100 \%$ of the objective;

- Setting up of associations: 404 out of 461 , that is $88 \%$ of the objective;

- Outstanding credit invested in the agricultural sector: Ariary 1, 125 million, i.e., 93\% of the objective. 


\section{IMPLEMENTATION OF THE MAP: RURAL DEVELOPMENT}

Inclusive Finance Program - MAG 60931 and AGEPMF Microfinance Project

- Institutional support;

- Improvement of the management of MFIs;

- Promotion of an increased and viable offer of microfinance products and services suiting the needs of the target groups in high-density zones;

Support Service to Agricultural Service Centers (CSAs)

- Setting up of 17 CSA

Boosting of the Agricultural Production

- 400 tons of biological fertilizers acquired

- 5 Workshops held for the launching of off-season crops 2008: Atsinanana, Analanjirofo, DIANA, Vakinankaratra, Amoron'i Mania.

Boosting of agricultural exports

- Production and dissemination of 31,000 and 36,000 sets of banana;

- 50 ha surface area for producing controlled seeds

- Design of new ranges of products: semi-crystallized products, jams, chips;

- 4,500 in-vitro plants of bananas resistant to black cercosporiosis and 5,000 in-vitro plants of Plantain banana produced.

Rehabilitation of the Perimeter of Lower Mangoky

- Reconstruction of a 40 linear meter long dyke and clearing of $68 \mathrm{Km}$ of drains;

- Rehabilitation of $140 \mathrm{Km}$ of concrete irrigation channels and 294 hydro-mechanic pieces of equipment.

Valorization of the Basin of Upper Mandrare Project -

Phase II

- equipping the inter commune land office and the ASC of Tsivony so that it becomes operational
- and development of $71 \mathrm{Ha}$ of irrigated microperimeters so that they become operational

- community reforestation of $63 \mathrm{Ha}$

Watershed Irrigated Perimeter Program

- 4 CSAs set up

- 163 farmers' associations and organizations trained and supported

- $1,900 \mathrm{Ha}$ of good water control surface areas Identification of 06 Communes for implementing land security actions.

Graph 8 : Evolution in yearly production of halieutic resources

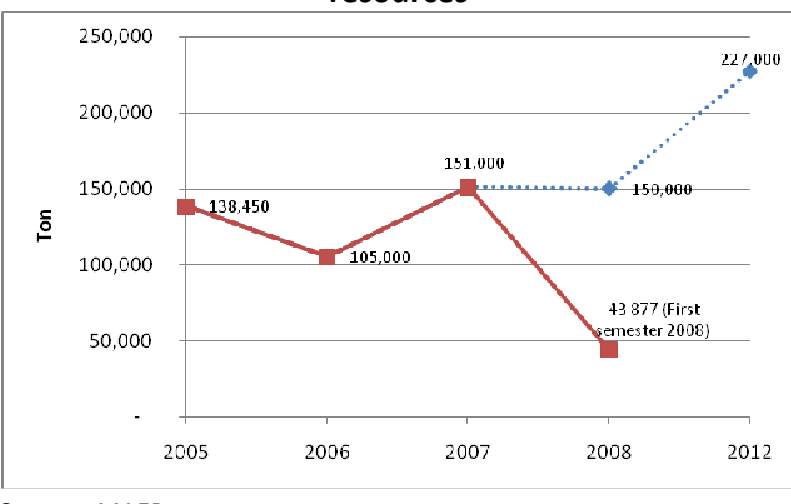

Source : MAEP

Rural Development Support Project

- Reception of 68 sub-projects of productive infrastructures, 643 sub-projects of agricultura activities, 14 sub-projects of non-agricultural activities

- Reinforcement of 3,470 farmers on sub-projects

Rural Income Promotion Program (PPRR)

- 4 infrastructure complexes of MAC built and equipped

- Rehabilitation/rebuilding/enhancing of $18.40 \mathrm{Km}$ of protective dams
- Demarcation of a 5,698Ha surface area as part of land security and establishment of 5,032 land titles

FIFAMANOR Support Project

- 29,512 potato pre-basic seeds produced

- 137.9T of potato basic seeds produced in station

- 16T of wheat basic seeds produced in station

- 3,013 cows and heifers covered and/or inseminated Anti Erosion Project

- Training, awareness raising, and mobilization among farmers in the intervention sites on the importance of anti-erosion (workshops, field visits, supervising farmers for land management techniques)

- Protection of erosion sites peripheral to canals and rice fields by establishing fascines, tree plantations and other means to fight erosion.

\section{Anti Locust}

- 2007 - 2008 infestation campaign: about 75,000 Ha

- 23 anti locust posts established and operational

The projects "Support to the fishers' communities of Toliara, Development and promotion of aquaculture, Surveillance of fishing of the Malagasy Plateau and continental talus, Shrimp resources management program, Fisheries health authority" contributed to:

- the capacity building of fishers,

- the environmental education campaign

- the production of 4,051,154 post larvae of shrimp and 28,000 young fish of Tilapia accessible to fish farmers

- the conducting of sea, air, land, and satellite surveillance: 87 days of surveillance by ship, 266 days of surveillance by mobile brigades, $40 \mathrm{~h} 35 \mathrm{mn}$ of surveillance by air 


\section{IMPLEMENTATION OF THE MAP: RURAL DEVELOPMENT}

- the drawing up of health products devoted for export

\section{RECOMMENDATIONS}

- Reinforce assets in information collection;

- Develop communication under Public-Private Partnership;

- Regarding mildew which continues to undermine potatoes, replace the farmers' seeds with seeds that are free of the disease, cultivate varieties that are resistant to the disease, treat crops;

- Sensitize livestock breeders on the importance of IA (genetic and health aspect, viability to service, and technical training);

- The improvement of the penetration rate of MFIs and the increase in density of the geographical coverage are partially linked to the remoteness of the zone not yet serviced. Actions in this direction should therefore be taken to achieve the objective;

- Increase studies of the micro-finance needs in areas not yet serviced, as these are a prerequisite to setting up new MFIs and to assessing and anticipating their viability.

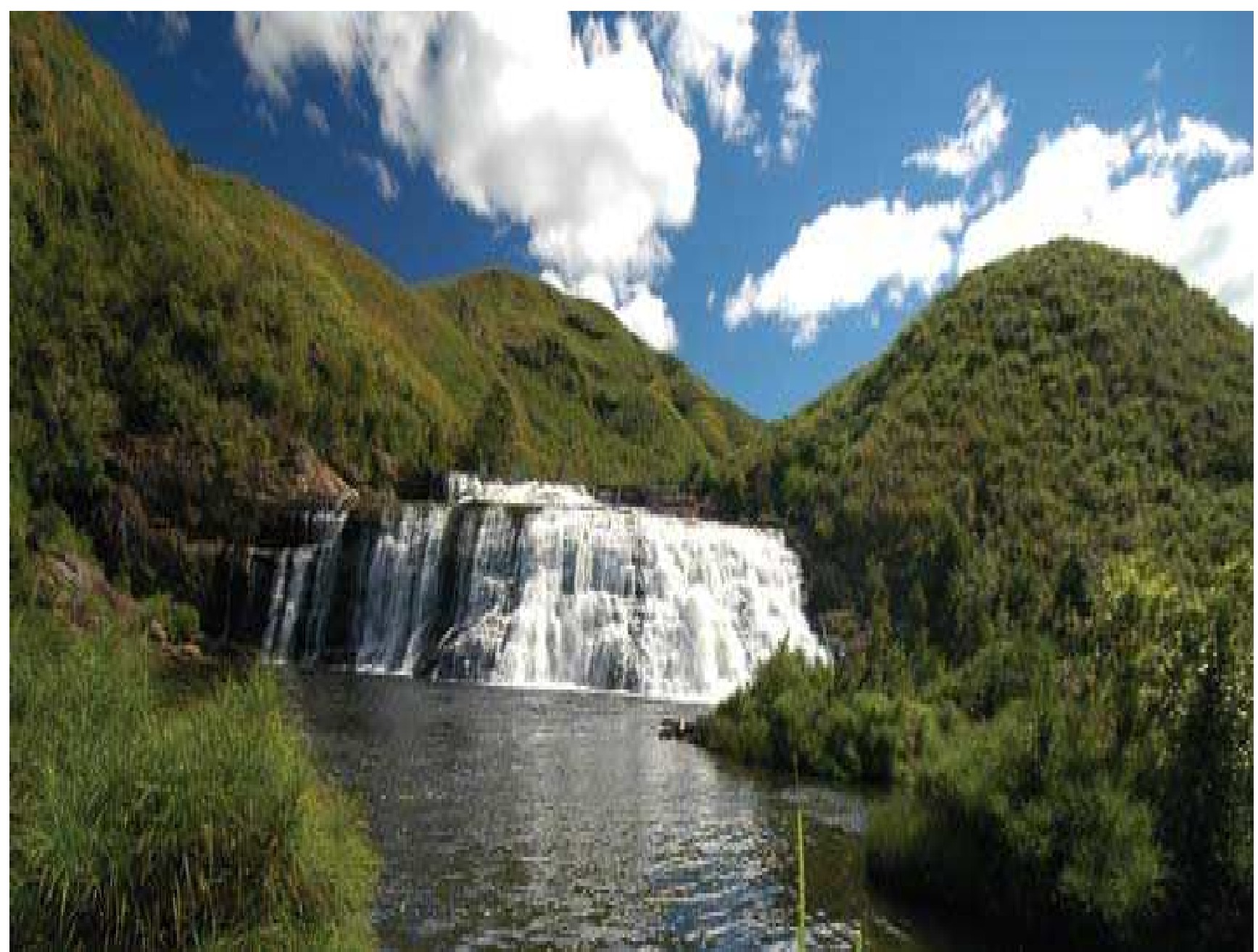


IMPLEMENTATION OF THE MAP: HEALTH, FAMILY PLANNING, AND THE FIGHT AGAINST HIV/AIDS

\section{Commitment 5: Health, Family Planning, and the Fight against HiV/AIDS}

Follow Up Of the Recommendations MAde In 2007

Recommendations made in 2007

Use the National Strategic Scheme as reference for the development of Regional schemes for fighting HIV/AIDS

Reinforce effective collaboration between SE/CNLS, the MoHFPSA, and partners as part of

STI/HIV/AIDS programs
Progress status as of the $\mathbf{1}^{\text {st }}$ semester of 2008

Sharing the PSN document among regions, developing the PSN
framework document for regional planning starting from the yea
2009 , and regional support in developing action plans in som
regions for the year 2008.
Convention of partnership between MoHFPSA and SE/CNLS signed in 2008,
Management Technical Committee set up at the Regional level

Observations

Sharing missions at regional

level on regional planning process are scheduled to prepare the 2009 planning 


\section{ANALYSIS OF PRIORITY INDICATORS}

Efforts initiated in year 2007 were sustained, especially regarding the allocation of medicines and supplies, the vaccine supply, and the control of communicable diseases.

Achievements are expressed by the levels of the following indicators:

Rate of use of outpatient visits in Basic Health Centers exceeding the average objective set for 2008

Table 10 : Rate of use of outpatient visits in Basic Health

\begin{tabular}{|l|r|r|r|r|r|}
\hline \multirow{2}{*}{$\begin{array}{l}\text { Indicator } \\
\text { Name }\end{array}$} & 2006 & 2007 & \multicolumn{2}{|c|}{2008} & 2012 \\
\cline { 4 - 6 } & & Objective & $\begin{array}{c}\text { 1st semester } \\
\text { Achievement }\end{array}$ & SNISE Objective \\
\hline $\begin{array}{l}\text { Rate of Use } \\
\text { of CSB } \\
\text { Outpatient } \\
\text { Consultations }\end{array}$ & 38.8 & 42.30 & $51 \%$ & $30.30 \%$ & 70 \\
\hline
\end{tabular}

The rate of CSB "outpatient" visits amounts to $30.3 \%$ against a 2008 objective set at $51 \%$ (that is, $59.4 \%$ of the objective). This performance is owed to the building/rehabilitation and equipment of CSBs, the setting up of a monitoring system, the recruitment and deployment of medical staff, and the allocation of medicines and quality supplies.

Building/rehabilitation and equipment of CSBs

- 37 CSB are built; 13 rehabilitated out of the 40 ones planned (completion rate: $42.5 \%$ ) and other CSB are being built or rehabilitated;

- $50 \%$ of the 40 equipment acquisition procedures are under way;

- Emergency triage being built at Ikongo and in Fenoarivo Be (achieved at 50\%)

- 7 CHRR out of the 10 ones planned (completion rate: $70 \%$ ) have an operational equity funds.
Availability of qualified, motivated, and equitably distributed staff, especially in CSBs and priority zones

- 45 female paramedical staff recruited and deployed in CSBs and in CSD maternity wards.

\section{Setting up of a Monitoring system}

- 96 Health Districts out of the 111 ones planned (completion rate: $86.49 \%$ ), have an operational monitoring system.

Allocation of quality pharmaceutical products and supplies:

The activity is enlarged to remote CSBs of the rural world Globally speaking, objectives are $99 \%$ completed.

-

- Essential drugs are available at a $95.7 \%$ rate

04 teaching hospitals, 16 CSBs, and 111 District health services equipped with medicines, quality perfusion liquid, consumable reagents, which amounts to $100 \%$ of the objective

- 07 Regions (Bongolava, Itasy, Haute matsiatra, Ihorombe, Alaotra Mangoro, Antsinanana, and Atsimo Andrefana) out of 06 planned ones have introduced the Improved Traditional Medicine at the Health Center level (318 /370 CSB).

Elimination of communicable diseases, including Malaria and Tuberculosis

\section{Malaria incidence at the CSB level:}

The malaria incidence rate at the $\mathrm{BHC}$ level decreased to $6 \%$ during the first term 2008, against an objective of $5 \%$ (completion rate: $83 \%$ ) thanks to reinforcement Indoor Residual Spraying (IRSC) preventive actions on high land or unstable area and MID (Long Lasting Insecticide Treated Nets) on stable areas (desert areas, coastal areas) :
- 300,000 households have been protected

- 92 Districts out of 92 planned ones have also applied Malaria Intermittent Preventive Treatment (IPT) among pregnant women.

\begin{tabular}{|l|r|r|r|r|r|}
\multicolumn{7}{|c|}{ Table 11 : Statistics of Malaria } \\
\hline \multirow{2}{*}{$\begin{array}{l}\text { Indicator } \\
\text { Name }\end{array}$} & 2006 & 2007 & \multicolumn{2}{|c|}{2008} & \multicolumn{2}{|c|}{2012} \\
\cline { 3 - 6 } & Objective & $\begin{array}{r}\text { 1st semester } \\
\text { Achievement }\end{array}$ & SNISE Objective \\
\hline $\begin{array}{l}\text { Malaria } \\
\text { incidence } \\
\text { rate at CSB } \\
\text { level }\end{array}$ & 17.6 & $7 \%$ & $5 \%$ & $6 \%$ & $1 \%$ \\
\hline $\begin{array}{l}\text { Malaria } \\
\text { mortality } \\
\text { rate in } \\
\text { hospital } \\
\text { environment }\end{array}$ & $17.50 \%$ & $13.90 \%$ & $13 \%$ & $8.85 \%$ & \\
\hline
\end{tabular}

Graph 9 : The malaria incidence rate - The mortality rate associated with malaria

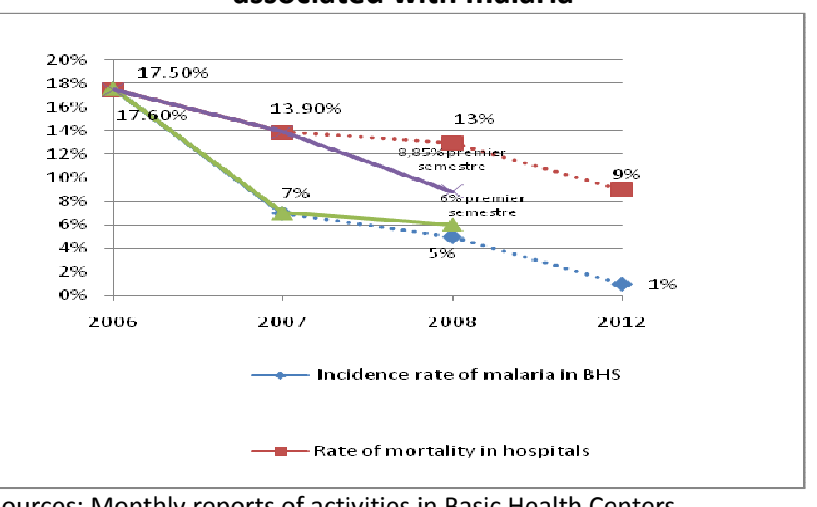

Sources: Monthly reports of activities in Basic Health Centers

Mortality rate associated with malaria in hospitals

The mortality rate associated with malaria in hospitals amounts to $8.85 \%$ against an expected rate of $13 \%$ (completion rate: $146.89 \%$ ). This good performance derives from: 
Among others, the availability of antimalarials such as ACT/RDT at the level of Health Centers and to staff training

\section{Tuberculosis:}

Satisfactory results regarding the rate of incidence of tuberculosis

The rate of curing from bacilliferous tuberculosis amounts to $80 \%$ against an objective of $82 \%$ following the application of a community based treatment of the disease with the community's participation:

- 1,509 people sick with TB out of the 2,500 planned ones; i.e., $65.36 \%$, are motivated by subsidies;

- $46 / 90$ providers are trained on the management of tuberculosis cases; i.e., $51 \%$.

Control and elimination of other endemic and epidemic diseases: these diseases have lately been of concern. They include plague, sarcopsyllosis, schistosomiasis, and filariasis.

- Lethality rate of plague: the rate decreased to $11 \%$ during the 1st term against an expected rate of $9 \%$ (completion rate: $89 \%$ ), owing to the allocation of kits in 21 Districts that are seats of plague against the 41 Districts planned (completion rate: $51.22 \%$ );

- 14 Districts out of 50 planned ones benefited from the punch operation against the epidemic of flea or sarcopsyllosis (completion rate: $26 \%$ );

- 500,000 against an objective of 100,000 , children in school age $(50 \%)$ in the 19 Districts out of the 21 ones were treated during mass distribution campaigns of free anti-schistosomiasis medicines;
- 17 Districts out of the 29 planned ones (completion rate: $58.62 \%$ ) benefited from a free anti-filariasis medicine distribution campaign;

- 09 Regions at risk out of the 9 ones planned benefited from the pre-positioning of emergency kits for endemic and epidemic diseases in the event of disasters

\section{Fight against HIV/AIDS}

The actions are hinged on the decentralization of the fight; the integration of HIV/AIDS prevention programs in national, regional, and local development programs and schemes; the setting up of screening centers; the management of PLHIVs' treatments and follow-up; making condoms available to youth aged 15 to 24; the communication strategy, and the capacity building of health workers.

The major indicators that reflect the situation, the trend, and the actions of the fight against HIV/AIDS include:

The prevalence of HIV among pregnant women which requires major investigation. However, the results of actions conducted allowed for uncovering the trend in prevalence.

- 31 Voluntary Counseling and Tests (VCT), 15 (CDT/CTV),, and 630 Mother-to-Child Transmission prevention sites et 630 sites for Mother To Child Transmission Prevention (PTME) are operational out of the 750 planned ones (completion rate: $90.13 \%$ );

- The percentage of people under ARV treatment who are alive 12 months after the start of the treatment is $56.84 \%$ against an objective of $95 \%$

- 104 Districts conducted at least one awareness-raising on HIV/AIDS prevention, accounting for a $94 \%$ achievement for all Regions.
The decentralization of the fight against HIV/AIDS is one of the strategies used to stimulate local response to STIs and HIV/AIDS.

A rate of involvement in the decentralization of the response estimated at $18 \%$ for the 1 st term, against an objective of $36 \%$ (i.e., $50 \%$ ).

In this respect, several actions were taken, including the allocation of physical and financial resources to the 22 Regions for the implementation and monitoring of regional schemes; support from Regions in the development of action plans : 5 plans out of 8 intended ones have been developed; regarding the development of local plans for fighting AIDS, 816 local plans, in all, out of 1,113 intended ones have been developed, (respectively i.e., $100 \%, 63.8 \%$, and $73.3 \%$ of objectives for the year 2008).

Rate of condom use among youth aged 15 to 24

Various activities were undertaken to achieve a condom rate of use of $25 \%$ among men and $10 \%$ among women:

- 6,349,044 condoms have been distributed against the objective of $17,500,000$ (i.e., $36 \%$ ); centers were out of Fimailo stock in the first semester. Nevertheless there has been an order for 15,000,000 Fimailo; the batch will be delivered in the course of the second semester of 2008.

Rate of use of screening centers (available only at the end of the year)

Activities conducted include:

- Training of 44 health workers at regional level, and will thereafter be in charge of training at the level of Districts ; it is a cascade training to reach the objective of 600 people trained

- Training of 20 physicians on sydenology, against and objective of 10 (i.e., 200\%);

- 105,439 people screened against an objective of 400,000 (completion rate: $26 \%$ ). Stock-outs of reagents were however reported in some health facilities. 


\section{Family Planning}

Table 12 : The contraceptive coverage rate

\begin{tabular}{|l|r|r|r|r|r|}
\hline \multirow{2}{*}{ Indicator Name } & 2006 & 2007 & \multicolumn{2}{|c|}{2008} & \multicolumn{2}{|c|}{2012} \\
\cline { 4 - 6 } & & & Objective & $\begin{array}{c}\text { 1st semester } \\
\text { Achievement }\end{array}$ & $\begin{array}{c}\text { SNISE } \\
\text { Objective }\end{array}$ \\
\hline $\begin{array}{l}\text { Contraception } \\
\text { coverage rate }\end{array}$ & $12 \%$ & $18 \%$ & $19 \%$ & $17.14 \%$ & $25 \%$ \\
\hline
\end{tabular}

The contraceptive coverage rate

The contraceptive coverage rate is $17.14 \%$ (situation as of $1^{\text {er }}$ quarter of 2008) against an objective of $19 \%$. The activities performed to increase the contraceptive coverage rate for a reduced average size of Malagasy families relate to what follows: FP site multiplication, FP extension, use of several contraceptive ranges, sensitization in Adolescent Reproductive Health (SRA) and Domiciliary Visits by Community Health Workers.

$100 \%$ of the Districts have at least one site offering one Long-Term Method LTM/Implanon;

- 319/810 upper and lower secondary schools have been sensitized in SRA, (i.e., 39.4\%); boosting is planned for the coming school year for a $50 \%$ achievement.

\section{Setting up of $I M C l$ sites}

\section{Setting up of $\mathrm{IMCl}$ sites}

- $11 \%$ of the Communes planned ones have $\mathrm{IMCl}$ sites against the objective of $25 \%$ for year 2008 (completion rate: $44 \%$ );

- 33 Districts out of the 55 ones (60\%) have introduced zinc/ORS in the management of diarrhea Immunization.

\section{Satisfactory DTPHep B3, B.C.G., and measles} immunization coverage rates

The DTPHep B3 immunization coverage rate is $59.5 \%$ against an annual objective of $85 \% 2008$ has been achieved at $70 \%$ right from the first semester of the year) ;

The BCG immunization coverage rate is $70.4 \%$ out of an annual objective of $97 \%$ i.e., $72.57 \%$ during the 1 st semester

The measles immunization coverage rate is $67 \%$ against an annual objective of $90 \%$, (annual objective achieved at $74.66 \%$ in the course of the 1st semester)

The following activities were carried out to achieve these results:

- Construction of cold chain installation in several regions

- Implementation of the micro-plan developed under way, in Districts of poor coverage and therefore subject to Reach Each District (ACD) ;

- $100 \%$ of the Districts are supplied with vaccines and injection equipment.

If the current trends are maintained, the objectives set for 2012 will no doubt be achieved.

Graph 10 : The DTPHep B3 immunization coverage rate

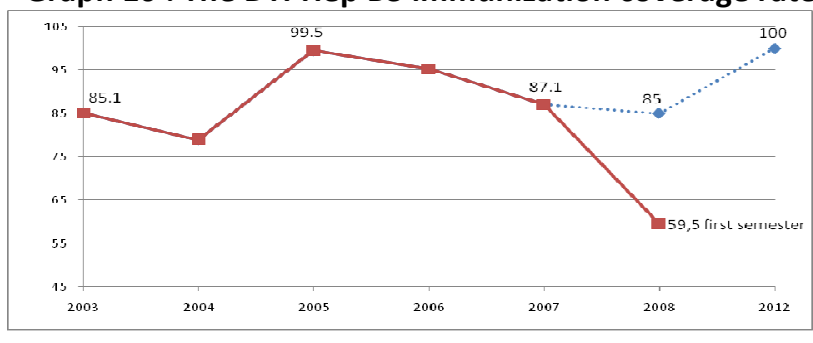

Source : MINSANPFPS

Reduction of neonatal mortality (MDG)

The maternal mortality rate for 100,000 Live Births (LB) and the neonatal mortality rate for 1,000 living births are not yet available. Trends can be derived from the level of the intermediate indicators obtained from the activities conducted at all levels to increase the use of emergency obstetrical and neonatal care.

- The assisted delivery rate in CSB and CHD is $18,5 \%$ against an annual objective of $27.2 \%$ (i.e., $68,01 \%$ );

- The Prenatal visit coverage rate is $\mathbf{5 3 . 3 \%}$ against an annual objective of $74 \%$, (i.e., $72.03 \%$ );

Various activities were conducted to achieve these results:

- The 22 Regions were equipped with 596,00 free individual delivery kits and 72 CSB with Basic Emergency Obstetrical and Neonatal Care Kits (SONUB), (objectives for year 2008 were achieved at $65 \%$ during this $1^{\text {st }}$ semester);

- are equipped with IC-section kits (objective achieved at $100 \%)$;

- 01 National Campaign for Mother and Child Health (SSME) was conducted during this 1 st term out of the 02 annual campaigns planned for the year.

\section{Malnutrition contro}

Malnutrition is included at the same time in national priorities and in MDGs. Its level is assessed based on the low weight indicator among children under 5 .

Proportion of children under 5 who are low weight during outpatient visits at CSB

The objective set for year 2008 , namely $14.4 \%$ is already achieved at $100 \%$, since the objective for this indicator was kept at the same level as for year 2007.

Proportion of children who are low weight at the community site level:

During the $1^{\text {st }}$ semester, the annual objective was reached at $88 \%$. Compared to the level achieved in 2007, an improvement by 3.4 points was recorded. Actions implemented to achieve these results include:

Making 44 CRENI and 44 CRENA (existing and new ones) operational and allocating inputs to them (in 


\section{IMPLEMENTATION OF THE MAP: HEALTH, FAMILY PLANNING, AND THE FIGHT AGAINST HIV/AIDS}

collaboration with ONN) and 36 CRENAM (WFP support) and 82 CRENAS (ONN collaboration and UNICEF support)

- 65 CSB promoted baby-friendly, against a forecast of 50 CSB ;

- Analysis of 638 samples of food products and delivery of 619 edibility certificates against an objective of 780 samples (82\%);

- Enrollment of 504,304 out of 524,162 children under 2 out of the 524,162 planned ones $(96.12 \%)$ in nutritional programs;

- Making operational of 5,500 community nutrition sites and awareness-raising on increasing harvests and on diversified diet.

Participation in SSME; Celebration of the National Nutrition Day

- Awareness-raising on nutrition at local radios, kitchen gardens in the school environment;

- Communication of health issues are part of the duties of health communities and community workers.

\section{Population adopting hygiene and health practices}

\section{Percentage of households using sanitation facilities}

- Surveys need to be conducted to assess this indicator. Even so, actions have been noted at health facility level and these should contribute to achieving the objectives set.

- 09 health facilities out of the 22 planned ones are equipped with incinerators. (i.e., 40.9\%)

Percentage of WASH friendly CSB: $2.74 \%$ of CSB out of the

$3 \%$ planned ones have become Wash friendly

\section{Share of the health budget in the full budget}

Low commitment rate as compared to the budget allocated to the sector

- The budget absorption rate is $40,14 \%$ for the operating budget and $14,24 \%$ for the investment budget.

The reasons raised for such discrepancies are the issue of access to the network at regional level as well as cumbersome procedures.

CONTRIBUTION OF TECHNICAL AND FINANCIAL PARTNERS TO THE RESULTS OF THE SECTORAL PROGRAMS AND THE PROJECTS PERFORMANCE

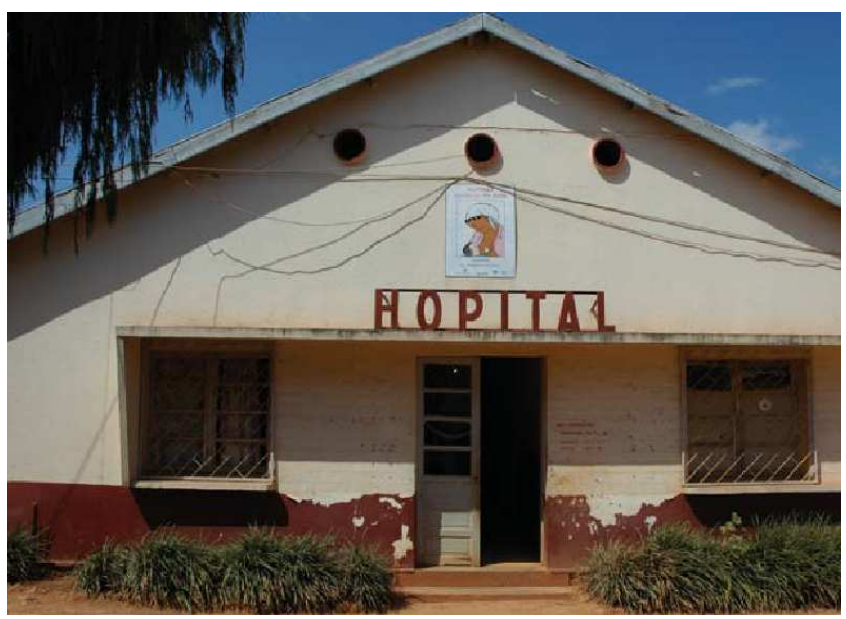

The World Bank supervision mission conducted a progress assessment for the most recent action plan of the Project for Developing a Sustainable Health System (PDSSP), a various component project, jointly financed by the World Bank, AFD, and GTZ in keeping with the Sector Wide
Approach (SWAP) process and the Second Multisectoral Project for the Prevention of STI/HIV/AIDS (PMPS 2).

The Sustainable Health System Development Project or PDSSP a has contributed to:

Strengthening the health services provision through: the signing and the implementation of the Action Program for Integrating Health Inputs (PAIS):

- the building and allocation of initial stocks of medicines to 48 CSB ;

- supplying of 12 anti-rabies vaccines storage centers;

- the allocation of kits and preparedness in the event of epidemics in 41 Districts that are seat to plague;

- the free mass treatment in 17 Districts where filariasis is endemic;

- the opening of 155 new Implanon sites.

The development and management of human resources: through:

- setting up of an incentive package to win the loyalty of Physicians and paramedical staff in the remote areas of 3 Regions, namely Melaky, Androy, and Vakinankaratra;

- organizing training on Key Surgery for CHD1 to be upgraded into CHD2 for 15 Physicians (training under way);

Development of the Health system funding

Making the 2009 Program Budget available;

- Finalization of 2008-2012 METF.

Improvement of maternal and child health through

- The Provision of a package of Maternal-Child free services during the Maternal and Child Health Week held twice a year;

- Fine-tuning process of the Community Approach under way; 


\section{IMPLEMENTATION OF THE MAP: HEALTH, FAMILY PLANNING, AND THE FIGHT AGAINST HIV/AIDS}

- Champion Commune Approach developed in 6 Regions;

- Paying-third system for universal access to C-section and pediatric emergencies in two regions (Boeny and DIANA);

- Increased prenatal consultation rate to $81 \%$

- Stabilizing of plague lethality rate to $16.3 \%$

The PMPS 2 Project

- Syphilis prevalence among sex workers decreased by $20 \%$, compared with 2005 ; the 2007 results indicated a reduction in the order of $26.5 \%$

- Progress in condom use among young people aged 15 to 24 years old and sex workers

The PNNC SEECALINE project, in collaboration with NNO contributed to the improvement of performances of projects falling into line with the sector program

- The implementation of the national nutrition policy (PNN) and the national nutrition action plan (PNAN), as part of the malnutrition control is indeed carried out at the preventive level (breastfeeding, national community nutrition program, micronutrient deficiencies control) as well as at the management level of children with severe acute malnutrition.

- Different programs and projects are implemented by Ministries and other actors and participants, in collaboration with ONN (multi-sector coordination structure) as well as with Regions, with support from technical and financial partners, with the aim of achieving the objectives set in the Madagascar Action Plan (MAP) and the State Overall Policy (PGE)

Other partners, namely FNUAP / UNICEF / OMS / GFATM / USAID contributed to the following projects:

- Support to the maternal and child survival policy;
- Support to the infectious and non-infectious disease control programs;

- Support to Family Planning.

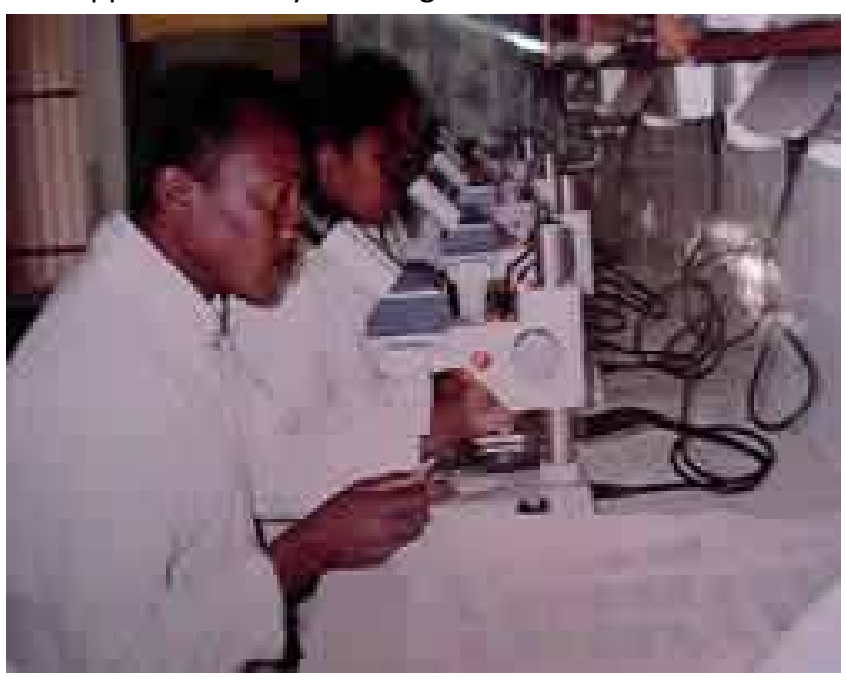

RECOMMENDATIONS - REVIEW OF THE SECTORAL PROGRAM

Observing the lack of involvement of the private sector and of associations and NGOs working in the field of health and social affairs in the achievement monitoring system per level, the following recommendations are made:

- Involve the private sector and associations and NGOs working in the field of health and social affairs in the planning-monitoring-evaluation process based on the Plan for Developing the Health and Social Protection Sector (PDSSPS)

- Consider the recommendations from the joint review oriented on priority topics: METF, Integrated Services Packages, and development of District and Regional Development Plans, Incentive system for health workers, Community participation, and Performance criteria at different levels of the health system, monitoring and evaluation.

- Prioritize the implementation of activities funded with subsidies

\section{As regards nutrition:}

- Prioritize malnutrition control in development policies, programs, and plans (sector, regional, municipal); further advocacy with decision-makers and at all levels is required;

- Close collaboration of the program with local authorities and technical services at the intervention zone level is also needed to ensure the program's success and social and economic development at the regional and local levels. The program can indeed not claim to fight malnutrition on its own, without involving entities to improve the social and economic situation of the community.

\section{Budgetary performance}

- Ensure the coaching by central level Directorates and Units on budgetary execution by the team of the Administrative and Financial Affairs Directorate.

- Replace GACs and SOAs who are no more operational (appointment of officers). 


\section{IMPLEMENTATION OF THE MAP: HIGH GROWTH ECONOMY}

\section{COMMITMENT 6: HIGH GROWTH ECONOMY}

\section{FOLLOW UP OF RECOMMENDATIONS MADE IN 2007}

FDIs

No up-to-date information is yet available to assess potential changes in the structures of FDIs as recommended last year.

\section{TOURISM}

\begin{tabular}{|c|c|c|}
\hline Recommendations in 2007 & Progress status as of the first semester of 2008 & Observations \\
\hline $\begin{array}{l}\text { Rehabilitate, as an urgent action, the hotel facilities destroyed by cyclones } \\
\text { Fame and Ivan in order to be ready for the next tourist season. }\end{array}$ & Effective for the private sector & \\
\hline $\begin{array}{l}\text { Initiate discussions to reinforce linkages of tourism with other sectors, } \\
\text { especially Public Works and Transport, Environment, Telecommunications } \\
\text { and Communications }\end{array}$ & Effective implementation & \\
\hline
\end{tabular}

\section{MINING}

\begin{tabular}{|c|c|c|}
\hline \multicolumn{3}{|l|}{ MINING } \\
\hline Recommendations in 2007 & Progress Status as of the 1st semester2008 & Observations \\
\hline $\begin{array}{l}\text { Implement the new system for collecting data on mineral duties at the } \\
\text { lower levels }\end{array}$ & $\begin{array}{l}\text { Order \#21895/07 on December } 20,2007 \text { sets the modalities for the collection of mineral duties. } \\
\text { Implementation has started. However, given that it is a complex tax (need for sustained IEC campaign at the } \\
\text { commune level); another order \#1442/2008 on July } 3^{\text {rd }}, 2008 \text { setting transitional collection modalities has been } \\
\text { enforced. }\end{array}$ & \\
\hline $\begin{array}{l}\text { Strengthen support to the private sector in processing mining products } \\
\text { and in extractive activities }\end{array}$ & $\begin{array}{l}\text { Training provided by Madagascar Gemology Institute (IGM) with : } \\
-147 \text { people trained in Stone Cutting } \\
\text { - } 166 \text { people trained in Gemology } \\
-6 \text { people trained in hand made jewellery }\end{array}$ & \\
\hline $\begin{array}{l}\text { Implement the actions to support the decentralized management of } \\
\text { mineral resources }\end{array}$ & $\begin{array}{l}\text { Efforts focused in the region of Anosy: } \\
\text { - completed rehabilitation of the building of the Inter regional Directorate (DIR) } \\
\text { - Operational Field Agents (but lack of budget for recruiting higher rank executives to lead the } \\
\text { DIR). }\end{array}$ & \\
\hline Reinforce the effective implementation of mining governance & $\begin{array}{l}\text { - Mining Administration Office (BAM) Ilakaka-Sakaraha: completed (but the recruitment of staff } \\
\text { for it to work depends on availability of budgetary posts). } \\
\text { - Adherence of Madagascar to the Extractive Industries Transparency Initiative (EITI): on good } \\
\text { rails (five regional workshops completed in five regions). }\end{array}$ & \\
\hline $\begin{array}{l}\text { Accelerate the progress towards the exploitation phase of the major } \\
\text { mining projects while respecting local communities and the environment }\end{array}$ & $\begin{array}{l}\text { The building works in the two major projects (ilmenite in Taolagnaro and nickel-cobalt) are progressing in accordance } \\
\text { with plans. } \\
\text { QMM shall begin extraction in early } 2009\end{array}$ & \\
\hline
\end{tabular}




\section{IMPLEMENTATION OF THE MAP: HIGH GROWTH ECONOMY}

\section{ANALYSIS OF THE QUANTUM LEAP}

- Three regional structures for receiving FDIs have been set up (EDBM);

- Laws on Investments and on Export Processing zones and Firms in Madagascar have been promulgated

- The payment of tax by wire transfer has been adopted in two Regional Services for Companies in Analamanga (i.e., 33\% of the objective for 2008);

- The online VAT service is operational;

- Six Authorized Management Centers are operational, i.e., $100 \%$ of the year's objective;

- The bill on exports has been finalized;

- The bill on public-private partnership has been designed and awaits adoption;

- The decree for application of the Companies Act and abrogating the provisions on minimal equity for Limited Liability Companies (SARL) and Sole Proprietorship with Limited Liability Companies (EURL) has been published.

\section{ANALYSIS OF INDICATORS}

\section{Economic Growth and Investments}

Madagascar's development plan until 2012 gives a driving role to the private sector through the promotion of investments, especially foreign direct investments.

Despite the oil and food price increase marking the national international economic context and the cyclone occurrence in the country in the first semester, the overall national production has increased. However, such contexts have led to review the initial programming of the $7.3 \%$ economic growth to $7.1 \%$.

Between June 2007 and June 2008, production in some main activity branches has increased except in that of livestock, which fell by $2.7 \%$. The highest increase is recorded in the "communication " sector at 57.2\%, followed by that of rail transportation at $55 \%$, that of BTP and construction materials respectively at $54 \%$ each. Tourism recorded the least dynamic increase in production, followed by insurance and sea transportation. It may be said that the production increases in these tertiary branches testify to the increase in national production.

The sectors of building works and building materials rank first in terms of turnover, with a $78 \%$ increase between the above mentioned periods. The turnover of the communication sector has increased by $34 \%$; this may be explained rather by parallel increase in the production volume in the sector; its ex factory price decreased $16 \%$. Road transportation and chemical industries are the sectors in which the biggest increases in ex-factory prices are recorded at $26 \%$ and $20 \%$ respectively.

\section{What about investment promotion?}

In the report "Doing Business Indicators 2008", in June 2007, Madagascar ranks $149^{\text {th }}$ out of 178 countries in terms of investment climate, compared to a ranking of $149^{\text {th }}$ out of 175 in 2006.

Compared with other benchmark countries, investment initiatives in Madagascar are impeded by three main barriers:

- Access to credit (176th/ 178): The difficult access to credit is mainly due to the lack of information on the conditions for accessing credits and to comparatively disadvantageous loan conditions (collaterals, etc.);

- Registration of property (165th/178): This is reflected by the high number of procedures required, the delay for processing files and applications, and the cost of registering the operations;

Concluding business contracts $\left(151^{\text {st }} / 178\right)$ (especially for legal aspects): The impediments are similar to those mentioned for registration of property.
This year, Madagascar plans for a gross investment rate that is 7 points higher than in 2007 , i.e., $35.5 \%$. It will be at $25.7 \%$ made up of private investments. Given the flow of FDIs currently estimated at SDR 441.5 million against an annual forecast of SDR 439 million, meaning that the 2008 annual objective is exceeded mid year. It may be envisaged that the annual investment forecast may be exceeded.

\section{Graph 11 : FDI Flow and Economic Growth Rate}

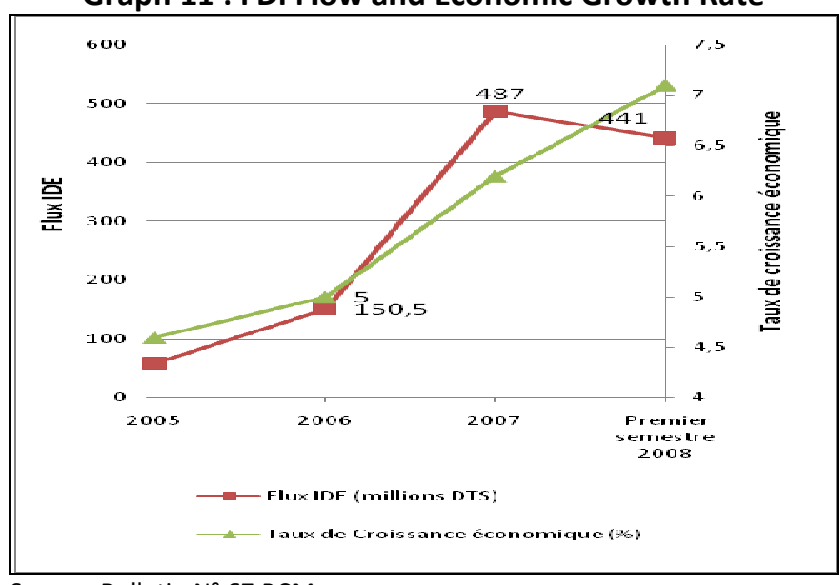

Source: Bulletin $\mathrm{N}^{\circ} 67 \mathrm{BCM}$

Several actions were undertaken over the last six months to promote business and boost investments:

- A dedicated industrial zone was identified and should be usable once the development works are completed;

- Twenty four applications for authorization from Export Processing Zone Firms have been filed

- Six Agro industrial Units have been established

- Three partnership agreements were negotiated and are awaiting signature (60\% of the annual objective): Madagascar-Canada; Madagascar-Italy; and Madagascar-Algeria; 


\section{IMPLEMENTATION OF THE MAP: HIGH GROWTH ECONOMY}

- Three regional structures for receiving FDIs have been set up;

- All the focal points of the EDM are now working in the Ministries and the Embassies;

- 755 applications were processed as part of facilitating investments, i.e., $61 \%$ of the annual objective;

- $75 \%$ of the annual objective in terms of investment visits have been achieved;

- The country has taken part or organized fairs, exhibitions, missions, etc. at the local, regional, and international levels through the activities of the Malagasy Embassies, Malagasy operators, road shows, etc.

- The administrative procedures for visas have been facilitated and new international norms were adopted (biometric passports, etc.)

- The CERDICs of Itasy and Bongolava are operational. The premises have been identified for the establishment of ten additional CERDIC this year, in the regions of Atsinanana, Vatovavy Fitovinanay, Atsimo Atsinanana, Menabe, and Vakinankaratra ;

- Six CERAM have been established $(100 \%$ of the objective set in the State's General Program) and 1,500 hand-made products have been certified ( $22 \%$ of the annual objective);

- Different bills on the establishment of 12 new Chambers of Commerce and Industry have been prepared (draft decrees and orders). In addition, 9 regions out of 12 have communicated requests from regional operators for the establishment of $\mathrm{CCls}$ in their Regions;

- Actions have been undertaken to fight informality and frauds: verification and standardization of measurement instruments, cleaning up of markets through the RRI approach;

Twenty-nine (29) cooperatives have benefited from strengthening (58\% of the annual objective).

Out of an annual objective for establishing 1500 SMEs, 693 have been established in this first semester including 325 foreign-owned companies.

- In addition, to support and build on the efforts to promote investments, three meetings between the private sector and the government were held to address the following topics:

- The Export Act: the bill has been finalized and should presented as such in the Council of Government and to the Parliament for adoption in the second session in 2008;

- The legal and institutional framework for publicprivate partnership: the bill on PPP has been designed, and should be presented to the committee in charge of reforming the business law, the Council of Ministers, and the Parliament;

- The Decree on minimum equity for companies: the decree on the Companies' Act application and abrogating the provision on minimum equity for Limited Liability Companies (SARL) and Sole Proprietorship with Limited Liability Companies (EURL).

Overall, the need to boost the national production has to be admitted, essentially:

- Develop strategies that may contribute to reduce the production factor costs by further improving the infrastructures required for increasing energy-, road-, port-, ICT-, related investments ....
- Enhance conditions for private sector access to long term credits...

- Diversify the types of large foreign investments; further solicit investments by manufacturing firms.

- Develop programs of assistance to producers and companies in their quality insurance approach,

- Support work for harmonizing the in force standards and for normative regulation in the framework of regional integrations (COMESA and SADC)

- Resort to off season cropping

Long-term bank credit granted to the private sector

Access to long-term bank credits is one of the main obstacles to investments in Madagascar.

However, the private sector is starting to benefit from more long-term bank credit. In the first semester of 2008, bank credits granted to the private sector amounted to Ariary 1,655 billion, $7.1 \%$ of which are long-term credit against 6.9 at the same period of last year. At this pace, the annual performance of $7.27 \%$ in 2007 could be exceeded this year.

The most recent statistics on microfinance institutions (December 2007) -- which are entities that may finance the activities of SME/SMIs, indicate outstanding loans of Ariary 70,093 million. It should be noted that the penetration rate of microfinance is $9.25 \%(93 \%$ of the annual objective) against $7.86 \%$ in June 2007

\section{Full Employment Promotion}

Full employment promotion was less dynamic in this first semester. Actually, except for the performance in establishing ten Information and Orientation Centers on Employment and Training (out of an annual objective of establishing five centers), the achievement rates for the 


\section{IMPLEMENTATION OF THE MAP: HIGH GROWTH ECONOMY}

other engaged actions are moderate compared with the annual objectives:

- 5,212 formal employments established, i.e., $10 \%$

- 02 Regional Committees for Employment Promotion Monitoring and Poverty Reduction (CRSPERP) established, i.e., $18 \%$

- In keeping with the implementation of the National Program for Support to Employment (PNSE) : 38 Credit Committees and 11 facilitators have been trained in culture of credit; 2572 beneficiaries have been sensitized on culture of credit and 06 representatives of the 06 Regions have been trained in culture of entrepreneurship, culture of credit and project arrangement.

\section{Prices and Inflation}

The increase in prices of main petroleum products, as well as those of food products has certainly entailed inflationist pressures worldwide. However, it can be said that the actions taken by the country in such context have contributed to mitigate the impact of such increases at the national level. Among others, this mainly consisted in what follows:

- Curbing the increase in monetary aggregates by keeping the same level of instruments (prime rate at $12 \%$, minimum requirements at $15 \%$ )

- Curbing the budget deficit by regulating expenditures; the deficit which was initially programmed at $4.9 \%$ will be reviewed downward to $4.4 \%$.

- State divestiture from the banking system for an amount of some Ariary 198 billion.

In addition, the national currency appreciation should be noted for this first semester. But it must be noted as well that the rice price decreased in the first semester, which is the harvesting period. Moreover, in order to face the international inflation and food crisis, the government has taken actions to improve the national production (off season cropping) and to strengthen the stocking of food stuff.

The Government means to continue and strengthen such actions for the whole year 2008 by planning to implement a program of social protection which consists in making targeted transfers to the poorest population such as in food for work and school feeding, subsidizing transportation, allowing temporary VAT exemption for rice and oil, as well as import tax and duty for some agricultural machines and materials and freezing electricity price (on a temporary basis).

Graph 12 : Variation in Consumption Price Indices for some main products (December 2007- June 2008)

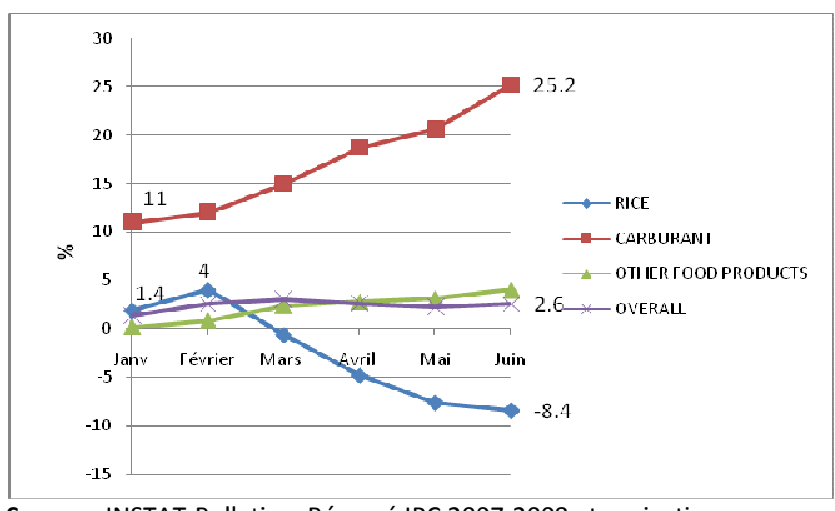

Source : INSTAT-Bulletin « Résumé IPC 2007-2008 et projection 2008-2012»

(Base 100 : moyenne des prix de Janvier 2000 à Décembre 2000) For 2008-2012 »

(Base 100: average of prices from January 2000 to December 2000)

For the year as a whole, the initial $8 \%$ forecast of increase in the general price level (average of periods) has been reviewed upward to $9.4 \%$.

Actually, between December 2007 and June 2008, the consumption price indices overall increased by $2.6 \%$.
Whereas this increase is neighboring $2 \%$ for the cities of Antananarivo, Toamasina, and Mahajanga, it is the most felt in the city of Toiler (6.2\%) and Antsiranana (5.4\%). The city of Fianarantsoa experienced the lowest increase with $1.7 \%$.

Still in the same period, the prices of semi imported and imported consumption goods became much more expensive than those of the local products respectively with $6.39 \%, 4.90 \%$, and $1.89 \%$ increases. From the perspective of production, the prices of processed food products fell by $5.90 \%$, of which that of rice fell by $8.34 \%$; those of main commodities also fell by $1.36 \%$. Conversely, the prices of unprocessed food products, as well as those of industrial manufactures products rose respectively by $6.11 \%$ and $5.23 \%$. Depending on the product function, the group of "Hotels, cafes, restaurants " experienced the highest $6.33 \%$ price increase, followed the $6.76 \%$ increase in transportations.

Graph 13 : Evolutions in exchange rates Evolution in Consumption Price Indices (aggregate)

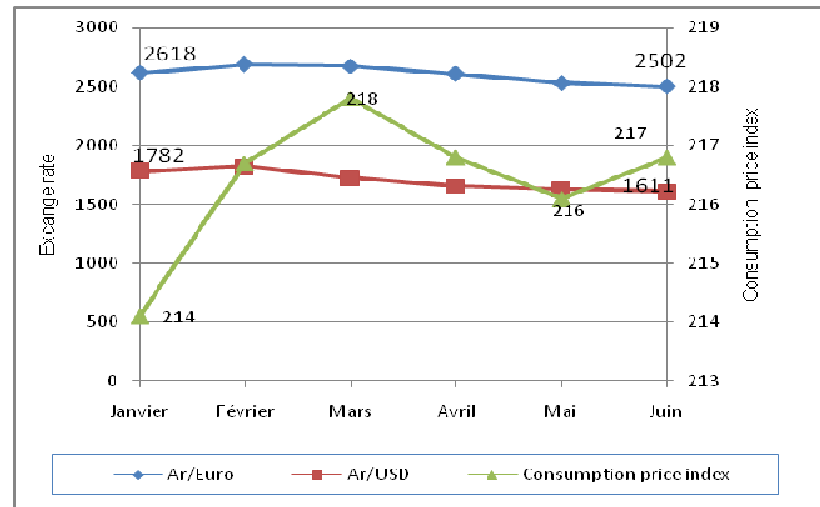

Sources: INSTAT-Bulletin $N^{\circ}$ 148- (Base 100 : moyenne des prix de Janvier 2000 à Décembre 2000) BCM-Bulletin No67 


\section{IMPLEMENTATION OF THE MAP: HIGH GROWTH ECONOMY}

On a year on year basis, between June 2007 and June 2008, consumption prices as a whole became more expensive by $9 \%$. It should be noted that the energy price significantly increased by $10.65 \%$ for the same period.

\section{Public Finance}

The implementation of strategies to reform the management of the government budget has led to the following achievements in the first semester:

- A restrictive budget policy with the suppression of some expenditures lines on the one hand and the increase in resources on the other hand, with a current estimated tax pressure rate at $12 \%$ against an annual forecast of $11.6 \%$;

- Improvement of the IT systems for the management of public resources;

- SIGFP has been installed in all ministries (25), in Financial Districts, and in the Institutions (PRM, PM, Senate, and Parliament);;

- TRADENET is now implemented in the customs office where SYDONIA ++ is operational (Toamasina, Antananarivo, Mahajanga; i.e., $75 \%$ of the implementation objective);

- The payment of tax through wire transfer has been adopted in two regional services of companies in Analamanga (i.e., 33\% of the objective in 2008);

- Established six Authorized Management Centers which became operational, i.e., $100 \%$ of the annual objective;

... and continues yielding results in terms of effective and healthy management of the government budget.

During the first semester, the overall operation of the Treasury resulted in:

- Total revenues of Ariary 1,053.9 billion (off grants), i.e., 53\% of the annual Ariary 1,978.5 Billion forecast (Amending Finance Law); the first semester objectives in tax revenues have been exceeded, i.e., Ariary 527.3 Billion of taxes collected out of an Ariary 454 Billion forecast, and Ariary 494 Billion in customs revenues mobilized, i.e., $97 \%$ of the semester objective.

- Total expenditures amounting to Ariary 1,271 Billion, i.e., $37 \%$ of annual programming.

At such pace, the budget deficit that was forecast at $4.9 \%$ this year is highly possible because it is currently estimated at $4.4 \%$.

However, efforts need to be made to optimize overall budget implementation, which is currently estimated at $36.90 \%$ (i.e., $50 \%$ of the objective). Such efforts will consist in improving the reporting system, financial controls, and external controls.

In addition, the late appointment of officials in technical Ministries is one of the origins of such low budget execution rate.

Furthermore more fiscal revenues could be expected through a better strategy of identifying new tax payers. ; the achievement in the first semester accounts only for $6 \%$ of the annual objective, i.e., 1,933 new tax payers identified by 33 Tax Centers.

\section{Foreign Trade}

Madagascar forecasts a trade deficit of SDR 1,197 million for year 2008 with imports estimated at SDR 2,106 million. Currently, the trade balance is SDR 564.4 Million against a deficit of SDR 279 Millions in June 2007.

In the course of this first semester, the figure for Madagascar export revenues is some SDR 414.3 Billion. These largely derive from export by Export Processing Zones (54\%). Vanilla and petroleum product exports account respectively for $4.38 \%$ and $4.85 \%$ of such revenues.

Compared to achievements in the same period last year, our exports, in value terms, have increased by $11 \%$. However, the rate of coverage of imports by exports which is about $42 \%$ for the first semester is 15 points lower compared to the previous year.

In fact, the overall imports of these last six months, and which are in the order of SDR 978.7 Million, have increased by $50 \%$ compared with the statistics of the period in 2007 . The value increase of about $160 \%$ of import of equipment goods (26\% of the total of our imports) for this first semester, compared with the data of the first semester of 2007 may explain such deterioration. In volume, while exports fell by $8 \%$ compared with the achievements as of June 2007 and as of June 2008, imports increased by about $34 \%$. EPZ exports fell by $8 \%$ versus a volume $30 \%$ increase in their exports. Between these periods, there should also be noted a significant increase of nearly $84 \%$ in the volume of raw materials imports.

Regarding performance in exchanges by the country with the main regional cooperation organizations during the first semester, the coverage rate of imports by exports with $I O C$ is the highest, in the order of $60 \%$, followed by that of COMESA by $22 \%$; the coverage rate with SADC is currently estimated at $9 \%$.

In terms of hard currency reserves, the country plans for 2.4 months of import for this year. For this first semester, the reserves in import months are estimated at 2.3 months, i.e., a 0.7 point regression compared with the 


\section{IMPLEMENTATION OF THE MAP: HIGH GROWTH ECONOMY}

performance as of the first semester of 2007 which was 3 months. The deterioration may be ascribed rather to high increase in the imports over the last six months (against the achievements as of June 2007) than to the volume of our minimum requirements which, in this month of June, are estimated at SDR 550.5 Million versus only SDR 474.5Million last year.

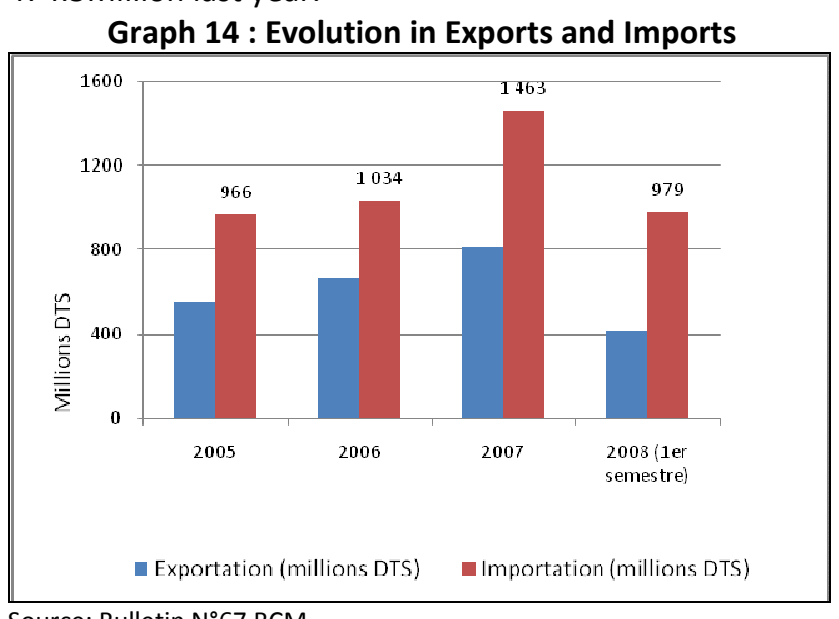

Source: Bulletin N67 BCM

Regarding prospects, measures and actions have to be taken to win in foreign exchanges. Among others, the point will be to strengthen export tax incentives for ordinary regime exporting firms, to diversify and strengthen the financial instruments in favor of exports, to facilitate the proceedings by the exporter through the establishment of one stop export desks..

In particular, in keeping with the sub regional cooperation, Madagascar has certainly a more advanced coverage rate with IOC. However, integration with the other regional markets should be further promoted as they offer more potential (conditionalities....); by operating with a larger volume of exchanges and customers, namely SADC and COMESA (SADC area GDP is in the order of US\$200 Billion and SADC and COMESA markets have hundreds of customers to be targeted). As part of the SADC cooperation, a project called « National Program for upgrading and modernizing industries in Madagascar» is planned to start next year. Its main objectives will be to promote investments, exports, technology, quality, local manufacturing. Initiatives for promoting investments are also proposed under the AfOA.

\section{Madagascar Foreign Debt}

Since the beginning of the year, the country has benefited from debt relief amounting to SDR 44.63 million, including SDR 33 million on the capital. Bilateral debt relief is the most significant at SDR 18.25 million, including 12.89 Million on capital. As part of the Initiative for Multilateral Debt Relief (MDRI), Madagascar benefited from a debt relief of SDR 11.93 million. Thus, our foreign debt service currently amounts to some SDR 7.08 million, i.e. half our debt service in 2007 . Regarding exports, such service is in the order of 1.6 against an annual forecast 2 , 5 ; as of the first semester of 2007, such service was 0,8 . As our export in value increased by $11 \%$ compared to last year this can rather be explained through the deterioration of such ratio by further service of debt recorded in this first semester.

During the first semester, the management of foreign debt resulted in:

- 3 loan agreements negotiated for an amount of US\$152,705 million;
- 05 loan agreements signed for an amount of US\$168,042 million;

- 03 grant agreements signed for an amount of US\$113,717 million;

- Withdrawals made on loans in April: Ariary 135.021 billion;

- Signing a second contract of debt-clearing and development (C2D) with France.

\section{Performance in Tourism}

Increase in direct employments created and low tourism revenues

- The cumulative number of direct employments created in the tourism sector is of 24,524 in the first semester of 2008 , which means the annual objective of 24,500 employments for year 2008 is already exceeded. Thus, the achievement rate is already $100 \%$ though we are only in the year first semester. The Project to standardize hotels and restaurants, and which is to intensively promote and develop the tourism sector, has contributed to additional 479 employments.

- The revenues generated by tourism were SDR 94.22 million during the first semester, against a SDR 236 million forecast for year 2008. The achievement rate is thus $39.92 \%$. The main reason for the poor performance is that we are still in the low season. Revenues will significantly increase as we enter the tourist season. It should be noted that during the six months of low season, the flow of non resident visitors increased by $10 \%$ compared to the same period in 2007.

- Several projects contribute to the development of the tourism sector. The Project to Extend the Economic 


\section{IMPLEMENTATION OF THE MAP: HIGH GROWTH ECONOMY}

Observatory of the Tourism Sector to the Regions aims at improving the production, dissemination, and use of statistics on tourism; the Project for the Development of National Tourism aims at enhancing the value of the social setting while preserving cultural integrity to ensure the well-being of each individual and to revitalize local communities. The Project of Standardization of hotels and restaurants and to monitor tourist activities aims at intensively promoting and developing the tourism sector

\section{Regression in mineral duty collection}

\section{Low rate of mineral duty collection}

- In 2007, the mineral duties collected amounted to Ariary 252.5 million. In the first semester of 2008, the collection of mineral duties amounted to Ariary 21.28 million, i.e., an achievement rate of $6 \%$ compared to the objective of Ariary 331.380 million set for this year. The general slowdown in mining activities due to the suspension of export of all mineral substances at the beginning of the year, then of uncut precious stones starting in July, on the one hand, and the delay in the collection of duties and rebates in the communes due to the suspension of export account for the low level of mineral duty collection.

Several large projects contribute to the intensive development of the mining sector. Under the Project for Mineral Resources Governance (PGRM) funded by IDA, the concept of a Mining Administrative Building (MAB) has been adopted for llakaka. Sakaraha was adopted and the facilities were effectively built. The eight Mining Environmental Units of the regional directorates are now operational, and the work at the scale of $1 / 100,000$ and $1 / 500,000$ have been completed. The maps should be available to the general public by July 2008 as part of strengthening geological infrastructure and updating geo-scientific information. Under the Project to Build the Institutional Capacity of the Mining Sector (PRISM) with the French Cooperation, the Mining Administration skills were strengthened and the geological and basic mining information were updated.

The main actions to be undertaken in the short and medium terms are as follows:

- Monitoring of the proposal for establishing a Mining Foundation for Community Development (FMDC) in the Region of Anosy, allowing channeling part of mining revenues for direct impact to communities. There should take place a follow up dialogue at the Ministries in charge of Mining, Decentralization, and Finance; and at the region level to come up with a real consensus in decentralized management of mining revenues.

- Following a request from OMNIS, assistance is being established in order to advise this organization in the decisions to be made regarding its participation of up to $20 \%$ in the QMM Project.

- The first phase of the study on mining taxation allowed identifying a diagnosis of the various mining regimes. The 2 nd phase allows a quantitative simulation of the upcoming State mining revenues and a formulation of detailed recommendations.

- The request for funding conveyed to EITI Trust Fund, which is being processed, is to be accelerated.

\section{CONTRIBUTION OF THE MAIN PROJECTS}

\section{Integrated growth poles project}

The IG2P has a disbursement rate of $64.94 \%$ to date. During the first three months, it achieved the following:
- Improving Access to Credit:

As part of creating partial guarantee at two commercial banks:

- GPP- BFV-SG-SHORE BANK: $41 \%$ of new borrowers; $7 \%$ of outstanding loans outside Antananarivo, 89 new loans made;

- GPP - BNI-CA-EURO GROUP: 75\% of new borrowers, $19 \%$ outstanding loans outside of Antananarivo, and 660 new loans made.

It was noted that the concentration of loans in the two poles of Antsirabe and Antananarivo limits the capacities of the MSMEs in the project development poles.

- Promoting Tourism 32 / 100 MSMEs trained in technique of reception, accommodation, catering, and e-marketing in the poles of Nosy Be, Antsirabe, and Taolagnaro - 56/200 in management, Business running, and Business Plan, 10 people from ONTM/MTC trained in English; and ONTM participated in 02 shows related to tourism development.

- 130 /200 MSMEs in Nosy Be and Taolagnaro have adhered to Worldhotel-Link.com

- Tourism related information system: established.

- Supporting and promoting crafts value chains: 6 value chains were selected, one micro-project on a value chain was funded in each pole, and 25 MSMEs/100 were trained in crafts-making;

- $\quad$ Supporting the establishment of three regional branches of the EDBM;

- Promoting exports: 30/150 engineers in textile have been trained. 


\section{IMPLEMENTATION OF THE MAP: CHERISH THE ENVIRONMENT}

\section{COMMITMENT 7: CHERISH THE ENVIRONMENT}

FOLLOW UP OF THE RECOMMENDATIONS MADE IN 2007

\begin{tabular}{|c|c|c|}
\hline Recommendations made in 2007 & Progress status during $1^{\text {st }}$ semester of 2008 & Observations \\
\hline $\begin{array}{l}\text { Involve all interveners, sector Ministries, decentralized territorial collectivities, the forces of law } \\
\text { and order, and the local population, so that control efforts may be combined at all levels }\end{array}$ & $\begin{array}{l}\text { Setting up of the Regional Planning and Monitoring-Evaluation } \\
\text { Platform (RPMEP) }\end{array}$ & \\
\hline As for ANGAP, one site should have just one donor & Achieved & \\
\hline $\begin{array}{l}\text { Each Protected Area should have a fire management plan including preventive as well as active } \\
\text { control. }\end{array}$ & Completed & \\
\hline
\end{tabular}




\section{IMPLEMENTATION OF THE MAP: CHERISH THE ENVIRONMENT}

\section{ANALYSIS OF PRIORITY INDICATORS}

Marked increase in the surface area of Protected Areas (PA)

$4,225,819 \mathrm{Ha}$ of PAs were attributed the temporary or final status, against an annual objective of $4,500,000$ ha. Of which:

- 2,576,591 ha (temporary status) (ANGAP sites)

- $1,649,228$ ha classified final

It is to be noted that the passage from temporary status to final status is long and depends on several sectors and Regional Consultations.

$4,225,819 \mathrm{Ha}$ of PAs were attributed the temporary or final status, against an annual objective of $4,500,000$ ha and 24,393 square plots are under surveillance in 27 PAs.

Regarding PA development and maintenance, $85 \mathrm{Km}$ circuits, $88 \mathrm{Km}$ boundaries, and 09 eco-tourist infrastructures were developed and maintained.

The number of tourists visiting PAs reached 39,752 against an expected number of 128,100 for year 2008 .

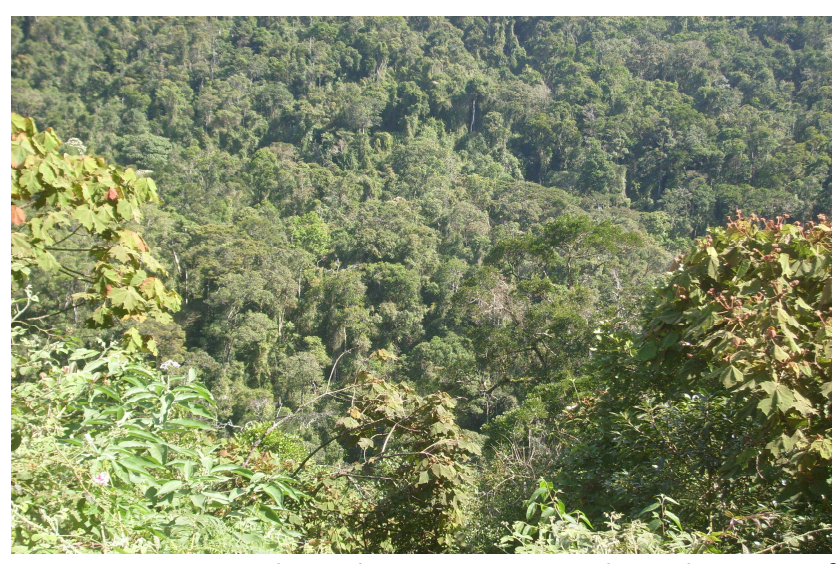

To ensure ecological monitoring and application of land, lake, sea, and coast ecosystems conservation measures, the PAs overall efficiency index of the ANGAP network reached $62 \%$, which amounts to a completion rate of $100 \%$ as compared to the objective set. The representation rate of the habitat in the system is $94 \%$ against an objective of $92 \%$.

Increase in the reforested and restored surface area

Achievements in reforestation matters include: $34,515 \mathrm{Ha}$ reforested that is, $138 \%$ of the objective set, 30,549 seedlings planted out, and $2,530 \mathrm{Kg}$ seeds produced. The main activities relate to the collaboration of the National Forest Seeds Silo (NFSS) and the Ambatovy Project on training on forest rehabilitation, reforestation actions over a surface area of $65 \mathrm{Ha}$ in Anjozorobe and $50 \mathrm{Ha}$ in Toamasina

As regards the implementation of the various plans, 15 development plans are being implemented - including 08 in the Region of Diana, 02 in Boeny, and 05 in the zones of the Natural Resources Sustainable Management Program (NRSM) and USAID, and 03 sector management plans (Prunus africa, Crocodylus niloticus, and Centella Asiatica) are revitalized, which amounts to a $75 \%$ completion rate. 400 households in the Region of Atsinanana and 80 in the Region of Haute Matsiatra adopted the use of alternative power (ethanol SPURE).

\section{Decreased burnt surface area}

The objective is to decrease the burnt surface area below the $350,000 \mathrm{Ha}$ mark in 2008 (that is, $45 \%$ of the $680,000 \mathrm{Ha}$ of the 2002 baseline year). The burnt surface area recorded during the $1^{\text {st }}$ term 2008 amounts to 979 $\mathrm{Ha}$, but it must be noted that the fire season is still to come in the following months.

The Ministry provided control efforts, namely by assigning Ariary 55,295,500 to DREEFTs, allocating 20 bicycles to the 18 fire brigades, presenting and legalizing 84
Dinas at the district level, sensitizing 120 communes and 402 Fokontany, planning activities relating to bushfires management over a 4-year period by PGDRN revitalizing/creating 200 fire control committees through training at the commune level.

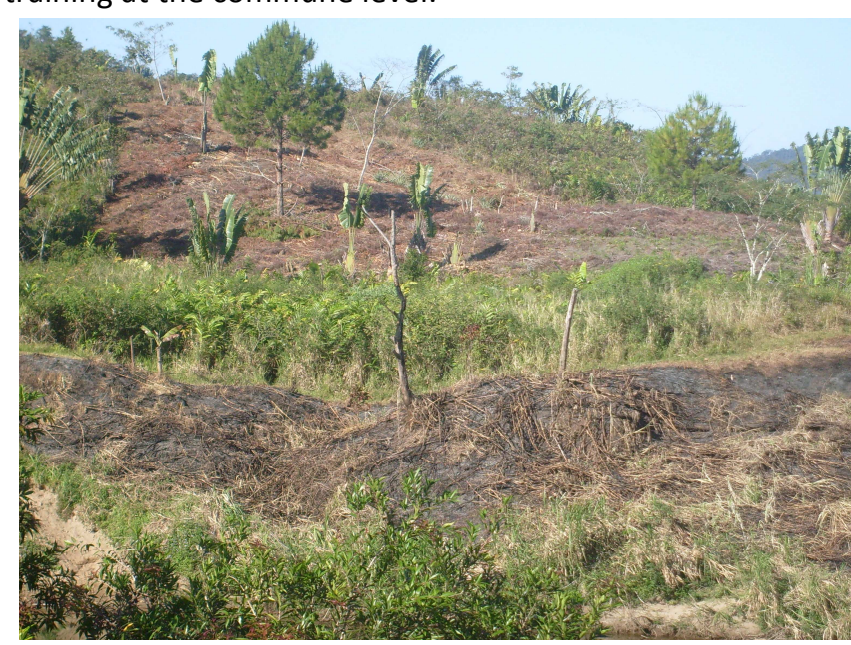

Funds collected for the Protected Areas and Biodiversity Foundation of Madagascar (FABM) The amount raised for PABFM reached USD 53,905,205 and is distributed as follows:

- US\$11,060,969 paid out (WWF, State/KFW, Cl, Melissa Moye, IDA, FFEM, AFD)

- US\$37,404,205 signed for (WWF, State/KFW, Cl, C2D, IDA, Melissa Moye, AFD, FFEM)

- US\$16,500,000 awaiting signing (GEF, KFW)

Forest and environmental receipts amount to $470.67 \%$ of the Ministry's operation and investment budget, owing to the sale of seized wood; however, this is a one-off situation, not an ongoing one. The receipts amount to Ariary 9,993,657,129.86 and are distributed as follows:

- Forest receipts strictly speaking: Ariary 583,000,000 


\section{IMPLEMENTATION OF THE MAP: CHERISH THE ENVIRONMENT}

- Receipts from the sale of wood seized: Ariary $9,410,657,129.86$

\section{Increased implementation of the Environmental} Education Policy

While the annual objective is set at $22 \%$, the percentage of primary, secondary, higher, and vocational facilities integrating environment curricula amounts to $13 \%$, distributed as follows:

- $08 \%$ in primary schools

- $04 \%$ in lower secondary schools

- $01 \%$ in upper secondary schools

Two (02) environmental education sessions are organized in collaboration with the Environmental Education Program Office (BPEE within the Ministry in charge of National Education and the Fanamby NGO.

\section{Reinforced Forest Control}

Regarding policing, control and the forest regulation framework:

- 22 Regional Inspection and Control Services (RICS) are appointed and 17 Regional Environmental Complaint Management Councils are set up

- 13 controls are conducted

- 08 traffickers arrested and 02 sanctioned

- 01 precious wood illegal exploitation identified in Vohémar

- 18 CIREEFs were supported for offence processing and seized forest products sale (188 forest agents, 86 magistrates, 60 police officers and 68 gendarmes, 09 Treasury officers, 11 ANGAP agents, and 02 process servers trained)

\section{Contribution Of Main Projects}

The results of the Environmental Program Support Project 3 funded by IDA, UNDP, USAID, Cl, WWF, WCS, the European Union, the German Cooperation, the Swiss Cooperation, the French Cooperation, and the Japanese Cooperation, are materialized through the management of the PA and forest ecosystems, the integration of the environmental dimension, and the improvement of the institutional mechanism.

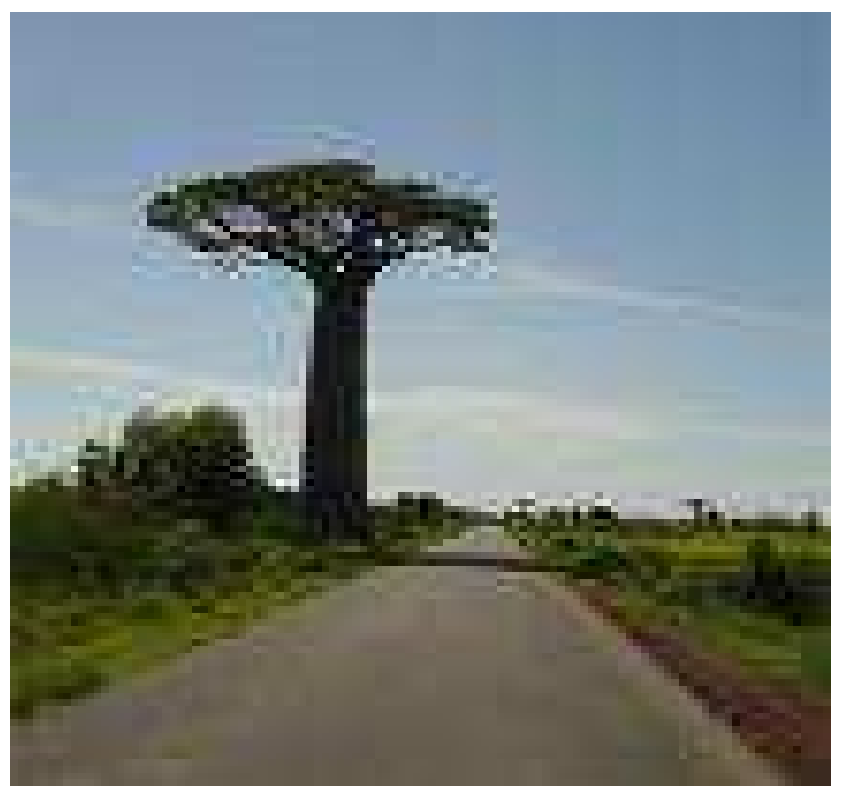

The "Development of the Second National Communication under the Convention on Climate Change" Project (UNDP), the "Community and Participatory Conservation of Biodiversity in the Forest Corridor of Anjozorobe" project (GEF/UNDP), the Biodiversity Protection and Valorization Pilot Project (FFEM), the Biologically Diverse Forest Ecosystems Conservation Program (USAID), the "Natural
Resources Sustainable Management Program" (PDGRM/GTZ), the "Bushfires Control" Project (ETAT), and the "Commune Reforestation Support" Project (ETAT) have positively contributed to the sector's performance. As for the "Seeds Harvest and Conservation" (ROYAL BOTANIC GARDENS), activities relating to seeds and seedlings production will only start in October

\section{Challenges AND OUTLOOKS}

Completion status of 2007 challenges and outlooks:

\begin{tabular}{|l|l|}
\hline $\begin{array}{l}\text { Challenges and Outlooks of Year } \\
\mathbf{2 0 0 7}\end{array}$ & Achievements during $\mathbf{1}^{\text {st }}$ term $\mathbf{2 0 0 8}$ \\
\hline $\begin{array}{l}\text { Ensure the fluidity of information } \\
\text { among decentralized services }\end{array}$ & $\begin{array}{l}\text { Setting up of the Regional Planning } \\
\text { and Monitoring-Evaluation Platform } \\
\text { (RPMEP) }\end{array}$ \\
$\begin{array}{l}\text { Reinforce linkages with the } \\
\text { Regions: technical supervision, } \\
\text { communication of information }\end{array}$ & \\
\cline { 1 - 2 } $\begin{array}{l}\text { Equip the 22 Regions with their } \\
\text { own regional control service }\end{array}$ & $\begin{array}{l}\text { The 22 Regional Inspection and } \\
\text { Control Services (RICS) are } \\
\text { effectively made operational }\end{array}$ \\
\hline
\end{tabular}

Challenges and outlooks for the $2^{\text {nd }}$ term 2008:

- Further integrate sector ministries in the environmental dimension

\section{RECOMMENDATIONS}

- Environment cells at the sectors' level should reinforce environmental advocacy with their respective decision-maker

- The capacities of the Regional Planning and Monitoring-Evaluation Platform (RPMEP) of each Region should be built to improve data reporting. 


\section{IMPLEMENTATION OF THE MAP: NATIONAL SOLIDARITY}

\section{COMMITMENT 8: NATIONAL SOLIDARITY}

\section{FOLLOW UP OF RECOMMENDATIONS MADE IN 2007}

\begin{tabular}{|c|c|c|}
\hline Recommendations made in 2007 & Progress status during 1st semester of 2008 & Observations \\
\hline Expand EKA activities to other Communes already defined in the action plan 2008; & $\begin{array}{l}\text { Making funds available to the } 209 \text { new } \\
\text { Communes targeted }\end{array}$ & \\
\hline \multicolumn{3}{|l|}{$\begin{array}{l}\text { Increase the budget of the EKA program, especially in RPI and mobilize other donors, } \\
\text { because UNICEF is currently the only donor; }\end{array}$} \\
\hline \multicolumn{3}{|l|}{$\begin{array}{l}\text { Research financial partners and potential investors for the development of the } \\
\text { cultural sector; }\end{array}$} \\
\hline \multicolumn{3}{|l|}{$\begin{array}{l}\text { Incite decentralized collectivities to integrate the youth and sports component } \\
\text { (especially the building of sports infrastructures) in their development program; }\end{array}$} \\
\hline Mobilize resources for the training of sportspeople to improve performances. & $\begin{array}{l}\text { 10/23 Television broadcasts } \\
\text { 21/33 Radio Broadcasts } \\
10 \text { News Broadcast } \\
01 \text { Press Trip }\end{array}$ & \\
\hline Extension of best practices and leadership success stories & $\begin{array}{l}\text { 10/23 Television broadcasts } \\
\text { 21/33 Radio Broadcasts } \\
10 \text { News Broadcast } \\
01 \text { Press Trip }\end{array}$ & $\begin{array}{l}\text { Restricted Broadcast Channels } \\
\text { Strengthen the collaboration with the } \\
\text { regional media in broadcasting the } \\
\text { program in the regions }\end{array}$ \\
\hline Train customary chiefs in leadership & & $\begin{array}{l}\text { Scheduled for the 3rd quadrimester (Week } \\
\text { of } 27 \text { October 2008) }\end{array}$ \\
\hline Citizen Mobilization and Participation & $\begin{array}{l}15 \text { training and sensitization sessions } \\
\text { A } 2 \text { month training promotion }\end{array}$ & $\begin{array}{l}\text { NLIM/CNPC/Civil Society Forum } \\
\text { NLIM/Faculty of Theology }\end{array}$ \\
\hline
\end{tabular}




\section{IMPLEMENTATION OF THE MAP: NATIONAL SOLIDARITY}

\section{ANALYSIS OF PRIORITY INDICATORS}

Number of national cultural (physical and non physical) heritages preserved

During the $1^{\text {st }}$ term 2008, four (04) categories of ancient cultural heritages were rehabilitated and restored, out of the six (06) planned ones (completion rate: 66\%). Activities aimed at contributing to the achievement of this indicator were conducted and include:

- the inventory and conservation on audiovisual and written media of 33 traditional Malagasy dances and music that are almost on the way of disappearing

- the inventory and conservation on audiovisual and written media of the Zafimaniry woodwork expertise;

- the inventory of traditional sports;

- the preservation of non physical heritages on brochures, such as: Fanompoambe, Savoir vivre, Famadihana, "Coup d'oeil".

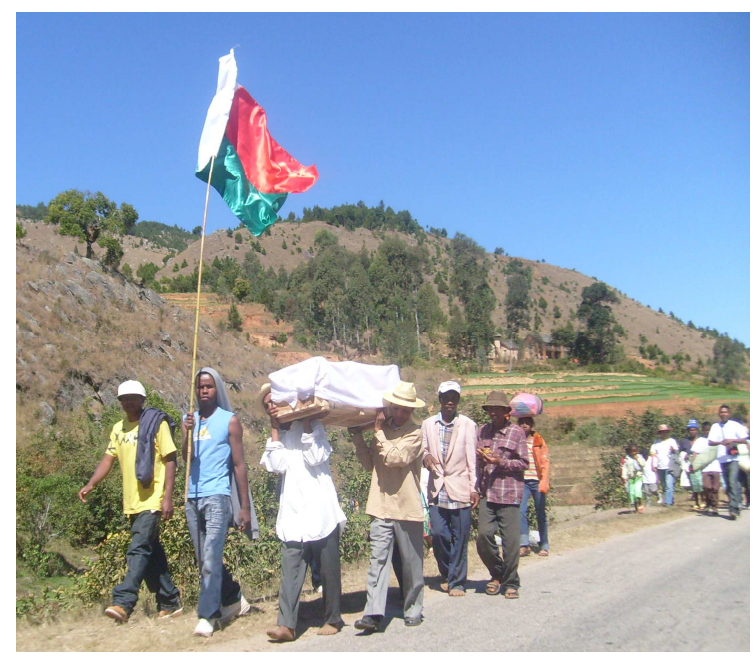

\section{Number of National Artistic Prizes Awarded}

- 1 prize batch for the "accordion" Contest awarded out of the 8 planned ones (12.5\%)

\section{Number of Art, Art Crafts, and Design Creations Supported}

Three (03) series of art creations were supported out of the 10 planned ones (33\%).

- International exhibition in South Africa:

- Participation of 2 Valiha players;

- 30 artworks (plastic) exhibited.

- Creation of Contemporary Dance by the TAHALA Company: Representation of Madagascar in Tunis "Danse Afrique Danse";

12 creations of visual art: $3^{\text {rd }}$ short films meeting in Madagascar.

Cumulative number of Regions supported in the organization of cultural events representative of their culture

- One Region supported ("Donia" Festival) out of the 9 Regions planned for this year (completion rate: $11 \%$ ). Discrepancies are due to material and financial problems.

By its mission, the NOAC is essentially called on operating in decentralized territorial collectivities for the valorization of regional specificities (Festivals; itinerant exhibitions; training of local artists, etc.). This requires adequate means, such as 4WD cars and substantial financial means.

Number of advertorials and documentaries produced

Four (04) advertorials and/or documentaries were produced out of the 04 ones planned (completion rate $100 \%)$
- "Mirehareha amin'ny maha Malagasy" broadcasted on the national television;

- Randrana andafy on MBS;

- Fito anabo 1 on MBS

- Awareness-raising media: Clip entitled "Hosoka", Brochures, Calendars.

\section{Number of brochures published}

Seven (07) brochures published (completion rate: 100\%):

- 2 issues of the "VAKOKA" information bulletin

- Catalogue on Malagasy traditional dances and music that are almost on the way of disappearing

- Brochure on the six (06) museums under the Ministry's supervision.

- Brochure on the Zafimaniry culture and woodwork expertise

- 2 brochures respectively entitled: "Kabary, vakoka tsy tontan'ny ela" and "Fanandroana tombamaso"

Number of cultural events created and supervised

- Two (02) regional cultural events on the topic: "True fihavanana: folklore, traditional literature as vectors of development" in the phase of preparation

Holding of events: DIANA in July and Haute Mahatsiatra in October, topic defined during the Presidential Dialogue.

\section{Number of challenges organized (organization of selected sport contests)}

Two challenges organized out of the three ones planned (66\%):

- Kitra fokontany in Toamasina 


\section{IMPLEMENTATION OF THE MAP: NATIONAL SOLIDARITY}

- Kitra fokontany in Taolagnaro

\section{Number of contests organized for the best} artists, sportspeople, and partners

Two contests organized out of the three planned (66\%):

- 01 Cultural contest organized: National "accordion" contest;

- 01 series of contests organized during Zafimaniry Days: prize of the Best Stall, prize of the Best Craftsperson, and prize of the Best Folklore Performance.

\section{Number of conventions signed between a Region and a Private Company for participation in a great event}

One Convention signed between the Ministry and the COFESTIN (Organizer of the Donia Festival)

Leadership Capacity Building among Members of civil society organizations and public sector officials, and Conduct Monitoring

\section{Capacity Building at Decentralized Level}

- All 22 Regions have benefited from the trainings (100\%). The subsidy in MAP budget fostered the training activities, hence the achievement of the objective. In addition, need for reinforcement in monitoring and evaluation.

- Training of 18 Districts out of 119 (15\%). Constraints are due to overlap with the election period. However, the training program is budgeted and the establishment of the PGDI2 financing is pending.

- Grouping up of 1,546 mayors at lavoloha (100\%).

\section{Training at Central Level}

- Training of 1,084 people in Short Training Courses (3 to 5 days) out of the 645 planned ones (168\%). NLIM provides an efficient and effective training, hence the related increasing demand.

- 1 to 3 day Thematic Workshop for 2,500 people out of the 4,600 planned ones (54.5\%). Confirmed renown for NLIM in terms of leadership: infrastructure and conference organization fostered further demand.

- Leadership course for 157 people, but necessity for a formal and more structured strategy

\section{Number of annually organized cultural and sport events promoting Interregional Exchange}

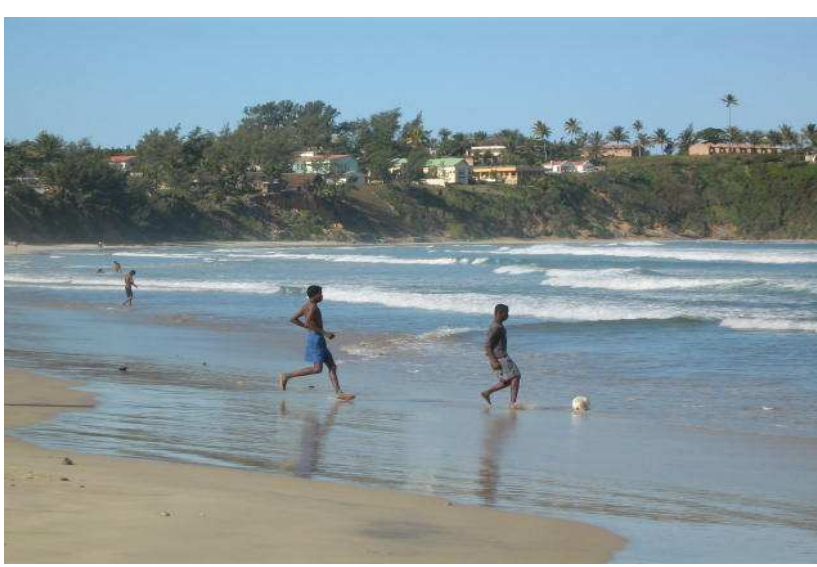

Organizing cultural events encourages dialogue and fosters culture sharing while strengthening national pride. Such events did reflect: i) the Professionalism of technicians in designing, conducting and animating cultural activities; ii) the collaboration with a network of partners involved in cultural development (Alliance Française).
- Series of Angano (tales), including: "Ny samoina alaina amin'ny vavany, ny olona afatotra amin'ny lelany “; Ny Hasin'ny teny teo amin'ny malagasy 08/02/08; Ibonimasibonimanoro; Ny Hasin'ny vady sy ny tokantrano ary ny lanjan'ny zanaka eo amin'ny malagasy 14/03/08; Ifaralahy diso fangataka, Ny fanehoan'ny malagasy ny fifandraisany amin'Andriamanitra 11/04/08; Imahazendana 09/05/08; Nosy Madagasikara, Ny toeran'i Madagasikara eo anivon'izao tontolo izao 13/06/08; Hain-teny, don-tany sy kapo tandroka.

Conference on the Topics:

- “Ny lalan-tsain'ny malagasy takarina avy amin'ny lalao Fanorona" 05/03/08;

- National solidarity and Organization: Status 04/06/08 ;

- "The Malagasy woman before colonization" 08/03/08; Women's International Day.

Forum on contemporary literature: Tononkalo/ Tononkira (Poems/Lyrics)

- Artist Singer Samoela 20/06/08;

- Artist Singer Henri Ratsimbazafy "Hira ho anao";

- Haingo "Ilo".

Exhibitions

- “Fanorona" Photos and game media, 05 to 08/03/08;

- Paintings including Raparivo;

- "Ny vary eo amin'ny fiaraha-monina Malagasy" Photos and books 04 to 07/06/08.

Sharing "Arofototse": Antandroy ways and customs, music and folklores

- Beko/Beko\&Blues 20/02/08;

- Fusion/Beko 16/04/08; 


\section{IMPLEMENTATION OF THE MAP: NATIONAL SOLIDARITY}

- Mangaliba/Tsapike 21/05/08;

- Beko 18/06/08.

Leisure: stage performances

- Teatra vakiana (FMTM);

- 5 projections of documentary and fiction films;

- 5 sessions of Tales for children;

- public and private media, various institutions, local artists, associations and NGOs).

Decreasing number of youth and children having no birth certificate

- the proportion of children and youth under 18 having no birth certificate, estimated at $31 \%$, seems to have decreased during this 1 st term 2008 (31.2\% in 2007). The objective set for 2008 is $24 \%$. The discrepancy is due to lateness in signing AWPs and in releasing funds. However, outlooks for the improvement of procedures are under way to increase this rate by making funds available to the 209 new targeted Communes.

- The computerization of civil status is aimed at achieving this indicator. As such, as part of the "POATELO" operation, 34 Councils of Administrative Boroughs and Districts benefited from the computerization of their civil status (completion rate: $2 \%$ ). A $100 \%$ achievement is expected at the end of the operation.

- A new Law on birth registration is approved in January 2008

- Competences were given to Heads of District to draft birth deeds

Low number of athletes participating in
international contests

During the $1^{\text {st }}$ term, the athletes' rate of participation in international competitions is very low, approximately
$14.6 \%$ corresponding to only 114 athletes out of the 776 planned distributed over the various disciplines.

Such weakness is explained namely by:

- The initial number which has been reduced to the quarter after the application of the selection criteria: only about one athlete out of four has been able to fulfill the required technical conditions;

- The international contests to which Madagascar planned to participate will be held instead during the second semester of the year.

\section{Number of law texts developed}

Texts have been developed to better establish and formalize sport activities: two (2) texts have been finalized out of the 3 planned standard statuses of the (Unisport, Omnisport, and Affinitaire), of which: the Standard Status of the Unisport Federation and the Draft Standard Status of the Omnisports Federations.

Furthermore,

- One first draft of the framework document of the National Policy of Sports has been developed;

- A draft Status for High Level Athletes has been developed.

\section{Promoting gender equality and women's autonomy}

Several actions were taken to attain the objectives set, so as to achieve this indicator. During the term, good performance was recorded:

- Fifteen (15) gender focal points are operational out of the 17 planned (completion rate: $88.24 \%$ );

- Networks of women leaders are operational in 11 Regions (completion rate: $50 \%$ ).
Improvement of the access of vulnerable groups to basic social services

Management actions were undertaken to achieve this indicator:

- Three (03) villages of social and economic insertion and rehabilitation are supported with production equipment (Ankarefo, Ampivoarana, and Andranofeno in the District of Ankazobe) instead of the 02 villages planned;

- 300 OVC (Orphans, Vulnerable Children) families are supported through Income Generating Activities and school assistance, out of the 300 (i.e., 100\%);

- 21 OVC sites are being set up (completion rate: $100 \%$ ).

Concerning the improvement of the security systems of the vulnerable and poorest:

- Four (04) networks of children's rights protection are set up, out of the 06 planned (66.67\%);

- Two cities, namely Antananarivo Renivohitra and Fianarantsoa I are concerned by the LEMIZO initiative out of the 04 planned (completion rate: $50 \%$ ).

\section{Safety Net}

Efforts have been made by the Government to secure access to basic food products and income generating activities for the most vulnerable households and strengthen resilience to rural community based shocks.

Nutritional Support, Income and Employment Generation:

The National Nutrition Office (ONN) in collaboration with the nutrition and food security sectors of the Ministries MINSANPF, MEN, MAEP, and the partners WFP, UNICEF... have been working together since May 2008 for developing an action plan in order to reduce the 


\section{IMPLEMENTATION OF THE MAP: NATIONAL SOLIDARITY}

vulnerability of the target groups in all urban, suburban, and rural areas, and to mitigate the impact of the worldwide food crisis. In that regards:

- 100 community based subprojects have been achieved over 151 Fokontany in 99 communes.

- 522,725 people-day temporary employments have been established for 28,127 beneficiaries.

- 335,378 linear meters of irrigation and dredging canals have been rehabilitated, with an estimate of cultivable surface area of 50,036 ha

Considering the current context, HIMO work as part of the activities of the Unit for Coordinating the Projects for Economic Recovery and social Action (CCPREAS) were temporarily suspended. However, the achievements related especially to ongoing construction and rehabilitation work for 16 buildings.

The number of formal employments established at the level of the Ministry of Civil Service, Work, and Social Laws amounts to 5,212. A number of 75 working children from vulnerable groups are trained st the Manjary Soa Center.

\section{Responses to Post Disaster Emergencies:}

The country was seriously affected by the passage of successive cyclones; FAME and IVAN were the most intensive ones, destroying many hydro agricultural infrastructures and harvests. The Unit for Nutritional Prevention and Security (UPSN), in its quality as an operational GRC Unit for ONN represented within the CRIC of the National Office for Risk and Disaster Management:

- Intervened through: (i) the cleaning of some victims of such disasters, (ii) the equipment with small batches of materials (shovels, spades, wheelbarrows...) for cleaning work, and (iii) agriculture recovery work through the rehabilitation of destroyed hydro agricultural networks. In that respect, 41 Communes of 30 Districts were involved in an emergency program

- Handing over of donations to BNGRC for the population affected by the disasters : 20 bags of sugar and 10 bags of rice

- Participated in the assessment of damages and losses.

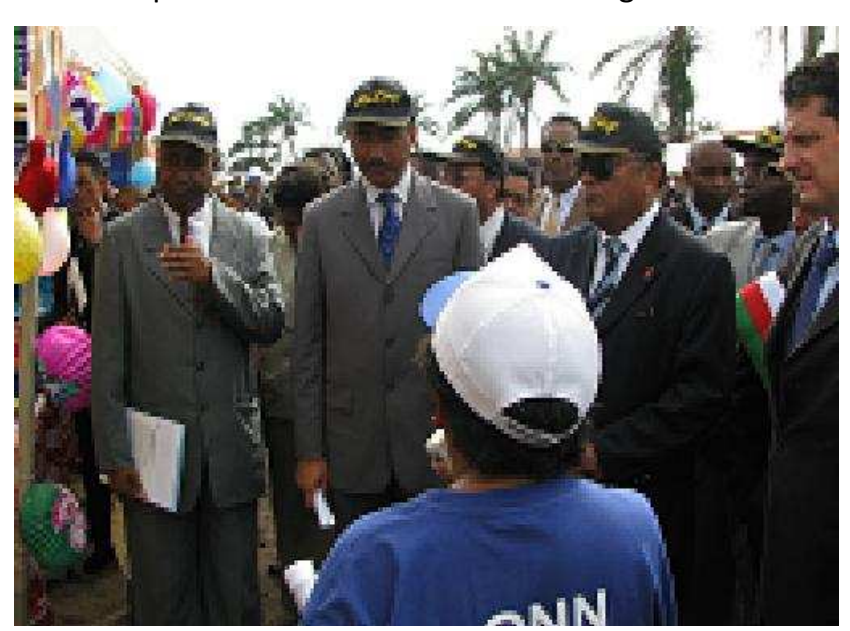

\section{Challenges AND OUTLOOKS}

- Inventory, collection analysis, and dissemination of information on the Malagasy culture and values, to optimize their management and use

- Making the cultural database, counseling services, and guidelines available to interested parties

- Development of researches on culture

- Promotion of creative youth

- Integration of the cultural aspirations, trends, and life of the different local communities concerned with the social and economic development process (Project/Program) and development of citizen participation

- Upgrading and application of legal frameworks governing the sports, culture, youth, and leisure sectors

- Development of cultural industries in all sectors

- Professionalizing and promoting of cultural actors and operations and their occupations

- Development of standardized sports and youth structures and infrastructures (Gymnasium, Sport Complexes, Multi-games fields, Youth clubs, etc.)

- Development of standardized structures and infrastructures for art teaching (Fine Art and Visual Art School, Drama School, Music Academy, Literature School, etc.), conservation of historic objects (museum, ancient works restoration workshop, expertise laboratory, etc.)

- Intensive research for financial partners and potential investors in the cultural sector.

\section{RECOMMENDATIONS}

- Clarify the programming and planning of leadership training with all ministries and regions.

- Institutionalize and budget for the training by NLIM.

- Increase the amount of budget (RPI) allocated to the "pre-exploitation fees" and "IT equipment" lines of the Public Investment Program (PIP) to put increased means (fuel, phone credits, etc.) at the disposal of local structures, for the performance of supervision, coaching, and data collection-recovery missions;

- Hold a donors mobilization meeting to finance activities planned for in the program. 


\section{IMPLEMENTATION OF THE MAP: NATIONAL SOLIDARITY}

- We perfectly know that some countries invest much in the sport and culture sectors. This should urge us to increase the budget allocated to the sport and cultural development, which annually amounts to only approximately $0.5 \%$ of the full budget.

- Madagascar is rich in biodiversity, cultural diversity, and resources. These should be managed and used adequately and in compliance with standards. Efforts should also be made to attract potential investors.

- Lack of infrastructures is a serious impediment to sports and cultural development.

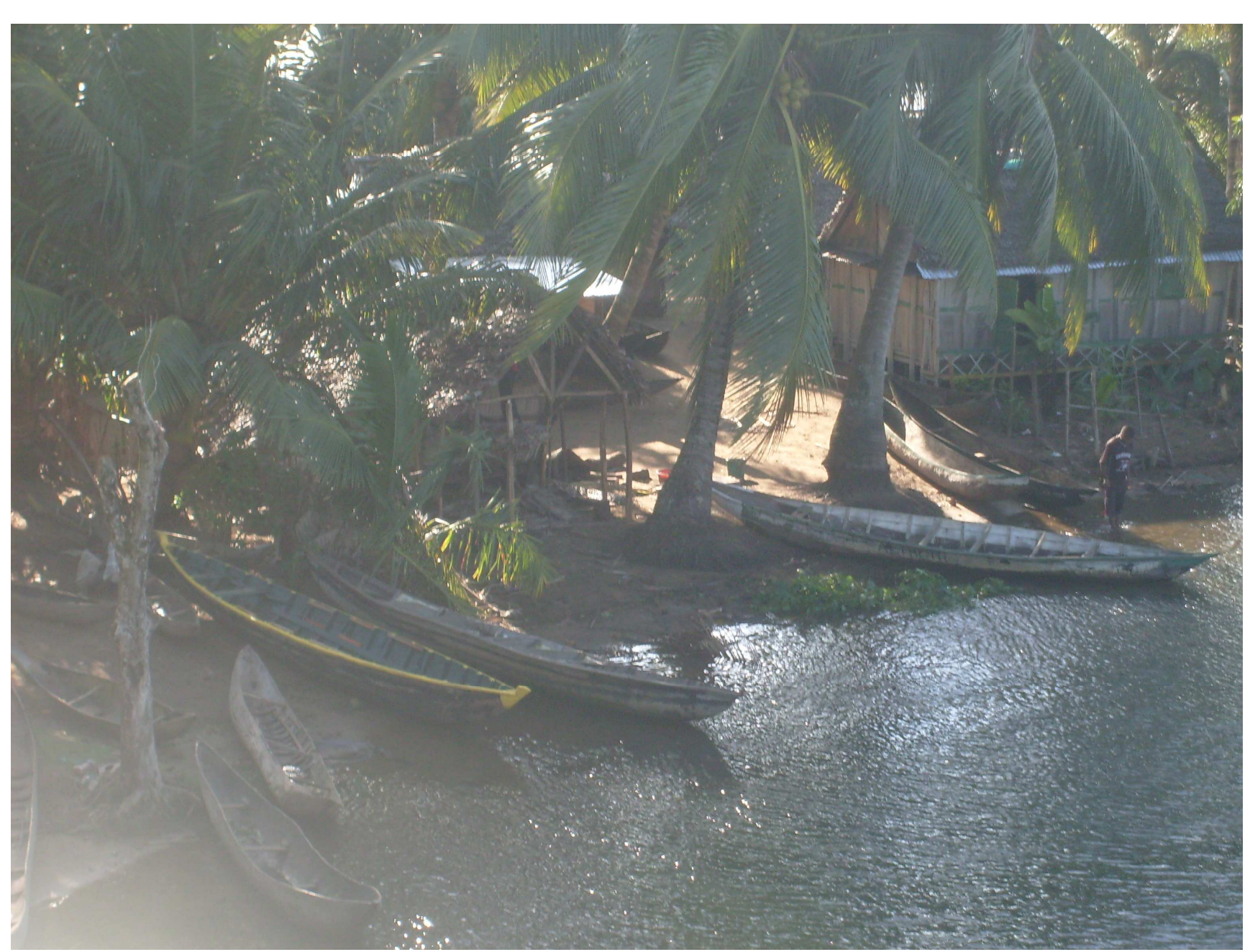




\section{FINANCING OF THE MAP}

Overall Situation of Financing/
Disbursements

The total resources recorded over the first semester are about Ariary 1271.1 Billion of which $69.2 \%$ internal resources and $30.7 \%$ foreign resources. Tax revenues amounting to some Ariary 1,021 Billion go on generating the larger share of such domestic resources. The $37 \%$ of total resources are allocated to investment expenditures, $28 \%$ to staff expenditures, $22 \%$ to running expenses, and $11 \%$ to the other expenditures.

We should notice that public resource mobilization and earmarking over these first six months result in an overall cash based balance of Ariary 66 Billion in which the net foreign financing is about Ariary 129.7 Billion. Running $37 \%$ of these total resources are allocated to investment, $28 \%$ to personal expenditures, $22 \%$ to functioning and $11 \%$ other expenditures.

Based on the annual programming for regulating expenditures at $50 \%$ for this first semester, the $37 \%$ overall budget execution rate, i.e., Ariary 1,271 Billion of committed expenditures is still moderate. Therefore, improvements of the budget reporting system, the financial control and external controls are asked for. In addition, the appointment of the officials in charge of the Budget execution in the Ministries should be activated.

Besides, the current Government strategy to leverage education for development is in line with the allocation of the highest share of the total Budget to such sector which accounts for $18 \%$. The Budget shares allocated to the other priority sectors which are Health, Agriculture, Water and Forests, and Public Works, are respectively $8.3 \%, 8.5 \%, 2.3 \%, 2 \%$, and $11.5 \%$.
Table 13 : Public Resources / Earmarking (in Ariary Billions)

\begin{tabular}{|c|c|c|c|}
\hline & $\begin{array}{c}2007 \\
\text { Achieved }\end{array}$ & $\begin{array}{c}2008 \\
\text { Programmed } \\
\text { (Amending } \\
\text { Finance Law) }\end{array}$ & $\begin{array}{l}\text { Committed as } \\
\text { of June } 2008\end{array}$ \\
\hline Total resources & 2,594 & 3,422 & $1,271.1$ \\
\hline $\begin{array}{l}\text { Internal } \\
\text { resources }\end{array}$ & 1,693 & 2,019 & 880.5 \\
\hline $\begin{array}{l}\text { Of which tax } \\
\text { Revenues }\end{array}$ & 1,573 & 1,931 & $1,021.5$ \\
\hline $\begin{array}{l}\text { Non tax } \\
\text { Revenues } \\
\end{array}$ & 35 & 32 & 32.4 \\
\hline $\begin{array}{l}\text { Net Internal } \\
\text { Financing }\end{array}$ & 83 & 90 & -198.7 \\
\hline $\begin{array}{l}\text { Privatization } \\
\text { Funds Revenues }\end{array}$ & 2 & 2 & 2.2 \\
\hline $\begin{array}{l}\text { Exceptional } \\
\text { Revenues } \\
\end{array}$ & - & 1.40 & 0.20 \\
\hline $\begin{array}{l}\text { Internal Arrears } \\
\text { Variation }\end{array}$ & - & -52.70 & 22.90 \\
\hline External Resources & 901 & $1,402.7$ & 390.6 \\
\hline Of which Grants & 593 & 788 & 260.9 \\
\hline $\begin{array}{l}\text { Net External } \\
\text { Funding } \\
\end{array}$ & 308 & 615 & 129.7 \\
\hline Total Expenditures & 2,594 & 3,422 & $1,271.1$ \\
\hline Staff Expenditures & 711.2 & 815 & 360.8 \\
\hline $\begin{array}{l}\text { Operating } \\
\text { Expenditures } \\
\end{array}$ & 432.4 & 755 & 284.9 \\
\hline Capital Expenditures & $1,049.9$ & 1,582 & 476.8 \\
\hline $\begin{array}{l}\text { Of which } \\
\text { Internal } \\
\text { Financing }\end{array}$ & $3,14.9$ & 468 & 111.8 \\
\hline $\begin{array}{l}\text { External } \\
\text { Financing } \\
\end{array}$ & 735 & 1113 & 365.0 \\
\hline Other Expenditures & 400.3 & 270 & 148.6 \\
\hline $\begin{array}{l}\text { Of which debt } \\
\text { Interest }\end{array}$ & 155.6 & 140 & 80.3 \\
\hline
\end{tabular}

ource: MFB-OGT - Juin 2008

In addition, the social sectors of Education and Health recorded respectively commitments rates of $52 \%$ and $35 \%$. Such commitments account for $34 \%$ of total sector based commitments as of the first semester.
Table 14 : Operating and Investment Expenditures of Priority Sectors (in Ariary Billions)

\begin{tabular}{|c|c|c|c|}
\hline & 2007 & $\begin{array}{l}\text { Amending } \\
\text { Finance Law } \\
2008\end{array}$ & $\begin{array}{l}\text { Committed 1st } \\
\text { Semester } \\
2008\end{array}$ \\
\hline \multicolumn{3}{|c|}{ Total for all Institutions and Ministries } & \multirow[b]{2}{*}{1,133} \\
\hline Total & $1,726,1$ & 3,073 & \\
\hline Salary & 636,3 & 765 & 690 \\
\hline Off Salary & 527.9 & 684 & 301 \\
\hline Investment & 561.9 & 1,624 & 141 \\
\hline Health & 152.2 & 256 & \multirow{8}{*}{299} \\
\hline Salary & 52.6 & 67 & \\
\hline Off Salary & 43.8 & 49 & \\
\hline Investment & 55.8 & 138 & \\
\hline Education & 392.2 & 570 & \\
\hline$\overline{\text { Salary }}$ & 231.5 & 278 & \\
\hline Off Salary & 109.4 & 121 & \\
\hline Investment & 51.2 & 170 & \\
\hline Agriculture & 63.3 & 263 & \multirow[t]{4}{*}{40} \\
\hline Salary & 13.1 & 17 & \\
\hline Off Salary & 11.2 & 20 & \\
\hline Investment & 39.0 & 226 & \\
\hline Water and Forests & 15.2 & 70 & \multirow[t]{4}{*}{12} \\
\hline Salary & 2.6 & 5 & \\
\hline Off Salary & 1.0 & 2 & \\
\hline Investment & 11.6 & 63 & \\
\hline Justice & 43.6 & 61 & \multirow[t]{4}{*}{38} \\
\hline Salary & 23.7 & 30 & \\
\hline Off Salary & 16.5 & 22 & \\
\hline Investment & 3.4 & 9 & \\
\hline Public Works & 142.5 & 353 & 42 \\
\hline Salary & 6.8 & 8 & \\
\hline Off Salary & 1.4 & 9 & \\
\hline Investment & 134.3 & 336 & \\
\hline
\end{tabular}

Source: MFB/DIP- June 2008

\subsection{INTERNAL FINANCING / DISBURSEMENTS}

The internal resources recorded over this first semester amount to Ariary 880 Billion, i.e., $44 \%$ of annual programming. Thanks to the improvements made through the various reforms in State Public Finance Management, tax revenues are continuing to provide the majority of such resources. The $15.7 \%$ 


\section{FINANCING OF THE MAP}

disbursement rate of internal financing remains low; this is only disbursement of Counter value funds. The same applies for the commitment rate which is only $25 \%$.

Table 15 : Public Investment Program Internal Financing

(in Ariary thousands)

\begin{tabular}{|l|l|l|}
\hline internal financing sources & $\begin{array}{l}\text { programmed } \\
\text { (amending finance } \\
\text { law 2008) }\end{array}$ & committed \\
\hline internal equity & $285,320,175$ & $81,969,764$ \\
\hline internal equity /vat & $140,532,825$ & $23,445,096$ \\
\hline equity/dti & $4,500,000$ & $11,474,908$ \\
\hline equity/countervalue funds & $24,767,000$ & 359,846 \\
\hline total & $455,120,000$ & $117,249,614$ \\
\hline
\end{tabular}
$455,120,000$

The capital expenditures of some Ariary 476.8 Billion, i.e., $30 \%$ of annual programming (Amending Finance Law 2008) are financed through $23.5 \%$ of our internal resources.

\subsection{EXTERNAL FINANCING / DISBURSEMENTS}

In the present first semester of 2008 , the $36.5 \%$ rate of disbursement for external financing, all donors considered, i.e., Ariary 425.7 Billion, remains moderate. Subsidies provide more than $50 \%$ of the total of such disbursements.

Table 16 : Public Investment Program External Financing

(in Ariary thousands)

\begin{tabular}{|l|r|r|}
\hline $\begin{array}{l}\text { EXTERNAL } \\
\text { FINANCING } \\
\text { SOURCES }\end{array}$ & $\begin{array}{l}\text { PROGRAMMED } \\
\text { (Amending Finance } \\
\text { Law 2008) }\end{array}$ & \multicolumn{1}{l|}{ DISBURSSED } \\
\hline SUBSIDIES & $596,610,000$ & $220,155,569$ \\
\hline STATE LOANS & $552,500,000$ & $188,472,832$ \\
\hline $\begin{array}{l}\text { OTHER PUBLIC } \\
\text { LOANS }\end{array}$ & $20,000,000$ & 360,756 \\
\hline TOTAL & $1,169,110,000$ & $408,989,157$ \\
\hline
\end{tabular}

Source: MFB/DIP - June 2008
It should be noted that the current status in commitment and disbursement rates of external financing depends on the availability of related information.

Table 17 : Status of foreign financing disbursement (In Ariary thousands)

\begin{tabular}{|c|c|c|c|c|}
\hline \multirow[b]{2}{*}{ Donors } & \multirow[t]{2}{*}{2007} & \multicolumn{3}{|c|}{ Disbursed Amounts as of June 2008} \\
\hline & & Subsidies & State Loans & $\begin{array}{c}\text { Total } \\
\text { Disbursed }\end{array}$ \\
\hline Multilateral & 655 & 194.5 & 141,9 & 336.4 \\
\hline IDA & 310,00 & 4,7 & 123,6 & 128,3 \\
\hline UE/BEI & 219,60 & 72,7 & - & 72,7 \\
\hline UE/FCV & & 17.3 & & 17.3 \\
\hline Of which PARP 2 & & $(15.6)$ & & $(15.6)$ \\
\hline UNICEF & 46,60 & 33,9 & - & 33,9 \\
\hline US AID & & 24,8 & - & 24,8 \\
\hline MCC & - & 24,9 & - & 24,9 \\
\hline FAD/BAD & 39,00 & 5,3 & 13,2 & 18,5 \\
\hline OTHERS & 39,80 & 10,9 & 5,1 & 16,0 \\
\hline Bilateral & 203,30 & 42,8 & 46,5 & 89,3 \\
\hline China & - & - & 46,5 & 46,5 \\
\hline France /AFD & 33,60 & 16,7 & - & 16,7 \\
\hline JAPAN & 14,40 & 16,3 & - & 16,3 \\
\hline Germany & 17,70 & 9,8 & - & 9,8 \\
\hline OTHERS & 137,60 & - & - & - \\
\hline TOTAL & 858,30 & 237.3 & 188,4 & 425.7 \\
\hline
\end{tabular}

The multilateral financing that were disbursed amount to some Ariary 336.4 Billion, and bilateral ones

In terms of disbursement of Subsidies on multilateral financing, UNICEF, USAID, as well as MCC are the main three donors, the respective disbursement rates of which are $108.22 \%, 75.7 \%$, and $66.10 \%$. Regarding bilateral financing, Germany, the disbursement rate of which is $71 \%$ is in pole position.

In terms of disbursement of loans on multilateral financing, IDA is on the front line and its disbursement rate is $47 \%$. On the side of bilateral financing, the rate of disbursement of loans with China is the highest one at $62.05 \%$ amount to Ariary 89.30 Billion.
Regarding volume and any received financing type, IDA, the European Union (EU), UNICEF, as well as China, are the main donors. Moreover, the European Union has disbursed Ariary 15.6 Billion as budgetary assistance added to subsidies of projects.

Table 18 : Use of Foreign Resources by Sector and Sub sector

\begin{tabular}{|c|c|c|}
\hline \multicolumn{3}{|c|}{ (In Ariary Billions) } \\
\hline Allocated to & $\begin{array}{c}\text { External disbursed } \\
2007 \\
\end{array}$ & $\begin{array}{c}\text { External disbursed } \\
\text { June } 2008\end{array}$ \\
\hline $\begin{array}{l}\text { Agriculture/livestock/fish } \\
\text { eries }\end{array}$ & 77,40 & 52,10 \\
\hline Industries and crafts & - & \\
\hline Mining & 13,80 & 6,00 \\
\hline Tourism & - & \\
\hline Environment & 53,30 & 16,10 \\
\hline PRODUCTVE SECTOR & 144,50 & 74,20 \\
\hline Transports & 310,20 & 98,40 \\
\hline Telecommunications & & \\
\hline Energy & 7,10 & - \\
\hline Water and Sanitation & 8,10 & 8,60 \\
\hline $\begin{array}{c}\text { Town planning and Land } \\
\text { Management }\end{array}$ & 70,20 & 92,70 \\
\hline $\begin{array}{l}\text { INFRASTRUCTURE } \\
\text { SECTOR }\end{array}$ & 395,60 & 199,70 \\
\hline Education and Training & 40,80 & 36,10 \\
\hline Health & 59,50 & 41,80 \\
\hline Social Action & 136,40 & 26,20 \\
\hline SOCIAL SECTOR & 236,70 & 104,10 \\
\hline Public Powers & 22,80 & 10,40 \\
\hline Sovereignty & 1,00 & \\
\hline Economy and Finance & 58.1 & 20,00 \\
\hline Overall Administration & 0.4 & - \\
\hline $\begin{array}{l}\text { ADMINISTRATIVE } \\
\text { SECTOR }\end{array}$ & 82,30 & 30,40 \\
\hline TOTAL & 859,10 & 408,40 \\
\hline
\end{tabular}

Source: MFB/DIP-June 2008

A larger share of such foreign resources is earmarked to infrastructure work, i.e., $49 \%$; and $25.5 \%$ of them are allocated to the social sector. Such expenditures in infrastructures involve mainly town work related to land management and transportation. 


\section{FINANCING OF THE MAP}

The productive sector benefited from the $18 \%$ of such foreign financing and the remaining part of the disbursements is earmarked to the administration.

Such foreign resource earmarking corresponds

to the order of priorities of the Madagascar Action Plan

in order to support first the country development process depending on the improvement of its infrastructures, but also in order that the contest is favorable to sustainable development.

\subsection{SITUATION OF EXTERNAL PAYMENTS}

Compared to the performance in 2007, export revenues raised by $11 \%$. Nevertheless, the rate of coverage of imports by exports which is about $42 \%$,i.e 15 points lower than the figures, one year ago.

Indeed, Madagascar trade exchanges with abroad resulted in a deficit trade balance of some SDR 564.5 Million (about Ariary 1,472 Billion) in which export revenues are estimated at SDR 414.3Million and import ones at SDR 978.7 Million. The balance status therefore deteriorated compared with the performance in the same period of last year in which the trade balance underwent a deficit of SDR 279 Million.

Over this first semester, the Foreign Direct Investment Flow played a predominant role in the status of the balance of payments which, despite a current balance marked by some deficit of SDR 133.8 Million in 2007) remains positive. Such flows increased by over $100 \%$ compared with the performance as of the first semester of 2007.

Consequently, the balance of payments highlighted an overall balance of some SDR 11.9 Million. But there should also be noted the influence, on such balance, of the increase in the withdrawals made as of the first semester; such withdrawals have increased by $100 \%$ compared with the situation in the same period in 2007. Our currency reserves in import months are estimated at 2.3 versus an achieved 3 Months in the first semester of 2007.

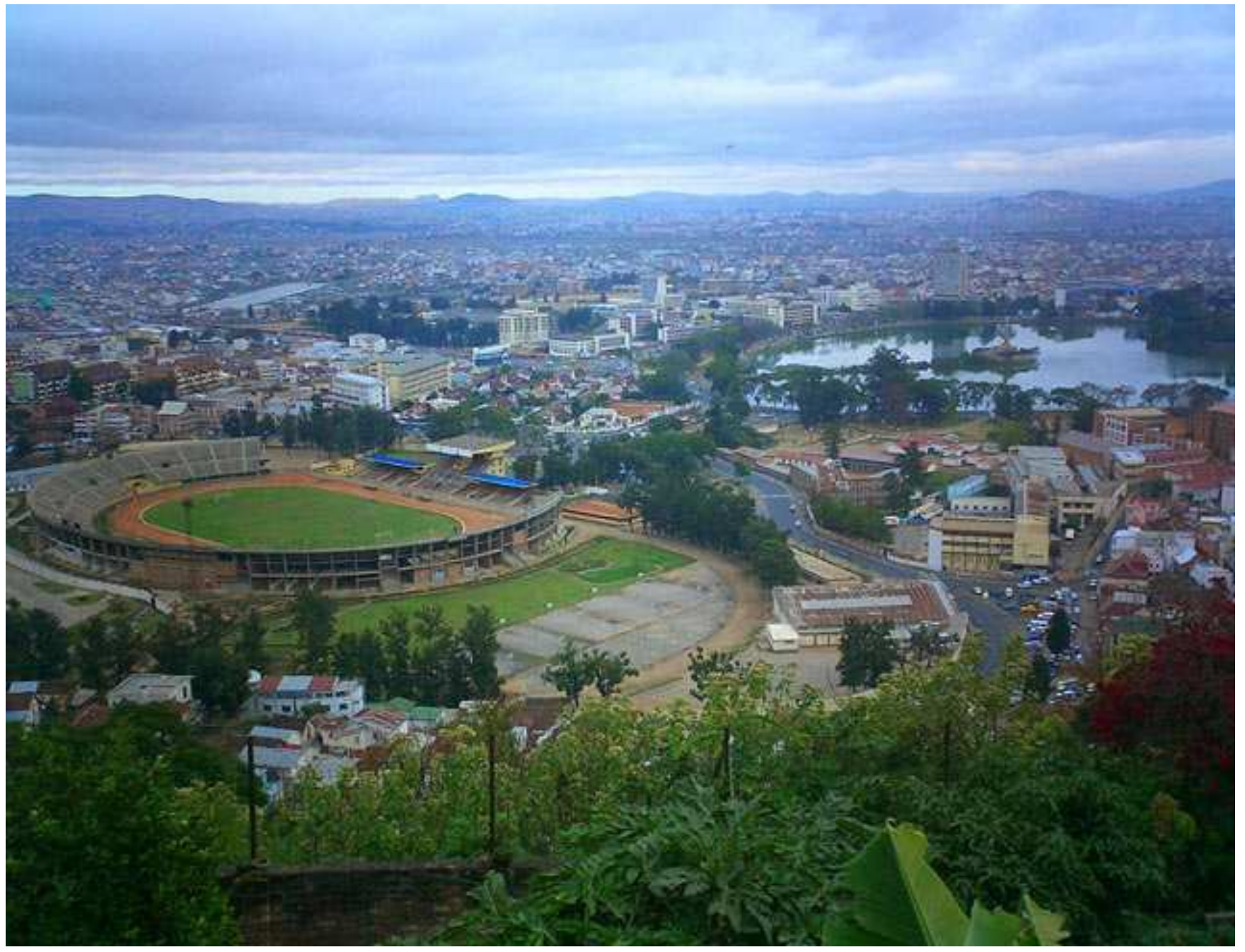




\section{PRIORITY INDICATORS}


COMMITMENT 1: RESPONSIBLE GOVERNANCE

\begin{tabular}{|c|c|c|c|c|c|c|c|c|c|c|}
\hline \multirow[b]{2}{*}{ Indicator Name } & \multirow[b]{2}{*}{2006} & \multirow[b]{2}{*}{2007} & \multicolumn{2}{|r|}{2008} & \multirow{2}{*}{$\begin{array}{c}2012 \\
\text { SNISE } \\
\text { Objective }\end{array}$} & \multirow{2}{*}{$\begin{array}{c}2015 \\
\text { MDG } \\
\text { Objective }\end{array}$} & \multirow[t]{2}{*}{ Definition of Indicators } & \multirow[t]{2}{*}{ Periodicity } & \multirow{2}{*}{\begin{tabular}{|c|} 
Verification \\
Source
\end{tabular}} & \multirow{2}{*}{ Observations } \\
\hline & & & Objective & $\begin{array}{c}\text { Achievement 1st } \\
\text { semester }\end{array}$ & & & & & & \\
\hline Crime Rate lower than or equal to 3.8 for 1000 & 4 & 1,8 & $<3,8$ & 0,75 & 2,6 & & Actually observed Number & Annual & MDN/SESI & \\
\hline Number of achieved urban security operations & 17702 & 35405 & 37175 & 35759 & & & & & SESI & \\
\hline Number of achieved marches maneuvers & & & 12 & 6 & & & & & MDN/SESI & \\
\hline $\begin{array}{l}\text { Implantation of at least seven (07) new Commissioner Offices for } \\
\text { Districts having none }\end{array}$ & 94 & 97 & 104 & 99 & & & Actually observed Number & & SESI & \\
\hline Number of implanted DAS & & & & 4 & & & & & MDN & \\
\hline Number of Set up Outreach Posts and Special Intrevention Groups & & & & 4 & & & & & MDN & \\
\hline Number of achieved rural security operations & & & 300 & 26 & & & & & MDN & \\
\hline Number of achieved general police rounds & 3000 & 3000 & 3750 & 3432 & & & & & SESI & \\
\hline Number ogf units established (special intervention force ) & & & & 1 pour les 3 corps & & & & & MDN & \\
\hline Number of cleaned and secured trade circuits & 31364 & 35405 & 37175 & 31035 & & & & & SESI & \\
\hline Number of red classified Districts that have been cleaned & 12 & $\begin{array}{r}\text { ramené de } \\
51 \text { à } 36 \\
\end{array}$ & 13 & 4 & 61 & & Actually observed Number & Annual & MDN/SESI & \\
\hline Number of established KIZO Guards & & & & 610 & & & & & MDN & \\
\hline Number of achieved general police rounds (TPG) & & & 3000 & 613 & & & & & MDN & \\
\hline $\begin{array}{l}\text { Number of gendarmerie units that have been set up and in line } \\
\text { with the new territory distribution }\end{array}$ & & & 15 & 7 & & & & & MDN & \\
\hline $\begin{array}{l}\text { Rate of increased effectiveness among Forces of Order in } \\
\text { repressing cattle thefts }\end{array}$ & & 10 & 30 & 84,6 & 60 & & $\begin{array}{l}\text { Actually observed Number } \\
\text { brought to } 100\end{array}$ & Annual & MDN/SESI & \\
\hline $\begin{array}{l}\text { Number of regional Dina homologated compared with the } \\
\text { number of dina sumitted to tribunals }\end{array}$ & & & & & & & & & MDN/SESI & \\
\hline Number of homologated dina that have been established & & 3 & 7 & & 17 & & Actually observed Number & Annual & MDN/SESI & \\
\hline $\begin{array}{l}\text { Number ofset up village based self defence entities (Mobile } \\
\text { Groups, Kalony, ...) }\end{array}$ & & & & & & & & & MDN/SESI & \\
\hline Number of Districts having the Social Security Plan & & 3 Régions & & 5 Régions et 29 Districts & 22 Régions & & & & MDN/SESI & \\
\hline Coverage Rate of the Exclusive Economic Zone (ZEE) & & 18 & 20 & & 40 & & $\begin{array}{l}\text { Covered surface area over total } \\
\text { surface area }\end{array}$ & Annual & MDN/SESI & \\
\hline $\begin{array}{l}\text { Number of flight hours made in the surveillance of air, land, and } \\
\text { sea space }\end{array}$ & & & $\begin{array}{c}330 \mathrm{~h} \text { de vol, } \\
150 \text { jours de } \\
\text { sortie en mer }\end{array}$ & $\begin{array}{r}54 \mathrm{~h} \text { de vol, } 21 \text { jours de } \\
\text { sortie en mer et } 25 \mathrm{~h} 25 \mathrm{mn} \\
\text { de sortie en vedette }\end{array}$ & & & & & MDN & \\
\hline World Bank Rule of Law Indicator (Base 100) & 48 & & & & 60 & & & Annual & World Bank & \\
\hline Average time limit for processing files: simple penal cases (day) & & 120 & & & & & $\begin{array}{l}\text { On average the case } \\
\text { processing timelimit }\end{array}$ & Annual & MINJUS & \\
\hline Average time limit for processing files : complex penal cases & & 450 & & & 180 & & $\begin{array}{l}\text { On average the case } \\
\text { processing timelimit }\end{array}$ & Annual & MINJUS & \\
\hline Ratio Convicted / alleged culprit in prisons & & & $51 / 49$ & $53 / 47$ & & & & & & \begin{tabular}{|l|} 
Indicator of \\
results that \\
determines \\
disbursement \\
of variable \\
tranches /EU
\end{tabular} \\
\hline
\end{tabular}


COMMITMENT 1: RESPONSIBLE GOVERNANCE

\begin{tabular}{|c|c|c|c|c|c|c|c|c|c|c|}
\hline \multirow[b]{2}{*}{ Indicator Name } & \multirow[b]{2}{*}{2006} & \multirow[b]{2}{*}{2007} & \multicolumn{2}{|r|}{2008} & \multirow{2}{*}{$\begin{array}{c}2012 \\
\text { SNISE } \\
\text { Objective }\end{array}$} & \multirow{2}{*}{$\begin{array}{c}2015 \\
\text { MDG } \\
\text { Objective }\end{array}$} & \multirow[t]{2}{*}{ Definition of Indicators } & \multirow[t]{2}{*}{ Periodicity } & \multirow{2}{*}{\begin{tabular}{|c|} 
Verification \\
Source
\end{tabular}} & \multirow[t]{2}{*}{ Observations } \\
\hline & & & Objective & $\begin{array}{l}\text { Achievement 1st } \\
\text { semester }\end{array}$ & & & & & & \\
\hline $\begin{array}{l}\text { Corruption Perception Index by Transparency International (base } \\
\text { 10) }\end{array}$ & & 3,2 & & 3,4 & 5 & & & Annual & BIANCO & \multirow{3}{*}{$\begin{array}{l}\text { Information } \\
\text { collection } \\
\text { under way }\end{array}$} \\
\hline $\begin{array}{l}\text { National Index on Integrity of actors in the National Integrity } \\
\text { System }\end{array}$ & & 2,83 & $\begin{array}{c}\text { hausse de } 0,5 \\
\text { point }\end{array}$ & & & & & & & \\
\hline $\begin{array}{l}\text { National Anti corruption Perception Index among Households;- } \\
\text { perception by Public agents and the Private Sector (CSI) }\end{array}$ & 2,5 & $\begin{array}{c}\text { hausse de } 0,5 \\
\text { point }\end{array}$ & 3,5 & & & & & Annual & CSI & \\
\hline $\begin{array}{l}\begin{array}{l}\text { Percentage of cases processed by BIANCO that are transmitted to } \\
\text { jurisdiction (\%) }\end{array} \\
\end{array}$ & & & 38 & 33 & 55 & & Percentage & Annual & BIANCO & \\
\hline $\begin{array}{l}\text { Percentage of procurements in the } 5 \text { pilot ministries Health, } \\
\text { Education, Transports, Public Works and Agriculture) which are } \\
\text { assessed as complying to procedures of the new regulatory and } \\
\text { legal framework (\%) }\end{array}$ & & 28,1 & $50 \%$ & $15 \%$ & & & $\begin{array}{l}\text { Ratio between the number of } \\
\text { compliant contracts and the } \\
\text { total number of contracts that } \\
\text { have been signed in these } 5\end{array}$ & Annual & ARMP & \\
\hline Tax Pressure rate $(\%)$ as a percentage of GDP & & 11,4 & 11,6 & 12,0 & 15,0 & & & Annual & MFB & $\begin{array}{l}\text { Indicator of } \\
\text { results that } \\
\text { determines } \\
\text { disbursement } \\
\text { of variable } \\
\text { tranches /EU }\end{array}$ \\
\hline PEFA (Public Expenditures and Finance Accountability): & & & & & & & & & & Discussion \\
\hline $\begin{array}{l}\text { Number of PEFA indicators with B scoring and above (overall } \\
\text { category) }\end{array}$ & & & 31 & 11 & & & & Tous les 2 ans & World Bank & \\
\hline $\begin{array}{l}\text { Number of PEFA indicators on budget preparation and execution } \\
\text { sur la préparation et exécution du budget (indicators } 1 \text { to } 7 \text { ) with B } \\
\text { scoring and above category (budget preparation and execution) }\end{array}$ & & & 4 & 2 & & & & Tous les 2 ans & World Bank & Bank \\
\hline $\begin{array}{l}\text { OR Number of PEFA indicators on budget monitoring (indicators } 22 \\
\text { to 25) with scoring higher than or equal to B (budget monitoring } \\
\text { category) }\end{array}$ & & & 2 & 1 & & & & Tous les 2 ans & World Bank & \\
\hline $\begin{array}{l}\text { OR Number of PEFA indicators on internal and external control } \\
\text { mechanism (indicators 20, 21, 26 to 28) with scoring higher than B } \\
\text { (internal and external controls) }\end{array}$ & & & & 0 & & & & Tous les 2 ans & World Bank & \\
\hline FDL established and operational (PGE) & & & & mis en place & & & & Annual & $\begin{array}{l}\text { MInter and } \\
\text { Decentraliza } \\
\text { tion }\end{array}$ & \\
\hline
\end{tabular}




\section{COMMITMENT 2: CONNECTED INFRASTRUCTURES}

\begin{tabular}{|c|c|c|c|c|c|c|c|c|c|c|}
\hline \multirow[b]{2}{*}{ Indicator Name } & \multirow[b]{2}{*}{2006} & \multirow[b]{2}{*}{2007} & \multicolumn{2}{|c|}{2008} & \multirow{2}{*}{\begin{tabular}{c|}
2012 \\
SNISE \\
Objective
\end{tabular}} & \multirow{2}{*}{\begin{tabular}{|c|}
2015 \\
MDG \\
Objective
\end{tabular}} & \multirow[b]{2}{*}{ Definition of Indicators } & \multirow[b]{2}{*}{ Periodicity } & \multirow[b]{2}{*}{ Verification Source } & \multirow[b]{2}{*}{ Observations } \\
\hline & & & Objective & $\begin{array}{r}\text { Achievement } \\
\text { 1st semester }\end{array}$ & & & & & & \\
\hline $\begin{array}{l}\text { Percentage of RN road networks that } \\
\text { have been tarred : } \\
\text { en bon état (\%) }\end{array}$ & & 48 & 61 & 48 & 91 & & $\begin{array}{l}\text { Condition of tarred National Roads (good, medium, poor condition) } \\
\text { according to combined circulability and transit criterion. Circulability: } \\
\text { permanence of their accessibility in month number / } 12\end{array}$ & semester based & $\begin{array}{l}\text { MTPM and CTD } \\
\text { Activity Reports }\end{array}$ & \\
\hline in medium condition (\%) & & 41 & 30 & 41 & 7 & & $\begin{array}{l}\text { Transit : average speed for covering the distance per category of motor } \\
\text { vehicle Total length of tarred RN: } 5713 \mathrm{~km} \text { in } 2007 \text { and } 7837 \mathrm{~km} \text { in } 2012\end{array}$ & semester based & $\begin{array}{l}\text { MTPM and CTD } \\
\text { Activity Reports }\end{array}$ & \\
\hline $\begin{array}{l}\text { Percentage of RN dirt road networks : in } \\
\text { good condition (\%) }\end{array}$ & & 10 & 10 & 11 & 56 & & $\begin{array}{l}\text { Condition of dirt RN good, medium, poor condition) according to } \\
\text { combined circulability and transit criterion. } \\
\text { Circulability : permanence of their accessibility in month number / } 12 \\
\text { Transit : average speed for covering the distance per category of motor } \\
\text { vehicle } \quad \text { total length of dirt RN : } 6033\end{array}$ & semester based & $\begin{array}{l}\text { MTPM and CTD } \\
\text { Activity Reports }\end{array}$ & \\
\hline in medium condition (\%) & & 19 & 19 & 19 & 21 & & $\mathrm{Km}$ in 2007 and $3909 \mathrm{Km}$ in 2012 & semester based & $\begin{array}{l}\text { MTPM and CTD } \\
\text { Activity Reports }\end{array}$ & \\
\hline $\begin{array}{l}\text { Rate of communes that have beend } \\
\text { removed from isolation and that are } \\
\text { accessible by road all year long }\end{array}$ & & 40 & 45 & 53 & 64 & & & Annual & $\begin{array}{l}\text { Report and basic } \\
\text { survey on road data }\end{array}$ & \\
\hline $\begin{array}{l}\text { Access rate of households to electrivity : } \\
\text { urbain(\%) }\end{array}$ & & 45 & 50 & & 76 & & $\begin{array}{l}\text { Number of households in urban areas having access to electricity out of } \\
\text { total number of households: JIRAMA provides electrification,but it is up } \\
\text { to consumers to undertake private connection or not from a network put }\end{array}$ & Annual & Statistics, Observation & \\
\hline rural (\%) & & 5 & 5,2 & & 10 & & $\begin{array}{l}\text { at their disposal, which makes it difficult to appralse the electrification } \\
\text { rate, which is not taken into consideration by MEM } \\
\text { The urban area definition is done according to the classification by }\end{array}$ & Annual & Statistics, Observation & \\
\hline Number of new conncetions to JIRAMA & & & 1500 & 200 & & & Number of new JIRAMA connections & semester based & & \\
\hline Number of localities that have been & & & 35 & 15 & & & Number of electrified localities & semester based & & \\
\hline fixed and mobile phone penetration rate & 6,3 & 12,2 & 19,70 & 16,70 & 32,89 & & $\begin{array}{l}\text { Number of subscribers in (fixed and mobile telephony) out of total } \\
\text { population number. } \\
\text { Expresses coverage in telephony and Internet in terms of users }\end{array}$ & Annual & \begin{tabular}{|l} 
MPTC/OMERT \\
Activity Report
\end{tabular} & MDG \\
\hline $\begin{array}{l}\text { Number of subscribers to portable phone } \\
\text { for } 100,000 \text { inhabitants) }\end{array}$ & & & & & & & $\begin{array}{l}\text { Total Number of subscribers to portable phone / Total Population } \\
\text { Number * } 100000\end{array}$ & semester based & $\begin{array}{c}\text { MPTC/OMERT Activity } \\
\text { Report }\end{array}$ & \\
\hline $\begin{array}{l}\begin{array}{l}\text { Number of phone lines for } 100,000 \\
\text { inhabitants) }\end{array} \\
\end{array}$ & & & & & & & Total Number of telephone lines / Total number of population* 100000 & semester based & $\begin{array}{c}\text { MPTC/OMERT Activity } \\
\text { Report }\end{array}$ & \\
\hline $\begin{array}{l}\text { Rate of population permanently having } \\
\text { access to drinking water at national level } \\
\text { (\%) }\end{array}$ & 38 & & 45 & & 65 & & Number of people serviced in drinking water /Total population & Annual & \begin{tabular}{|l|} 
Directory of \\
Sector/MEM/EPM- \\
INSTAT activity Report \\
-MDG Report
\end{tabular} & MDG \\
\hline rural (\%) & 31,6 & & 36 & & 57 & & Number of population serviced in urban areas /Total population number & Annual & & \\
\hline
\end{tabular}




\section{COMMITMENT 2: CONNECTED INFRASTRUCTURES}

\begin{tabular}{|c|c|c|c|c|c|c|c|c|c|c|}
\hline \multirow[b]{2}{*}{ Indicator Name } & \multirow[b]{2}{*}{2006} & \multirow[b]{2}{*}{2007} & \multicolumn{2}{|c|}{2008} & \multirow{2}{*}{\begin{tabular}{|c|}
2012 \\
SNISE \\
Objective
\end{tabular}} & \multirow{2}{*}{\begin{tabular}{|c|}
2015 \\
$\begin{array}{c}\text { MDG } \\
\text { Objective }\end{array}$
\end{tabular}} & \multirow[b]{2}{*}{ Definition of Indicators } & \multirow[b]{2}{*}{ Periodicity } & \multirow[b]{2}{*}{ Verification Source } & \multirow[b]{2}{*}{ Observations } \\
\hline & & & Objective & $\begin{array}{l}\text { Achievement } \\
\text { 1st semester }\end{array}$ & & & & & & \\
\hline $\begin{array}{l}\text { Number de nouveaux branchements } \\
\text { JIRAMA }\end{array}$ & & & 1000 & 342 & 394400 & & Number of new connections to JIRAMA & & & \\
\hline $\begin{array}{l}\text { Number of water points in rural areas } \\
\text { (water points that have been set up in off } \\
\text { JIRAMA areas) }\end{array}$ & & & 1200 & 356 & 41200 & & Total number of water points implanted in off JIRAMA areas & & & \\
\hline $\begin{array}{l}\text { Rate of population permanently having } \\
\text { access to hygiene infrastrucures at } \\
\text { national level (\%) }\end{array}$ & 52 & & 59 & & 71 & & $\begin{array}{l}\text { Ratio between number of people having access to latrines out of the } \\
\text { total population number }\end{array}$ & Annual & \begin{tabular}{|l|} 
Directory of \\
Sector/MEM/EPM- \\
INSTAT activity Report \\
-MDG Report
\end{tabular} & MDG \\
\hline urban (\%) & 77 & & 82 & & 87 & & & Annual & Directory of & \\
\hline rural (\%) & 45 & & 46 & & 66 & & & Annual & Sector/MEM/EPM- & \\
\hline $\begin{array}{l}\text { Number of latrines and sanitary facilities } \\
\text { that have been built }\end{array}$ & & & 7000 & 938 & 1925382 & & $\begin{array}{l}\text { Cumulative number of latrines and sanitation facilities built within a year, } \\
\text { i.e.; a cumulative total of } 705,92 \text { new latrines and sanitation facilities } \\
\text { built over the } 2007 \text { to } 2012 \text { period }\end{array}$ & Annual & $\begin{array}{l}\text { Activity Report } \\
\text { /Database : } \\
\text { MEM/DGEA, MINSAN, } \\
\text { MENRS, MFB, CTD, } \\
\text { STD, Private Sector }\end{array}$ & \\
\hline
\end{tabular}




\section{COMMITMENT 3: EDUCATIONAL TRANSFORMATION}

\begin{tabular}{|c|c|c|c|c|c|c|c|c|c|c|}
\hline \multirow[b]{2}{*}{ Priority Indicator Name } & \multirow[b]{2}{*}{2006} & \multirow[b]{2}{*}{2007} & \multicolumn{2}{|r|}{2008} & \multirow{2}{*}{\begin{tabular}{c|}
2012 \\
SNISE \\
Objective
\end{tabular}} & \multirow{2}{*}{$\begin{array}{c}2015 \\
\text { MDG } \\
\text { Objective } \\
\text { OMD }\end{array}$} & \multirow[b]{2}{*}{ Definition of Indicators } & \multirow[b]{2}{*}{ Periodicity } & \multirow[b]{2}{*}{ Verification Sources } & \multirow[b]{2}{*}{ Observations } \\
\hline & & & Objective & $\begin{array}{l}\text { Achievement 1st } \\
\text { semester } 2008\end{array}$ & & & & & & \\
\hline $\begin{array}{l}\text { Number of Operational Public and Community } \\
\text { based Pre school Centers }\end{array}$ & & 195 & 300 & 222 & & & $\begin{array}{l}\text { Total number of pre school } \\
\text { divided by the population } \\
\text { aged } 3 \text { to } 5\end{array}$ & Annual & DEFP/MEN annual activity report & \\
\hline $\begin{array}{l}\text { Number of newly established Pre school } \\
\text { Centers }\end{array}$ & ? & $?$ & 71 & 165 & & & $\begin{array}{l}\text { Total number of pre school } \\
\text { divided by the population } \\
\text { aged } 3 \text { to } 5\end{array}$ & Annual & DEFP/MEN annual activity report & \\
\hline $\begin{array}{l}\text { Number of developed an validated law texts } \\
\text { governing pre school }\end{array}$ & & & 2 & $\begin{array}{r}1 \text { achieved and } 1 \\
\text { under way }\end{array}$ & & & $\begin{array}{l}\text { Total number of pre school } \\
\text { divided by the population } \\
\text { aged } 3 \text { to } 5\end{array}$ & Annual & DEFP/MEN annual activity report & \\
\hline Number of trained Pre school Educationalists & 22 & 280 & 300 & $\begin{array}{r}50 \text { trained } \\
\text { and the remaining } \\
\text { ones under way }\end{array}$ & 3,152 & & $\begin{array}{l}\text { Total number of pre school } \\
\text { divided by the population } \\
\text { aged } 3 \text { to } 5\end{array}$ & Annual & DEFP/MEN annual activity report & \\
\hline $\begin{array}{l}\text { Number of pre school Centers equipped with } \\
\text { Collective Didactic Furniture and Materials }\end{array}$ & & & 300 & $\begin{array}{r}\text { Studies achieved } \\
\text { Execution under way }\end{array}$ & & & $\begin{array}{l}\text { Total number of pre school } \\
\text { divided by the population } \\
\text { aged } 3 \text { to } 5\end{array}$ & Annual & DEFP/MEN annual activity report & \\
\hline Sensitization & & & & $\begin{array}{r}\begin{array}{r}\text { sensitization } \\
\text { campaigns }\end{array} \\
\end{array}$ & & & & & & \\
\hline $\begin{array}{l}\text { Gross Enrolment Rate in Primary Education } \\
\text { (\%) } \\
\text { Net Enrolment Rate(\%) }\end{array}$ & $\begin{array}{r}121 \\
83\end{array}$ & $\begin{array}{r}122 \\
84\end{array}$ & $\begin{array}{r}122 \\
86\end{array}$ & $\begin{array}{r}124 \\
86\end{array}$ & 98 & 100 & $\begin{array}{l}\text { Ratio between the number of } \\
\text { enrolled pupils and the } \\
\text { population aged } 6 \text { to } 10\end{array}$ & Annual & $\begin{array}{l}\text { MEN, INSTAT Statistic Setrvice, MEN } \\
\text { statistic directory/Indicator of results } \\
\text { determining the release of variable } \\
\text { tranches/EU }\end{array}$ & MDG \\
\hline Number of built/ rehabilitated classrrooms & & & 2 & $\begin{array}{r}617 \text { classrooms built } / \\
\text { rehabilitated }\end{array}$ & & & $\begin{array}{l}\text { Total number of classrooms } \\
\text { built in primary school }\end{array}$ & Annual & $\begin{array}{l}\text { Annual Activity Report for the Service } \\
\text { of Constructions and inputs/DGEFA }\end{array}$ & \\
\hline Number of newly recruited FRAM teachers & & 15 & 2 & 2 & & & $\begin{array}{l}\text { Total number of FRAM } \\
\text { teachers who have been }\end{array}$ & Annual & DRH annual Activity Report & \\
\hline $\begin{array}{l}\text { Number of new entrants in CP1 equipped with } \\
\text { school kits }\end{array}$ & 994 & 950 & 900 & 941,318 & & & Total kits distributed & Annual & $\begin{array}{l}\text { Annual Activity Report for the Service } \\
\text { of Constructions and inputs/DGEFA }\end{array}$ & \\
\hline $\begin{array}{l}\text { Number of primary schools benefiting from } \\
\text { school canteens }\end{array}$ & & & 200 & 272 & & & $\begin{array}{l}\text { Total Number of Primary } \\
\text { Schools benefiting from } \\
\text { school canteens }\end{array}$ & Annual & DEFP annual activity report & \\
\hline
\end{tabular}




\section{COMMITMENT 3: EDUCATIONAL TRANSFORMATION}

\begin{tabular}{|c|c|c|c|c|c|c|c|c|c|c|}
\hline \multirow[b]{2}{*}{ Priority Indicator Name } & \multirow[b]{2}{*}{2006} & \multirow[b]{2}{*}{2007} & \multicolumn{2}{|r|}{2008} & \multirow{2}{*}{$\begin{array}{c}2012 \\
\text { SNISE } \\
\text { Objective }\end{array}$} & \multirow{2}{*}{$\begin{array}{c}2015 \\
\text { MDG } \\
\text { Objective } \\
\text { OMD }\end{array}$} & \multirow[b]{2}{*}{ Definition of Indicators } & \multirow[b]{2}{*}{ Periodicity } & \multirow[b]{2}{*}{ Verification Sources } & \multirow[b]{2}{*}{ Observations } \\
\hline & & & Objective & $\begin{array}{l}\text { Achievement 1st } \\
\text { semester } 2008\end{array}$ & & & & & & \\
\hline $\begin{array}{l}\begin{array}{l}\text { Enrolment rate in lower secondary schools } \\
\text { (gross) in \% }\end{array} \\
\text { (F) }\end{array}$ & & 33 & 34 & 36 & & & \begin{tabular}{|l|} 
Ratio between the total \\
number of pupils and the \\
population aged 11 to 14
\end{tabular} & Annual & DFPT & \\
\hline $\begin{array}{l}\text { Number of classrooms built/rehabilitated in } \\
\text { lower secondary schools }\end{array}$ & & & 400 & $\begin{array}{r}152 \text { classrooms } \\
\text { built/rehabilitated }\end{array}$ & & & $\begin{array}{l}\text { Total number of classrooms } \\
\text { built in lower secondary } \\
\text { schools }\end{array}$ & Annual & $\begin{array}{l}\text { Annual Activity Report for the Service } \\
\text { of Constructions and inputs/DGEFA }\end{array}$ & \\
\hline $\begin{array}{l}\text { Number of teachers of lower secondary } \\
\text { schools who have been trained }\end{array}$ & & & 1,500 & under way & & & \begin{tabular}{|l|} 
Total number of teachers in \\
lower secondary schools who
\end{tabular} & Annual & INPF annual Activity Report & \\
\hline Enrolment rate in Lycées (gross) in \% & & 10,5 & 11 & 11.6 & & & \begin{tabular}{|l|} 
Ratio between the total \\
number of pupils and the \\
population aged 15 to 17
\end{tabular} & Annual & $\begin{array}{l}\text { MEN Statistic Service, Annual activity } \\
\text { report }\end{array}$ & \\
\hline $\begin{array}{l}\text { Number de built/ rehabilitated classrooms in } \\
\text { Lycées }\end{array}$ & & & 200 & $\begin{array}{r}67 \text { built } \\
62 \text { under way }\end{array}$ & & & $\begin{array}{l}\text { Total number of classrooms } \\
\text { built in Lycées }\end{array}$ & Annual & $\begin{array}{l}\text { ME, INSTAT Statistic Service, DES } \\
\text { Annual activity report }\end{array}$ & \\
\hline Number of teachers trained & & & 200 & 120 & & & $\begin{array}{l}\text { tutal number of teachers in } \\
\text { lycées who have been }\end{array}$ & Annual & $\begin{array}{l}\text { MEN Statistic Service, DFPT Annual } \\
\text { activity report }\end{array}$ & \\
\hline $\begin{array}{l}\text { Achievement Rate in } 5 \text { year Primary Education } \\
\text { (\%) }\end{array}$ & 57 & 54.3 & 67 & & 85 & 100 & $\begin{array}{l}\text { Ratio between the number of } \\
\text { non repeater pupils in CM2 } \\
\text { and the population aged } 10 .\end{array}$ & Annual & $\begin{array}{l}\text { MEN, INSTAT Statistic Services, MEN } \\
\text { statistic directory/Indicator of results } \\
\text { determining the release of variable } \\
\text { tranches/UE }\end{array}$ & MDG \\
\hline $\begin{array}{l}\text { Number of children who are out of School } \\
\text { and/or have specific needs and who are } \\
\text { integrated in the formal sector }\end{array}$ & & & 1 & & & & & Annual & DEFP annual activity report & \\
\hline $\begin{array}{l}\text { Number of teachers trained in Inclusive } \\
\text { Education }\end{array}$ & & & 760 & & & & & Annual & DEFP annual activity report & \\
\hline $\begin{array}{l}\text { Number of classrooms built in the fokontany } \\
\text { having no school }\end{array}$ & & & 250 & & & & & Annual & $\begin{array}{l}\text { Annual Activity Report for the Service } \\
\text { of Constructions and inputs/DGEFA }\end{array}$ & \\
\hline \begin{tabular}{|l|}
$\begin{array}{l}\text { Number of classrooms built in incomplete } \\
\text { cycle schools }\end{array}$ \\
\end{tabular} & & & 750 & & & & & Annual & $\begin{array}{l}\text { Annual Activity Report for the Service } \\
\text { of Constructions and inputs/DGEFA }\end{array}$ & \\
\hline Number of newly recruited FRAM teachers & & & 2 & & & & & Annual & DRH annual activity report & \\
\hline $\begin{array}{l}\text { Number of schools equipped with School } \\
\text { Funds }\end{array}$ & & & 23 & 24 & & & $\begin{array}{l}\text { Total number of schools } \\
\text { equipped with school funds }\end{array}$ & Annual & DEFP annual activity report & \\
\hline $\begin{array}{l}\text { Number of new entrants in CP1 equipped with } \\
\text { school kits }\end{array}$ & & & 950 & & & & Total kits distributed & Annual & $\begin{array}{l}\text { Annual Activity Report for the Service } \\
\text { of Constructions and inputs/DGEFA }\end{array}$ & \\
\hline Number of educational inputs distributed & $1,201,600$ & $3,705,009$ & $4,166,300$ & $3,500,000$ & & & $\begin{array}{l}\text { Total educational inputs that } \\
\text { have been distributed }\end{array}$ & Annual & $\begin{array}{l}\text { Annual Activity Report for the Service } \\
\text { of Constructions and inputs/DGEFA }\end{array}$ & \\
\hline $\begin{array}{l}\text { Number of FRAM teachers who have been } \\
\text { subsidized }\end{array}$ & & 23 & 34 & 29 & & & $\begin{array}{l}\text { Total number of FRAM } \\
\text { teachers who have been }\end{array}$ & Annual & DRH annual activity report & \\
\hline
\end{tabular}




\section{COMMITMENT 3: EDUCATIONAL TRANSFORMATION}

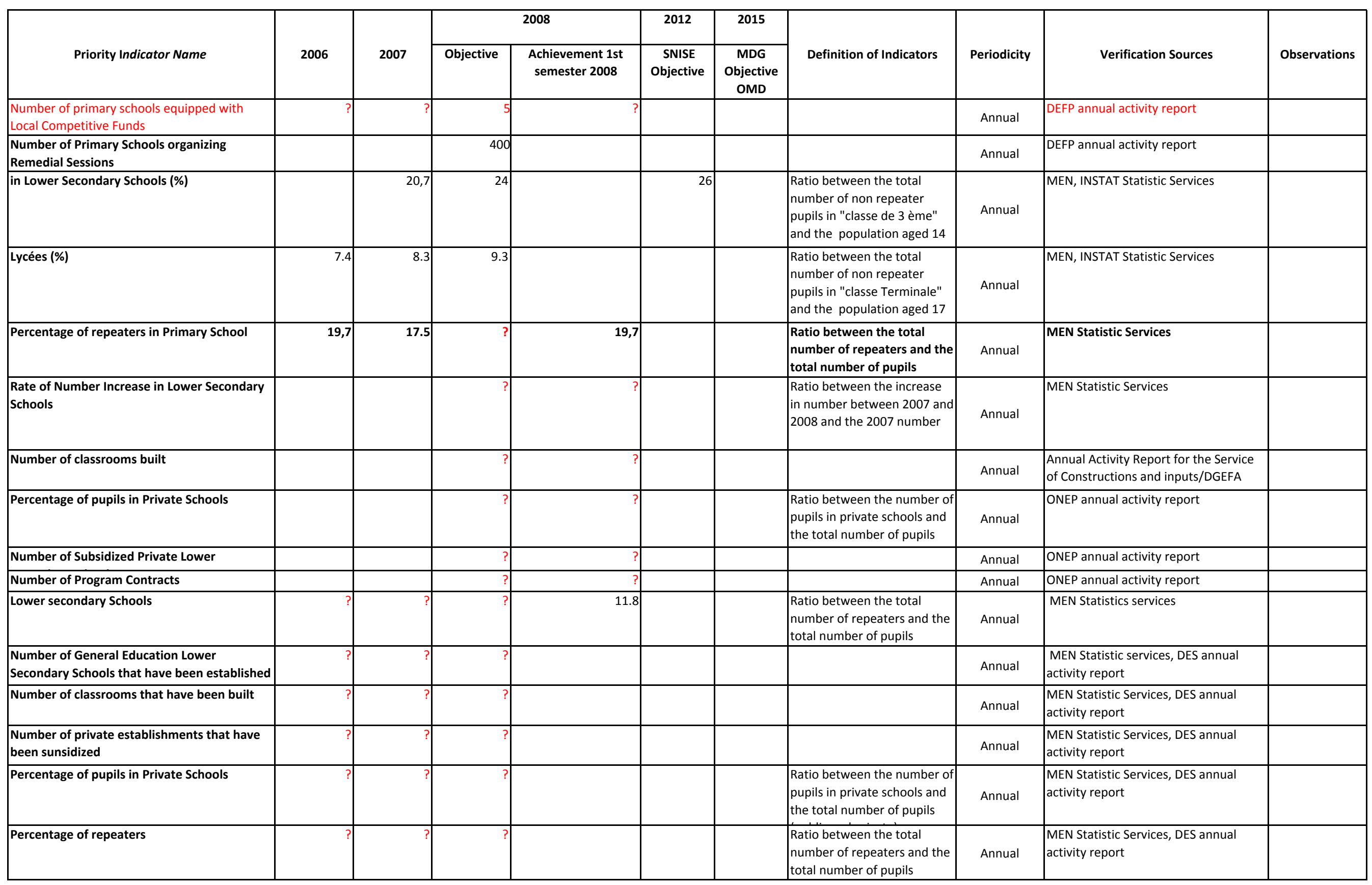




\section{COMMITMENT 3: EDUCATIONAL TRANSFORMATION}

\begin{tabular}{|c|c|c|c|c|c|c|c|c|c|c|}
\hline \multirow[b]{2}{*}{ Priority Indicator Name } & \multirow[b]{2}{*}{2006} & \multirow[b]{2}{*}{2007} & \multicolumn{2}{|r|}{2008} & \multirow{2}{*}{\begin{tabular}{|c|}
2012 \\
SNISE \\
Objective
\end{tabular}} & \multirow{2}{*}{$\begin{array}{c}2015 \\
\text { MDG } \\
\text { Objective } \\
\text { OMD }\end{array}$} & \multirow[b]{2}{*}{ Definition of Indicators } & \multirow[b]{2}{*}{ Periodicity } & \multirow[b]{2}{*}{ Verification Sources } & \multirow[b]{2}{*}{ Observations } \\
\hline & & & Objective & $\begin{array}{l}\text { Achievement 1st } \\
\text { semester } 2008\end{array}$ & & & & & & \\
\hline $\begin{array}{l}\text { Number Of ITC Centers that have been } \\
\text { secured and equipped at the level of lycées }\end{array}$ & $?$ & $?$ & $?$ & & & & & Annual & DTIC annual activity report & \\
\hline $\begin{array}{l}\text { Number of Teachers trained in vocational and } \\
\text { Technical Training }\end{array}$ & & & 200 & under way & & & & Annual & & \\
\hline $\begin{array}{l}\text { Number of students for } 100,000 \text { inhabitants in } \\
\text { Higher Education }\end{array}$ & 286 & 292 & 323 & 350 & & & \begin{tabular}{|l|} 
Total number of students in \\
higher education $* 100,000$ \\
inhabitants / Total number of \\
inhabitants
\end{tabular} & Annual & $\begin{array}{l}\text { Annual syrvey of hihger education. } \\
\text { Department in charge: Schooling } \\
\text { Service and DGESR }\end{array}$ & \\
\hline $\begin{array}{l}\text { Number of Higher Education graduated over a } \\
\text { year }\end{array}$ & & & 7 & & & & $\begin{array}{l}\text { Total number of students in } \\
\text { higher education who have } \\
\text { graduated }\end{array}$ & Annual & & \\
\hline $\begin{array}{l}\text { Number of people enrolled in literacy } \\
\text { programs }\end{array}$ & & 14,351 & 23 & 12 & 219 & & \begin{tabular}{|l|} 
Total number of learners \\
enrolled in literacy programs
\end{tabular} & Annual & DALPHA annual report & MDG \\
\hline $\begin{array}{l}\text { Institutional literacy mechanism has been } \\
\text { established }\end{array}$ & & & 3 & & & & $\begin{array}{l}\text { Decrees and Orders that } \\
\text { define the roles of the } \\
\text { various actors, the quality } \\
\text { standards for conducting } \\
\text { literacy, business } \\
\text { classification, the } \\
\text { management mechanism for } \\
\text { a support funds... }\end{array}$ & Annual & $\begin{array}{l}\text { In charge: DALPHA. Recourse to } \\
\text { national consultants. }\end{array}$ & \\
\hline $\begin{array}{l}\text { Strategy Document for Scaling up adult and } \\
\text { youth Literacy }\end{array}$ & & & 1 & Draft developed & & & $\begin{array}{l}\text { Document defining the } \\
\text { national strategy for scaling } \\
\text { up literacy }\end{array}$ & Annual & Responsible: DALPHA. & \\
\hline $\begin{array}{l}\text { Number of literacy programs developed for } \\
\text { under } 15 \text { children }\end{array}$ & & & 1 & & & & & Annual & Annual Report DALPHA & \\
\hline $\begin{array}{l}\text { Budget for Education compared with total } \\
\text { budget (\%) }\end{array}$ & 17.4 & 22.7 & & & & & $\begin{array}{l}\text { Budget share allocated to } \\
\text { Education compared with } \\
\text { total budget }\end{array}$ & Annual & $\begin{array}{l}\text { Result Indicator determining the } \\
\text { disbursement of variable tranches /EU }\end{array}$ & \\
\hline
\end{tabular}


COMMITMENT 4 : RURAL DEVELOPMENT

\begin{tabular}{|c|c|c|c|c|c|c|c|c|c|c|}
\hline \multirow[b]{2}{*}{ Indicator Name } & \multirow[b]{2}{*}{2006} & \multirow[b]{2}{*}{2007} & \multicolumn{2}{|c|}{2008} & \multirow{2}{*}{$\begin{array}{c}2012 \\
\text { Objective } \\
\text { SNISE }\end{array}$} & \multirow{2}{*}{$\begin{array}{c}2015 \\
\text { Objective } \\
\text { OMD }\end{array}$} & \multirow[b]{2}{*}{ Definitions of indicators } & \multirow[b]{2}{*}{ Periodicity } & \multirow[b]{2}{*}{$\begin{array}{c}\text { Verification } \\
\text { Source }\end{array}$} & \multirow[b]{2}{*}{ Observations } \\
\hline & & & Objective & $\begin{array}{l}\text { Achievement 1st } \\
\text { semester }\end{array}$ & & & & & & \\
\hline Percentage of secured surface area (\%) & & & 13 156ha & 8403 ha soit $64 \%$ & & & & *qyarterly & MAEP & \\
\hline Set up and operational Land tenure shops & & & 260 & 43 & & & & & & \\
\hline Number of land certificates issued & 1100 & 3500 & 72500 & 3937 & & & & & & \\
\hline Number of land titles established & 500000 & 512265 & 40000 & 5674 & & & & & & \\
\hline $\begin{array}{l}\text { Number of Local Land Occupation Plans (PLOF) that have } \\
\text { been developed }\end{array}$ & & & 258 & 92 & & & & & & \\
\hline Financing institution penetration rate (\%) & $8 \%$ & $9 \%$ & $10 \%$ & $925 \%$ & $14 \%$ & & \begin{tabular}{|l} 
Number of Finance \\
institutions(IF)/M icro finance \\
institutions (IM F) that have been \\
installed in the area / total IF /IM F \\
number in the area) X 100
\end{tabular} & Annual & MAEP & \\
\hline $\mathrm{Nb}$ of new funds established & & & & & & & & & & \\
\hline Rice Output (tons/ha) & 2,78 & 2,8 & & Récolte en cours & 6 & & Production (in ha) / Surface area (in ha) & Annual & MAEP & \\
\hline Rice production (Tons) & 3640000 & 4070000 & 5000000 & Récolte en cours & 10500000 & & Total quantity of rice produced & Quarterly & MAEP & \\
\hline Number of cattle head & 9200000 & 9650000 & & nd & 12000000 & & $\begin{array}{l}\text { Cattle: aggreagte details of agriculture } \\
\text { farming produced every year }\end{array}$ & Annual & MAEP & \\
\hline Keeping at $\mathbf{8 0} \%$ otr rate of vaccination of bovine cattle & & & $80 \%$ & $42 \%$ & & & & & & \\
\hline Annual fishing resource production (Tones) & 105000 & 116750 & 150000 & 43877 & 227000 & & $\begin{array}{l}\text { Resources derived from botj sea and } \\
\text { continental fishing produced every year }\end{array}$ & & & \\
\hline
\end{tabular}




\section{COMMITMENT 5: HEALTH, FAMILY PLANNING, AND FIGHT AGAINST HIV/AIDS}

\begin{tabular}{|c|c|c|c|c|c|c|c|c|c|c|}
\hline \multirow[b]{2}{*}{ Indicator Name } & \multirow[b]{2}{*}{2006} & \multirow[b]{2}{*}{2007} & \multicolumn{2}{|r|}{2008} & \multirow{2}{*}{\begin{tabular}{|c|}
2012 \\
$\begin{array}{c}\text { Objective } \\
\text { SNISE }\end{array}$
\end{tabular}} & \multirow{2}{*}{$\begin{array}{c}2015 \\
\text { Objective } \\
\text { OMD }\end{array}$} & \multirow[b]{2}{*}{ Definitions of indicators } & \multirow[b]{2}{*}{ Periodicity } & \multirow[b]{2}{*}{ Verification Source } & \multirow[b]{2}{*}{ Observations } \\
\hline & & & Objective & $\begin{array}{c}\text { Achievement 1st } \\
\text { semester }\end{array}$ & & & & & & \\
\hline Rate of Use of outpatient consultations at CSB & 38,8 & 42,30 & $51 \%$ & $30,30 \%$ & 70 & & $\begin{array}{l}\text { Percentage of new cases } \\
\text { compared with total population }\end{array}$ & Monthly & $\begin{array}{l}\text { Basic Health Center (CSB) } \\
\text { Monthly activity report }\end{array}$ & \\
\hline Number of CSB built & & 67 & 40 & $\begin{array}{r}37 \text { built } 13 \\
\text { rehabilitated, the } \\
\text { remaining part is } \\
\text { under way }\end{array}$ & & & Number of CSB built & Monthly & MINSANPFPS Activity Report & FID, STATE \\
\hline Number of CSB equipped & & 96 & 40 & 20 & & & Number of CSB equipped & Monthly & MINSANPFPS Activity Report & \\
\hline Incidence rate of malaria at the level of CSBs & 17,6 & $7 \%$ & $5 \%$ & $6 \%$ & $1 \%$ & & $\begin{array}{l}\text { Number of malaria cases times } \\
100 / \text { total population }\end{array}$ & Monthly & $\begin{array}{l}\text { Monthly Acctivity Report } \\
\text { (RM A) of CSB }\end{array}$ & \\
\hline Malaria mortality rate in hospital ebvironment & $17,50 \%$ & $13,90 \%$ & $13 \%$ & $8,85 \%$ & $9 \%$ & & $\begin{array}{l}\text { Number of malaria related } \\
\text { mortality times } 100 \text { number of } \\
\text { death cases }\end{array}$ & Monthly & RMA of Hospital centers & \\
\hline Tuberculosis incidence rate for 100,000 inhabitants) & & $98 \%$ & $98 \%$ & $98 \%$ & $90 \%$ & $90 \%$ & $\begin{array}{l}\text { Proportion of new tuberculosis } \\
\text { cases }\end{array}$ & & & OMD/SNISE \\
\hline Rate of curing baciliferous tuberculosis & $78 \%$ & $80 \%$ & $82 \%$ & $80 \%$ & $90 \%$ & & $\begin{array}{l}\text { Number of sick people who } \\
\text { were cured after } 8 \text { treatment } \\
\text { months times } 100 \text { compared } \\
\text { with sick people under }\end{array}$ & Annual & MINSANPFPS Activity Report & $\begin{array}{l}\text { Year } n-1 \text { Indicator of } \\
\text { results determining the } \\
\text { release of variable } \\
\text { tranches/EU }\end{array}$ \\
\hline $\begin{array}{l}\text { Number of people sick with tuberculosis motivated by } \\
\text { subsidies }\end{array}$ & & & 2500 & 1509 & 960 & & & & & \\
\hline \multicolumn{11}{|l|}{ HIV prevalence among pregnant women } \\
\hline Rate of involvement in decentralization of response & & & & & & & & & SE/CNLS & \\
\hline Rate of use of condoms for young people aged 15 to 24 & & & 17500000 & 6349044 & & & & & SE/ CNLS & \\
\hline $\begin{array}{l}\text { Percentage of people under ARV treatment who are alive } \\
12 \text { months after the beginning of ARV intake (PGE) }\end{array}$ & & $90 \%$ & $95 \%$ & $14 / 26 \mathrm{PVVIH}$ & & & $\begin{array}{l}\text { Number of people under ARV } \\
\text { treatment who are alive } 12 \\
\text { months times } 100 / \text { Total } \\
\text { number under ARV after the } \\
\text { beginning of ARV intake }\end{array}$ & Monthly & MINSANPFPS Activity Report & \\
\hline Synthetic Fecundity index & $\begin{array}{r}5,2(2003 \\
/ 2004)\end{array}$ & & & & 3 & & & Every 5 years & EDS & \\
\hline
\end{tabular}


COMMITMENT 5: HEALTH, FAMILY PLANNING, AND FIGHT AGAINST HIV/ AIDS

\begin{tabular}{|c|c|c|c|c|c|c|c|c|c|c|}
\hline \multirow[b]{2}{*}{ Indicator Name } & \multirow[b]{2}{*}{2006} & \multirow[b]{2}{*}{2007} & \multicolumn{2}{|r|}{2008} & \multirow{2}{*}{\begin{tabular}{|c|}
2012 \\
Objective \\
SNISE \\
\end{tabular}} & \multirow{2}{*}{$\begin{array}{c}2015 \\
\text { Objective } \\
\text { OMD }\end{array}$} & \multirow[b]{2}{*}{ Definitions of indicators } & \multirow[b]{2}{*}{ Periodicity } & \multirow[b]{2}{*}{ Verification Source } & \multirow[b]{2}{*}{ Observations } \\
\hline & & & Objective & $\begin{array}{c}\text { Achievement 1st } \\
\text { semester }\end{array}$ & & & & & & \\
\hline Infantile and juvenile mortality rate (under 5 for 1,000 ) & & $\begin{array}{r}94(2003 \\
/ 2004)\end{array}$ & & & 47 & 60 & $\begin{array}{l}\text { Proportion of children who die } \\
\text { before their 5th birthday }\end{array}$ & Every 5 years & EDS & \\
\hline Infantile and juvenile mortality rate (under 1 for 1,000 ) & & $\begin{array}{r}58(2003 \\
/ 2004)\end{array}$ & & & 35 & 35 & $\begin{array}{l}\text { Propotion of children who die } \\
\text { before they are } 1 \text { year old }\end{array}$ & Every 5 years & EDS & \\
\hline Infantile mortality rate ( 1 to 5 ) for 1,000 & & & & & & & & & & $\begin{array}{l}\text { Indicator of results } \\
\text { determining the release } \\
\text { of variable tranches/EU }\end{array}$ \\
\hline \multicolumn{11}{|l|}{ Infantile-juvenile. Infantile mortality rate : } \\
\hline $\begin{array}{l}\text { Percentage of communes having IM Cl community based } \\
\text { sites in priority areas }\end{array}$ & & $5 \%$ & $50 \%$ & $11 \%$ & & & $\begin{array}{l}\text { Number of communes having } \\
\text { IM Cl community based sites }\end{array}$ & Monthly & MINSANPFPS Activity Report & \\
\hline $\begin{array}{l}\text { Number of districts which introduced Zinc/SRO for } \\
\text { diarrhea management (PGE) }\end{array}$ & & 12 & 55 & 33 & & & $\begin{array}{l}\text { Number of districts which have } \\
\text { introduced Zinc / SRO for the } \\
\text { management of diarrhea }\end{array}$ & Monthly & M INSANPFPS Activity Report & \\
\hline $\begin{array}{l}\text { Immunization coverage rate in DTCHep B3 ( among less } \\
\text { than } 1 \text { year old children ) }\end{array}$ & 95,3 & $80,00 \%$ & $85,00 \%$ & $59,50 \%$ & 1 & & \multirow{3}{*}{$\begin{array}{l}\text { proportion of children who have } \\
\text { received all } 3 \text { doses of the } \\
\text { DTCHépB vaccine }\end{array}$} & Monthly & RM A of CSB and CHD & $\begin{array}{l}\text { Indicator of results } \\
\text { determining the release } \\
\text { of variable tranches/EU }\end{array}$ \\
\hline BCG coverage rate & $95,20 \%$ & $96 \%$ & $97 \%$ & $70,00 \%$ & $100 \%$ & & & & & \\
\hline anti measles coverage rate & $83,80 \%$ & $85 \%$ & $90 \%$ & $67 \%$ & $100 \%$ & & & & & \\
\hline Neo natal mortality rate for 1,000 living births & & $\begin{array}{r}2003- \\
2004)\end{array}$ & & & 17 & & $\begin{array}{l}\text { M ortality rate of less than } 28 \\
\text { day newly born for } 1,000 \text { live } \\
\text { births }\end{array}$ & Every 5 years & EDS & \\
\hline $\begin{array}{l}\text { Proportion of maternal deaths at the level of CSB } \\
\text { and CHD }\end{array}$ & & & $\begin{array}{r}\text { moins de } \\
1 \%\end{array}$ & $0,15 \%$ & & & & & $\mathrm{CHD}$ and CSB & \\
\hline \multicolumn{11}{|l|}{ Maternal/ Neo natal portality rate: } \\
\hline $\begin{array}{l}\text { Rate of assisted delivery in CSB and CHD (\%) } \\
\text { ou }\end{array}$ & & 29,50 & 27,2 & $18,5 \%$ & 50 & & $\begin{array}{l}\text { Percentage of deliveries which } \\
\text { take place in public health } \\
\text { centers compared with expected } \\
\text { pregnancies }\end{array}$ & Annual & MINSANPFPS & \\
\hline CPN Coverage rate & $68 \%$ & $71 \%$ & $74 \%$ & $53,3 \%$ & $71 \%$ & & \begin{tabular}{|l|} 
Number of women in \\
prenatalconsultations \\
$* 100 /$ Number of reproductive \\
age women
\end{tabular} & Annual & MINSANPFPS & \\
\hline
\end{tabular}




\section{COMMITMENT 5: HEALTH, FAMILY PLANNING, AND FIGHT AGAINST HIV/ AIDS}

\begin{tabular}{|c|c|c|c|c|c|c|c|c|c|c|}
\hline \multirow[b]{2}{*}{ Indicator Name } & \multirow[b]{2}{*}{2006} & \multirow[b]{2}{*}{2007} & \multicolumn{2}{|r|}{2008} & \multirow{2}{*}{\begin{tabular}{|c|}
2012 \\
Objective \\
SNISE
\end{tabular}} & \multirow{2}{*}{$\begin{array}{c}2015 \\
\text { Objective } \\
\text { OMD }\end{array}$} & \multirow[b]{2}{*}{ Definitions of indicators } & \multirow[b]{2}{*}{ Periodicity } & \multirow[b]{2}{*}{ Verification Source } & \multirow[b]{2}{*}{ Observations } \\
\hline & & & Objective & $\begin{array}{c}\text { Achievement 1st } \\
\text { semester }\end{array}$ & & & & & & \\
\hline $\begin{array}{l}\text { Number of hospital centers equipped with laparo- } \\
\text { caesarian e kit }\end{array}$ & & & 5 & $\begin{array}{r}\text { C CHRR et } 2 \\
\text { CHD2 dotés de } \\
\text { kit laparo- } \\
\text { césarienne } \\
\end{array}$ & & & & & Central & \\
\hline Number of national SSME campaigns & & 2 & 2 & 1 & & & $\begin{array}{l}\text { Number of national SSME } \\
\text { campaigns }\end{array}$ & & MINSANPFPS Activity Report & $\begin{array}{l}\text { Planned in April and } \\
\text { October }\end{array}$ \\
\hline $\begin{array}{l}\text { Proportion of children with weight deficit who have been } \\
\text { in outpatient consultations of CSB (\%) }\end{array}$ & 15,6 & 16,4 & 14,4 & 14,4 & 14 & & $\begin{array}{l}\text { Number of children with weight } \\
\text { deficit in CSB outpatient } \\
\text { consultations }\end{array}$ & Monthly & $\begin{array}{l}\text { M INSANPFPS/ONN Activity } \\
\text { Report }\end{array}$ & \\
\hline $\begin{array}{l}\text { Proportion of children with weight deficit at community } \\
\text { based sites }(\%)\end{array}$ & & 38 & 25 & 22 & 28 & & & Monthly & & \\
\hline $\begin{array}{l}\text { Share of Health Budget compared with the total budget } \\
\text { (\%) }\end{array}$ & 7,5 & 8,40 & 9 & 9 & & & & & & \\
\hline \multicolumn{11}{|l|}{$\begin{array}{l}\text { Rate of commitment compared with the budget allocated } \\
\text { to the sector }(\%)\end{array}$} \\
\hline Running (\%) & & & 90 & 36,13 & & & & & $\begin{array}{l}\text { Central, Regions, and } \\
\text { Districts }\end{array}$ & \\
\hline Investment (\%) & & & 90 & 12,82 & & & & & Central and Regions & \\
\hline
\end{tabular}


COMMITM ENT 6: HIGH GROWTH ECONOMY

\begin{tabular}{|c|c|c|c|c|c|c|c|c|c|c|}
\hline \multirow[b]{2}{*}{ Indicators } & \multirow[b]{2}{*}{2006} & \multirow[b]{2}{*}{2007} & \multicolumn{2}{|r|}{2008} & \multirow{2}{*}{$\begin{array}{c}2012 \\
\text { NIMES } \\
\text { objective }\end{array}$} & \multirow{2}{*}{$\begin{array}{c}2015 \\
\text { MDG } \\
\text { objective }\end{array}$} & \multirow[b]{2}{*}{$\begin{array}{l}\text { Definition of } \\
\text { indicators }\end{array}$} & \multirow[b]{2}{*}{ Periodicity } & \multirow[b]{2}{*}{ Verification source } & \multirow[b]{2}{*}{ Observations } \\
\hline & & & Objective & \begin{tabular}{|l|} 
1st semester \\
achievements or review of \\
forecasts
\end{tabular} & & & & & & \\
\hline Economic growth rate (\%) & 4,6 & 6,3 & 7,3 & 7,1 & 10,0 & & & \multirow[t]{3}{*}{ Annual } & \multirow{3}{*}{\begin{tabular}{|l} 
M ECI- \\
INSTAT/M FB
\end{tabular}} & \multirow{3}{*}{$\begin{array}{l}\text { IResult indicator } \\
\text { determining the freeing } \\
\text { of the variable }\end{array}$} \\
\hline GDP per capita (USD) & 288 & 375 & 466 & 512 & 647 & - & & & & \\
\hline Inflation rate (CIP average ) & 10,8 & 10,3 & 8 & 9,4 & 5 & - & & & & \\
\hline Budget deficit (as \% of GDP) & 4,3 & 2,8 & 4,9 & 4,4 & 0,37 & - & & Annual & M ECI-DEEM & \\
\hline Fiscal pressure rate (\%) & 10,7 & 11,4 & 11,6 & 12 & 15 & - & & Annual & $\begin{array}{l}\text { M FB(revue } \\
\text { trimestrielle } \\
\text { dépenses } \\
\text { publiques) }\end{array}$ & $\begin{array}{l}\text { Result indicator } \\
\text { determining the freeing } \\
\text { of the variable } \\
\text { tranches/EU }\end{array}$ \\
\hline $\begin{array}{l}\text { Number of Approved Management Centers set up } \\
\text { and operational }\end{array}$ & - & - & 6 & 6 & & & & Punctual & MFB & \\
\hline Number of new tax payers identified & - & - & 32500 & 1933 & & & & & & \\
\hline $\begin{array}{l}\text { Number of Regional Services for Enterprises applying } \\
\text { the wire transfer payment procedure }\end{array}$ & - & - & 6 & 2 & & & & & & \\
\hline $\begin{array}{l}\text { Number of electronic exchange platforms TRADENET } \\
\text { implemented in customs office operating with } \\
\text { SYDONIA ++ }\end{array}$ & - & - & 6 & 3 & & & & & & \\
\hline Overall budget implementation (commitment \%) & - & & 75 à $80 \%$ & 36,9 & & & & Quarterly & $\begin{array}{l}\text { M FB(quarterly } \\
\text { review of public } \\
\text { expenditures) }\end{array}$ & $\begin{array}{l}\text { Result indicator } \\
\text { determining the freeing } \\
\text { of the variable } \\
\text { tranches/EU }\end{array}$ \\
\hline $\begin{array}{l}\text { Total revenues (including grants) (in billion ariary) } \\
\text { (cash basis) }\end{array}$ & - & & $\begin{array}{c}2269,2 \\
\text { (LFR) }\end{array}$ & $\begin{array}{c}1111,7 \\
\text { (May 2008) }\end{array}$ & & & & Quarterly & MFB/BCM & \\
\hline Total expenditures (in billion ariary) (cash basis) & - & & $\begin{array}{l}3422,4 \\
\text { (LFR) }\end{array}$ & $\begin{array}{c}1094,8 \\
\text { (May 2008) }\end{array}$ & & & & Quarterly & MFB/BCM & \\
\hline Ranking in the Doing Business Report & 149/175 & 149/175 & - & 149/178 & 80 & & $\begin{array}{l}\text { From Doing } \\
\text { Business in } \\
\text { Madagascar }\end{array}$ & Annual & $\begin{array}{l}\text { Enquête Doing } \\
\text { Business BCM }\end{array}$ & \\
\hline Number of cooperatives revitalized & & & 50 & 29 & & & & Punctual & M ECI-DPPE & \\
\hline Number of CERDIC set up & & & 10 & 1 & & & & Punctual & M ECI-DPPE & \\
\hline Number of CERAM set up & & & 6 & 6 & & & & & M ECI-DPA & \\
\hline
\end{tabular}


COMMITM ENT 6: HIGH GROWTH ECONOMY

\begin{tabular}{|c|c|c|c|c|c|c|c|c|c|c|}
\hline \multirow[b]{2}{*}{ Indicators } & \multirow[b]{2}{*}{2006} & \multirow[b]{2}{*}{2007} & \multicolumn{2}{|r|}{2008} & \multirow{2}{*}{$\begin{array}{c}2012 \\
\begin{array}{c}\text { NIMES } \\
\text { objective }\end{array}\end{array}$} & \multirow{2}{*}{$\begin{array}{c}2015 \\
\text { MDG } \\
\text { objective }\end{array}$} & \multirow[b]{2}{*}{$\begin{array}{l}\text { Definition of } \\
\text { indicators }\end{array}$} & \multirow[b]{2}{*}{ Periodicity } & \multirow[b]{2}{*}{ Verification source } & \multirow[b]{2}{*}{ Observation: } \\
\hline & & & Objective & \begin{tabular}{|l|} 
1st semester \\
achievements or review of \\
forecasts
\end{tabular} & & & & & & \\
\hline Number of Chambers of Trade revitalized & & & & 0 & & & & & & \\
\hline Number of new CCl set up & & 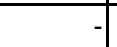 & 11 & 0 & & & & & M ECI-STEP & \\
\hline Investment rate (\%) & 23,2 & 28,3 & - & 35,5 & 30 & & & \multirow[t]{4}{*}{ annual } & \multirow[t]{3}{*}{ M ECl-DEEM } & \\
\hline Public investment rate (\% of GDP) & 10,2 & 7,6 & - & 9,7 & 12,6 & & & & & \\
\hline Private investment rate (\% of GDP) & 13 & 20,7 & - & 25,7 & 17,4 & & & & & \\
\hline Flow of FDIs ( in million SDR) & 150,5 & 652,1 & 439 & 441,5 & 259 & & & & $\mathrm{BCM}$ & \\
\hline $\begin{array}{l}\text { Number of agreements signed as part of investment } \\
\text { promotion }\end{array}$ & - & \begin{tabular}{l|l}
- & \\
\end{tabular} & 5 & $\begin{array}{c}\text { 3 APPI negotiated } \\
\text { and awaiting official } \\
\text { signing }\end{array}$ & & & & Punctual & M ECI-DADI & PGE \\
\hline FDls reception structures set up at regional level & - & - & 3 & 3 & & & & \multirow[t]{3}{*}{ Punctual } & \multirow[t]{3}{*}{ EDBM } & \\
\hline EDBM 's new headquarters completed & - & - & 1 & 1 & & & & & & \\
\hline $\begin{array}{l}\text { EDBM 's focal points established in M inistries and } \\
\text { Embassies }\end{array}$ & - & - & Oui & Oui & & & & & & \\
\hline $\begin{array}{l}\text { Quarterly meetings between Government and } \\
\text { private sector held }\end{array}$ & - & - & 4 & 3 & & & & Quarterly & M ECI-DPPE & \\
\hline Survey on business climante established & - & - & 1 & 1 & & & & \multirow[t]{6}{*}{ Punctual } & \multirow[t]{4}{*}{ EDBM } & \\
\hline Number of judges trained on the law on investment & - & - & 12 & 12 & & & & & & \\
\hline $\begin{array}{l}\text { Number of applications processed as part of } \\
\text { facilitating investments }\end{array}$ & - & - & 1200 & 755 & & & & & & \\
\hline $\begin{array}{l}\text { Number of regions benefiting from IEC as part of } \\
\text { shifting to the formal sector }\end{array}$ & - & - & 22 & 3 & & & & & & \\
\hline $\begin{array}{l}\text { Number of dedicated investment zones identified } \\
\text { and developed }\end{array}$ & - & - & 1 & 1 identified & & & & & \multirow[t]{2}{*}{ M ECI-DPPE } & \\
\hline Number of international missions organized & - & - & 5 & 3 & & & & & & \\
\hline $\begin{array}{l}\text { LT credit granted to private sector ( } \% \text { of total } \\
\text { credits) }\end{array}$ & 4,78 & 7,72 & 8 & 7,1 & & & & Annual & $\mathrm{BCM}$ & \\
\hline Microfinance's penetration rate (\%) & 7,6 & 7,6 & 10 & 9,25 & & & & Annual & M FB-DGT & \\
\hline Outsanding loans of M FI (million ariary) & - & & & 70093 & & & & & & \\
\hline
\end{tabular}


COMMITM ENT 6: HIGH GROWTH ECONOMY

\begin{tabular}{|c|c|c|c|c|c|c|c|c|c|c|}
\hline \multirow[b]{2}{*}{ Indicators } & \multirow[b]{2}{*}{2006} & \multirow[b]{2}{*}{2007} & \multicolumn{2}{|r|}{2008} & \multirow{2}{*}{$\begin{array}{c}2012 \\
\text { NIMES } \\
\text { objective }\end{array}$} & \multirow{2}{*}{$\begin{array}{c}2015 \\
\text { MDG } \\
\text { objective }\end{array}$} & \multirow[b]{2}{*}{$\begin{array}{l}\text { Definition of } \\
\text { indicators }\end{array}$} & \multirow[b]{2}{*}{ Periodicity } & \multirow[b]{2}{*}{ Verification source } & \multirow[b]{2}{*}{ Observation: } \\
\hline & & & Objective & \begin{tabular}{|l|} 
st semester \\
achievements or review of \\
forecasts
\end{tabular} & & & & & & \\
\hline Number of MFI members & - & - & 500000 & 370000 & & & & & M FB-DGT & \\
\hline Unemployment rate among youth 15 to 24 years & - & - & \begin{tabular}{l|l}
- & \\
\end{tabular} & $\mathrm{NA}$ & & & & Annual & $\begin{array}{l}\text { M FPTLS/Simula } \\
\text { tion INSTAT }\end{array}$ & \\
\hline $\begin{array}{l}\text { Unemployment rate among young men 15-24 in } \\
\text { urban areas (ref NIM ES) }\end{array}$ & 9,1 & 9,1 & 8,5 & \multirow{4}{*}{ NA } & & & & \multirow[t]{4}{*}{ Annual } & \multirow[t]{4}{*}{$\begin{array}{l}\text { M FPTLS/ } \\
\text { INSTAT }\end{array}$} & \\
\hline $\begin{array}{l}\text { Unemployment rate among young women 15-24 in } \\
\text { urban areas (ref NIM ES) }\end{array}$ & 18,9 & 18,9 & 16,3 & & & & & & & \\
\hline Sub-employment rate in rural areas (\%) & 45,5 & 45,5 & 38,4 & & & & & & & \\
\hline $\begin{array}{l}\text { Sub-employment rate due to inadequate work } \\
\text { supply (\%) }\end{array}$ & 40 & 40 & 37 & & & & & & & \\
\hline Number of formal jobs created & - & - & 50000 & 5212 & & & & \multirow[t]{3}{*}{ Punctual } & \multirow[t]{3}{*}{ M FPTLS } & \\
\hline $\begin{array}{l}\text { Number of Regional Committees for M onitoring } \\
\text { Employment Promotion and Poverty Reduction } \\
\text { created }\end{array}$ & - & - & 11 & 2 & & & & & & \\
\hline $\begin{array}{l}\text { Number of Employement information and } \\
\text { Orientation Centers created in the } 22 \text { regions }\end{array}$ & - & - & 5 & 10 & & & & & & \\
\hline Hard currency reserves (in months of imports) & 2,9 & 2,9 & 2,4 & 2,3 & 6 & - & & \multirow[t]{3}{*}{ Quarterly } & \multirow[t]{5}{*}{$\mathrm{BCM}$} & \\
\hline Trade balance (in million SDR) & $-372,3$ & $-655,1$ & -1197 & $-564,4$ & & & & & & \\
\hline Balance of payments (in million SDR) & 159 & 148,4 & 49 & $-3,1$ & & & & & & \\
\hline Exports (FOB) (in billion SDR) & 670 & 808 & 909 & 414,3 & & & & \multirow[t]{2}{*}{ Monthly } & & \\
\hline Imports (FOB) (in billion SDR) & 1042 & 1463 & 2106 & 978,7 & & & & & & \\
\hline Rate of coverage import/export (SADC) (\%) & 12,3 & - & 16,87 & 8,95 (1st quarter) & 32,85 & & & \multirow[t]{3}{*}{ Monthly } & \multirow[t]{3}{*}{ MECI-INSTAT } & \\
\hline ate of coverage import/export (COM ESA) (\%) & 23,7 & - & 26,1 & 22,05 & 35,06 & & & & & \\
\hline Rate of coverage import/export (COI) (\%) & 89 & - & 98,09 & 60,93 & 131,78 & & & & & \\
\hline SADC trade protocol implemented & - & - & & 100 & & & & \multirow[t]{2}{*}{ Punctual } & \multirow[t]{2}{*}{ MECI-DRIIE } & \\
\hline $\begin{array}{l}\text { National, regional, and international trade events } \\
\text { organized }\end{array}$ & - & - & & 28 foires & & & & & & \\
\hline $\begin{array}{l}\text { Renforcement de capacité dispensé aux Régions:les } \\
\text { régionaux sur les accords commerciaux }\end{array}$ & - & - & 22 & 22 & & & & Punctual & M ECI-DRIIE & \\
\hline
\end{tabular}


COMMITM ENT 6: HIGH GROWTH ECONOMY

\begin{tabular}{|c|c|c|c|c|c|c|c|c|c|c|}
\hline \multirow[b]{2}{*}{ Indicators } & \multirow[b]{2}{*}{2006} & \multirow[b]{2}{*}{2007} & \multicolumn{2}{|r|}{2008} & \multirow{2}{*}{$\begin{array}{c}2012 \\
\begin{array}{c}\text { NIMES } \\
\text { objective }\end{array}\end{array}$} & \multirow{2}{*}{$\begin{array}{c}2015 \\
\text { MDG } \\
\text { objective }\end{array}$} & \multirow[b]{2}{*}{$\begin{array}{l}\text { Definition of } \\
\text { indicators }\end{array}$} & \multirow[b]{2}{*}{ Periodicity } & \multirow[b]{2}{*}{ Verification source } & \multirow[b]{2}{*}{ Observations } \\
\hline & & & Objective & $\begin{array}{l}\text { 1st semester } \\
\text { achievements or review of } \\
\text { forecasts }\end{array}$ & & & & & & \\
\hline $\begin{array}{l}\text { Commercial information centers set up and } \\
\text { operational }\end{array}$ & - & - & 1 & 1 & & & & Punctual & & \\
\hline $\begin{array}{l}\text { Number of Madagascar's showcases operational } \\
\text { abroad }\end{array}$ & - & - & 21 & $\begin{array}{r}01 \text { ambulatory mini } \\
\text { showcase }\end{array}$ & & & & Punctual & MAE & PGE \\
\hline $\begin{array}{l}\text { Number of conventions, agreements, and protocols } \\
\text { signed and/or ratified }\end{array}$ & - & - & 30 & & & & & & & \\
\hline $\begin{array}{l}\text { Amounts of products from priority sectors shown } \\
\text { during the show cases (annual 2008) }\end{array}$ & - & - & $\begin{array}{r}\text { au moins } \\
50 \% \\
\end{array}$ & $\mathrm{NA}$ & & & & & & \\
\hline Number of SM Es created & - & - & 1500 & 693 & & & & & MECI-DADI & \\
\hline $\begin{array}{l}\text { Logistic infrastructure to support exports (cold chain) } \\
\text { established }\end{array}$ & - & - & - & No & & & & Punctual & M ECI/EDBM & \\
\hline $\begin{array}{l}\text { Single structure for international trade negotiations } \\
\text { set up and operationa (National Council for } \\
\text { International Trade) }\end{array}$ & - & - & - & No & & & & & & \\
\hline One-stop shop for exports set up & - & - & - & No & & & & & & \\
\hline Number of Quality M anagement Systems set up & - & - & 15 & 0 & & & & & & \\
\hline Fund dedicated to exports set up & - & - & $-\quad$ & $\mathrm{No}$ & & & & & & \\
\hline Number of crafts certified & - & - & 7000 & 1500 & & & & & MECI-DPA & \\
\hline Number of products labelled "M adagascar" & - & - & 2 & 0 & & & & & & \\
\hline Number of standardized laboratories accredited & - & & 1 & 0 & & & & & M ECI-DCQPC & \\
\hline $\begin{array}{l}\text { Debt service as a percentage of goods and service } \\
\text { exports }\end{array}$ & 5,92 & 1,7 & 2,5 & 1,6 & & & & annual & M FB-DDP/BCM & MDG \\
\hline Debt service (billions ariary) (end of May 2008) & $\cdot$ & 13,9 & ND & 7,07 & & & & & & \\
\hline Cumulative number of direct jobs created in tourism sector & & 24500 & 24500 & 24524 & 40100 & & Cumullative number & Quarterly & MEEFT & \\
\hline
\end{tabular}




\section{COMMITM ENT 6: HIGH GROWTH ECONOMY}

\begin{tabular}{|c|c|c|c|c|c|c|c|c|c|c|}
\hline \multirow[b]{2}{*}{ Indicators } & \multirow[b]{2}{*}{2006} & \multirow[b]{2}{*}{2007} & \multicolumn{2}{|r|}{2008} & \multirow{2}{*}{$\begin{array}{c}2012 \\
\begin{array}{c}\text { NIMES } \\
\text { objective }\end{array}\end{array}$} & \multirow{2}{*}{$\begin{array}{c}2015 \\
\begin{array}{c}\text { MDG } \\
\text { objective }\end{array}\end{array}$} & \multirow[b]{2}{*}{$\begin{array}{l}\text { Definition of } \\
\text { indicators }\end{array}$} & \multirow[b]{2}{*}{ Periodicity } & \multirow[b]{2}{*}{ Verification source } & \multirow[b]{2}{*}{ Observations } \\
\hline & & & Objective & \begin{tabular}{|l|}
$\begin{array}{l}\text { lst semester } \\
\text { achievements or review of } \\
\text { forecasts }\end{array}$ \\
\end{tabular} & & & & & & \\
\hline Revenues generated by the tourism sector (millions SDR) & & 211 & 236 & 94,22 & 370 & & $\begin{array}{l}\text { amount provided by } \\
\text { Central bank based } \\
\text { on the total amount } \\
\text { of currencies } \\
\text { exchanged by tourist } \\
\text { during their stays }\end{array}$ & Quarterly & MEEFT & \\
\hline
\end{tabular}




\section{COMMITMENT 7: CHERISH THE ENVIRONMENT}

\begin{tabular}{|c|c|c|c|c|c|c|c|c|c|}
\hline \multirow{2}{*}{ Indicator Name } & \multirow{2}{*}{2006} & \multirow{2}{*}{2007} & \multicolumn{2}{|r|}{2008} & \multirow{2}{*}{$\frac{2012}{\text { Objective SNISE }}$} & \multirow{2}{*}{$\frac{2015}{\text { Objective MDG }}$} & \multirow{2}{*}{ Periodicity } & \multirow{2}{*}{ Verification Source } & \multirow{2}{*}{ Observations } \\
\hline & & & Objective & $\begin{array}{c}\text { Achievement 1st } \\
\text { semester }\end{array}$ & & & & & \\
\hline Surface area of established protected areas (in thousands of ha ) & 4 & 876.6 & 5 & 4,226 & 6 & - & Semester & MEEFT & \multirow{7}{*}{$\begin{array}{l}\text { New indicators } \\
\text { adopted in SNISE }\end{array}$} \\
\hline Amount of mobilized capital (in USD thousands) & 18 & 33 & 35 & 54 & 50 & - & Semester & MEEFT/PTF & \\
\hline Rate of reduction of burnt surface areas (\%) & 32 & 33 & 35 & 0.28 & 70 & - & Annual & MEEFT & \\
\hline Percentage of surface areas covered with forests (\%) & 22,6 & & & & & - & Annual & MEEFT & \\
\hline Reforested and rehabilitated surface areas (ha) & 36 & 18 & 25 & 35 & 540 & - & Quarterly & MEEFT & \\
\hline $\begin{array}{l}\text { Percentage of curricula in primary, secondary, tertiary, and } \\
\text { vocational education mainstreaming the environmental } \\
\text { dimension (\%) }\end{array}$ & - & $\begin{array}{c}100 \text { (primary) } \\
90 \text { (secondary) } \\
25 \text { (techn and voc) } \\
\text { un module dans } 06 \\
\text { universités }\end{array}$ & $22 \%$ & $\begin{array}{c}13 \% \text { of which: } 8 \% \\
\text { (primary), } 4 \% \text { (lower } \\
\text { secondary schools), } 1 \% \\
\text { (lycée) }\end{array}$ & 90 & $\cdot$ & Semester & MEEFT & \\
\hline Number of established forest control units & & & 22 & 22 & 23 & - & Annual & MEEFT & \\
\hline
\end{tabular}




\section{COMMITMENT 8: NATIONAL SOLIDARITY}

\begin{tabular}{|c|c|c|c|c|c|c|c|c|c|c|}
\hline \multirow[b]{2}{*}{ Indicator Name } & \multirow[b]{2}{*}{2006} & \multirow[b]{2}{*}{2007} & \multicolumn{2}{|l|}{2008} & \multirow{2}{*}{$\begin{array}{l}2012 \\
\text { Objective } \\
\text { SNISE }\end{array}$} & \multirow{2}{*}{$\begin{array}{l}2015 \\
\text { Objective } \\
\text { MDG }\end{array}$} & \multirow[b]{2}{*}{ Definition of indicators } & \multirow[b]{2}{*}{ Periodicity } & \multirow[b]{2}{*}{$\begin{array}{l}\text { Verification } \\
\text { Source }\end{array}$} & \multirow[b]{2}{*}{ Observations } \\
\hline & & & Objective & \begin{tabular}{|c|} 
Achievements \\
1st Semester \\
\end{tabular} & & & & & & \\
\hline $\begin{array}{l}\text { Number of saved national cultural heritages (material and } \\
\text { immaterial) }\end{array}$ & 3 & 7 & Six (06) & 4 & 20 & & & Annual & $\begin{array}{l}\text { Activity } \\
\text { report/SECL }\end{array}$ & \begin{tabular}{|l|} 
Partners : \\
National Committee
\end{tabular} \\
\hline $\begin{array}{l}\text { Cumulative percentage of regions that have been pre surveyed in } \\
\text { Cultrual Heritage }\end{array}$ & & & $\begin{array}{r}50 \% \text {, i;e., eleven (11) } \\
\text { Regions }\end{array}$ & & & & $\begin{array}{l}\text { Pre survey for inventory and } \\
\text { assessment }(10 \% \text { increase per year } \\
\text { ) }\end{array}$ & & \begin{tabular}{|l|} 
Rapport \\
d'activités/SECL
\end{tabular} & \begin{tabular}{l|} 
for heritage \\
UNESCO \\
International \\
\end{tabular} \\
\hline available Database on heritages & & & $\begin{array}{r}\text { Available database on } \\
\text { heritages }\end{array}$ & & & & & & & \\
\hline Number of awarded national artistic prizes & & & 8 & 1 & & & & & & \\
\hline $\begin{array}{l}\text { Number of supported art handicraft, art handicraft, and design } \\
\text { creations }\end{array}$ & & & 10 & 3 & & & 12 covered regions & & & \\
\hline \multicolumn{11}{|l|}{ Rate of national participation in elections } \\
\hline \multirow[t]{4}{*}{$\begin{array}{l}\text { Leadership capacity building among members of civil society and } \\
\text { public sector officials, and conduct monitoring thereof }\end{array}$} & & & Central: 5,275 people & 3,741 people & & & & & NLIM & \\
\hline & & & 22 Regions & 22 Regions & & & & & & \\
\hline & & & 119 districts & 18 Districts & & & & & & \\
\hline & & & 1,546 Mayors & 1,546 Mayors & & & & & & \\
\hline $\begin{array}{l}\text { Develop leadership capacity building among citizens and conduct } \\
\text { monitoring thereof }\end{array}$ & & & 10,941 & & & & & & NLIM & \\
\hline \multirow[t]{3}{*}{$\begin{array}{l}\text { Organize forums, colloquiums, conferences, and meetings for } \\
\text { experience sharing and extend best practices }\end{array}$} & & & 23 television programs & 10 & & & & & NLIM & \\
\hline & & & 33 radio programs & 21 & & & & & & \\
\hline & & & briadcasts in news & 10 & & & & & & \\
\hline $\begin{array}{l}\text { Cumulative number of regions that are supported in the organization } \\
\text { of events that are representative of their culture }\end{array}$ & & & 9 & 1 & & & $10 \%$ increase per year & & & \\
\hline \multicolumn{11}{|l|}{ Number of produced advertals and documentaries } \\
\hline Number of edited booklets & & & 7 & 7 & & & & & & \\
\hline \multicolumn{11}{|l|}{ Number of established and supervised cultural meetings } \\
\hline Number of athletes participating in international contests & 78 & 393 & 776 athletes & 114 Athletes & 1358 & - & & Annual & $\begin{array}{l}\text { Mission reports } \\
\text { by } \\
\text { delegations/MJS }\end{array}$ & \\
\hline $\begin{array}{l}\text { Number of organized challenges (organization of selected collective } \\
\text { sport contests) }\end{array}$ & & & 3 & 2 & & & & & & \\
\hline \multicolumn{11}{|l|}{ Number of organized cultural and language games } \\
\hline \multicolumn{11}{|l|}{$\begin{array}{l}\text { Number of organized contests with prizes to best artists, } \\
\text { sportspeople, partners }\end{array}$} \\
\hline \multicolumn{11}{|l|}{$\begin{array}{l}\text { Number of conventions signed between a region and aprivate } \\
\text { company for participation in a major event }\end{array}$} \\
\hline \multicolumn{11}{|l|}{$\begin{array}{l}\text { Number of developed texts, of which : } \\
\text { Three (03) standard statutes of Federations (Unisport, Omnisport, } \\
\text { Affinitaire) }\end{array}$} \\
\hline Number of Statutes of high level athletes & & & 1 & & & & & & & \\
\hline
\end{tabular}




\section{COMMITMENT 8: NATIONAL SOLIDARITY}

\begin{tabular}{|c|c|c|c|c|c|c|c|c|c|c|}
\hline \multirow[b]{2}{*}{ Indicator Name } & \multirow[b]{2}{*}{2006} & \multirow[b]{2}{*}{2007} & \multicolumn{2}{|l|}{2008} & \multirow{2}{*}{$\begin{array}{c}2012 \\
\begin{array}{c}\text { Objective } \\
\text { SNISE }\end{array} \\
\end{array}$} & \multirow{2}{*}{$\begin{array}{c}2015 \\
\text { Objective } \\
\text { MDG }\end{array}$} & \multirow[b]{2}{*}{ Definition of indicators } & \multirow[b]{2}{*}{ Periodicity } & \multirow[b]{2}{*}{$\begin{array}{l}\text { Verification } \\
\text { Source }\end{array}$} & \multirow[b]{2}{*}{ Observations } \\
\hline & & & Objective & $\begin{array}{c}\text { Achievements } \\
\text { 1st Semester }\end{array}$ & & & & & & \\
\hline $\begin{array}{l}\text { Rate of under } 18 \text { children and young people having no birth deed } \\
(\%)\end{array}$ & & 31,2 & 24 & $\begin{array}{r}31 \% \text { i.e., } \\
130,363 \text { people })\end{array}$ & & & & Annual & $\begin{array}{l}\text { Census at level of } \\
\text { fokontany/Ministr } \\
\text { y of Interior }\end{array}$ & \\
\hline $\begin{array}{l}\text { Rate of mayorships, administrative and geographical districts with } \\
\text { computerized civil status (IR); }\end{array}$ & & & 100 i.e., 1,700) & , 34 Mayorships) & & & & & & \\
\hline \multicolumn{11}{|l|}{ Number of monthly programs at RNM and at TVM } \\
\hline Proportion of seats occupied by women in Parliament (\%): & & & & & & & & & MINSAPFPS & MDG \\
\hline Senate & 5 & 10 & & & & & & & & \\
\hline National Assembly & & 7,9 & & & & & & & & \\
\hline \multicolumn{11}{|l|}{ Number of regions having operational women leader networks } \\
\hline \multicolumn{11}{|l|}{ Access of vulnerable groups to basic social services } \\
\hline \multicolumn{11}{|l|}{ Number of established child protection networks } \\
\hline Number of supported OEV families (Orphans, Vulnerable children) & & & 300 & 300 & & & & & & \\
\hline \multicolumn{11}{|l|}{ Safety Net } \\
\hline Number of temporary employments that have been created & & & $1,350,000$ men day & $\begin{array}{r}522,725 \text { men } \\
\text { day (ONN) }\end{array}$ & & & & & & \\
\hline
\end{tabular}




\section{DISBURSEMENT}


AFD DISBURSEMENT Status as of June 2008

(en Millions USD)

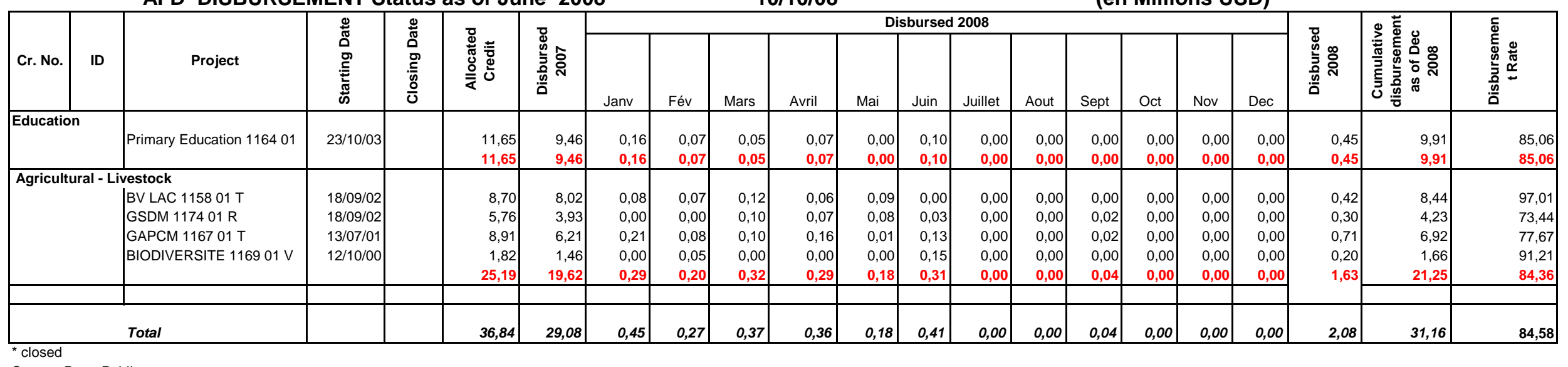

Source: Dette Publique 
ADBA Disbursement Status as of May 2008

$10 / 10 / 08$

(In USD Millions )

\begin{tabular}{|c|c|c|c|c|c|c|c|c|c|c|c|c|c|c|c|c|c|c|c|c|c|}
\hline \multirow[b]{2}{*}{ Cr. No. } & \multirow[b]{2}{*}{ ID } & \multirow[b]{2}{*}{ Project } & \multirow{2}{*}{ 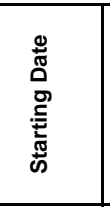 } & \multirow{2}{*}{ 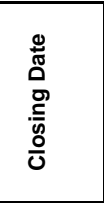 } & \multirow{2}{*}{ 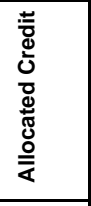 } & \multirow{2}{*}{ 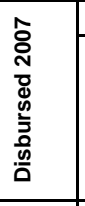 } & \multicolumn{12}{|c|}{ Disbursed 2008} & \multirow{2}{*}{ 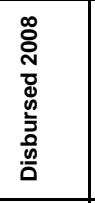 } & \multirow{2}{*}{ 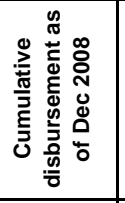 } & \multirow{2}{*}{ 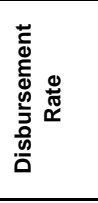 } \\
\hline & & & & & & & Jan & Feb & March & April & May & June & July & August & Sept & Oct & Nov & Dec & & & \\
\hline \multirow{3}{*}{\multicolumn{2}{|c|}{ Education }} & School & $24 / 02 / 00$ & $31 / 12 / 08$ & 1,00 & 0,32 & 0,00 & 0,00 & 0,00 & 0,00 & 0,11 & 0,02 & 0,00 & 0,00 & 0,00 & 0,00 & 0,00 & 0,00 & 0,13 & 0,45 & 45,00 \\
\hline & & Support to General Education & $24 / 02 / 00$ & $31 / 12 / 08$ & 8,00 & 2,03 & 0,00 & 0,02 & 0,06 & 0,13 & 0,34 & 0,38 & 0,00 & 0,00 & 0,00 & 0,00 & 0,00 & 0,00 & 0,93 & 2,96 & 37,00 \\
\hline & & & & & 9,00 & 2,35 & 0,00 & 0,02 & 0,06 & 0,13 & 0,45 & 0,40 & 0,00 & 0,00 & 0,00 & 0,00 & 0,00 & 0,00 & 1,06 & 3,41 & 37,89 \\
\hline \multirow{5}{*}{\multicolumn{2}{|c|}{ Energy }} & & & & & & & & & & & & & & & & & & & & \\
\hline & & $\begin{array}{l}\text { Energy sector Development 3rd } \\
\text { Group Hydroel Plant Andek }\end{array}$ & $07 / 07 / 05$ & $31 / 12 / 09$ & 6,50 & 0,15 & 0,00 & 0,03 & 0,00 & 0,00 & 0,00 & 0,05 & 0,00 & 0,00 & 0,00 & 0,00 & 0,00 & 0,00 & 0,08 & 0,23 & 3,54 \\
\hline & & Inter Conn Electric Abe Ambositra & $22 / 11 / 00$ & $31 / 03 / 08$ & 0,25 & 0,03 & 0,09 & 0,00 & 0,00 & 0,04 & 0,04 & 0,00 & 0,00 & 0,00 & 0,00 & 0,00 & 0,00 & 0,00 & 0,17 & 0,20 & \\
\hline & & AEPA Ambalavao Manjakandriana & $28 / 08 / 03$ & $30 / 04 / 09$ & 5,20 & 0,00 & 0,15 & 0,00 & 0,00 & 0,00 & 0,07 & 0,00 & 0,00 & 0,00 & 0,00 & 0,00 & 0,00 & 0,00 & 0,22 & 0,22 & \\
\hline & & & & & 11,95 & & & & 0,00 & & 0,11 & 0,05 & 0,00 & 0,00 & 0,00 & 0,00 & 0,00 & 0,00 & & 0,65 & $\begin{array}{l}4,23 \\
5,44\end{array}$ \\
\hline \multirow{4}{*}{\multicolumn{2}{|c|}{ Infrastructure }} & & & & & & & & & & & & & & & & & & & & \\
\hline & & \begin{tabular}{|l|} 
Rehabilitation and Const RN 6 \\
Ambondromamy Port-Berge
\end{tabular} & 03/05/01 & & 14,00 & 10,56 & 0,15 & 0,08 & 0,00 & 0,66 & 0,15 & 0,00 & 0,00 & 0,00 & 0,00 & 0,00 & 0,00 & 0,00 & 1,04 & 11,60 & 82,86 \\
\hline & & $\begin{array}{l}\text { Road Sambaina Faratsiho Soav } \\
\text { Rehabilitation and Const Bridge RN4 } \\
5-25\end{array}$ & $\begin{array}{l}17 / 10 / 05 \\
07 / 04 / 94\end{array}$ & $31 / 12 / 08$ & $\begin{array}{l}8,50 \\
7,00\end{array}$ & $\begin{array}{l}0,00 \\
3,50\end{array}$ & $\begin{array}{l}0,00 \\
0,00\end{array}$ & $\begin{array}{l}0,00 \\
0,00\end{array}$ & $\begin{array}{l}0,00 \\
0,00\end{array}$ & $\begin{array}{l}0,00 \\
0,00\end{array}$ & $\begin{array}{l}0,00 \\
0,00\end{array}$ & $\begin{array}{l}0,00 \\
0,00\end{array}$ & $\begin{array}{l}0,00 \\
0,00\end{array}$ & $\begin{array}{l}0,00 \\
0,00\end{array}$ & $\begin{array}{l}0,00 \\
0,00\end{array}$ & $\begin{array}{l}0,00 \\
0,00\end{array}$ & $\begin{array}{l}0,00 \\
0,00\end{array}$ & $\begin{array}{l}0,00 \\
0,00\end{array}$ & $\begin{array}{l}0,00 \\
0,00\end{array}$ & $\begin{array}{l}0,00 \\
3,50\end{array}$ & 0,00 \\
\hline & & & & & 29,50 & 14,06 & 0,15 & 0,08 & 0,00 & 0,66 & 0,15 & 0,00 & 0,00 & 0,00 & 0,00 & 0,00 & 0,00 & 0,00 & 1,04 & 15,10 & 51,19 \\
\hline & & Total & & & 50,45 & 16,59 & 0,39 & 0,13 & 0,06 & 0,83 & 0,71 & 0,45 & 0,00 & 0,00 & 0,00 & 0,00 & 0,00 & 0,00 & 2,57 & 19,16 & 37,98 \\
\hline
\end{tabular}

Source: MFB/DDP 
World Bank Disbursement Status as of August 2008

08/10/08

(In USD Millions)

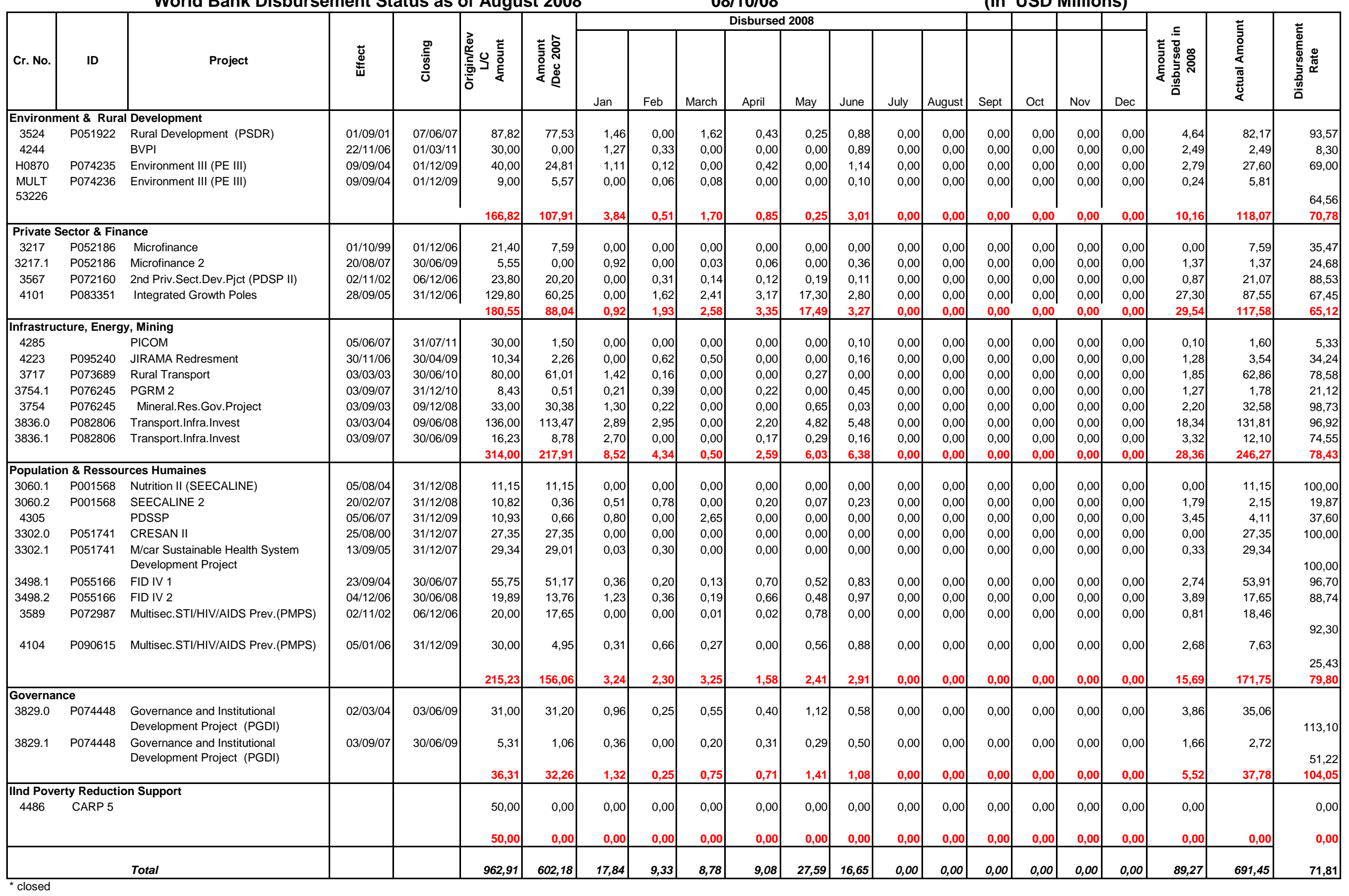

Source: Dette Publique 
CHINA Disbursement Status as of June 2008

\begin{tabular}{|c|c|c|c|c|c|c|c|c|c|c|c|c|c|c|c|c|c|c|c|c|c|}
\hline & & CHIINA DIS & ement & Sta & s as & I Jun & 2000 & & \multirow{2}{*}{\multicolumn{10}{|c|}{$\frac{\text { Disbursed } 2008}{29 / 0 / / 08}$}} & \multirow{3}{*}{ 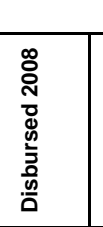 } & \multirow{3}{*}{ 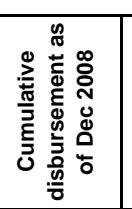 } & \multirow{3}{*}{ 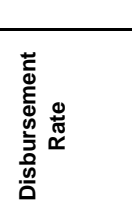 } \\
\hline \multirow{2}{*}{ Cr. No. } & \multirow{2}{*}{ ID } & \multirow{2}{*}{ Project } & \multirow{2}{*}{ 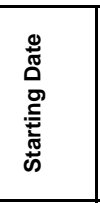 } & \multirow{2}{*}{ 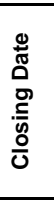 } & \multirow{2}{*}{ 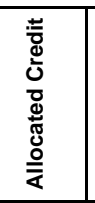 } & \multirow{2}{*}{ 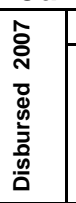 } & \multicolumn{5}{|c|}{$\begin{array}{l}\text { Disbursed } 2008 \\
\end{array}$} & & & & & & & & & & \\
\hline & & & & & & & Jan & $\mathrm{Feb}$ & March & April & May & June & July & August & Sept & Oct & Nov & Dec & & & \\
\hline \multirow{2}{*}{\multicolumn{2}{|c|}{ Infrastructure }} & & & & & & & & & & & & & & & & & & & & \\
\hline & & \begin{tabular}{|l|} 
Construction 5 Star Hotel \\
\end{tabular} & $26 / 09 / 07$ & & 50,00 & 0,00 & 19,83 & 0,00 & 4,91 & 0,00 & 0,00 & 7,36 & 0,00 & 0,00 & 0,00 & 0,00 & 0,00 & 0,00 & 32,10 & 32,10 & 64,20 \\
\hline & & & & & & & & & & & & & & & & & & & & & \\
\hline & & TOTAL & & & 50,00 & 0,00 & 19,83 & 0,00 & 4,91 & 0,00 & 0,00 & 7,36 & 0,00 & 0,00 & 0,00 & 0,00 & 0,00 & 0,00 & 32,10 & 32,10 & 64,20 \\
\hline
\end{tabular}

Source: Dette Publique 
CHINA Disbursement Status as of June 2008

\begin{tabular}{|c|c|c|c|c|c|c|c|c|c|c|c|c|c|c|c|c|c|c|c|c|c|}
\hline & & CHIINA DIS & ement & Sta & s as & I Jun & 2000 & & \multirow{2}{*}{\multicolumn{10}{|c|}{$\frac{\text { Disbursed } 2008}{29 / 0 / / 08}$}} & \multirow{3}{*}{ 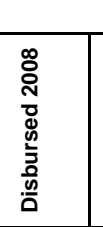 } & \multirow{3}{*}{ 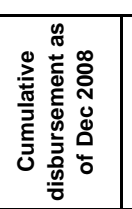 } & \multirow{3}{*}{ 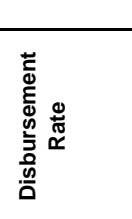 } \\
\hline \multirow{2}{*}{ Cr. No. } & \multirow{2}{*}{ ID } & \multirow{2}{*}{ Project } & \multirow{2}{*}{ 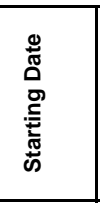 } & \multirow{2}{*}{ 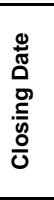 } & \multirow{2}{*}{ 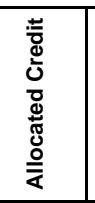 } & \multirow{2}{*}{ 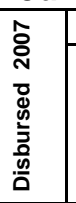 } & \multicolumn{5}{|c|}{$\begin{array}{l}\text { Disbursed } 2008 \\
\end{array}$} & & & & & & & & & & \\
\hline & & & & & & & Jan & $\mathrm{Feb}$ & March & April & May & June & July & August & Sept & Oct & Nov & Dec & & & \\
\hline \multirow{2}{*}{\multicolumn{2}{|c|}{ Infrastructure }} & & & & & & & & & & & & & & & & & & & & \\
\hline & & \begin{tabular}{|l|} 
Construction 5 Star Hotel \\
\end{tabular} & $26 / 09 / 07$ & & 50,00 & 0,00 & 19,83 & 0,00 & 4,91 & 0,00 & 0,00 & 7,36 & 0,00 & 0,00 & 0,00 & 0,00 & 0,00 & 0,00 & 32,10 & 32,10 & 64,20 \\
\hline & & & & & & & & & & & & & & & & & & & & & \\
\hline & & TOTAL & & & 50,00 & 0,00 & 19,83 & 0,00 & 4,91 & 0,00 & 0,00 & 7,36 & 0,00 & 0,00 & 0,00 & 0,00 & 0,00 & 0,00 & 32,10 & 32,10 & 64,20 \\
\hline
\end{tabular}

Source: Dette Publique 
Disbursement Status as of July 2008 FAD DONATION

10/10/08

(In USD Millions)

\begin{tabular}{|c|c|c|c|c|c|c|c|c|c|c|c|c|c|c|c|c|c|c|c|c|}
\hline \multirow[b]{2}{*}{ Cr. No. } & \multirow[b]{2}{*}{ Project } & \multirow{2}{*}{ 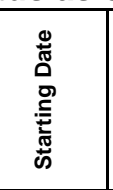 } & \multirow{2}{*}{$\begin{array}{l}\frac{9}{\pi} \\
\frac{0}{0} \\
\frac{5}{0} \\
\frac{0}{0}\end{array}$} & \multirow{2}{*}{ 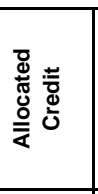 } & \multirow{2}{*}{ 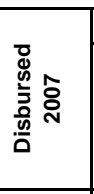 } & \multicolumn{12}{|c|}{ Disbursed 2008} & \multirow{2}{*}{ 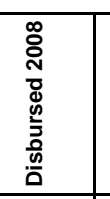 } & \multirow{2}{*}{ 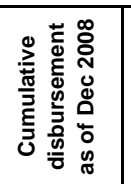 } & \multirow{2}{*}{ 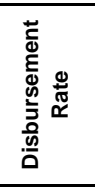 } \\
\hline & & & & & & Jan & Feb & March & April & May & June & July & August & Sept & Oct & Nov & Dec & & & \\
\hline Road & Road Project Prov. Tulear & $30 / 11 / 04$ & $31 / 12 / 10$ & $\begin{array}{l}2,80 \\
2,80\end{array}$ & $\begin{array}{l}0,24 \\
0,24\end{array}$ & $\begin{array}{l}0,00 \\
0,00\end{array}$ & $\begin{array}{l}0,24 \\
0,24\end{array}$ & $\begin{array}{l}0,00 \\
0,00\end{array}$ & $\begin{array}{l}0,01 \\
0,01\end{array}$ & $\begin{array}{l}0,07 \\
0,07\end{array}$ & $\begin{array}{l}0,00 \\
0,00\end{array}$ & $\begin{array}{l}0,00 \\
0,00\end{array}$ & $\begin{array}{l}0,00 \\
0,00\end{array}$ & $\begin{array}{l}0,00 \\
0,00\end{array}$ & $\begin{array}{l}0,00 \\
0,00\end{array}$ & $\begin{array}{l}0,00 \\
0,00\end{array}$ & $\begin{array}{l}0,00 \\
0,00\end{array}$ & $\begin{array}{l}0,32 \\
0,32\end{array}$ & $\begin{array}{l}0,56 \\
0,56\end{array}$ & $\begin{array}{l}20,00 \\
20,00\end{array}$ \\
\hline Budgetary Si & $\begin{array}{l}\text { es } \\
\text { Strenght fine Istitution aim to } \\
\text { good Gov } \\
\text { Gov }\end{array}$ & $13 / 01 / 05$ & $31 / 12 / 09$ & $\begin{array}{l}8,85 \\
8,85\end{array}$ & $\begin{array}{l}1,31 \\
1,31\end{array}$ & $\begin{array}{l}0,00 \\
0,00\end{array}$ & $\begin{array}{l}0,05 \\
0,05\end{array}$ & $\begin{array}{l}0,00 \\
0,00\end{array}$ & $\begin{array}{l}0,29 \\
0,29 \\
\end{array}$ & $\begin{array}{l}1,23 \\
1,23\end{array}$ & $\begin{array}{l}0,04 \\
0,04\end{array}$ & $\begin{array}{l}0,00 \\
0,00 \\
\end{array}$ & $\begin{array}{l}0,00 \\
0,00\end{array}$ & $\begin{array}{l}0,00 \\
0,00\end{array}$ & $\begin{array}{l}0,00 \\
0,00\end{array}$ & $\begin{array}{l}0,00 \\
0,00\end{array}$ & $\begin{array}{l}0,00 \\
0,00\end{array}$ & $\begin{array}{l}1,61 \\
1,61\end{array}$ & $\begin{array}{l}2,92 \\
2,92\end{array}$ & $\begin{array}{l}32,99 \\
32,99 \\
\end{array}$ \\
\hline $\begin{array}{l}\text { Agriculture - } \\
\text { Livestock }\end{array}$ & Fight against locust & 08/05/01 & $31 / 12 / 08$ & $\begin{array}{l}0,91 \\
0,91\end{array}$ & $\begin{array}{l}0,68 \\
0,68\end{array}$ & $\begin{array}{l}0,00 \\
0,00\end{array}$ & $\begin{array}{l}0,00 \\
0,00\end{array}$ & $\begin{array}{l}0,00 \\
0,00\end{array}$ & $\begin{array}{l}0,00 \\
0,00\end{array}$ & $\begin{array}{l}0,00 \\
0,00\end{array}$ & $\begin{array}{l}0,00 \\
0,00\end{array}$ & $\begin{array}{l}0,00 \\
0,00\end{array}$ & $\begin{array}{l}0,00 \\
0,00\end{array}$ & $\begin{array}{l}0,00 \\
0,00\end{array}$ & $\begin{array}{l}0,00 \\
0,00\end{array}$ & $\begin{array}{l}0,00 \\
0,00\end{array}$ & $\begin{array}{l}0,00 \\
0,00\end{array}$ & $\begin{array}{l}0,00 \\
0,00\end{array}$ & $\begin{array}{l}0,68 \\
0,68\end{array}$ & $\begin{array}{l}74,73 \\
74,73\end{array}$ \\
\hline Education & Education III & 17/12/98 & $30 / 06 / 08$ & $\begin{array}{l}0,74 \\
0,74\end{array}$ & $\begin{array}{l}0,04 \\
0,04\end{array}$ & $\begin{array}{l}0,00 \\
0,00\end{array}$ & $\begin{array}{l}0,00 \\
0,00\end{array}$ & $\begin{array}{l}0,00 \\
0,00\end{array}$ & $\begin{array}{l}0,00 \\
0,00\end{array}$ & $\begin{array}{l}0,00 \\
0,00\end{array}$ & $\begin{array}{l}0,00 \\
0,00\end{array}$ & $\begin{array}{l}0,00 \\
0,00\end{array}$ & $\begin{array}{l}0,00 \\
0,00\end{array}$ & $\begin{array}{l}0,00 \\
0,00\end{array}$ & $\begin{array}{l}0,00 \\
0,00\end{array}$ & $\begin{array}{l}0,00 \\
0,00\end{array}$ & $\begin{array}{l}0,00 \\
0,00\end{array}$ & $\begin{array}{l}0,00 \\
0,00\end{array}$ & $\begin{array}{l}0,04 \\
0,04\end{array}$ & 5,41 \\
\hline Health & $\begin{array}{l}\text { Health II } \\
\text { Supporting Fight against } \\
\text { Communicable Diseases /AIDS }\end{array}$ & $\begin{array}{l}13 / 07 / 99 \\
06 / 07 / 06\end{array}$ & $\begin{array}{l}31 / 12 / 08 \\
30 / 12 / 10\end{array}$ & $\begin{array}{r}1,14 \\
9,06 \\
10,20\end{array}$ & $\begin{array}{l}1,06 \\
2,20 \\
3,26\end{array}$ & $\begin{array}{l}0,00 \\
0,00 \\
0,00\end{array}$ & $\begin{array}{l}0,07 \\
0,00\end{array}$ & $\begin{array}{l}0,00 \\
0,00 \\
0,00\end{array}$ & $\begin{array}{l}0,00 \\
0,05 \\
0,05\end{array}$ & $\begin{array}{l}0,00 \\
0,03 \\
0,03\end{array}$ & $\begin{array}{l}0,00 \\
0,60\end{array}$ & $\begin{array}{l}0,00 \\
0,00\end{array}$ & $\begin{array}{l}0,00 \\
0,00 \\
0,00\end{array}$ & $\begin{array}{l}0,00 \\
0,00 \\
0,00\end{array}$ & $\begin{array}{l}0,00 \\
0,00 \\
0,00\end{array}$ & $\begin{array}{l}0,00 \\
0,00 \\
0,00\end{array}$ & $\begin{array}{l}0,00 \\
0,00 \\
0,00\end{array}$ & $\begin{array}{l}0,07 \\
0,68 \\
0,75\end{array}$ & $\begin{array}{l}1,13 \\
2,88 \\
4,01\end{array}$ & $\begin{array}{l}99,12 \\
31,79\end{array}$ \\
\hline & TOTAL & & & 23,50 & 5,53 & 0,00 & 0,36 & 0,00 & 0,35 & 1,33 & 0,64 & 0,00 & 0,00 & 0,00 & 0,00 & 0,00 & 0,00 & 2,68 & 8,21 & 34,94 \\
\hline
\end{tabular}


Disbursement Status as of JULY 2008 FAD LOAN

10/10/08

(In USD Millions)

\begin{tabular}{|c|c|c|c|c|c|c|c|c|c|c|c|c|c|c|c|c|c|c|c|c|}
\hline \multirow[b]{2}{*}{ Cr. No. } & \multirow[b]{2}{*}{ Project } & \multirow{2}{*}{ 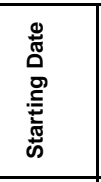 } & \multirow{2}{*}{$\begin{array}{l}\frac{0}{\pi} \\
\frac{0}{0} \\
\frac{5}{0} \\
\frac{0}{0}\end{array}$} & \multirow{2}{*}{ 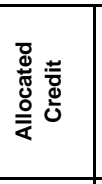 } & \multirow{2}{*}{ 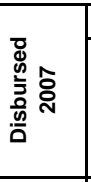 } & \multicolumn{12}{|c|}{$\begin{array}{l}\text { Disbursed } 2008 \\
\end{array}$} & \multirow{2}{*}{ 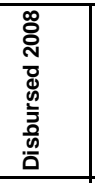 } & \multirow{2}{*}{ 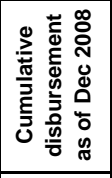 } & \multirow{2}{*}{ 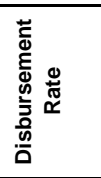 } \\
\hline & & & & & & Jan & Feb & March & April & May & June & July & August & Sept & Oct & Nov & Dec & & & \\
\hline \multirow[t]{4}{*}{ Road } & RN1 BIS Rehab & 20/10/05 & $31 / 03 / 08$ & 13,84 & 10,07 & 0,00 & 1,82 & 0,12 & 0,06 & 0,00 & 0,00 & 0,00 & 0,00 & 0,00 & 0,00 & 0,00 & 0,00 & 2,00 & 12,07 & 87,21 \\
\hline & Recovery from Cyclone Disasters & $23 / 11 / 06$ & $31 / 12 / 07$ & 3,08 & 1,86 & 0,00 & 0,90 & 0,00 & 0,00 & 0,00 & 0,00 & 0,00 & $0,0 c$ & 0,00 & 0,00 & 0,00 & 0,00 & 0,90 & 2,76 & \\
\hline & Road Project Prov Tulear & $30 / 11 / 04$ & $31 / 12 / 10$ & 46,62 & 5,13 & 0,00 & 0,44 & 0,00 & 1,94 & 0,00 & 0,00 & 0,00 & $0,0 c$ & 0,00 & 0,00 & 0,00 & 0,00 & 2,38 & 7,51 & 16,11 \\
\hline & & & & 63,54 & 17,06 & 0,00 & 3,16 & 0,12 & 2,00 & 0,00 & 0,00 & 0,00 & 0,00 & 0,00 & 0,00 & 0,00 & 0,00 & 5,28 & 22,34 & 35,16 \\
\hline \multirow{5}{*}{$\begin{array}{l}\text { Agriculture - } \\
\text { Livestock }\end{array}$} & & & & & & & & & & & & & & & & & & & & \\
\hline & Fight against locust & 08/05/01 & $31 / 12 / 08$ & 8,53 & 5,99 & 0,00 & 0,00 & 0,00 & 0,10 & 0,42 & 0,00 & 0,00 & 0,00 & 0,00 & 0,00 & 0,00 & 0,00 & 0,52 & 6,51 & 76,32 \\
\hline & MANOMBO Project & $25 / 03 / 08$ & $31 / 12 / 13$ & 14,54 & 0,00 & 0,00 & 0,00 & 0,00 & 0,00 & 0,00 & 0,00 & 0,00 & $0,0 c$ & 0,00 & 0,00 & 0,00 & 0,00 & 0,00 & 0,00 & 0,00 \\
\hline & Lower Mangoky Rehabilitation & $17 / 12 / 99$ & $31 / 12 / 08$ & 14,80 & 15,59 & 0,00 & 0,15 & 0,00 & 0,00 & 0,00 & 0,00 & 0,00 & $0,0 c$ & 0,00 & 0,00 & 0,00 & 0,00 & 0,15 & 15,74 & 106,35 \\
\hline & & & & 23,33 & 21,58 & 0,00 & 0,15 & 0,00 & 0,10 & 0,42 & 0,00 & 0,00 & 0,00 & 0,00 & 0,00 & 0,00 & 0,00 & 0,67 & 22,25 & 95,37 \\
\hline \multirow[t]{5}{*}{ Aide Budgetaire } & & & & & & & & & & & & & & & & & & & & \\
\hline & PARP 2 & $14 / 07 / 08$ & $30 / 06 / 11$ & 84,00 & 0,00 & 0,00 & 0,00 & 0,00 & 0,00 & 0,00 & 0,00 & 0,00 & $0,0 c$ & 0,00 & 0,00 & 0,00 & 0,00 & 0,00 & 0,00 & 0,00 \\
\hline & & & & 84,00 & 0,00 & 0,00 & 0,00 & 0,00 & 0,00 & 0,00 & 0,00 & 0,00 & $0,0 c$ & 0,00 & 0,00 & 0,00 & 0,00 & 0,00 & 0,00 & 0,00 \\
\hline & Education III & $17 / 12 / 98$ & $30 / 06 / 08$ & 23,68 & 3,10 & 0.00 & 1,14 & 0,00 & 0.15 & 0,31 & 0.30 & 0.00 & 0,00 & 0.00 & 0,00 & 0,00 & 0,00 & 1.90 & 5,00 & 21.11 \\
\hline & & & & 23,68 & 3,10 & 0,00 & 1,14 & 0,00 & 0,15 & 0,31 & 0,30 & 0,00 & $0,0 c$ & 0,00 & 0,00 & 0,00 & 0,00 & 1,90 & 5,00 & 21,11 \\
\hline \multirow[t]{4}{*}{ Health } & & & & & & & & & & & & & & & & & & & & \\
\hline & Health II & $13 / 07 / 99$ & $31 / 12 / 08$ & 18,42 & 12,36 & 0,00 & 0,07 & 0,00 & 0,46 & 0,00 & 0,25 & 0,00 & $0,0 c$ & 0,00 & 0,00 & 0,00 & 0,00 & 0,78 & 13,14 & 71,34 \\
\hline & Lutte MST/SIDA & 06/07/06 & $30 / 12 / 10$ & 9,54 & 2,38 & 0,00 & 0,47 & 0,00 & 0,00 & 0,00 & 0,00 & 0,00 & 0,00 & 0,00 & 0,00 & 0,00 & 0,00 & 0,47 & 2,85 & 29,87 \\
\hline & & & & 18,42 & 12,36 & 0,00 & 0,07 & 0,00 & 0,46 & 0,00 & 0,25 & 0,00 & $0,0 c$ & 0,00 & 0,00 & 0,00 & 0,00 & 0,78 & 13,14 & 71,34 \\
\hline \multirow[t]{6}{*}{ Social } & & & & & & & & & & & & & & & & & & & & \\
\hline & AEPA & 08/05/01 & $31 / 12 / 08$ & 11,74 & 7,12 & 0,00 & 0,21 & 0,17 & 0,08 & 0,24 & 0,41 & 0,00 & 0,00 & 0,00 & 0,00 & 0,00 & 0,00 & 1,11 & 8,23 & 70,10 \\
\hline & Projer & $17 / 12 / 98$ & $31 / 12 / 07$ & 11,76 & 11,15 & 0,00 & 0,46 & 0,04 & 0,00 & 0,02 & 0,02 & 0,00 & 0,00 & 0,00 & 0,00 & 0,00 & 0,00 & 0,54 & 11,69 & 99,40 \\
\hline & AEPA Rural Area & 02/03/06 & $31 / 12 / 09$ & 77,00 & 2,24 & 0,00 & 0,00 & 0,00 & 0,19 & 0,33 & 0,26 & 0,00 & 0,00 & 0,00 & 0,00 & 0,00 & 0,00 & 0,78 & 3,02 & 3,92 \\
\hline & Fisher Community support & 02/03/06 & $31 / 12 / 12$ & 9,36 & 0,60 & 0,00 & 0,00 & 0,00 & 0,00 & 0,00 & 0,00 & 0,00 & 0,00 & 0,00 & 0,00 & 0,00 & 0,00 & 0,00 & 0,60 & 6,41 \\
\hline & & & & 109,86 & 21,11 & 0,00 & 0,67 & 0,21 & 0,27 & 0,59 & 0,69 & 0,00 & 0,00 & 0,00 & 0,00 & 0,00 & 0,00 & 2,43 & 23,54 & 21,43 \\
\hline & TOTAL & & & 322,83 & 75,21 & 0,00 & 5,19 & 0,33 & 2,98 & 1,32 & 1,24 & 0,00 & 0,00 & 0,00 & 0,00 & 0,00 & 0,00 & 11,06 & 86,27 & 26,72 \\
\hline
\end{tabular}


IFAD Disbursement Status as of May 2008

$10 / 10 / 08$

(In USD Millions)

\begin{tabular}{|c|c|c|c|c|c|c|c|c|c|c|c|c|c|c|c|c|c|c|c|c|c|}
\hline \multirow[b]{2}{*}{ Cr. No. } & \multirow[b]{2}{*}{ ID } & \multirow[b]{2}{*}{ Project } & \multirow{2}{*}{ 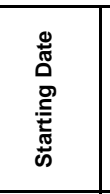 } & \multirow{2}{*}{ 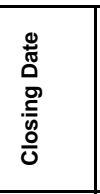 } & \multirow{2}{*}{ 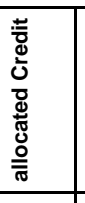 } & \multirow{2}{*}{ 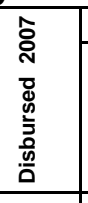 } & \multicolumn{12}{|c|}{ Disbursed 2008} & \multirow{2}{*}{ 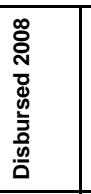 } & \multirow{2}{*}{ 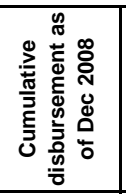 } & \multirow{2}{*}{ 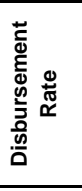 } \\
\hline & & & & & & & Jan & Feb & March & April & May & June & July & August & Sept & Oct & Nov & Dec & & & \\
\hline \multicolumn{2}{|c|}{ Financial } & PPRR 621 MG & $22 / 02 / 04$ & $30 / 06 / 07$ & 14,00 & 3,92 & 0,16 & 0,18 & 0,08 & 0,37 & 0,03 & 0,17 & 0,00 & 0,00 & 0,00 & 0,00 & 0,00 & 0,00 & 0,99 & 4,91 & $\begin{array}{l}35,07 \\
35,0\end{array}$ \\
\hline \multirow{2}{*}{\multicolumn{2}{|c|}{ Agriculture-Livestock }} & & & & 14,00 & 3,92 & 0,16 & 0,18 & 0,08 & 0,37 & 0,03 & 0,17 & 0,00 & 0,00 & 0,00 & 0,00 & 0,00 & 0,00 & 0,99 & 4,91 & 35,07 \\
\hline & & $\begin{array}{l}\text { PROSPERER } 737 \text { MG } \\
\text { PAD2M } 689 \text { MG }\end{array}$ & $\begin{array}{l}18 / 12 / 07 \\
15 / 05 / 06\end{array}$ & $\begin{array}{l}31 / 12 / 15 \\
31 / 12 / 14\end{array}$ & $\begin{array}{l}18,29 \\
13,11 \\
31,40\end{array}$ & $\begin{array}{l}0,00 \\
0,74 \\
0,74\end{array}$ & $\begin{array}{l}0,00 \\
0,08 \\
0,08\end{array}$ & $\begin{array}{l}0,00 \\
0,00 \\
0,00\end{array}$ & $\begin{array}{l}0,00 \\
0,69 \\
0,69\end{array}$ & $\begin{array}{l}0,00 \\
0,03 \\
0,03\end{array}$ & $\begin{array}{l}1,01 \\
0,10 \\
1,11\end{array}$ & $\begin{array}{l}0,00 \\
0,00 \\
0,00\end{array}$ & $\begin{array}{l}0,00 \\
0,00 \\
0,00\end{array}$ & $\begin{array}{l}0,00 \\
0,00 \\
0,00\end{array}$ & $\begin{array}{l}0,00 \\
0,00 \\
0,00\end{array}$ & $\begin{array}{l}0,00 \\
0,00 \\
0,00\end{array}$ & $\begin{array}{l}0,00 \\
0,00 \\
0,00\end{array}$ & $\begin{array}{l}0,00 \\
0,00 \\
0,00\end{array}$ & $\begin{array}{l}1,01 \\
0,90 \\
1,91\end{array} \mid$ & $\begin{array}{l}1,64 \\
2,65\end{array}$ & $\begin{array}{r}0,00 \\
12,51 \\
8,44\end{array}$ \\
\hline \multirow{2}{*}{\multicolumn{2}{|c|}{ Social }} & MANDRARE 2548 MG & $31 / 01 / 01$ & $30 / 06 / 08$ & $\begin{array}{l}13,59 \\
13,59\end{array}$ & $\begin{array}{l}11,99 \\
11,99\end{array}$ & $\begin{array}{l}0,21 \\
0,21\end{array}$ & $\begin{array}{l}0,31 \\
0,31\end{array}$ & $\begin{array}{l}0,00 \\
0,00\end{array}$ & $\begin{array}{l}0,34 \\
0,34\end{array}$ & $\begin{array}{l}0,00 \\
0,00\end{array}$ & $\begin{array}{l}0,17 \\
0,17\end{array}$ & $\begin{array}{l}0,00 \\
0,00\end{array}$ & $\begin{array}{l}0,00 \\
0,00\end{array}$ & $\begin{array}{l}0,00 \\
0,00\end{array}$ & $\begin{array}{l}0,00 \\
0,00\end{array}$ & $\begin{array}{l}0,00 \\
0,00\end{array}$ & $\begin{array}{l}0,00 \\
0,00\end{array}$ & $\begin{array}{l}1,03 \\
1,03\end{array}$ & $\begin{array}{l}13,02 \\
13,02\end{array}$ & $\begin{array}{l}95,81 \\
95,81\end{array}$ \\
\hline & & Total & & & 58,99 & 16,65 & 0,45 & 0,49 & 0,77 & 0,74 & 1,14 & 0,34 & 0,00 & 0,00 & 0,00 & 0,00 & 0,00 & 0,00 & 3,93 & 20,58 & 34,89 \\
\hline
\end{tabular}

Source: Dette Publique 
KUWEITI FUNDS Disbursement Status as of May 2008

$10 / 10 / 08$

(in USD Millions

\begin{tabular}{|c|c|c|c|c|c|c|c|c|c|c|c|c|c|c|c|c|c|c|c|c|c|}
\hline \multirow[b]{2}{*}{ Cr. No. } & \multirow[b]{2}{*}{ ID } & \multirow[b]{2}{*}{ Projet } & \multirow{2}{*}{ 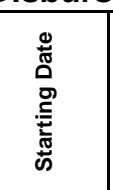 } & \multirow{2}{*}{ 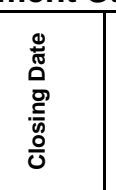 } & \multirow{2}{*}{ 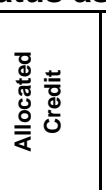 } & \multirow{2}{*}{ 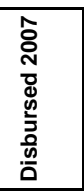 } & \multicolumn{12}{|c|}{ Disbursed 2008} & \multirow{2}{*}{ 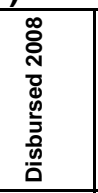 } & \multirow{2}{*}{ 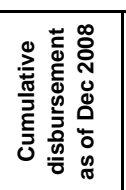 } & \multirow{2}{*}{ 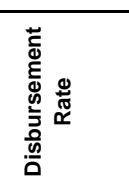 } \\
\hline & & & & & & & Jan & Feb & March & April & May & June & July & August & Sept & Oct & Nov & Dec & & & \\
\hline \multirow{2}{*}{\multicolumn{22}{|c|}{ Infrastructure }} \\
\hline & & & & & & & & & & 0,00 & 0,00 & 0,17 & 0,00 & 0,00 & 0,00 & 0,00 & 0,00 & 0,00 & 0,23 & $\begin{array}{ll}0,63 \\
\end{array}$ & 4,36 \\
\hline & & Rehabilitation RN 6 & $31 / 12 / 00$ & $31 / 12 / 08$ & \begin{tabular}{|l|}
12,03 \\
\end{tabular} & 9,88 & 0,00 & 0,54 & 0,00 & 0,00 & 0,00 & 0,03 & 0,00 & 0,00 & 0,00 & 0,00 & 0,00 & 0,00 & 0,57 & 10,45 & 86,87 \\
\hline & & & & & & & & & & & & & & & & & & & & & \\
\hline & & & & & & & & & & & & & & & & & & & & & \\
\hline & & TOTAL & & & 26,47 & 10,28 & 0,00 & 0,60 & 0,00 & 0,00 & 0,00 & 0,20 & 0,00 & 0,00 & 0,00 & 0,00 & 0,00 & 0,00 & 0,80 & \begin{tabular}{|c|}
11,08 \\
\end{tabular} & 41,86 \\
\hline
\end{tabular}

Source: Dette Publique 
OECO Disbursement Status as of June 2008

$10 / 10 / 08$

(In USD Millions

\begin{tabular}{|c|c|c|c|c|c|c|c|c|c|c|c|c|c|c|c|c|c|c|c|c|c|}
\hline \multirow[b]{2}{*}{ Cr. No. } & \multirow[b]{2}{*}{ ID } & \multirow[b]{2}{*}{ Project } & \multirow{2}{*}{ 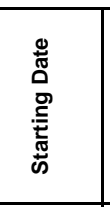 } & \multirow{2}{*}{ 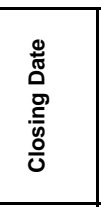 } & \multirow{2}{*}{ 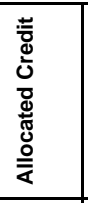 } & \multirow{2}{*}{ 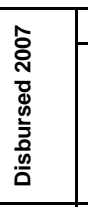 } & \multicolumn{12}{|c|}{ Disbursed 2008} & \multirow{2}{*}{ 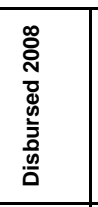 } & \multirow{2}{*}{ 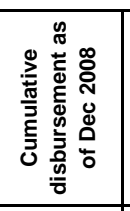 } & \multirow{2}{*}{ 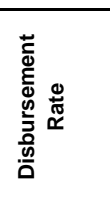 } \\
\hline & & & & & & & Jan & Feb & March & April & May & June & July & August & Sept & Oct & Nov & Dec & & & \\
\hline \multirow{2}{*}{\multicolumn{2}{|c|}{$\begin{array}{r}\text { Social } \\
722 \mathrm{P}\end{array}$}} & & & & & & & & & & & & & & & & & & & & \\
\hline & & $\begin{array}{l}\text { Primary and Secondary Education } \\
\text { Communicable Disease Control }\end{array}$ & $\begin{array}{l}27 / 05 / 98 \\
12 / 01 / 05\end{array}$ & $31 / 03 / 07$ & $\begin{array}{r}10,00 \\
6,00\end{array}$ & $\begin{array}{l}1,16 \\
0,00\end{array}$ & $\begin{array}{l}0,00 \\
0,00\end{array}$ & $\begin{array}{l}0,00 \\
0,00\end{array}$ & $\begin{array}{l}0,32 \\
0,00\end{array}$ & $\begin{array}{l}0,11 \\
0,00\end{array}$ & $\begin{array}{l}0,32 \\
0,00\end{array}$ & $\begin{array}{l}0,00 \\
0,00\end{array}$ & $\begin{array}{l}0,00 \\
0,00\end{array}$ & $\begin{array}{l}0,00 \\
0,00\end{array}$ & $\begin{array}{l}0,00 \\
0,00\end{array}$ & $\begin{array}{l}0,00 \\
0,00\end{array}$ & $\begin{array}{l}0,00 \\
0,00\end{array}$ & $\begin{array}{l}0,00 \\
0,00\end{array}$ & $\begin{array}{l}0,75 \\
0,00\end{array}$ & $\begin{array}{l}1,91 \\
0,00\end{array}$ & $\begin{array}{r}19,10 \\
0,00\end{array}$ \\
\hline \multicolumn{2}{|l|}{$748 P$} & Education Improvement & $30 / 10 / 99$ & $31 / 03 / 07$ & $\begin{array}{l}10,00 \\
26,00\end{array}$ & $\begin{array}{l}2,07 \\
3,23\end{array}$ & $\begin{array}{l}0,12 \\
0,12\end{array}$ & $\begin{array}{l}0,00 \\
0,00\end{array}$ & $\begin{array}{l}0,31 \\
0,63\end{array}$ & $\begin{array}{l}0,09 \\
0,20\end{array}$ & $\begin{array}{l}0,27 \\
0,59\end{array}$ & $\begin{array}{l}0,00 \\
0,00\end{array}$ & $\begin{array}{l}0,00 \\
0,00\end{array}$ & $\begin{array}{l}0,00 \\
0,00\end{array}$ & $\begin{array}{l}0,00 \\
0,00\end{array}$ & $\begin{array}{l}0,00 \\
0,00\end{array}$ & $\begin{array}{l}0,00 \\
0,00\end{array}$ & $\begin{array}{l}0,00 \\
0,00\end{array}$ & $\begin{array}{l}0,79 \\
1,54\end{array}$ & $\begin{array}{l}2,86 \\
4,77\end{array}$ & $\begin{array}{l}28,60 \\
18,35 \\
\end{array}$ \\
\hline \multirow{2}{*}{\multicolumn{2}{|c|}{$\begin{array}{l}\text { Agricultural } \\
792 \mathrm{P}\end{array}$}} & & & & & & & & & & & & & & & & & & & & \\
\hline & & Lower Mangoky Rehabilitation & 08/06/00 & $31 / 12 / 08$ & 8,02 & 2,50 & 0,00 & 0,02 & 0,00 & 0,10 & 0,00 & 0,00 & 0,00 & 0,00 & 0,00 & 0,00 & 0,00 & 0,00 & 0,12 & 2,62 & \\
\hline \multicolumn{2}{|l|}{$970 P$} & PPRR & $12 / 05 / 04$ & $31 / 12 / 12$ & $\begin{array}{r}7,70 \\
15,72 \\
\end{array}$ & $\begin{array}{l}0,98 \\
3,48 \\
\end{array}$ & $\begin{array}{l}0,00 \\
0,00 \\
\end{array}$ & $\begin{array}{l}0,00 \\
0,02 \\
\end{array}$ & $\begin{array}{l}0,00 \\
0,00 \\
\end{array}$ & $\begin{array}{l}0,06 \\
0,16 \\
\end{array}$ & $\begin{array}{l}0,25 \\
0,25 \\
\end{array}$ & $\begin{array}{l}0,00 \\
0,00 \\
\end{array}$ & $\begin{array}{l}0,00 \\
0,00 \\
\end{array}$ & $\begin{array}{l}0,00 \\
0,00 \\
\end{array}$ & $\begin{array}{l}0,00 \\
0,00 \\
\end{array}$ & $\begin{array}{l}0,00 \\
0,00 \\
\end{array}$ & $\begin{array}{l}0,00 \\
0,00 \\
\end{array}$ & $\begin{array}{l}0,00 \\
0,00 \\
\end{array}$ & $\begin{array}{l}0,31 \\
0,43 \\
\end{array}$ & $\begin{array}{l}1,29 \\
3,91 \\
\end{array}$ & $\begin{array}{l}16,75 \\
24,87 \\
\end{array}$ \\
\hline \multirow{4}{*}{\multicolumn{2}{|c|}{ Infrastructure }} & & & & & & & & & & & & & & & & & & & & \\
\hline & & Andekaleka Control Hydroelectric & $21 / 12 / 05$ & $31 / 03 / 10$ & 6,50 & 0,00 & 0,00 & 0,00 & 0,00 & 0,00 & 0,00 & 0,00 & 0,00 & 0,00 & 0,00 & 0,00 & 0,00 & 0,00 & 0,00 & 0,00 & 0,00 \\
\hline & & Rehabilitation of Roads Prov Tulear & $21 / 12 / 05$ & $31 / 12 / 09$ & 7,00 & 0,00 & 0,00 & 0,00 & 0,00 & 0,00 & 0,00 & 0,00 & 0,00 & 0,00 & 0,00 & 0,00 & 0,00 & 0,00 & 0,00 & 0,00 & 0,00 \\
\hline & & & & & 13,50 & 0,00 & 0,00 & 0,00 & 0,00 & 0,00 & 0,00 & 0,00 & 0,00 & 0,00 & 0,00 & 0,00 & 0,00 & 0,00 & 0,00 & 0,00 & 0,00 \\
\hline & & Total & & & 55,22 & 6,71 & 0,12 & 0,02 & 0,63 & 0,36 & 0,84 & 0,00 & 0,00 & 0,00 & 0,00 & 0,00 & 0,00 & 0,00 & 1,97 & 8,68 & 15,72 \\
\hline
\end{tabular}

Source: Dette Publique 
Portfolio Status for SCAC Financed Projects

\begin{tabular}{|c|c|c|c|c|c|c|c|c|c|}
\hline Cr. No. & Type & Project Title & $\begin{array}{l}\text { Starting } \\
\text { Date }\end{array}$ & $\begin{array}{l}\text { Closing } \\
\text { Date }\end{array}$ & Project Amount & Old Payments & 2008 Payments & $\begin{array}{c}\text { Cumulative } \\
\text { Payments }\end{array}$ & $\begin{array}{c}\text { Balance to be } \\
\text { paid }\end{array}$ \\
\hline 2001003800 & ETAT & Tourism Sector & & & 510712,00 & 492240,51 & 0,00 & 492240,51 & 18471,49 \\
\hline 2001007200 & ETAT & Research in Agronomy and in Environment & & & 570000,00 & 540594,53 & 25529,20 & 566123,73 & 3876,27 \\
\hline 2001009800 & ETAT & FSD V & & & 1120500,00 & 1059689,78 & 33724,83 & 1093414,61 & 27085,39 \\
\hline 2002002100 & ETAT & Support to Sports and Youth Initiatives & & & 456000,00 & 455003,44 & 801,50 & 455804,94 & 195,06 \\
\hline 2002004800 & ETAT & PAISE & & & 580000,00 & 577507,73 & 0,00 & 577507,73 & 2492,27 \\
\hline 2002007000 & MOB & SIST & & & 111600,00 & 67907,82 & 9168,59 & 77076,41 & 34523,59 \\
\hline 2002008800 & ETAT & ART MADA & & & 475261,00 & 471164,20 & 1959,14 & 473123,34 & 2137,66 \\
\hline 2002009600 & ETAT & support to Bilingualism & & & 1350000,00 & 1175338,91 & 145380,03 & 1320718,94 & 29281,06 \\
\hline 2002010900 & ETAT & Natural Resource Management & & & 767000,00 & 720310,83 & 0,00 & 720310,83 & 46689,17 \\
\hline 2003000600 & MOB & Support to ZZSP Artistic Expressions & & & 15000,00 & 15000,00 & 0,00 & 15000,00 & 0,00 \\
\hline 2003004900 & ETAT & PRISMM - Support to Mining Sector & & & 1260000,00 & 1137273,96 & 51982,21 & 1189256,17 & 70743,83 \\
\hline 2003006700 & MOB & $\begin{array}{l}\text { Regionalization and Harmonization of the } \\
\text { Epidemiosurveillance Networks }\end{array}$ & & & 83940,41 & 66110,00 & 1665,84 & 67775,84 & 16164,57 \\
\hline 2004001700 & ETAT & PARAF & & & 570000,00 & 203563,72 & 71606,68 & 275170,40 & 294829,60 \\
\hline 2004005500 & ETAT & Airport Security & & & 1160000,00 & 457235,42 & 209689,03 & 666924,45 & 493075,55 \\
\hline 2004005600 & MOB & Audiovisual Heritage and Cultural Diversity & & & 155000,00 & 57956,62 & 43895,54 & 101852,16 & 53147,84 \\
\hline 2005001800 & ETAT & ASPIC & & & 1259000,00 & 476989,73 & 126680,92 & 603670,65 & 655329,35 \\
\hline 2001002200 & MOB & CORUS & & & 99745,43 & 98892,55 & 0,00 & 98892,55 & 852,88 \\
\hline 2002011100 & $\mathrm{MOB}$ & $\begin{array}{l}\text { Written Medium and Documentary Access in ZSP } \\
\text { Countries }\end{array}$ & & & 12500,00 & 12466,40 & 0,00 & 12466,40 & 33,60 \\
\hline 2005008200 & MOB & Co development Program & & & 300000,00 & 34198,00 & 0,00 & 34198,00 & 265802,00 \\
\hline 2006005000 & ETAT & Consolidating the Rule of Law & & & 1660000,00 & 252203,39 & 138974,38 & 391177,77 & 1268822,23 \\
\hline 2006002500 & ETAT & FSD VI & & & 1100000,00 & 206947,20 & 31543,00 & 238490,20 & 861509,80 \\
\hline 2007000100 & ETAT & MADES & & & 1875460,00 & 0,00 & 61943,47 & 61943,47 & 1813516,53 \\
\hline & & TOTALS & & & 15491718,84 & 8578594,74 & 954544,36 & 9533139,10 & 5958579,74 \\
\hline
\end{tabular}

Source: SCAC dated 08/07/2008 
European Union Disbursement Situation as of June 2008

\begin{tabular}{|c|c|c|c|c|c|c|c|c|c|c|c|c|}
\hline \multirow[b]{2}{*}{ Cr. No. } & \multirow[b]{2}{*}{ Project } & \multirow{2}{*}{ 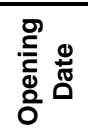 } & \multirow{2}{*}{$\begin{array}{l}\frac{O}{\bar{D}} \\
\frac{\mathrm{E}}{\mathrm{D}} \\
\frac{\mathrm{O}}{0}\end{array}$} & \multirow{2}{*}{ 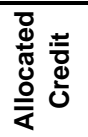 } & \multirow{2}{*}{ 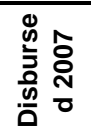 } & \multicolumn{6}{|c|}{ Décais. 2008} & \multirow{2}{*}{ 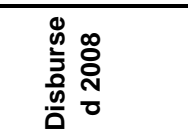 } \\
\hline & & & & & & Jan & Feb & Mar & April & May & June & \\
\hline 9 ACP MAG 006-9 ACP MAG022 & Consolidation of Democratization Process (Phase II) & & & & & & & & & & & 85054,28 \\
\hline 9ACP MAG 007 & Technical Cooperation Facility & & & & & & & & & & & 131956,87 \\
\hline 9ACP MAG 010 & $\begin{array}{l}\text { Program of Support to Communes and rural Organizations for the } \\
\text { Development of the South (ACORDS) }\end{array}$ & & & & & & & & & & & 2194207,74 \\
\hline UNICECAM DP4 & Microfinance Promotion and Development & & & & & & & & & & & 1147452,62 \\
\hline 9ACP MAG 025 & $\begin{array}{l}\text { Strengthening the Office supporting the National Official in charge of } \\
\text { Ordering Payments (ex-PARP) }\end{array}$ & & & & & & & & & & & 412038,46 \\
\hline 9ACP MAG008 & Program of support to Poverty Reduction HEALTH & & & & & & & & & & & 2953,85 \\
\hline 9ACP MAG 014 & Community support in the area of Good Governance & & & & & & & & & & & 1069940,38 \\
\hline $\begin{array}{l}\text { PS n06/2006"Support to FNDPC"STABEX,PS } \\
\text { N05/2006Support to sAPE Negotiation } \\
\text { Process, Studies on taxation of investments(9 } \\
\text { ACP MAG 007) }\end{array}$ & Support to MICDSP & & & & & & & & & & & 21976,44 \\
\hline $\begin{array}{l}\text { CONTRACT TRANSTEC PSN01/2007 CTHT- } \\
\text { PS N02/2006 CNCC-AT CTHT,CSA } \\
\text { Banane,SOFRECO,ITAL TREND }\end{array}$ & Reboosting Agricultural Exports & & & & & & & & & & & 234345,88 \\
\hline 8 ACP MAG 046 & Developing Livestock in the south West & & & & & & & & & & & 303336,83 \\
\hline 8ACP MAG 037-9ACP019 & Environmental Program Phase III(PE III) & & & & & & & & & & & 687774,31 \\
\hline 9ACP MAG 004-9ACP MAG011 & RN 6 Rehabilitation & & & & & & & & & & & 14105672,91 \\
\hline 8ACP MAG 30-9ACP MAG -015 & $\begin{array}{l}\text { Cyclone Damage and Programs for Rehabilitating Road and road } \\
\text { Maintenance Infrastructures }\end{array}$ & & & & & & & & & & & 250774,04 \\
\hline 8ACP MAG 045 & $\begin{array}{l}\text { Removing the Sambava/Antalaha Region and the Program of } \\
\text { Community Support to Road Maintenance from Isolation }\end{array}$ & & & & & & & & & & & 84678,21 \\
\hline Contract n996-9ACP MAG 017 & $\begin{array}{l}\text { Strengthening Metal Bridge RN 7-(RN 10-13-25) and Rehabilitation of } \\
\text { RNs in the South East }\end{array}$ & & & & & & & & & & & 3997722,53 \\
\hline 9ACP MAG 002 & Studies on National Roads in the South of Madagascar & & & & & & & & & & & 194244,17 \\
\hline 9ACP MAG 009 & $\begin{array}{l}\text { National Program for Rehabilitating the Network in the south of } \\
\text { Madagascar }\end{array}$ & & & & & & & & & & & 2975047,49 \\
\hline \multirow[t]{2}{*}{ Contract n`1009 - Contract nº 1097} & Fontrol of Bridge RN5 Nord and Sava - Work in Sainte Marie & & & & & & & & & & & 276463,87 \\
\hline & TOTAL & & & & & & & & & & & 28295606,76 \\
\hline
\end{tabular}

Source: European Union 
USAID Disbursement Status as of the Second Quarter of 2008

\begin{tabular}{|c|c|c|c|c|c|c|c|c|c|c|c|}
\hline \multirow[b]{3}{*}{ Cr. No. } & \multirow[b]{3}{*}{ Project } & \multirow{3}{*}{ 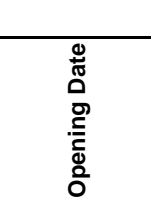 } & \multirow{3}{*}{ 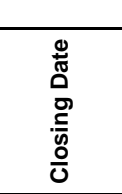 } & \multirow{3}{*}{ 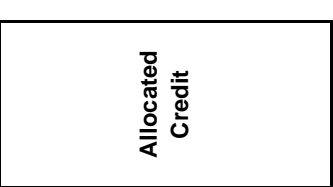 } & \multirow{2}{*}{\multicolumn{6}{|c|}{ Disbursed 2008}} & ons ) \\
\hline & & & & & & & & & & & \multirow{2}{*}{ 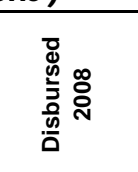 } \\
\hline & & & & & Jan & Feb & Mar & April & May & June & \\
\hline Governace & Program for Improving Governance in target Areas & $08 / 08 / 2003$ & $30 / 09 / 09$ & 9359707 & & & & & & & 568164,0 \\
\hline Health & $\begin{array}{l}\text { Program for Increased Use of Selected Health Services and } \\
\text { Products, and Improved Practices }\end{array}$ & 26/08/03 & $30 / 09 / 13$ & $\begin{array}{c}69610952 \text { (dont } 14895000 \\
\text { de PL480 titre II) }\end{array}$ & & & & & & & 12094924 \\
\hline Environment & $\begin{array}{l}\text { Program for Forest Ecosystems that are biologically diverse } \\
\text { conserved }\end{array}$ & 08/08/2003 & $30 / 09 / 09$ & 36592528 & & & & & & & 1611218 \\
\hline
\end{tabular}

Source USAID 